\title{
The Sensorial Latency of Urban Spaces
}


A 120 point thesis submitted to the School of Architecture and Design, Victoria University of Wellington, in the fulfilment of the requirements for the degree of Masters of Interior Architecture

February 2018 
How can the sounds of the city stimulate an engaging sensory experience that enriches the everyday performances of urban life?

\section{[Sensorial ]}

"pertaining to sense or sensation,"

"to perceive, feel" : sentire [Latin]

$$
\text { [Latency ] }
$$

the state of existing but not yet being manifested or developed.

The sensory elements present in the urban realm are largely left untapped. The experience of urban spaces can be improved through sensory based design to enrich one's experience of their city. 
Architecture provides the platform for the inherent connections between people and their city to flourish. The urban realm naturally invites diverse people to inhabit and interact together, giving city life its vibrancy. Urban spaces encourage spontaneous interactions between people and with architecture, to produce creative acts of play and liberating moments of leisure. It has been suggested that these events encapsulate the everyday performance of the city and are the antithesis to everyday life. It is argued this performance is often ignored in modern urban design. It has been noted that Wellington's waterfront offers areas where momentary and impotent engagement can be developed into meaningful experiences.

Simultaneously, the importance and potency of sound within urban spaces may be undervalued. It is often argued that modern cities assault our senses with sounds leading to discomfort and distracted inhabitation, contributing to a lack of engagement. Urban sounds are commonly dampened in public spaces to combat this assault, but with more thoughtful design these sounds can be reinterpreted to augment the innate everyday performances. This thesis proposes that controlling how people experience urban sounds through architecture can create a deep sensory performance that increases engagement, awareness and interaction.

This research explores ways to harness the latent sounds of the city to form meaningful connections between people and their city while providing moments of play and leisure. Once isolated and harnessed, the urban sounds' unique and intrinsic power can aid the development of urban spaces, thus producing greater significance within the urban fabric. There will be focus on the connection between the senses, performance and the urban context. The opportunity to enable the acceptance of the environment and reflection on their city marks an important role within the urban fabric.

Concurrently, this research explores how an intuitive drawing-led process can integrate and challenge the boundaries of both interior and the exterior urban realm. Other interior architectural strategies, together with soundscape design and urban interior principles aid this interdisciplinary exploration. 
I would firstly like to thank my ever enthusiastic supervisor Philippe Campays, whose unrelenting positivity, knowledge and encouragement helped sustain stimulation and excitement throughout the project. Also to my family who have supported me during the course of the year- this can't have been done without them. Lastly to all the friends that have supplied relief among the stress of the last year. 


\section{TABLE OF CONTENTS}

Abstract

Introduction 2

People + City

1 Orientating to the Urban

introduction 6

understanding urban space + people 6

the role of leisure

play + leisure 8

2 Experiencing Urban Space

introduction 11

initial analysis $\quad 12$

the conceptual triad - Henri Lefebvre 14

Wellington paradigm 26

Wellington + urban rhythms 28

effects of urban rhythms 32

conclusion / site of intervention 34

City + Performance

$3 \quad$ Performance within cities

introduction 38

echoes of literature $\quad 38$

people + performance 44 
$4 \quad$ Performance in Wellington Waterfront

$\begin{array}{lll}\text { introduction } & & 46 \\ \text { performance analysis } & 1 & 48 \\ & 2 & 50 \\ & 3 & 52 \\ \text { LUX light festival } & & 53 \\ \text { conclusions } & & 56\end{array}$

Performance + Interior Architecture

5 Sounds in the Urban

introduction 60

soundtrack of the city 61

soundscape 62

sonic analysis 64

soundwalk: 1

$2 \quad 69$

$6 \quad$ Sound as Design

introduction $\quad 70$

aural architecture $\quad 70$

precedents $\quad 72$

7 Intuitive Drawing-led design

introduction 78

preliminary intuitive drawing $\quad 79$

experiment $1+1 a$ : sound as visual 82

experiment $2+2 a$ : impulsivity 90

reflections 96

spatial arrangement exploration 97 
Into the Abstract

introduction 99

refined spatial arrangement $\quad 100$

intuitive drawing as abstract 101

rationalising concepts $\quad 117$

soundscape analysis 119

conclusions 120

9 Developed design 123

Threshold of Sound 124

Convergence Space 145

Rhythmic Seclusion 162

The Sensorial Latency of Urban Spaces 182

$\begin{array}{ll}\text { Conclusions } & 192\end{array}$

List of Figures 196

Bibliography 199 
To enrich city + urban

performance

\section{Affects people}

Sound + architecture

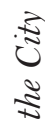

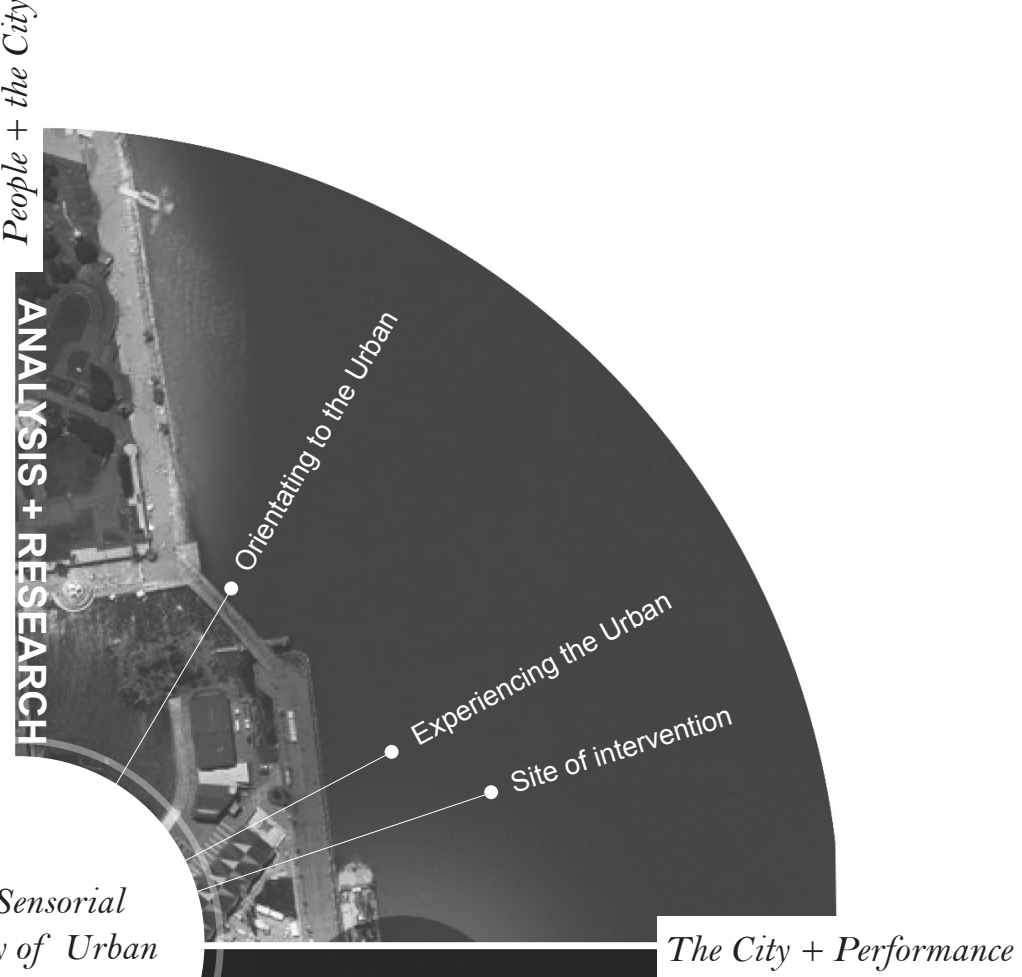

The Sensorial

Latency of Urban

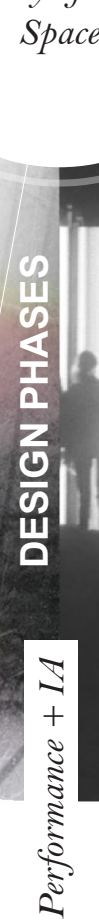

The City + Performance 
The Sensorial Latency of Urban Spaces addresses the notion that modern urban spaces need to harness sensory based design in order to connect people to their surroundings and to each other. It is argued that contemporary cities are becoming increasingly fast paced and saturated with stimulation, particularly sound. As a result the experience of the urban context is becoming fleeting and unengaging. With this change comes the need for urban designers to adjust how urban spaces are analysed, perceived and designed. This research proposes integrating interior strategies, namely sensory design, into the design of Wellington's urban waterfront to create spaces that engage and stimulate. Using sound thoughtfully in the design process can connect people with their environment to produce an individualised, meaningful experience. Interior discipline strategies will be used in the realm of urban design.

Additionally, the notions of everyday performance and play + leisure will be studied. These aspects contain intrinsic qualities that can be emphasised in urban spaces to aid connection and reflection. The combination of these concepts with sensory design will be explored.
The structure of this thesis is developed across four chapters. The first chapter People + the City frames the research within the urban realm. This chapter focusses heavily on the work of Quentin Stevens and Henri Lefebvre who concentrate on experience of people in public spaces and the role of urban spaces in the city. This research leads to comprehensive techniques to experientially analyse Wellington's waterfront.

The following chapter titled The City + Performance focuses on the role of play + leisure and performance in the production of urban spaces. The potential of sound in public spaces to engage, stimulate and affect one's experience is discussed.

The third chapter Performance + Interior Architecture contains the design stages where the research and analyses refine and combine to form concepts and developed design outcomes. With the discovery of sound's potency in urban spaces, Murray Schafer's soundscape design, Malte Wagenfeld's idea of the soundtrack of the city and Aural architecture are explored. These concepts provide significant impetus for the design phases. The way in which the city's sounds can be integrated with sensory design and the urban was the main investigation through this chapter.

The fourth and final chapter presents the findings and conclusions of the relationship between the interior discipline and the urban domain. Sonic and sensory design as a tool to enrich urban spaces, and the importance of play + leisure and everyday performance are also reflected on. 


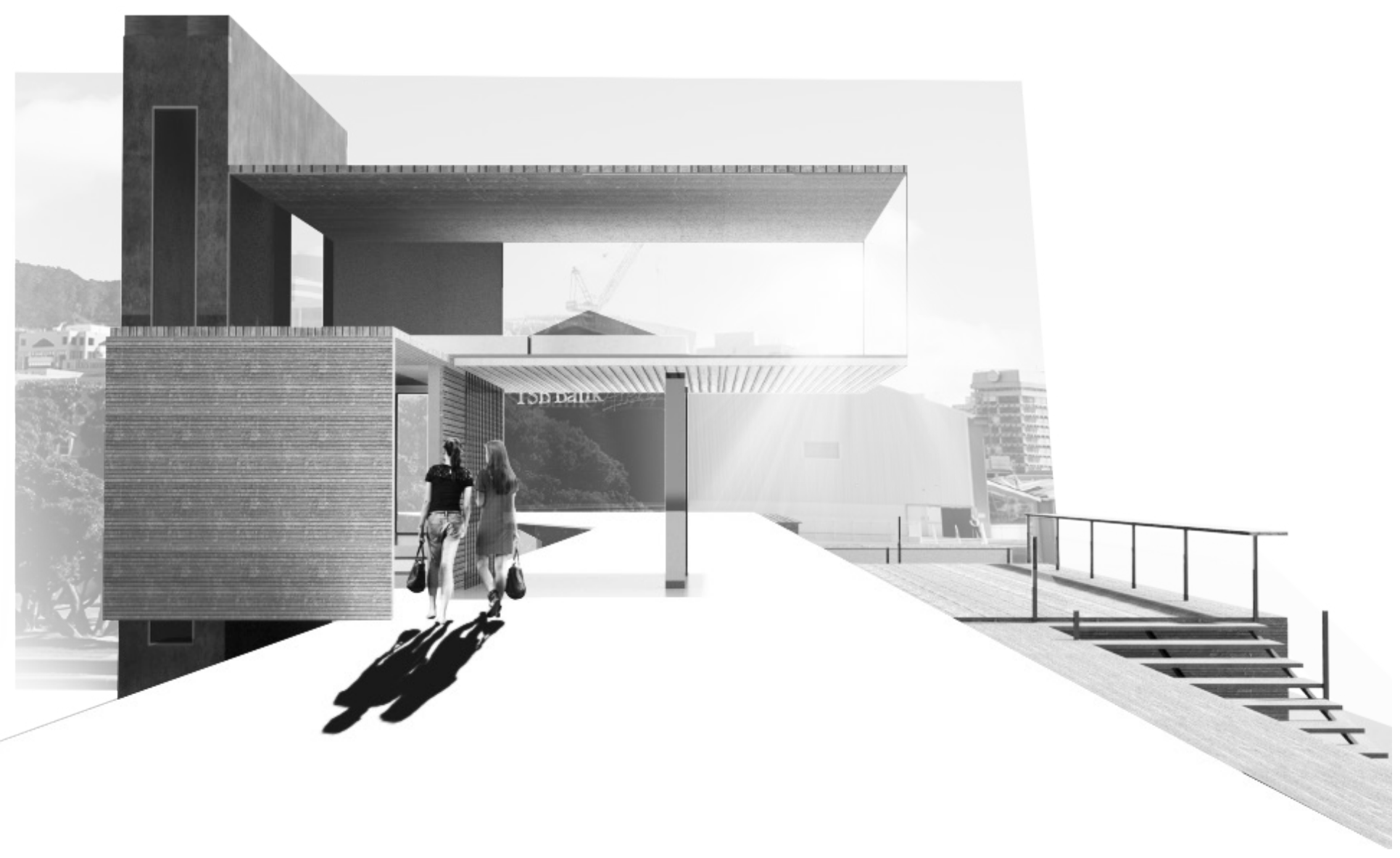




\section{PEOPLE + THE CITY}


ORIENTATING TO THE URBAN REALM

\section{Introduction}

Approaching the urban domain coming from the interior architecture discipline requires a reorientation to respond to the differences in scales, number of occupants and sensory qualities of spaces. Strategies in urban design theories and analyses can assist this by offering glimpses into the unique behaviours and subtleties contained within the urban realm. This chapter will concentrate on two areas: the role of urban spaces, and how people respond and engage with the urban fabric. These aspects create a link to the interior architecture discipline.

It is often stated that people and their interactions create the beauty and complexity of public spaces (Stevens, p.5). Here the role of urban design theories is to assist understanding the complexity of people within their city. The findings from the literature enable critical discussion on the research proposal, its relevance to the interior discipline and the betterment of public spaces.

\section{Understanding urban spaces + people}

The connection between people and their city is a phenomenon that we as members of society often fail to engage with or be aware of. Nevertheless, our responses, interactions and behaviour in public spaces still affect others' experiences. This lack of connection and awareness rests heavily on architecture and the urban fabric's underwhelming effect on one's experience. Creating focal points of occupation, providing large areas of circulation or areas of isolation are common roles of the public space in the modern city.
This thesis will specifically look at the role of urban spaces in Wellington's waterfront and its reconfiguration for a better engagement of people with its spaces.

In his book The Ludic City: Exploring the Potential of Public Spaces, Quentin Stevens dives into the ideal role of public spaces. Stevens wishes to emphasise the intrinsic playfulness of urban spaces. By discussing works by theorists such as Henri Lefebvre, Walter Benjamin, and William H. Whyte, Stevens compiles critiques, observations and explorations of urban spaces. According to Stevens, urban spaces have the responsibility to challenge predetermined societal constraints of the everyday life. The mental or physical separation that is facilitated through urban spaces can create meaningful instances of interaction, contemplation and reflection. This mode of occupation is suggested by architecture, not enforced by it. The juxtaposition to everyday life is needed to allow people and a city to form its own identity and create meaningful culture; taking the ideas from Phillips and LeGates (1981) Stevens writes "urban life means engaging with and developing behaviour which is unfamiliar, testing the usefulness of pre-existing social rules and roles" (p.9). 
This development of behaviour determines special characteristics of the urban context for its diverse occupants. Diversity is a natural aspect of the urban context, not just diverse people, ages etc. but also "different orders of sensory experience, social interaction, regulation and movement" (Edensor, p.82) are free to be expressed. Urban spaces provide opportunities for this diversity to converge free of fixed parameters. It is through freedom and liberation that the urban realm can contest the boundaries of everyday life (Stevens, p.30). Stevens argues that freedom produces creative and spontaneous interactions and behaviours that leads to an innate playfulness of urban space; encapsulated in the term 'play'. Stevens suggests urban spaces need to become the antithesis to the everyday, which can be manifested through play. Though play is a "largely neglected aspect of people's experience of urban society" (Stevens, p.1), designers need to become aware of its importance.

"...Ethics, social, psychological constraints set rules and boundaries which preserve social structure...Play ignores these boundaries."

(Stevens, p.30)
The need for everyone to succumb to play is not needed however, the response to these moments of play also produce stimulation and engagement. Creative responses and interactions to play create a performer-audience dynamic that can connect people together. Stevens' correlation between, performance and play can be seen when people have freedom to react, engage and mix with diverse people. In this setting, diversity can act as the catalyst for unplanned play and creatively spontaneous events: the city's vibrant everyday performance. Architecture can create a platform for this to unfold. If urban spaces invoke play for diverse people and celebrate the performance of the city and the people within then the beauty of the urban realm can be encapsulated. Architecture and urban design tend to undervalue the importance and potency of this notion.

"The organization of people's activities in and around public spaces contributes to their theatrical quality... diversity of people using urban public space maximise the likelihood that there will be something interesting to watch." (Stevens, p.40) 


\section{The Role of Leisure}

Resting heavily on Lefebvre's '3 Principles of Leisure', Quentin Stevens discusses the importance of leisure in everyday life. Leisure is a typical main function of urban spaces but realising it in a more sophisticated manner is vital. Lefebvre designated leisure as a distinct part of everyday life (Stevens, p.19). Therefore, Stevens and Lefebvre together suggest play and leisure contribute heavily to urban spaces. The mental state induced by leisure allows a "critique of life's dimensions" and it also "reflects life's other dimensions" (Stevens, p.19). Whether it is contemplating the working life or critiquing the modern city, the focussing and isolation of thoughts often produce a connection between people and their life or city. Reflecting on life's other dimensions helps connect play and performance to leisure. As "people tend to spend a lot of their time at the boundary of public space" (Stevens, p.118) creating leisure spots incite an audience of sorts. Though, Lefebvre states "reducing public leisure activity to defined functions reduces what it means to be at leisure" (Stevens, p.200); the struggle begins in determining and analysing where this prescription starts and stops.

\section{Play + Leisure}

The role of designing for play + leisure offers an area concentration in the scope of urban design. As Amin suggests in his 2006 paper "Collective culture and urban public space", public spaces' complexities and temporalities do not overwhelm people because social context and architectural qualities combine to mitigate.
Together play + leisure can accommodate and evoke various temporalities and rhythms that mitigate and merge with the qualities of the urban fabric to serve specific experiential needs.

"The atmosphere of a public space, its aesthetics and physical architecture, its historical status and reputation, its visual cultures, subtly define performances of social life in public."

(Amin) 
As discussed earlier, play can increase the connection between strangers. This is paralleled by Amin: "seeing people different from oneself responding to the same setting in similar ways creates a temporary bond". This somewhat resonates with William $\mathrm{H}$. Whyte's idea of triangulation, the phenomenon of people connecting over an external stimulus prompting "people to talk to each other as though they were not [strangers]"- stimulus including people, performance, music, an interesting object etc (Whyte, p.94). Witnessing others interact can contribute and add to the social and cultural environment of the urban space and can improve social relations between people. It is suggested that play is especially proficient in increasing the emotional bond between people, the informal, spontaneous interactions exposes people's personalities in ways that everyday life cannot (Stevens, p. 47-48).

In this thesis, the understanding of urban spaces has been developed through the reading of theoretical texts. There has been a conscious effort to maintain focus on people and their experience and the bettering of urban spaces. Experiencing the city with play + leisure in mind will push the analyses into more comprehensive territory. 


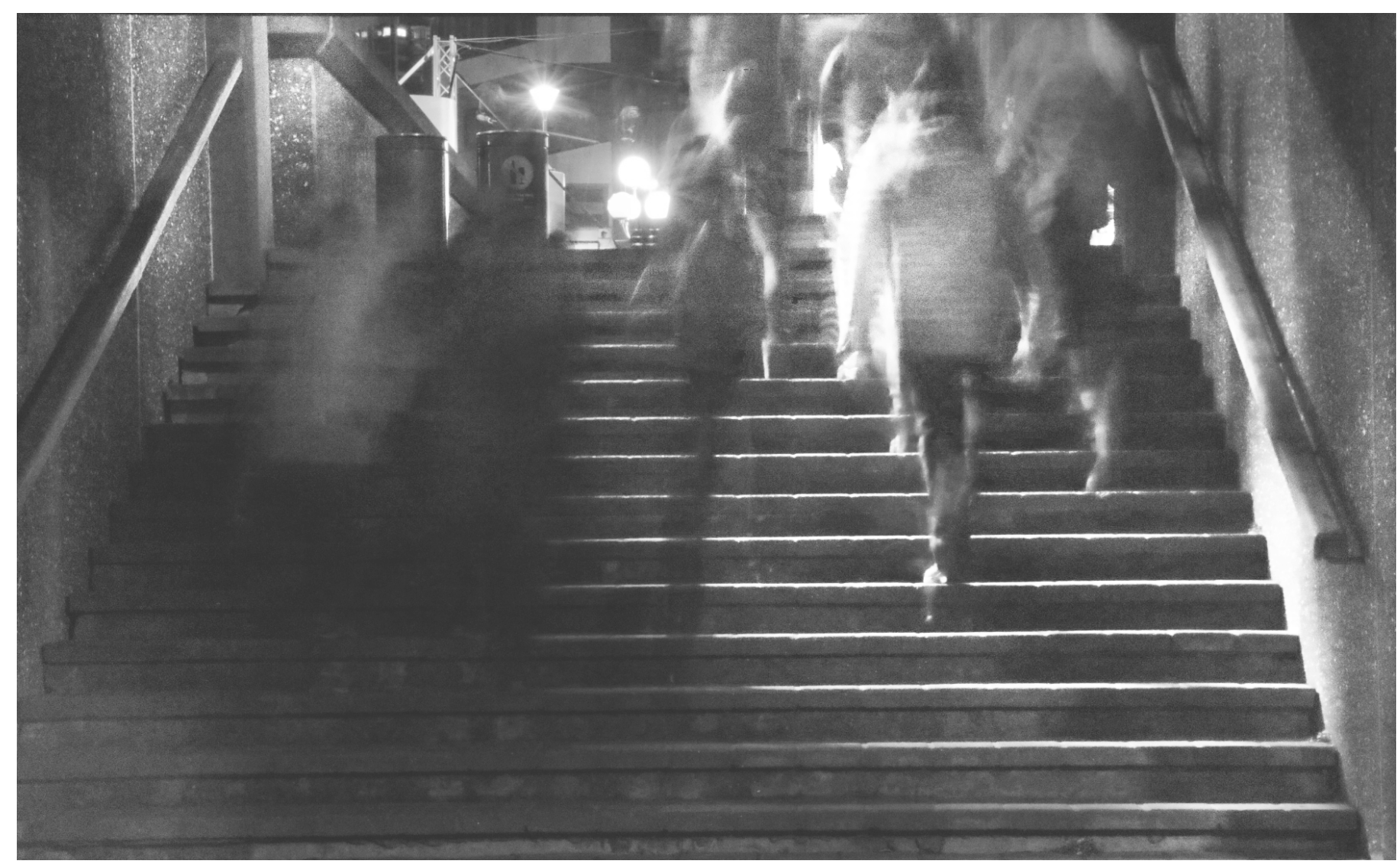

fig. 1.1: frank kitts park 


\section{[2] EXPERIENCING URBAN SPACE}

\section{Introduction}

Stevens' notions, mentioned earlier, will be tested in this next chapter. First these key elements will be utilised to analyse Wellington's urban space, specifically the waterfront promenade. A series of experiments will be designed to draw the research further into the urban realm. The findings will be used to test and analyse various spaces, leading to a thorough analysis of Wellington's waterfront and how Wellingtonians use these urban spaces. It is expected the success of the spaces will ebb and flow. The reasoning for behaviours, patterns, and architectural successes and failures, derived from the literature, will be specific to Wellington's waterfront.

Firstly, an initial analysis that uses current knowledge and insights from theorists will be undertaken. Afterwards, additional ideas from Lefebvre's comprehensive work will produce more refined, sophisticated results. Experiencing the waterfront more akin to Lefebvre's analyses will enable a better understanding of the experiences of the waterfront. It will also assist in understanding the texts themselves. The analysis experiments will primarily use experientialled techniques eluded to by Quentin Stevens and Lefebvre. The way in which people use and experience the waterfront, the effect of the existing architecture and the speed and rhythms will be expanded upon. By engrossing myself and becoming a member of the performance of

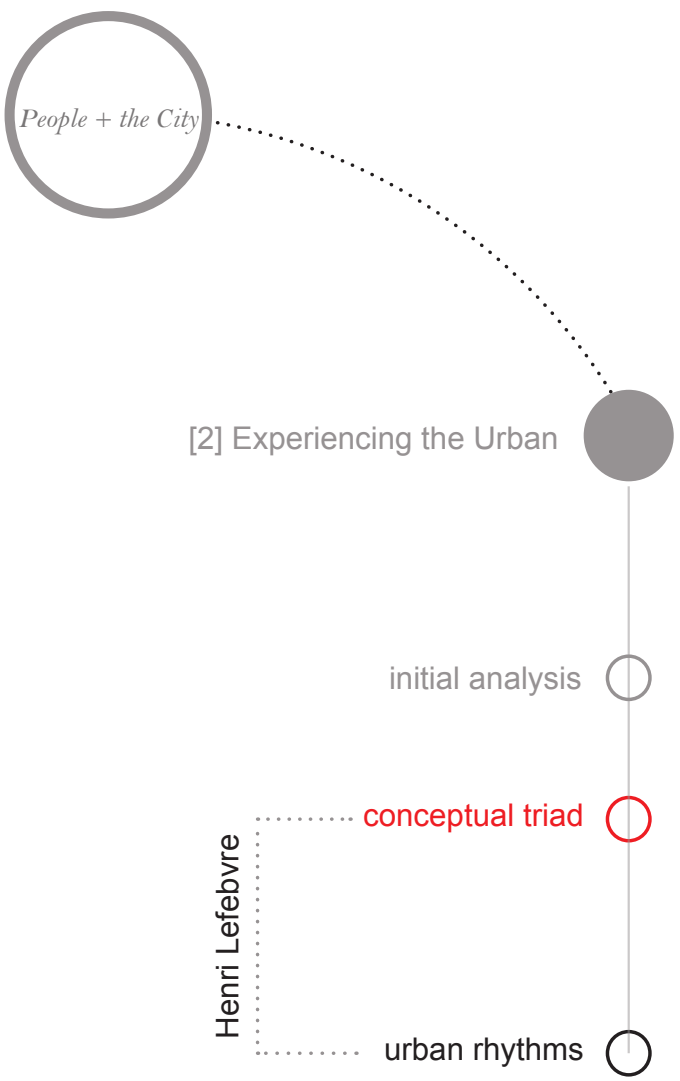
the city a deeper appreciation and understanding will transpire. 


\section{Initial Analysis}

Identifying moments of play + leisure along Wellington's waterfront offers an idea of the engagement over the various spaces. There are numerous opportunities to undergo leisure, the Wellington City Council has purposefully provided these. In some areas the effect on the immediate surroundings is positive, emanating relaxation and community. Noticeable points of play include the playground at the northern end of Frank Kitts Park and at the jumping platform outside Te Papa. Other examples of play include children inventively climbing on the large seats and partitions. Acts of everyday play are often found in open space, where there is space to play without inconvenience- an observation validated by Jan Gehl's report of Wellington: "the highest number of cultural activities and children playing are found on the waterfront where the space is wide enough for children to run around freely. As such, the waterfront is the playground of Wellington - a potential to be explored."

The waterfront causes diverse people to congregate. People walk leisurely at varying speeds, skateboarders, runners and cyclists use the space together. There are work commuters, tourists, locals, families, groups of friends, individuals.
In his text, Amin also introduces the idea of rhythms in public spaces. There is an overall rhythm experienced along Wellington's waterfront. This is an interesting aspect of the performance of the overall area. Generally, the waterfront has a quick rhythm, though there are moments of change. It was observed that the rhythmic change brought about a spatial awareness. For example, when the paths narrow into a thin connective bridge over the waterways people funnel into it condensing everyone involved; a person's "presence in public space are noted tacitly or consciously by participants" (Amin, 2006). This rhythmic element is an illustration of another innate aspect of urban life that tends to go unnoticed but has an impactful effect on the experience and performance of the space.

"The repetition of these rhythms results in the conversion of public space into a patterned ground that proves essential for actors to make sense of the space, their place within it, and their way through it."

(Amin) 


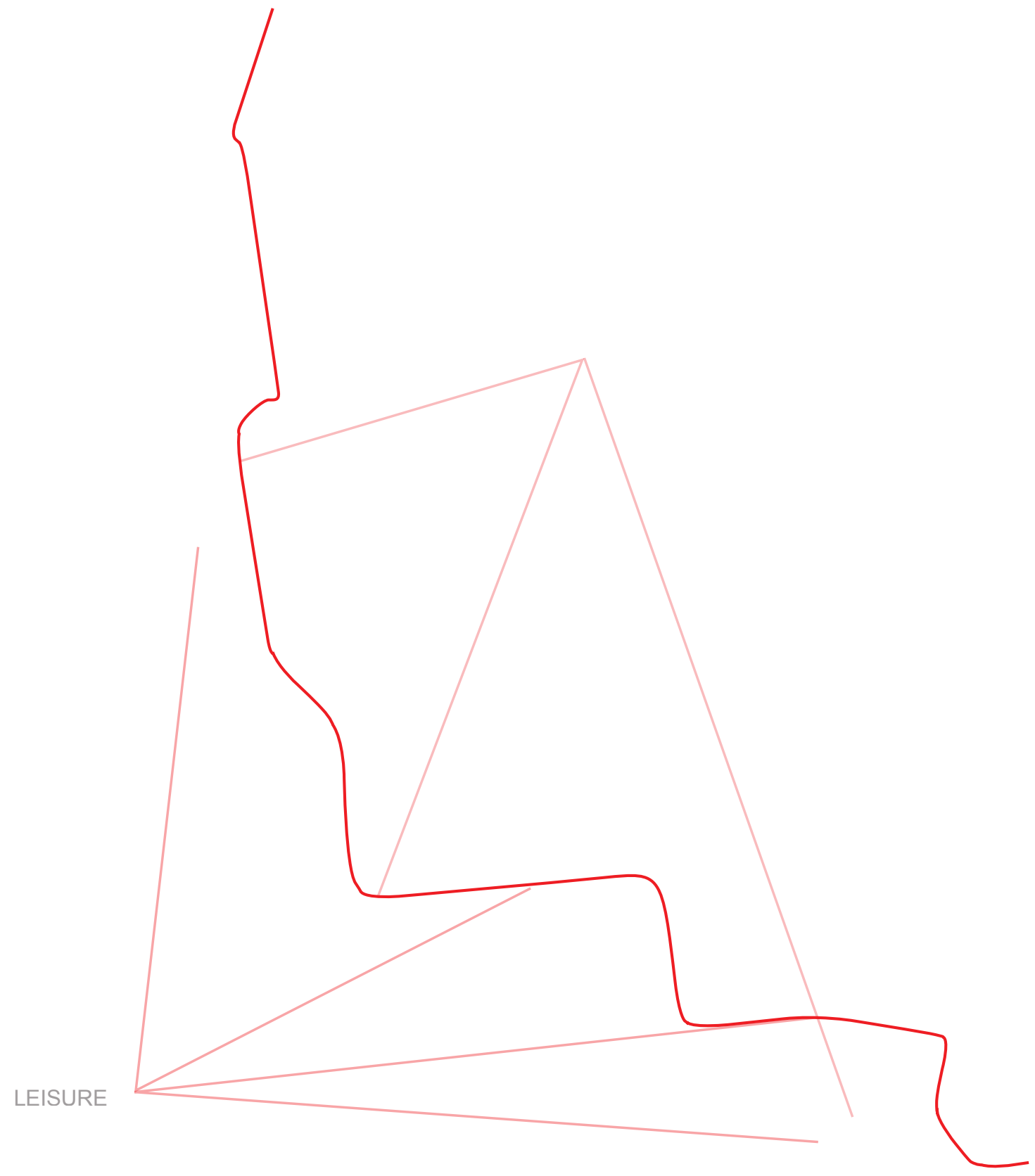

fig. 1.2: Wellington waterfront promenade: leisure + play

$$
100 \mathrm{~m}
$$

People + City - Understanding urban space

13 


\section{The Conceputal Triad - Henri Lefebvre}

According to Stevens, Lefebvre reflects on the production of urban and social spaces, the formulation of the well-known 'conceptual triad' enables this. The three components Representations of space, Spatial practices and Representational spaces - help understand urban environments and create a foundation for analysis. Stevens, states that more often than not critics examine the 'spatial practices' section but fail to connect with the other aspects; the latter two are immaterial and focus on experiential awareness over observation (p.6). 'Spatial practices' can be defined as what actually occurs, "the material social interactions occurring within space". 'Representations of space' relates to the "perceptions of the 'reality' of social life in space". It uses social 'codes' as a measure as it is determined by one's understanding and belief of the material space and understanding of social life. 'Representational space', as Stevens' defines, "whether they have material existence or not, are meanings, references to ideas about social space" (p.6). Symbolism, imagery and a lived experience is essential in analysing urban experiences in this regard; the mixing of the real physical world with association is key. The latter two introduce the notion of perceptions becoming meaning, the act of experiencing a material urban space (Stevens, p.6-7)(Watkins).

Venturing beyond 'spatial practices' allows the analyses to become more substantial. A similar notion was discussed in Rochus Urban Hinkel's article "Private encounters and public occupations: a methodology for the exploration of public space" in Urban Interior. Hinkel aims to "propose an alternative, or additional research model... a methodology that investigates the area of interest- public spaces- from the inside, rather than from the outside" (p.80) As this project suggests, analysis can develop from the traditional model of photographic documentation, historical research and planning regulations etc. (similar in effect to 'spatial practices'). Hinkel poses that it is imperative for researchers to "become immersed in public space in order to better understand it" (p.83). This is where the analysis of the public realm can develop past 'spatial practices' and the 'traditional' method.

There are 4 distinct areas identified in Wellington's waterfront: Waitangi Park/Clyde Quay Wharf area, Te Papa museum, Frank Kitts Parks (FKP) and the newly reinvigorated Kumutoto area. Each area will be examined using Lefebvre's conceptual triad strategy, and the results will speak of the people + city paradigm in Wellington waterfront. 


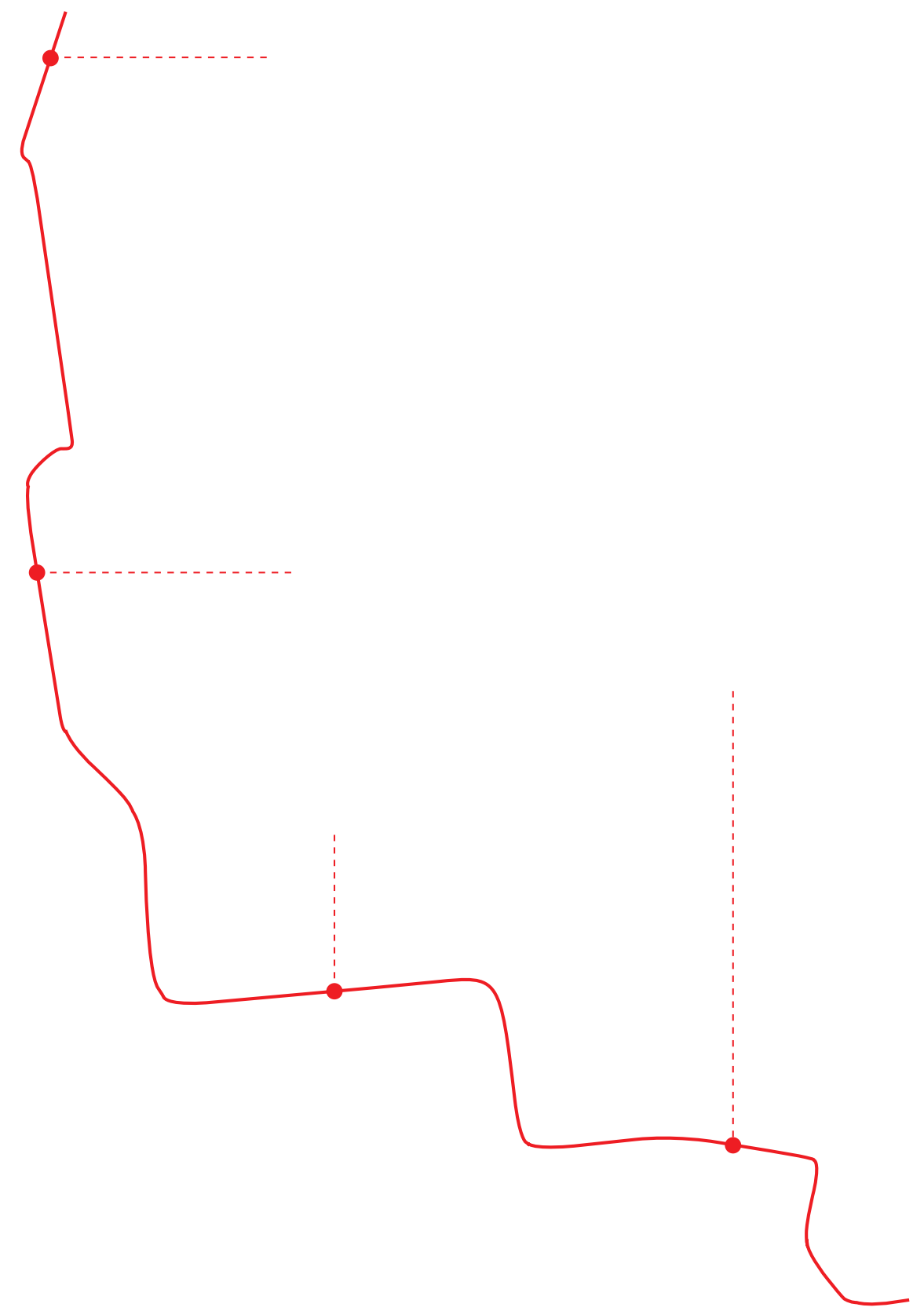




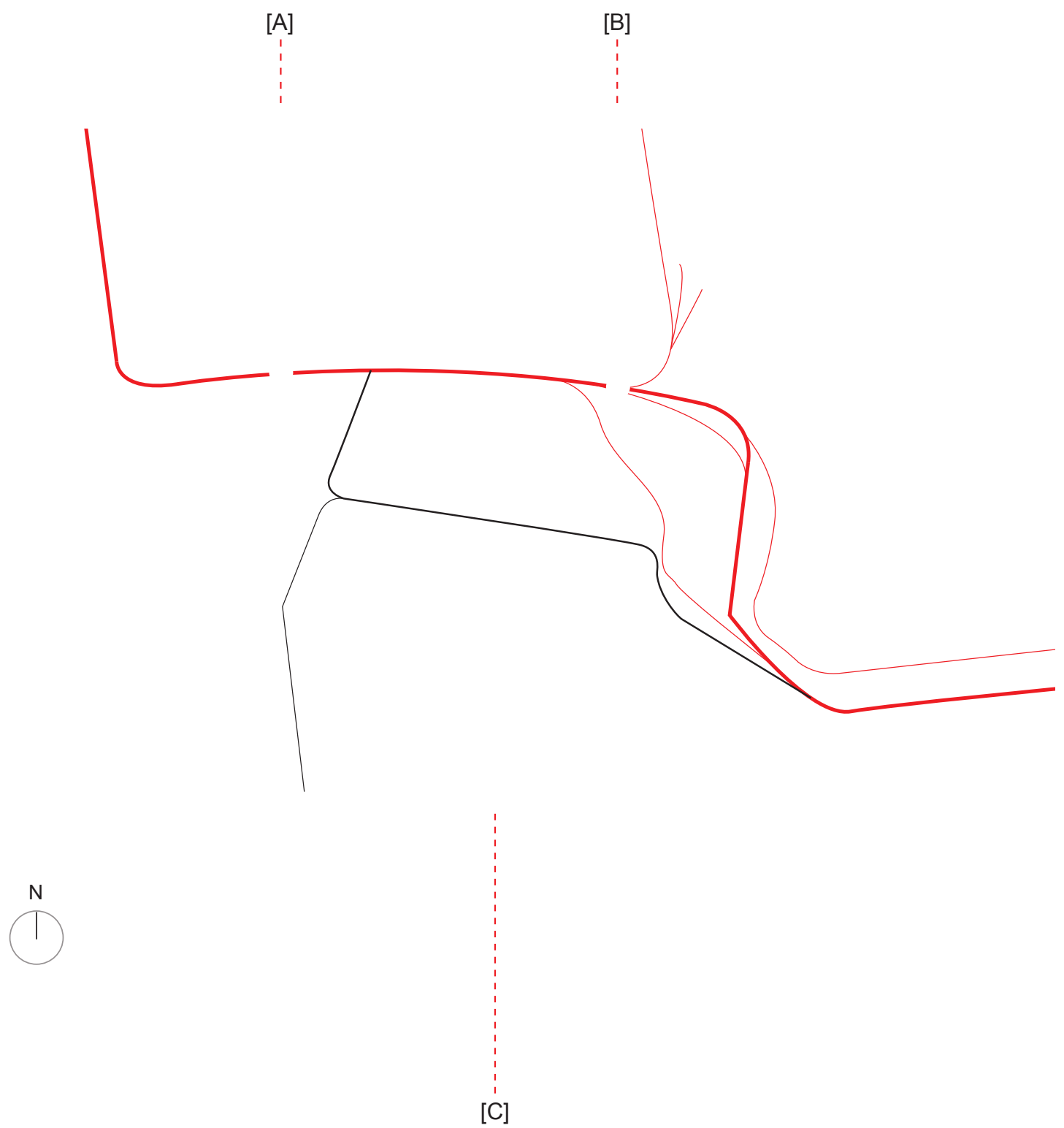

16 People + City - Understanding urban Space 
The area around Clyde Quay Wharf bridges Oriental Bay with the CBD waterfront. The linear movement in the area is rarely interrupted, even with the introduction of playful, unpredictable scooters and bikes. The way people respond to playful events and explore the area reflects the character of this space. It appears that there is a sense of freedom here as was the acceptance of uncontrollable aspects; the social 'codes' that often determine public space seem undecided and malleable. The apartments frame the pathways and exaggerate the perspective of the space. Visually, the Clyde Quay Apartments were distorted by the sails and masts confusing the eye, leading it down towards the pathway and people.

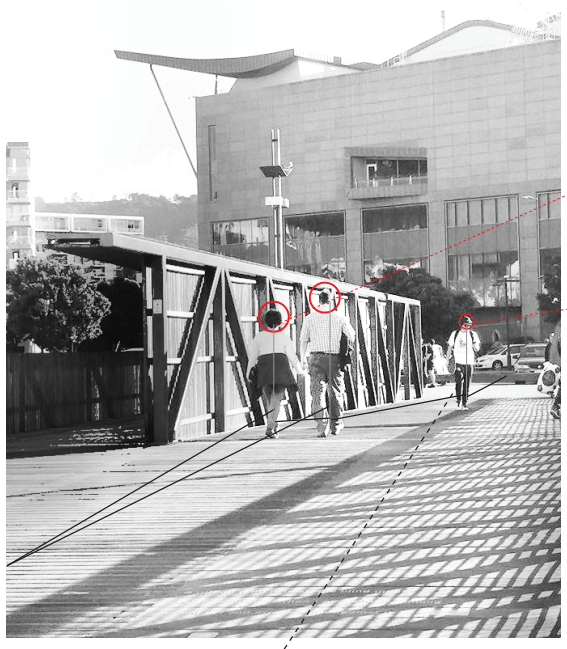

fig. 1.5: blocking ,óf green space

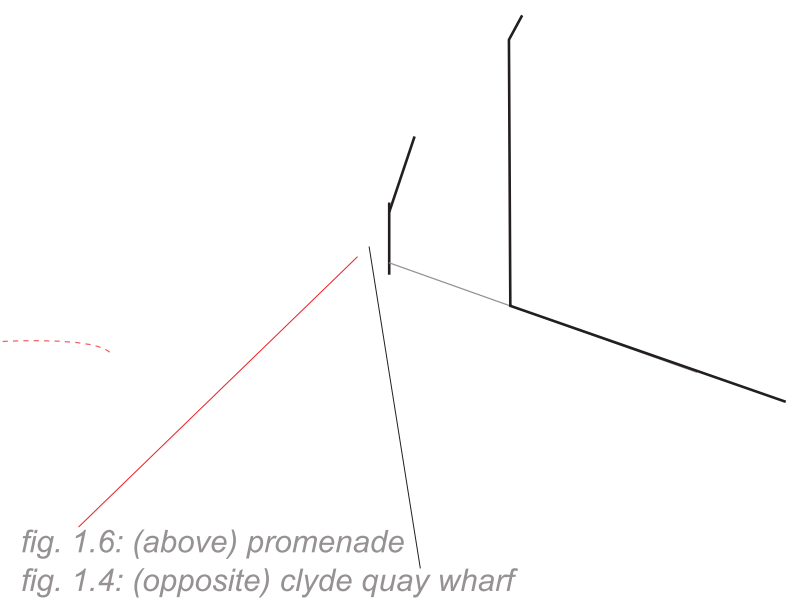




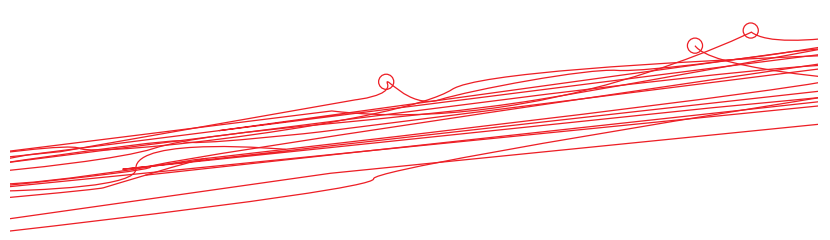

fig. 1.7: linear meandering $[A]$

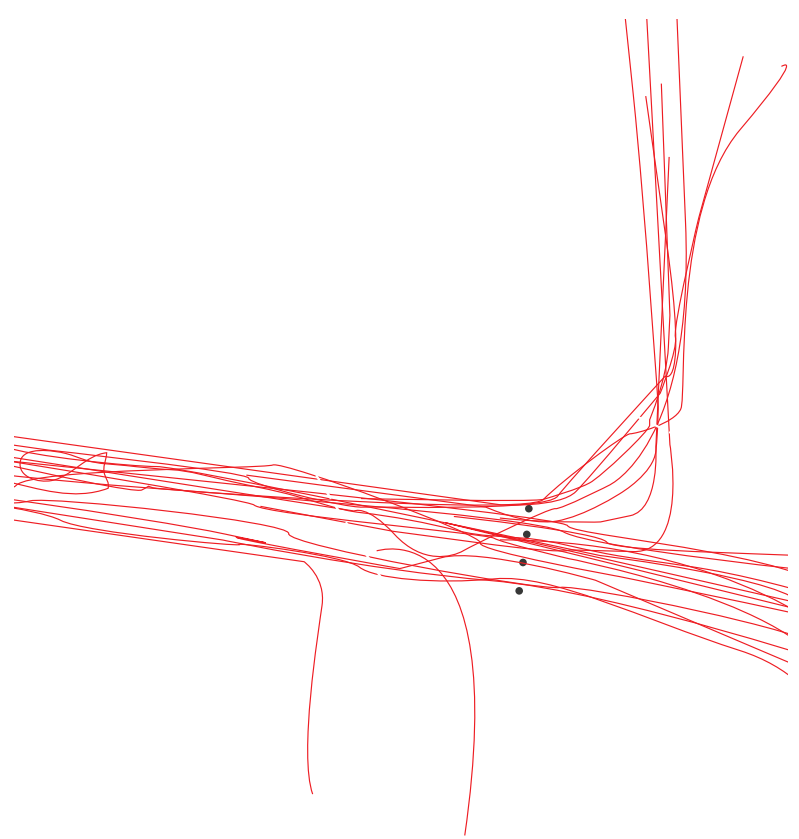

fig. 1.8: converging / diverging junction [B] 


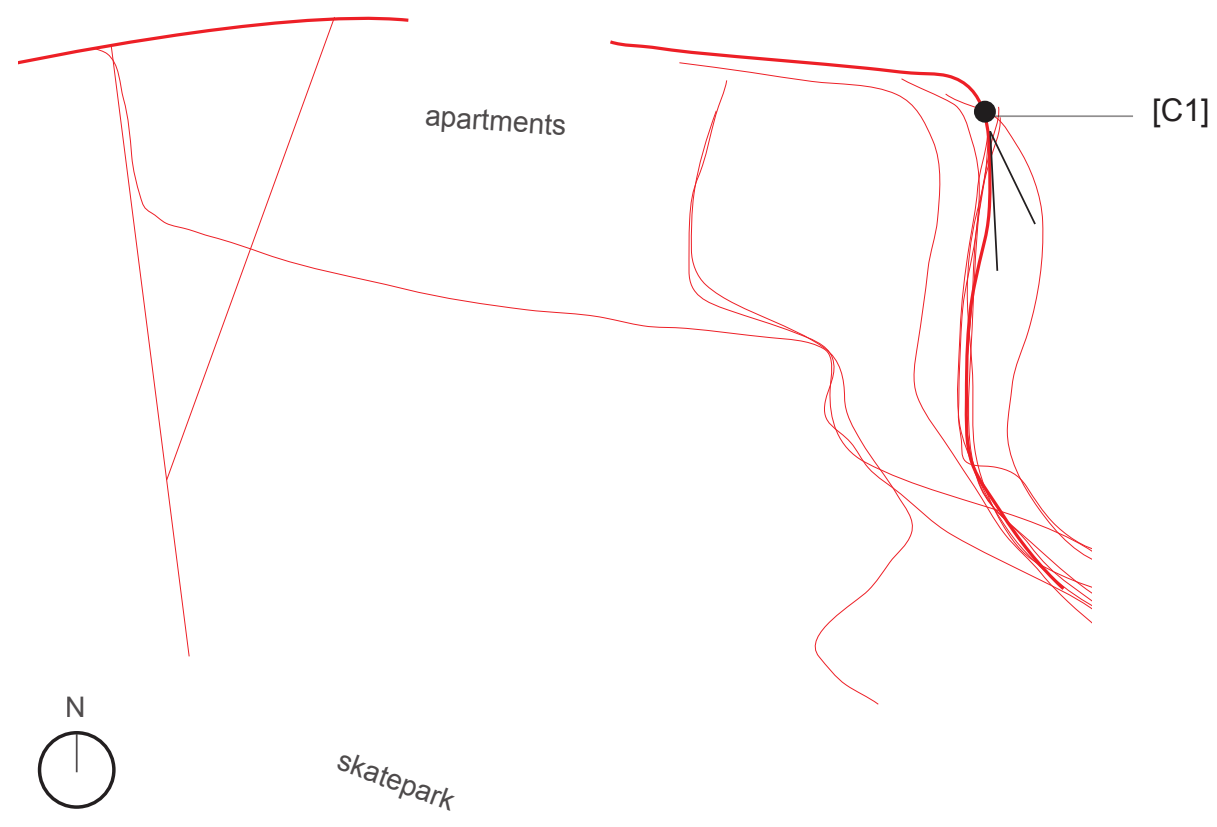

fig. 1.9: perimeter-based movement \& groupings [C]

Analysis shows there is a dislocation between the promenade and the green space. Vegetation and the apartments hid the presence of the grass area. In the green space people were undergoing leisure and play, though these people arrived at the park with the intention to play, it didn't occur spontaneously. Other people took notice of and enjoyed the play. The connection introduced by Stevens and Amin was observed.

At point $\mathrm{C}$, the path splits, one slopes down to the water under a canopy of trees, the other continues on. People tended to simply follow the path that holds true rather than venture down and engage with the water. An elevation change is a bigger deterrent than the water and greenery is as an attraction. 
2. TE PAPA AREA

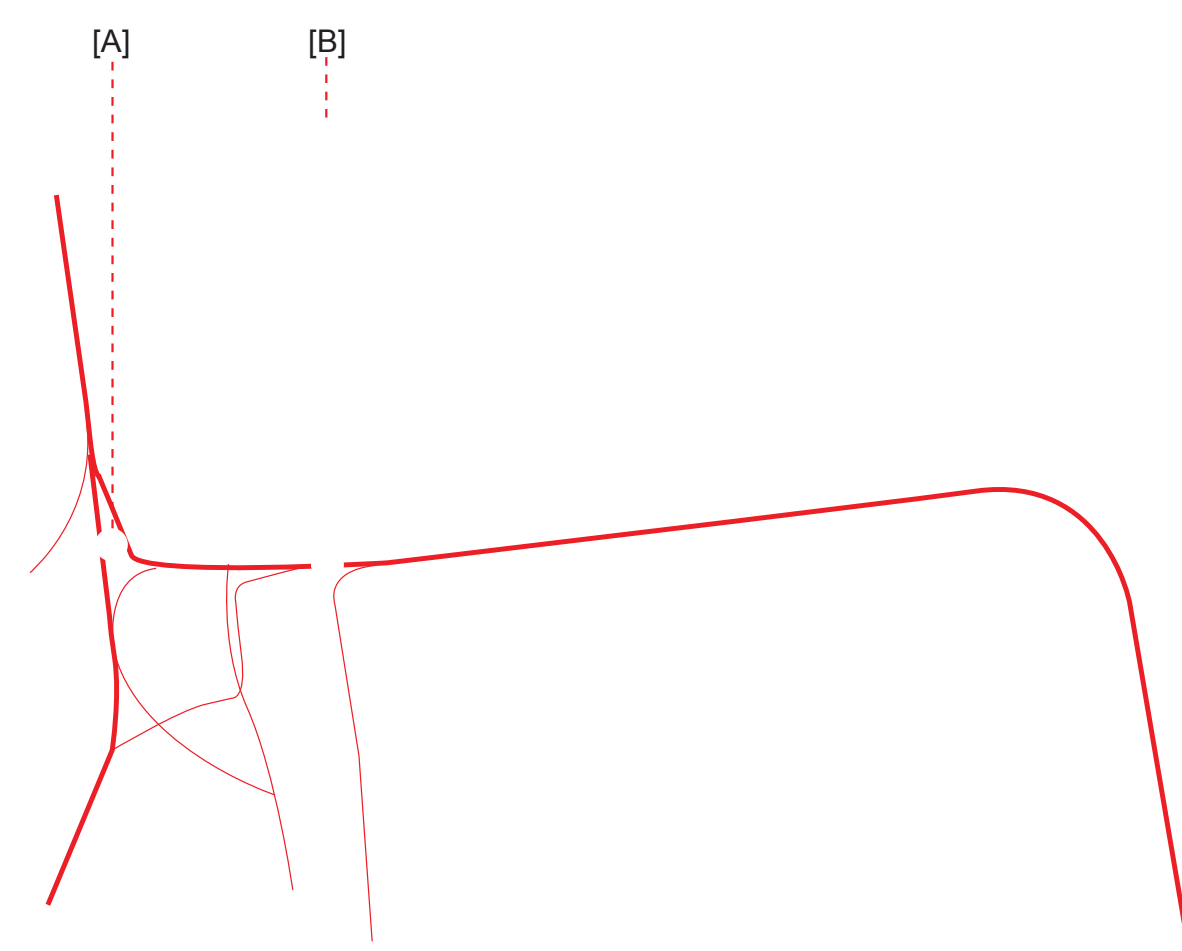

N

(1) 


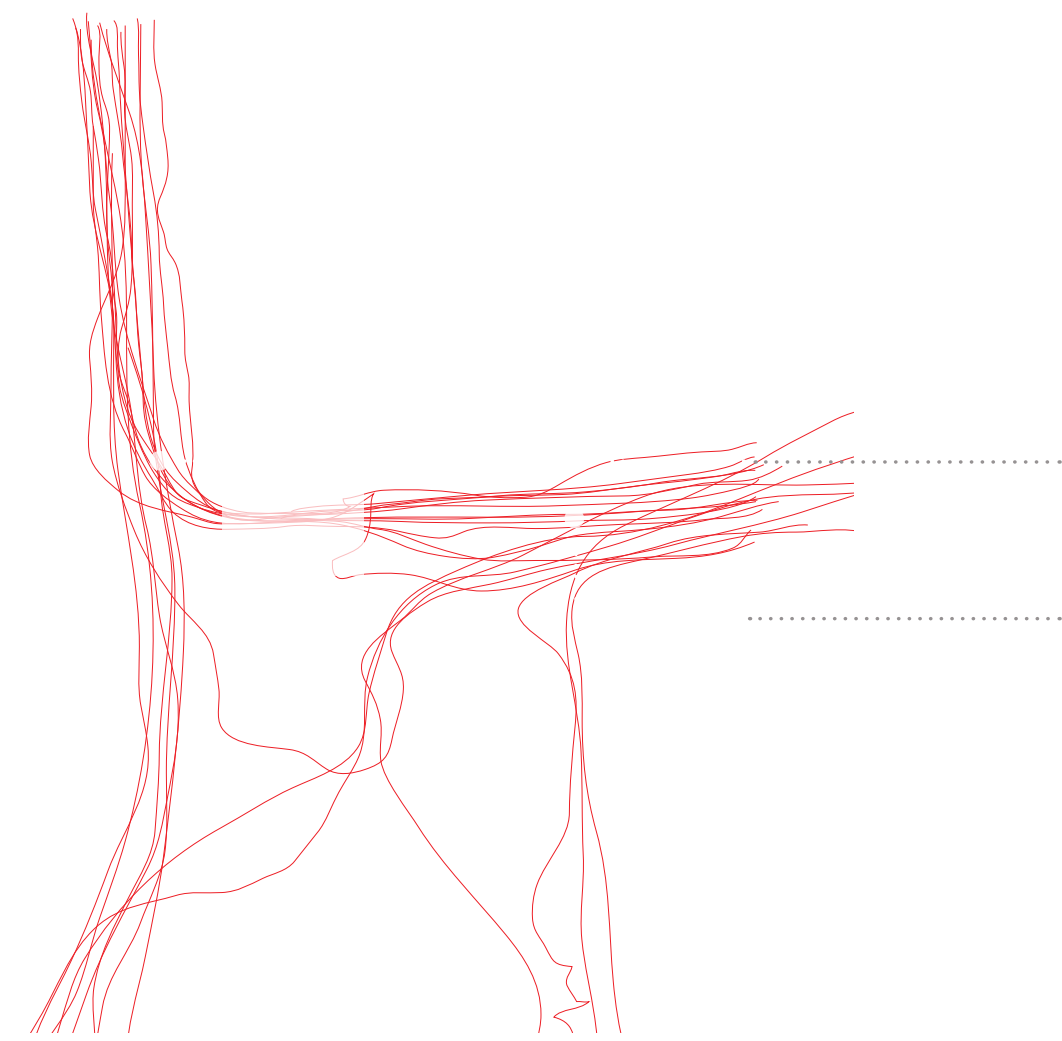

meanderers:

a point where either conscious travel reengages or wandering continues down the path.

moment of pause and decision-making Often exploration is preferred because the area offers much intrigue.

\section{street performers:}

this area in particular is a popular space for street performers and buskers. This adds to the atmosphere of the area.

fig. 1.11: (above) convergence $[A+B]$

fig. 1.10: (opposite) te papa area

This space is well-used because of the convergence of several main pathways. The small bridge acts as a funnel for all foot and cycle traffic. People travel at varying speeds here due to the opportunities for discovery and engagement with the surroundings. Meandering people explore and discover, while other people transition with little contemplation. The elements of discovery and the encouragement for exploration inform the 'Representational spaces'. It seems the space offers a point of difference along the waterfront, which in turn propagates stimulation. 


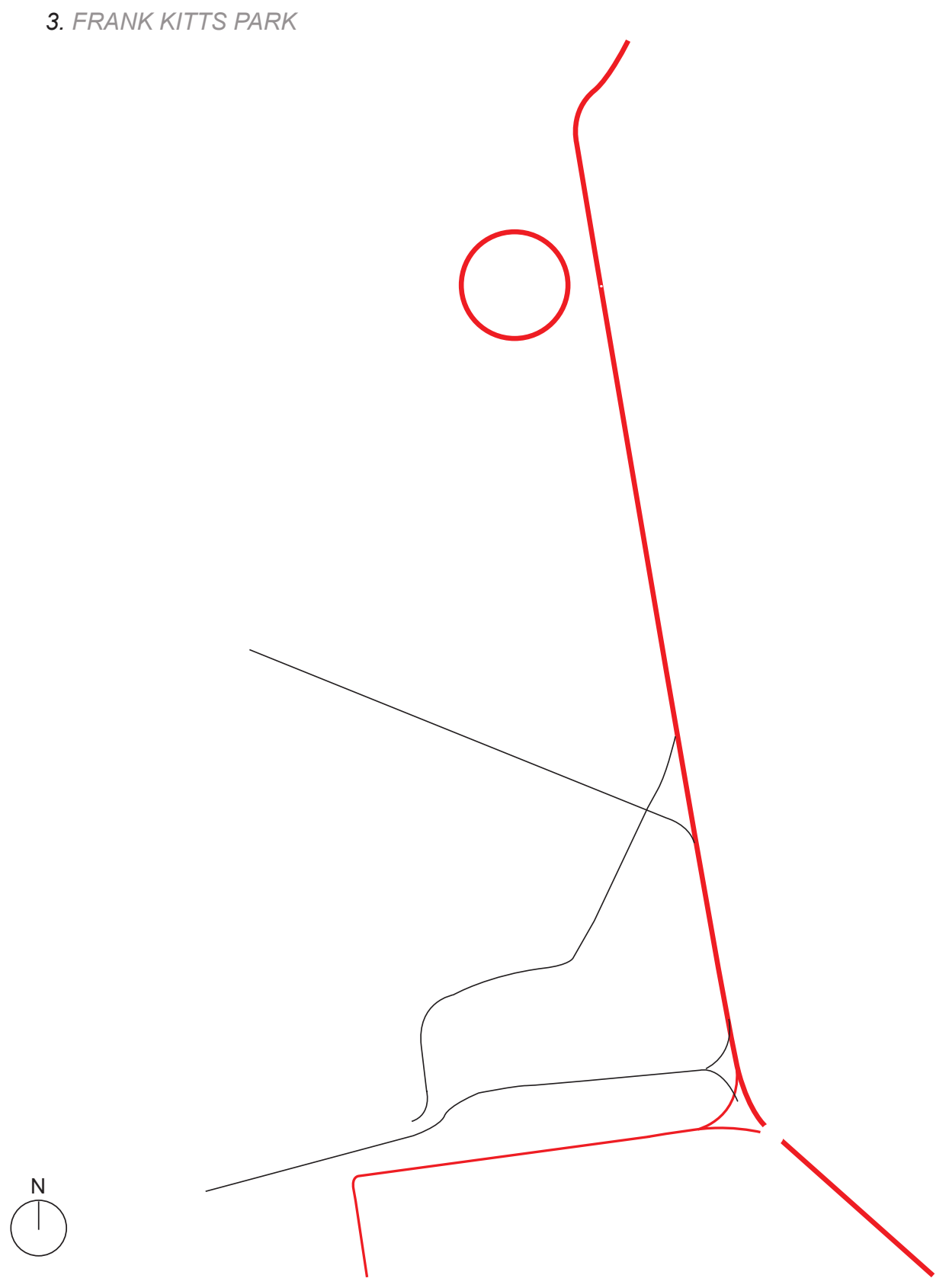


As a central green space, Frank Kitts Park fails to attract a significant amount of people. The promenade itself accommodates for many people but there is stark difference in number of inhabitants inside the Park. Sitting between the CBD and waterfront, the Park should be a focal point for diverse groups of people. The obstructing concrete wall forces monotonous, linear movement that segregates people and restricts free movement. Additionally, the elevated park surface completely prevents visual, conscious connection; resulting in a gap in the urban fabric (Bteich). Currently, Frank Kitts Park sits along the route for diverse users: daily commuters, tourists, people exercising and local people wandering their city. Also, a small number of working people use it during their lunch break, weather dependant. The juxtaposition of the promenade and the park's usage is dramatic and there is great potential to create engagement between the different users that is left untapped.

The concrete wall and the proportionately thin promenade push people quickly through the space and therefore away from the greenspace. It seems this pace reduces the activity and the spontaneous events (interactive, aural or visual) that is found in the other areas. The repetition of monotony is dominating, though the space livens towards the playground in the northern end. Regarding the architectural influence on the area, there is little. What activates the immediate environment are cafes and the playground.
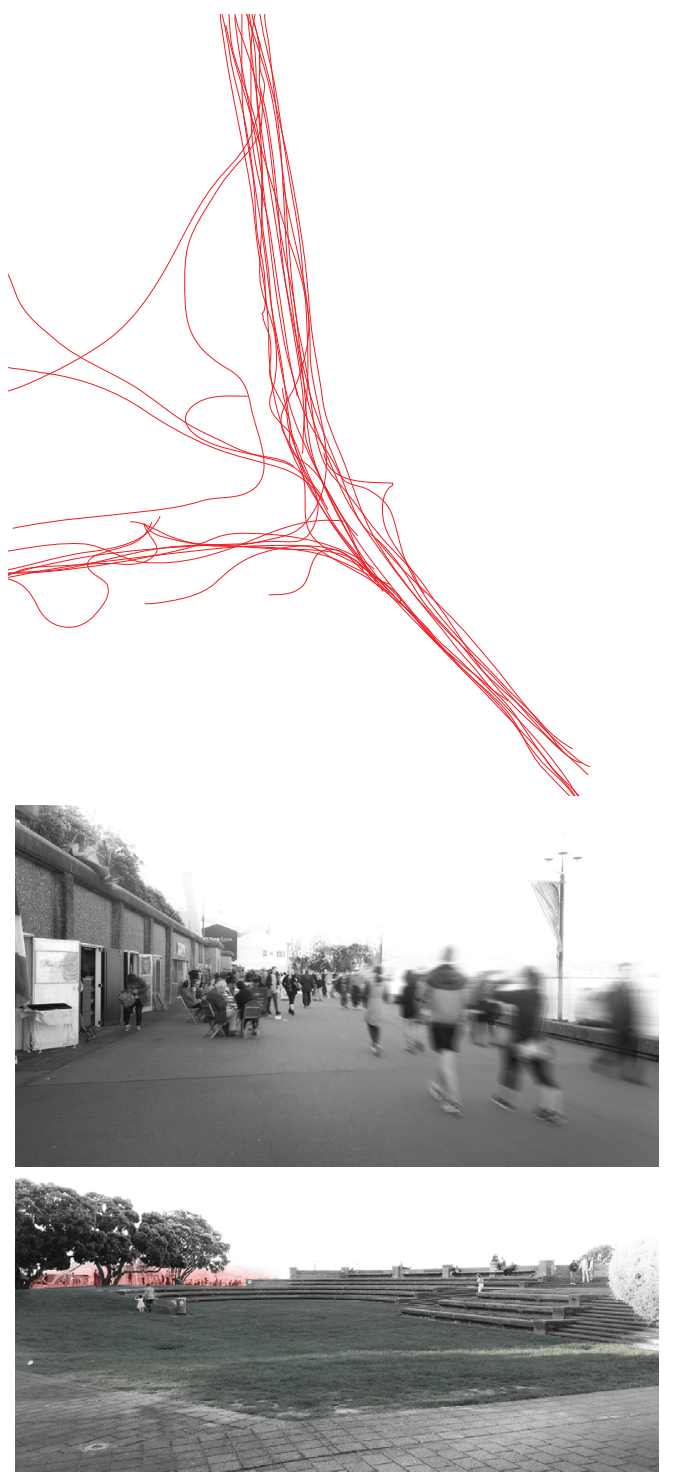

fig. 1.13: (above) promenade / park juxtaposition [A]

fig. 1.12: (opposite) frank kitts park 
4. KUMUTOTO AREA

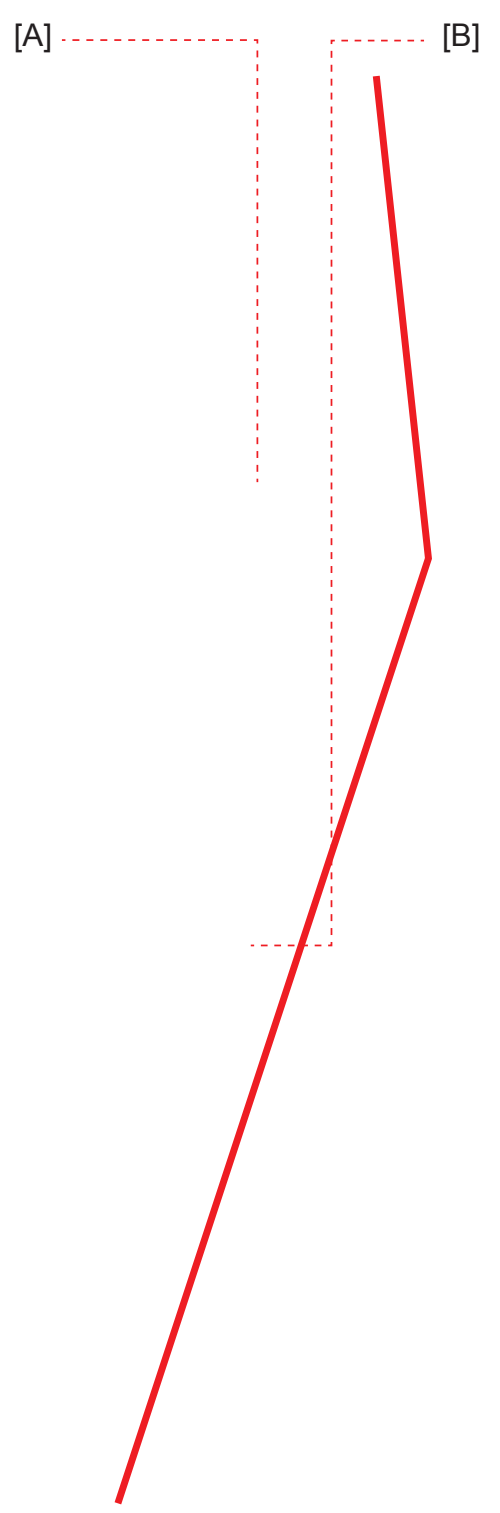


This area has a fascinating cycle of occupation as the business workers from the CBD arrive here for lunch, changing the space entirely. The sudden influx of leisure escaping the everyday gives a realistic, routine validation of Stevens' writings. In general, the experience of the space differs from the previous waterfront areas because its location on the outskirts of the CBD the sense of claustrophobia reduces, the number of tourists decrease and the rhythm slows significantly. Because of this the space is perceived as accessible and welcoming, and the 'rules' seem almost non-existent thus determined by the person themselves. fig. 1.15: (above) meandering + leisure spot $[A+B]$

fig. 1.14: (opposite) kumutoto area 


\section{Wellington Paradigm/Analysis conclusions}

Diverse usage

Throughout the waterfront various people use the spaces differently; the mixing of slower walkers, exercisers and cyclists create a fluidity of intertwined rhythm. Regardless of whether the path is wide or narrow the different users comingle without frustration or annoyance; perhaps this is due to the quicker exercisers being adept to dealing with this coexistence on the waterfront or maybe the urban fabric has been designed thoughtfully to accommodate for this.

\section{Social codes}

Overall, the waterfront has malleable social codes, meaning people are comfortable to push the 'boundaries' of the space and feel at ease. The lack of prescription indicates tacitly that the space is free and relaxed so playful acts and disruptions or inconveniences are met with positivity or indifference. Pre-determined functions conflict with the spontaneity of public life. The malleable social codes are communicated to people via the diverse users' coexistence, as mentioned above, and their various speeds as well as the wide pathways and multiple seating opportunities. We can understand Wellington's social characteristic through the relaxed atmosphere of the waterfront, the moments of exploration and discovery further emphasise the playfulness that is sought.

\section{Re-engagement}

As stated earlier, moments of enforced reengagement and conscious movement occur at funnelling points. This is seen thrice along the waterfront: the thin bridges at the Clyde Quay wharf, Te Papa area and Frank Kitts Park disrupt the spatial rhythm and increase one's spatial awareness. This a successful element in connecting people to others and their surroundings.
Because of the aforementioned social codes, people are left unperturbed at the funnelling yet the experiential juxtaposition occurs nonetheless.

\section{Routine leisure}

The waterfront accommodates for working people as a break from the everyday. A daily influx of people evokes relaxation and compelling relief to be amongst the urban, this develops into a collective desire to experience leisure. This is an example of a spatial rhythm that transcends the physical elements that originates from the distinct part of life, leisure. There is a need to provide leisure spaces. With the business district adjacent there is potential to develop this idea where Frank Kitts Park can become a focal point for this pattern.

\section{Changes of levels}

As seen in Frank Kitts Park and in Clyde Quay wharf area, the majority of people appear to rather travel on an unchanging path than a path that changes elevation. It is how the respective ascent and descent are presented that determines success. An opening that requires either knowledge or immense curiosity to enter into it can work but not as a main entrance. Where elevation changes work on the waterfront is at moments of leisure, as seen in Kumutoto area and Frank Kitts Park's amphitheatre; people explore to find a comfortable area to interact with the water or to sit either for privacy. 


\section{Wellington + Urban Rhythms}

Amin's writing hints at the importance of rhythm in urban spaces: "every public space has its own rhythms of use and regulation, frequently changing on a daily or seasonal basis" (2006). The above analysis revealed some of the waterfront's rhythms; particular Frank Kitts Park's unrelenting rhythm and the Kumutoto area's occupational rhythm. According to Amin, this rhythm is a pattern that tacitly communicates sensory and behavioural information, similar to the 'social codes' in Lefebvre's triad. Rhythms were found to have patterning or repetition as an innate quality specific to that space. Further exploration into these urban rhythms led to Filipa Wunderlich's "Symphonies of Urban Places: Urban Rhythms as Trace of Time in Places" and her extrapolation of Lefebvre's Rhythmanalysis.

Lefebvre's ideas of 'Rhythmanalysis' evokes his own triad's 'representational spaces', the lived experience. "Rhythms as inherent elements of everyday life can be perceived in urban spaces" (Wunderlich, p.97), these are constrained by the urban fabric, behaviours of people, social settings of the specific place and by culture. Urban rhythms "are specific to cities, thus urban places" and can be broken down into two core characteristics "they embody time and are place specific" (Wunderlich, p.91). It is the interaction between people, people and spaces, people and events within the same time space that give birth to urban rhythms, while creating the spontaneity and excitement in the public realm- a remarkably indistinguishable definition to Stevens' idea of play. According to Lefebvre, everyday life rhythms have repetition, measure and movement. Repeated accentuated moments occur in time and space that originate from people's movements within a spatial context.
"Social, spatial and natural rhythms together influence" (Wunderlich, p.92) a temporal aspect of city life that helps ascertain the identity of the place, as the social codes are directly influenced.

It is within time where the urban rhythms are commonly perceived. The term given to movement "or the perception of movement as suggested" by the people-space relationship is 'Spatial Rhythms' (Wunderlich, p.92). It is suggested urban spaces are also 'polyrhythmic', "a compound of everyday life rhythms and spatial rhythms" (Wunderlich, p.98) that occurs nowhere else in the city. Considering the diversity of the spaces, the waterfront can be labelled as polyrhythmic. 


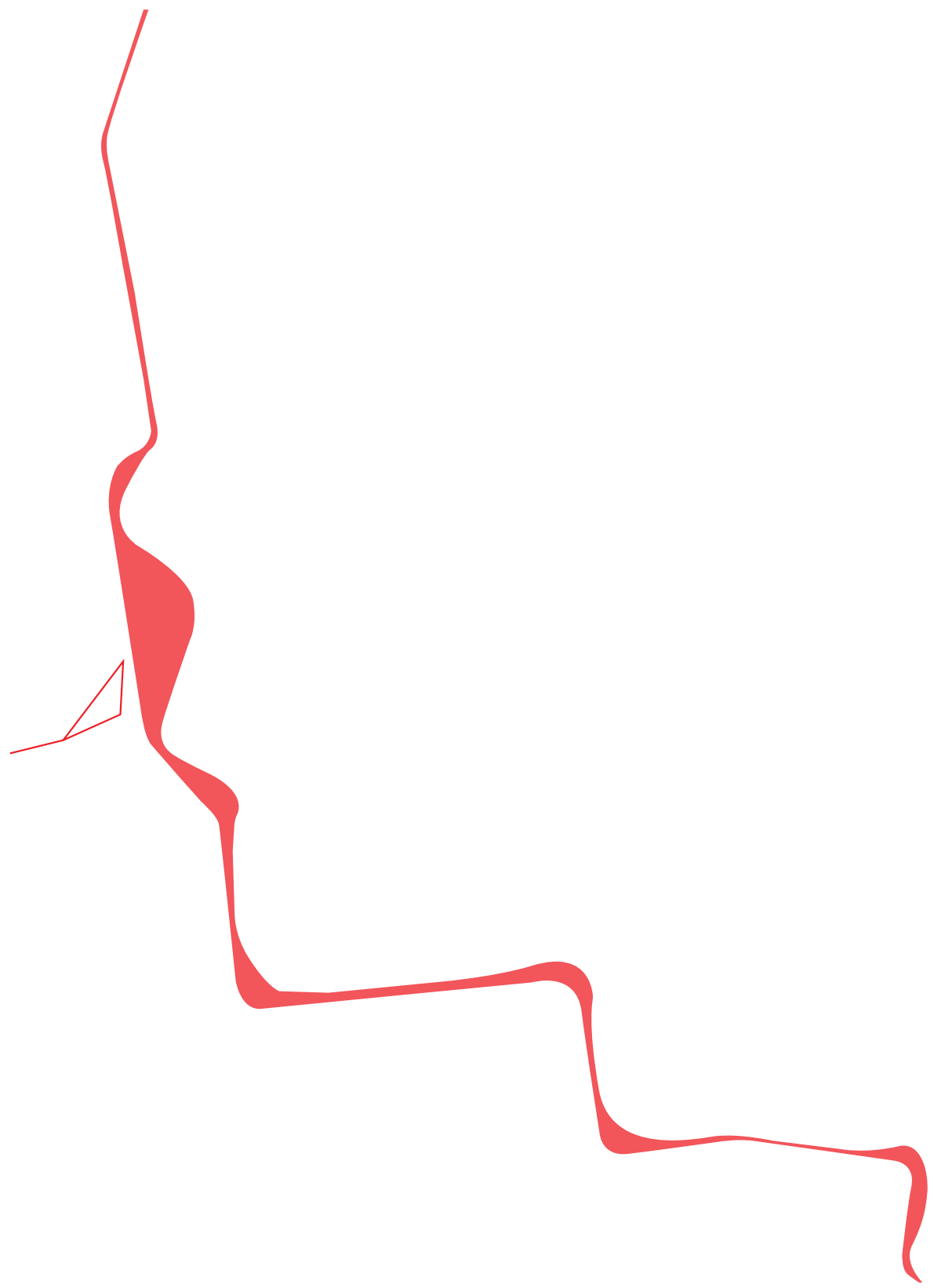

fig. 1.16: Rhythm analysis: speed + engagement direction 
The urban and spatial rhythm can be partially identified through the speed of movement through the site and the interactions between the people within space at one time. Initially the speeds of each space were compared and through the waterfront the estimated direction of visual and conscious engagement were documented (fig. 1.16) In areas of leisure orientated to people, the static spatial rhythms develop, numerous people come into consciousness at some regularity and these create moments of connection. In the Kumutoto area there is periodical occupancy during the working day lunchtime and the extended moments of leisure engulfing the space; it is also seen at the playground at Frank Kitts Park where the kids often undergo play and become the subject of attention for nearby people, moving or otherwise. These two examples show simple 'everyday' observations that contribute, yet even when the dominant events are not occurring the memory lingers within the intuitive space of people's minds:

"One subconsciously recognises these social everyday life rhythms as part of these spaces and they contribute to the building of the image and remembrance of those spaces as places. Often, urban rhythms become even more important than physical characteristics of places, thus becoming collective representations and memories of them...they take the form of representations, memories and ways of engaging with urban places."

(Wunderlich, p.106-107)
A tertiary analysis of the waterfront will help refine the understanding of the literature. This will be achieved by focusing on the 'spatial rhythms': the general speeds within the four areas and observing the apparent engagement between people, and between people and the architecture/city. Presenting the direction of the engagement, by using the representational spaces aspect will also reiterate the problems and effects of the urban fabric in the spaces. Experiencing the urban rhythms and observing from afar will ensure the process reflects the previous analyses. 


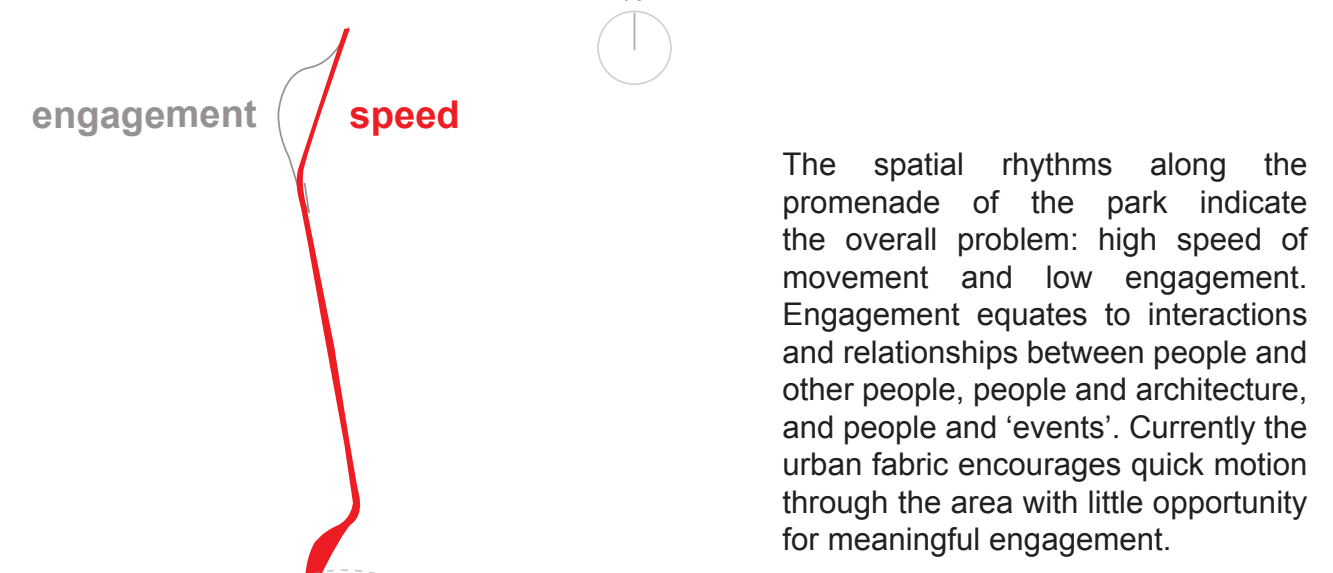

Frank Kitts park

Te Papa area

secondary rhythms (traffic)

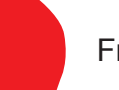

Frank Kits park

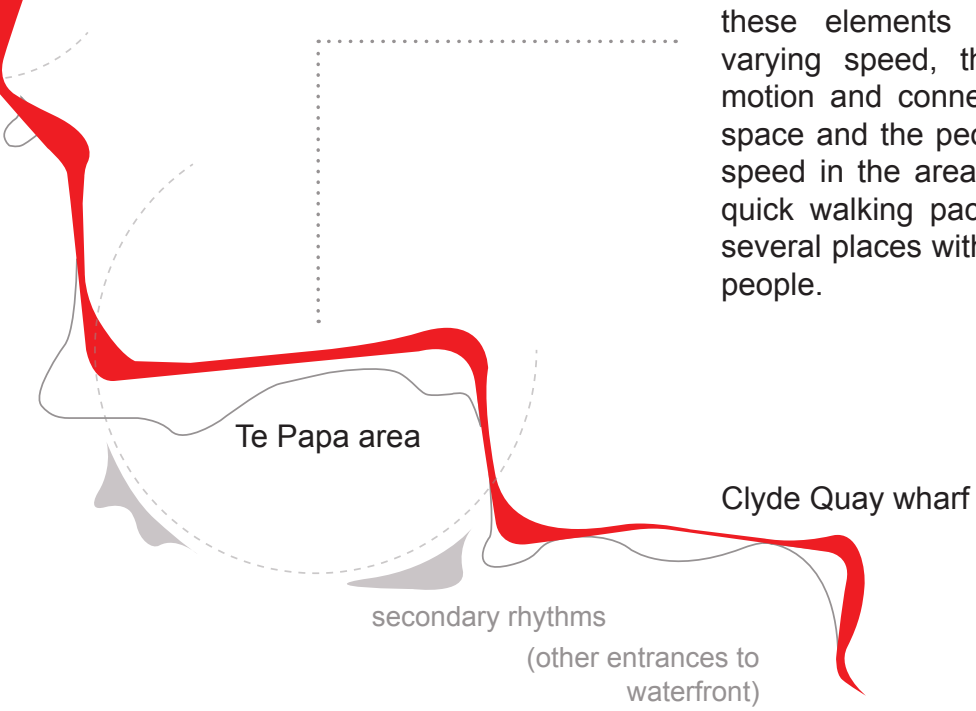

Rhythm analysis:

magnitudes + secondary
Elements of discovery, changes in the path and thoughtful seating attribute to more successful spatial rhythms; these elements provide points of , therefore conscious people within it. The pith the condensing of

\section{rhythms diagram}




\section{Effects of Urban Rhythms}

There is a general speed along the waterfront. Across the promenade near Frank Kitts Park the speed increases and the engagement decreases, an inadequate urban rhythm. Whereas in the Te Papa area the engagement is high and the speed is low/medium, a successful spatial rhythm; there are regular moments of play in this area too, suggesting an encouraging correlation between everyday performance and urban rhythms.

The complexity of the polyrhythmic spaces is perceived clearly, but difficult to represent visually. The successes and failures have been identified above using Lefebvre's strategies, and urban rhythm analysis reflect similar conclusions. Failings are seen where a space lacks variance and offers few opportunities for play + leisure or chances to connect with others.

"The concentration and superimposition of social and human activity, overlaid by forces of nature and constrained by man-made spaces, makes urban places an exciting context to study a broad variety of urban rhythms."

(Wunderlich, p.98) 
Along Frank Kitts Park's promenade (top) there is slight variety in the speeds, this creates a tedious experience of the space. The highly repetitive movement makes it difficult to distinguish a notable rhythm. People fail to engage with their own journey because of this space suffers.

Clyde Quay wharf (middle) prospers from contextual stimulation and atmosphere of boats, cafes, apartments and the backdrop of the Wellington city. This area gains a rhythm through the contrasting speeds of people but also in the condensing of people at each entrance and then the consequential expansion towards the middle. This pattern is interesting to experience and observe and is a good example of the repetition, measure and movement in urban rhythms.

Polyrhythmic qualities can be seen in the Te Papa area (bottom), multiple points of entry produces constant convergence that blends people in the most rhythmic point on the waterfront. The convergence forms an experientially engaging focal point that creates a successful urban rhythm.
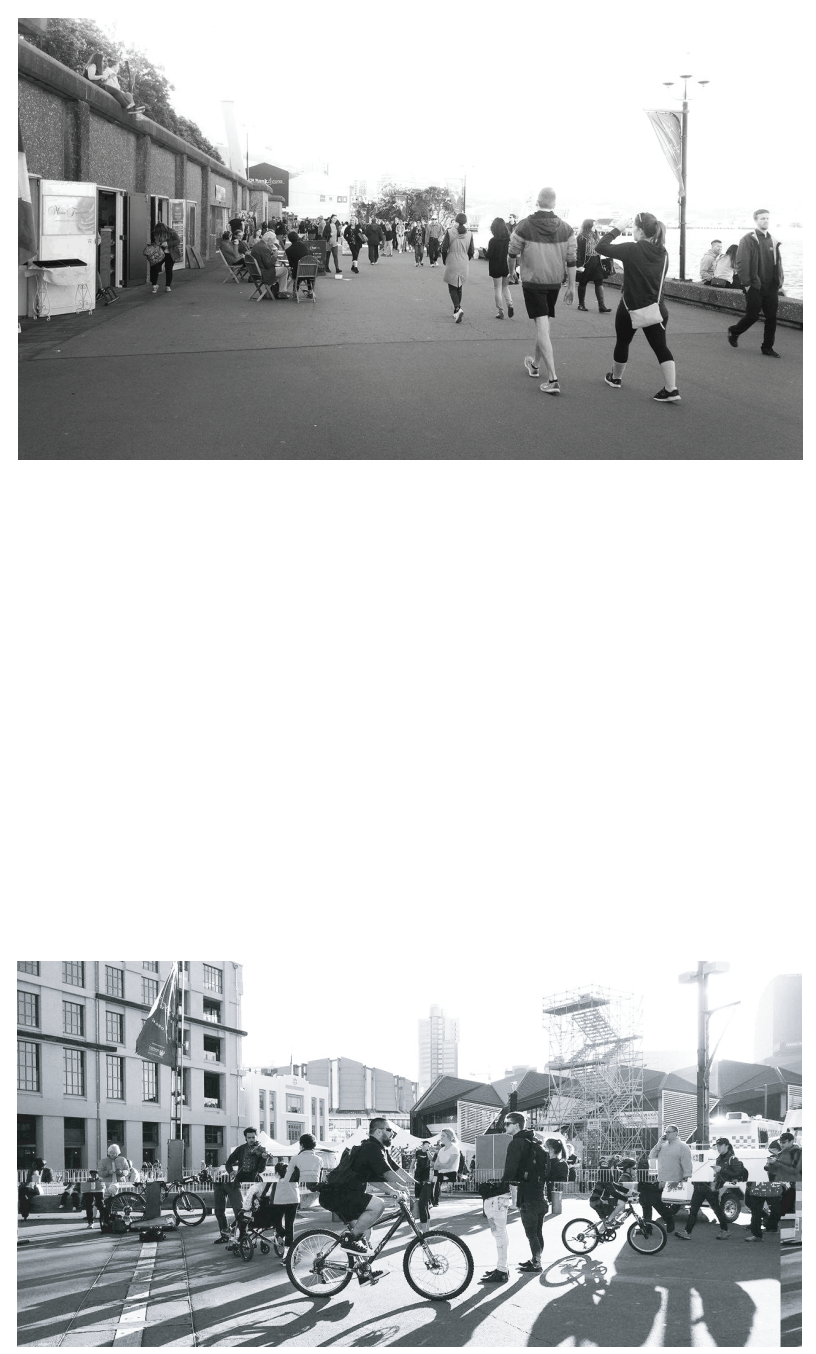

fig. 1.17: comparing different areas 


\section{Conclusions / Site of intervention}

There are genuinely successful spaces along the promenade that prosper from relaxed social codes and accommodating atmosphere; the moments of everyday performance, play and leisure are formed and reciprocated by these social codes. The thread of Lefebvre's comprehensive works travels further into the research with the introduction of urban rhythms and rhythmanalysis. The analysis validated the literature and asked interesting questions about Wellington's waterfront. Notably, the concept that lingering traces of these rhythms significantly adds the identity of the space holds merit. The similarities between urban rhythm analysis and play + leisure is uncanny, and the relationship between the two offers opportunity to develop the way in which urban spaces are analysed. Successes and failures have been identified through the various analyses of Wellington's waterfront. While different critiques and observational or experiential techniques were used, one area was found to be inadequate in each analysis: Frank Kitts Park.

Out of the research and analysis emerges the need for Frank Kitts Park to be improved. The area's engagement and effect on the milieu is insignificant. The analyses, namely conceptual triad and urban rhythms, can be used to devise objectives to reimagine the Park as a focal point for greenery, play + leisure and experiential affection. The intervention's scope needs to be determined, but the genesis of its function can begin here.
While it is stated regular rhythms offer a sense of ease and well-being, Wunderlich makes a point that disruptions to the rhythm can contribute positively, disruption can improve the "meaning and stability" of the place, giving examples of "exceptional events... street performance... or the meeting of a good friend" (p.108). This concept could perhaps determine Frank Kitts Park's role on the waterfront: to encourage a disruption of the urban and spatial rhythms through architecture's implementation. Public space must be the antithesis to everyday life, but this idea can be reconfigured to fit within the waterfront's context. Frank Kitts Park could disturb the rhythm and form a point of difference to the rest of the waterfront. Simultaneously, the site can be reimagined to concentrate on encouraging play and leisure to create moments with meaningful engagement and stimulation. The proposed direction will require further research into performance and people's behaviours within before beginning large steps into the design, this is a crucial stage to further narrow the scope of the research while also keeping people and experience in focus. 

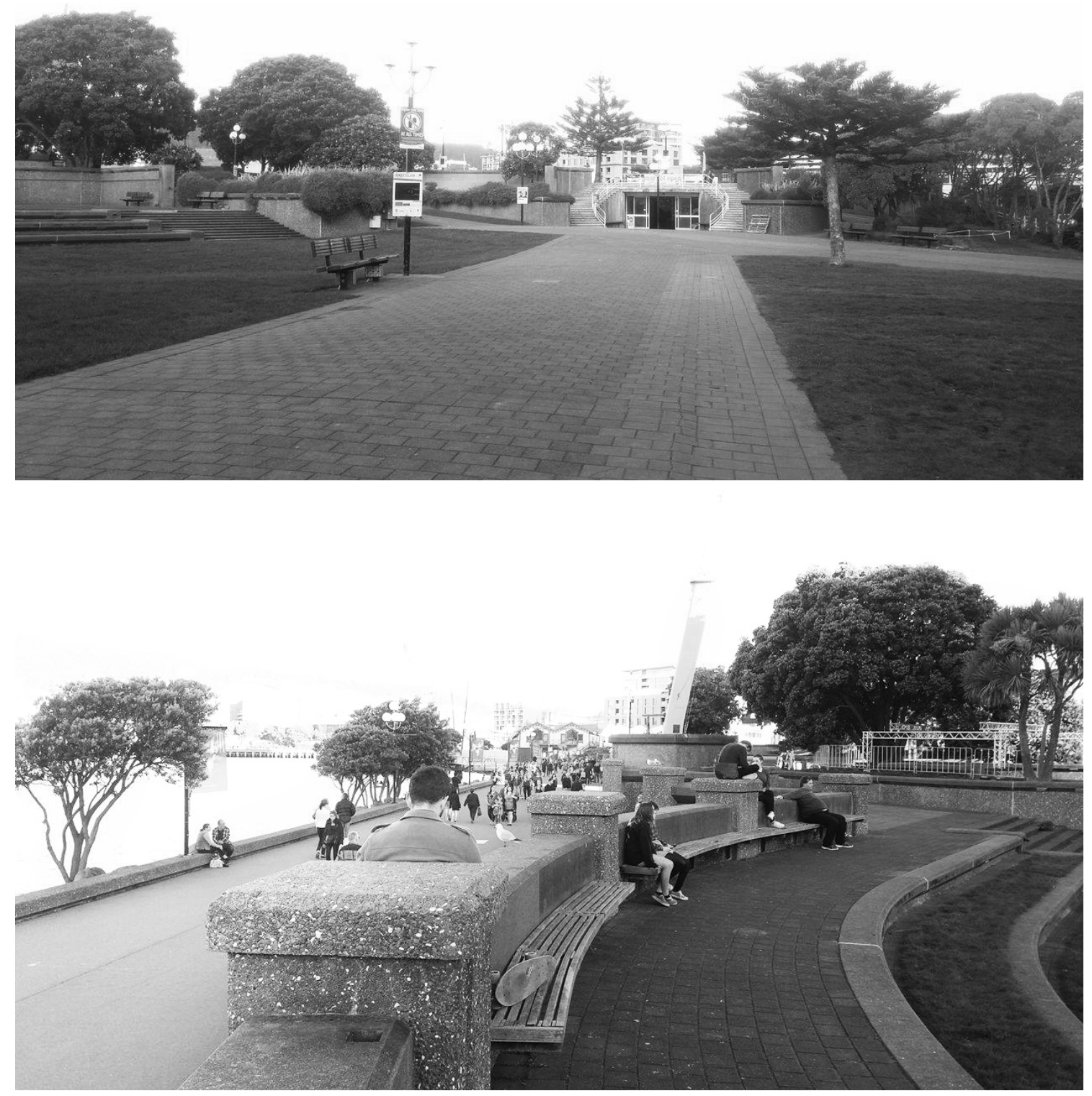

fig. 1.18: frank kitts park varying occupation 


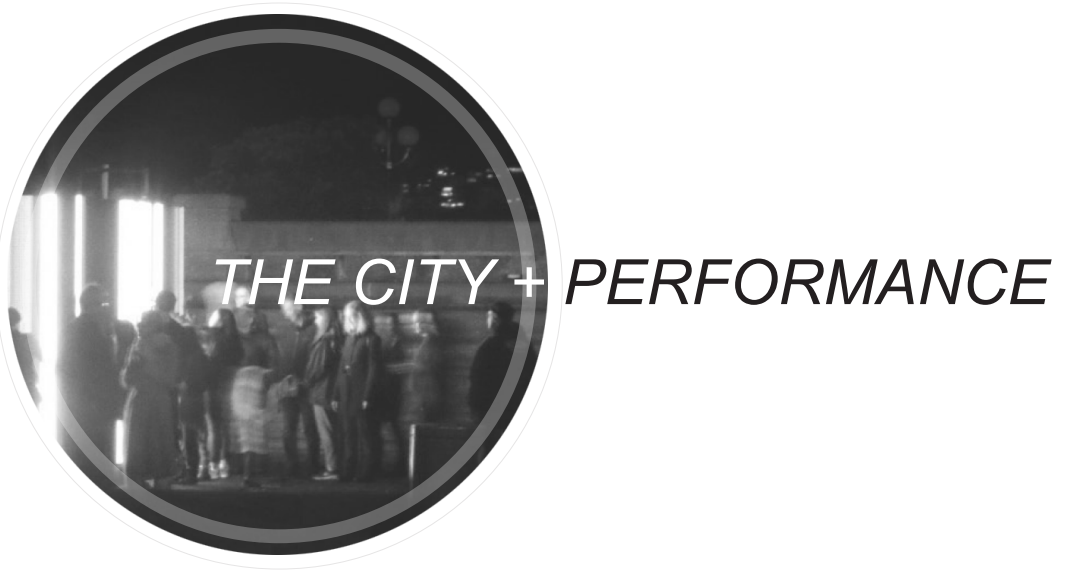




\section{[3] \\ PERFORMANCE WITHIN CITIES}

\section{Introduction}

This chapter will discuss the interconnections between the city, performance and human behaviours. The previous chapter looked at how Wellington's waterfront's urban spaces operate and how experiential analysis can produce comprehensive conclusions, this section focusses on Wellington and what performance means in its specific context. The first part of this chapter discusses people and performance; the second part looks into the sensory and experiential qualities of the waterfront's performances, this will allow the research to travel further into the interior design realm while also testing the urban-based literature.

\section{Echoes of literature}

"Music Performance in Public Space: Changing Perception, Changing Urban Experience?" written by Vivian Doumpa \& Dr Brian Doucet investigates the power of music to change the experience of an urban space. While the writers focus on music and its significance in bettering a public space, some findings can be linked to performance. Doumpa \& Doucet observed and compared human behaviour in two situations in the same area, one control situation and one with a band playing music. A notable finding was that people were more willing to engage and contribute to the space. The text identifies three critical aspects for a quality public space: accessibility and how the space is used, community and sociability, and sense of comfort. Comfort entails physical characteristics, but also 'social-psychological' characteristics like attractiveness, pleasure and safety. Diverse people who are comfortable will be encouraged to inhabit for longer periods.
It is argued here that music is a powerful weapon to "revitalize memories, emotions and perceptions" (Doumpa\&Doucet, p.2) in the urban realm, these key words are potent.

One cannot simply replace Doumpa \& Doucet's ideas of music with performance, especially in the context performance is explored here (everyday performance). There are aspects of the text that parallel both Stevens and Wunderlich, therefore the terms below have been extrapolated to connect the texts and discuss people engaging with performances in the city. The breakdown of these six terms and ideas is important in finding relevant points of interest and discovering what can be used to analyse and critique Wellington's waterfront further. 
Triangulation

"The process by which external stimulus provides a linkage between people and prompts strangers to talk to each other as though they were not"

(Whyte, p.94)

Triangulation provides an example of an inherent phenomenon that occurs in the urban context. City life in its natural state facilitates human responses and reactions but performance, may it be an unusual person, music or an interesting object that are outside preconceived social roles, is particularly proficient in producing triangulation. Performance orientates the audience that creates a close proximity between people and giving "strangers a common base for interaction" and linkage.

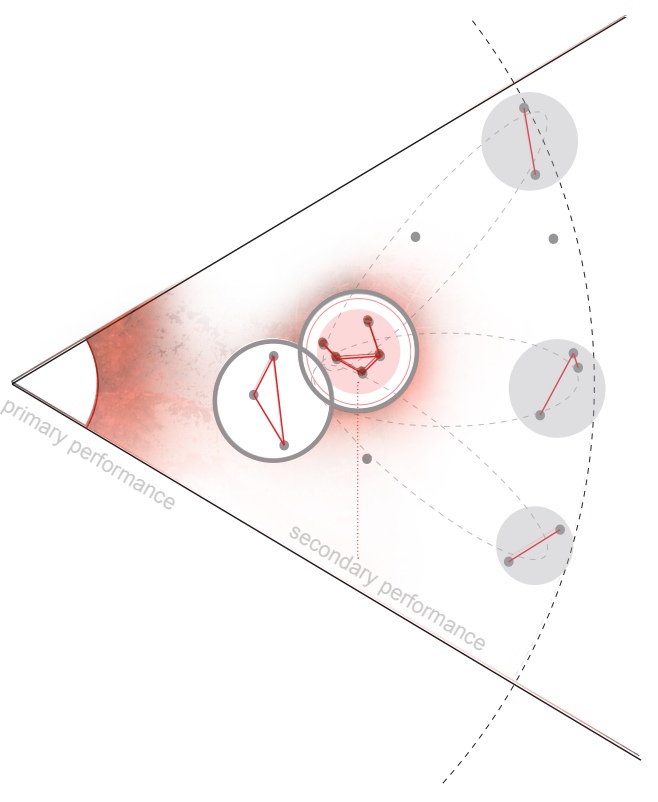

triangulation between people can culminate into a type of performance that gets transfered into the overall environment 


\section{Music cognition}

The perceiving of sounds or music happens continuously in public spaces, and once the senses are activated the mental processing of certain sounds lead to individual perceptions and emotions. This process is labelled as Music cognition by Doumpa \& Doucet. Exploring this notion can be an effective step forward; auditory aspects can initialise an experience and combine with other sensory elements to create an overall affecting experience.

\section{Same time space}

"People often spend more time transitioning through space rather than inhabiting specific places"

This reflection by Lisa Chandler on city life is regularly seen on Wellington's waterfront where the majority undergo goal-orientated travel. People tend to travel through the public space with minimal reflection on their environment or experience, preventing meaningful engagement. This idea is a critique on public life that fits well within the urban rhythms analysis.

Performances have the ability to slow this transition as the audience must exist in the same "place and at the same time as the [performers]" (Doumpa \& Doucet, p.2) to effectively perceive and enjoy the performance, environment or experience. 


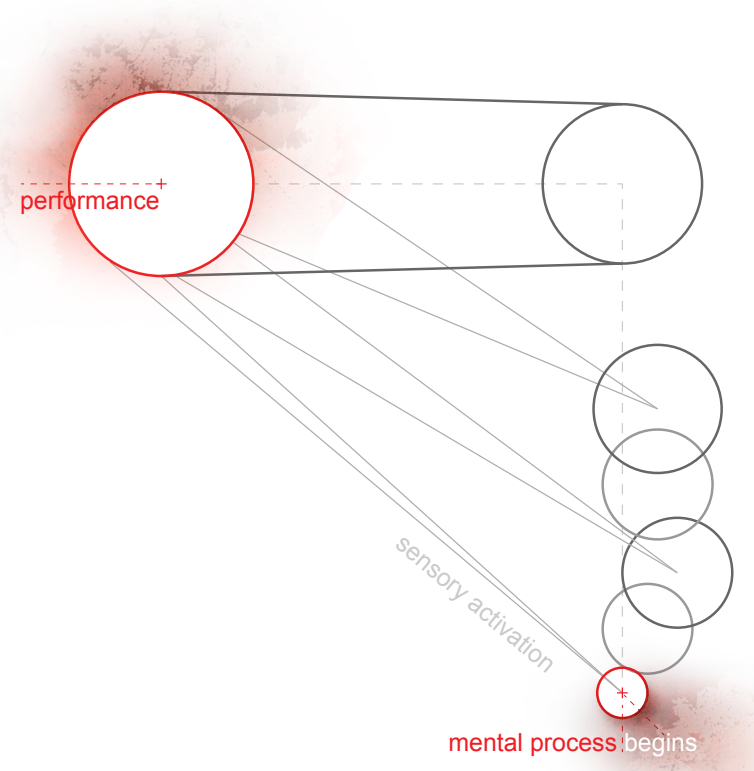

(above) music cognition (below) same time space 


\section{On the periphery}

In The Ludic City, Stevens observes the public and people's behaviour and social patterns. Several conclusions can be made and treated as general patterns in the use of public spaces. One such observation is that people "tend to spend a lot of their spare time at the boundary of public space" (Stevens, p.118)

Sitting on the periphery of performance spaces creates an audience devoid of outward commitment, "seeing without being singled out" (Stevens, p.118) as an observer. This freedom gives people a sense of leisure and offers engagement without obligation. This idea can inform spaces for concealed engagement at a distance, with the perceptions and experiences of the performance differing to the 'primary' audience spaces.

\section{The presence of people}

"What attracts people most, it would appear, is other people"

(Whyte, p.105)

Implementing music and performance into a public space has a noticeably positive effect on people's engagement to their immediate surroundings. Doumpa \& Doucet infer that live music is successful in public spaces because it means the space must be inhabited with other people. This reassurance makes it more attractive, safe and comfortable. Using interactive interventions that produce music or sounds can attract people in combination with music cognition. 

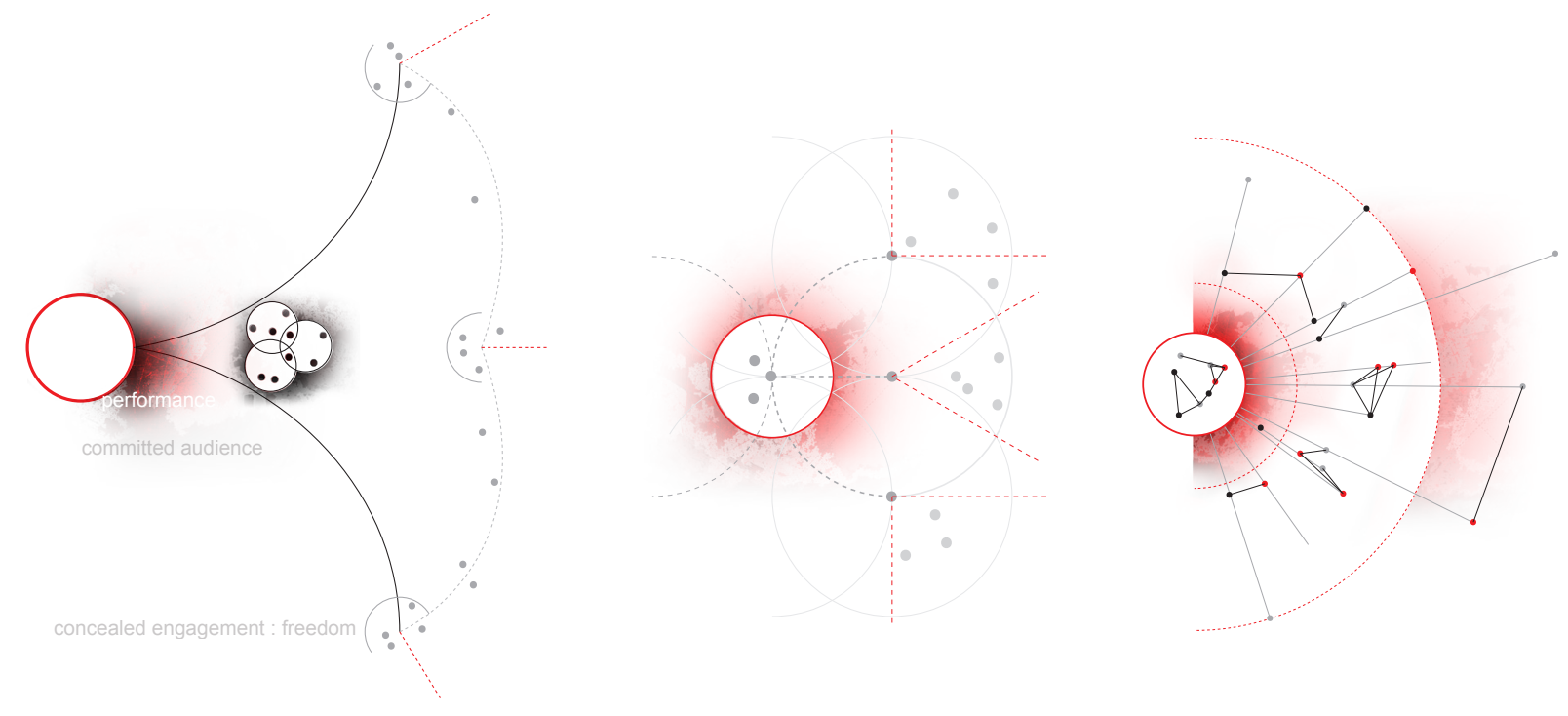

\section{Mixing trajectories}

Creating a focal point "where social and cultural trajectories are met and interact"; these interactions between "diverse individuals, their mixing, is which gives city life its special characters and possibility"

These two statements, from Doumpa and Doucet (p.3), and Stevens (p.5) respectively, complement each other and provides another goal for the design intervention: to facilitate this 'mixing of trajectories'. Creating a space that attracts and affects people at a fundamental level will therefore create a space where the diverse collective are engaged with the city and with each other, thus adding to the character and performance of the city. 


\section{Summary}

The ideas discussed can be utilised to integrate and emphasise everyday behavioural phenomena into the design intervention. The underlying presence of performance and how it can improve stimulation, experience and engagement is particularly successful. Innate moments of play + leisure and everyday performances can be analogous to the performer, with the public acting as the spectators.

Interactive moments of play can reach multiple people with different social and cultural characteristics, therefore creating a bond between these strangers. Furthermore, the freedom of occupation and the encouragement to engage and interact can meaningfully accommodate for the diversity of public spaces. The opportunity to spectate on the periphery leaves a sense of ease on the person, while consequently attracting others who become part of the audience or the performance itself. The effect of the performance whether it is music, sounds, or people talking and engaging with each other can be inviting. The individual mental and emotional response to these moments can become memorable. It can also be said that performance can affect complex urban rhythms and people's spatial patterns.

By understanding people in their city and how performance influences people's experience, the subtle intimacy of urban space is beginning to surface. The breakdown of these six ideas (right) is important in finding relevant avenues to analyse and critique Wellington's waterfront further.

Triangulation

Music cognition

People on the periphery

Same time space

People attract people Mixing Trajectories 


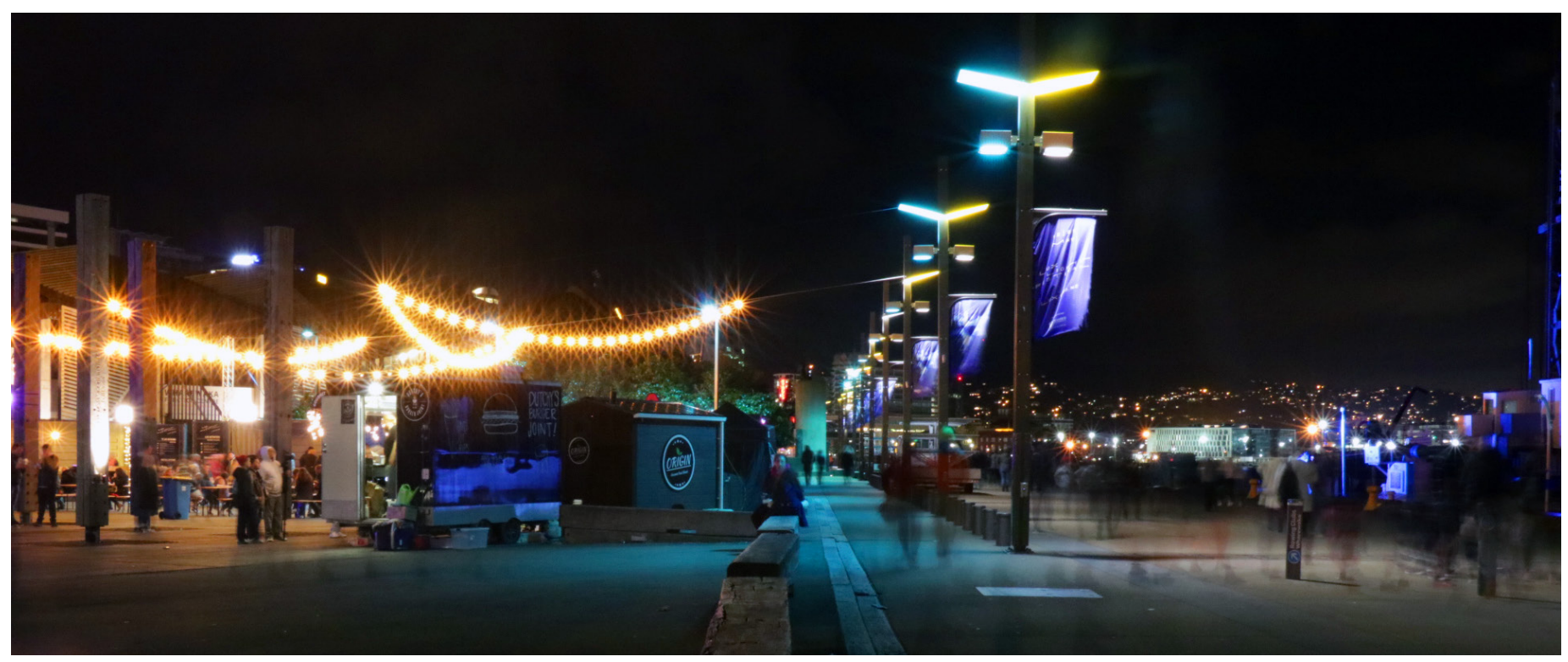

fig. 2.1: LUX light festival 


\section{[4] PERFORMANCE IN WELLINGTON WATERFRONT}

\section{Introduction}

The following section will analyse a series of performances experientially. The aim of this section is to better understand the previous research, but also to discuss how performance can affect an area and if performance hinders or empowers everyday performances.

Along the waterfront there are numerous street acts who perform to the myriad of people inhabiting. Wellington's council encourages these performances but limit the number and noise. Through the analysis in chapter one, the Te Papa area and Frank Kitts Park were deemed most successful and least successful, respectively. The Te Papa area is popular for performances, perhaps due to the heavy thoroughfare; it seems appropriate to investigate how existing performances affect the urban context. Fig. 2.2 shows the four performances that were experienced, these are not permanently there.

Frank Kitts Park is home to several events in the year but the majority lack experiential and contextual significance. An annual event, the LUX light festival is one event that affects people and transforms Frank Kitts Park. The event contrasts with the everyday and provides a rare opportunity for play to transpire. The popular public event celebrates artist's installations for ten days, and the waterfront and Frank Kitts Park are illuminated with joyful lights. 


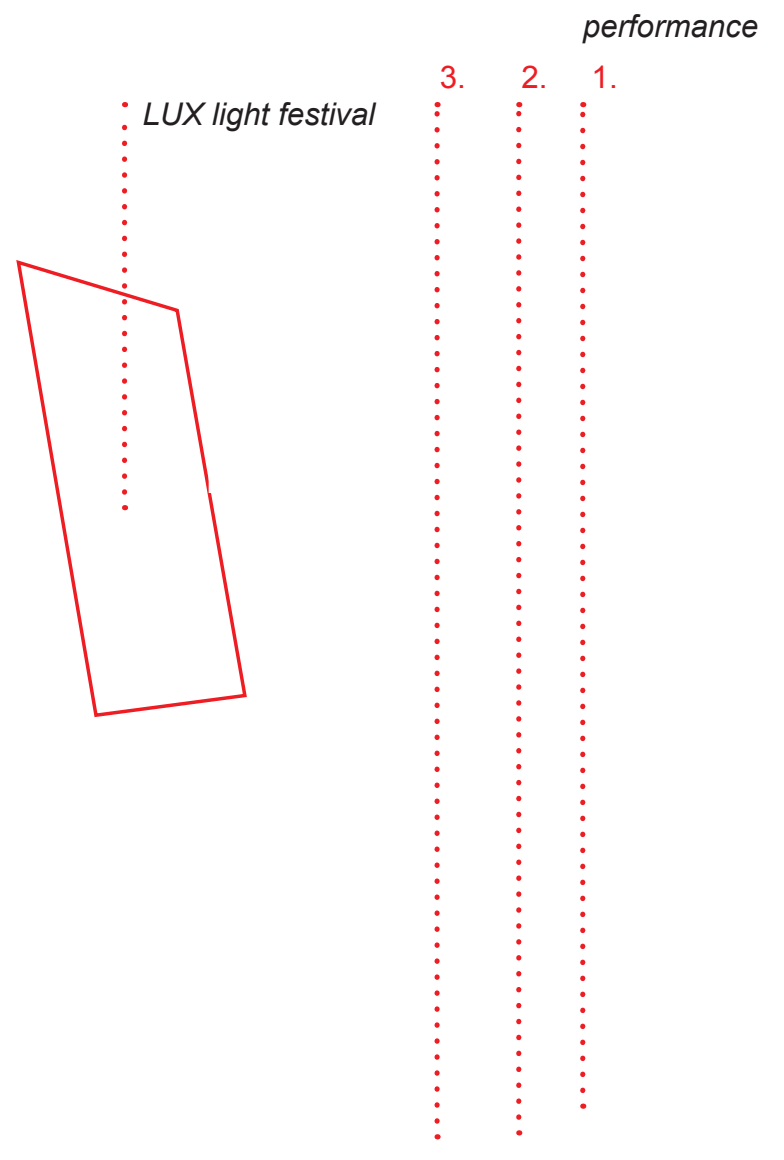

fig. 2.2: performance in the city 


\section{Performance 1: Guitarist}

This guitarist played atmospheric rock interludes, the sound stretched far down the waterfront. The music seemed to blend with surrounding spaces and the existing atmosphere by emanating relaxation and calm. By experiencing and observing others during the performance, the effect of the performance creating comfort within people whilst invoking reflection and revitalize emotions was reaffirmed.

There were a number of people sitting enjoying and visually engaging, and noticeably people walking past engaged temporarily. Several people who were approaching the area, still outside the collective area took notice of the music, and when they got closer they slowed to inhabit for an extended amount of time; this suggests music cognition does affect one's experience.

There was a sense of a collective, where one merges with the vibrant sense of community. The lack of sensory stimulation is realised abruptly upon leaving. The 'stage' for the performer is undetermined so the boundary of performer and audience is blurred. Similar to how the music affects the atmosphere of the space, this undefined boundary affects how people engage.

The location provided seating that was canopied by the trees outside Te Papa. People tended to sit around the safety of nature, the sounds, warm weather and the cover of trees seem to open up more extreme acts of leisure. 

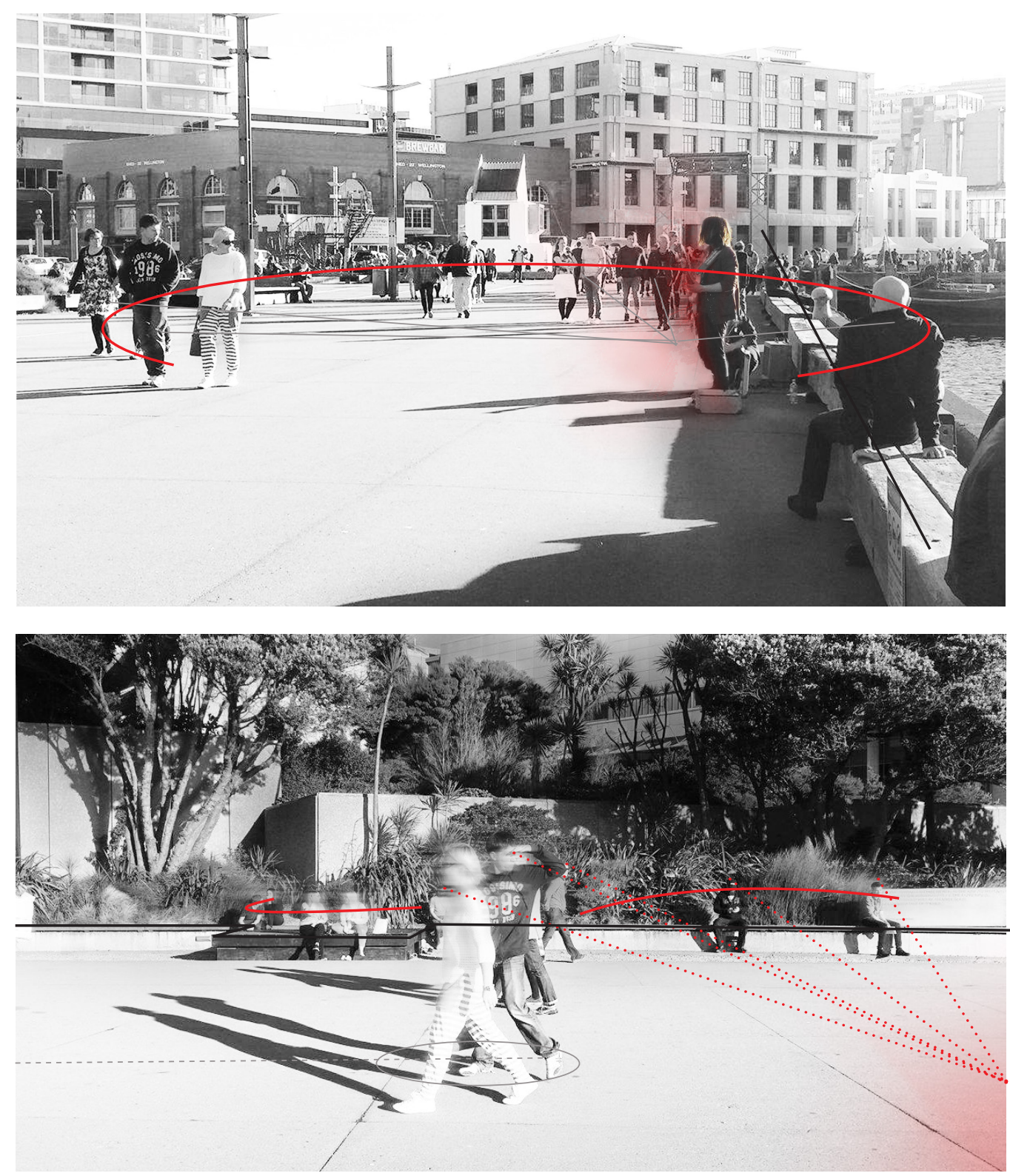

fig. 2.3: people / performance relationship 
Performance 2: Juggler on a Unicycle

NOTE: school holidays

One of Wellington's popular street performers was in the middle of an act upon approach to the proposed site, a large crowd was encircling the performer. Looking at the crowd, it was easy to see the validation of the 'people on the periphery' notion. Some people's attention waxed and waned which showed the freedom being on the periphery allows. These people also tended to move on after their curiosity and excitement was satisfied. The elevated performer gave adequate visibility for the people on the outer.

The type of performance relied heavily on engaging the people completely, what Wellington council call a 'circle act'. Engagement was achieved through verbal interaction between the performer and the crowd. Being in the same time space was crucial for the act to be successful, this gave an air of anticipation and spontaneity. Because of the vocals, people were aware of him or aware that something was happening, even at great distances. An interesting observation was that people who were wandering past slowed down to glance at the performance and temporarily be part of the collective. It seemed almost instinctual to gravitate towards the mass to observe as well, even if it was only for a brief time. People were given room to pass through the space (seen in the bottom image). As a spatial study, the collective naturally develops to envelop but not obstruct non-engagers. From afar it was easy to see there was a collection of people, the open space enabled this. 

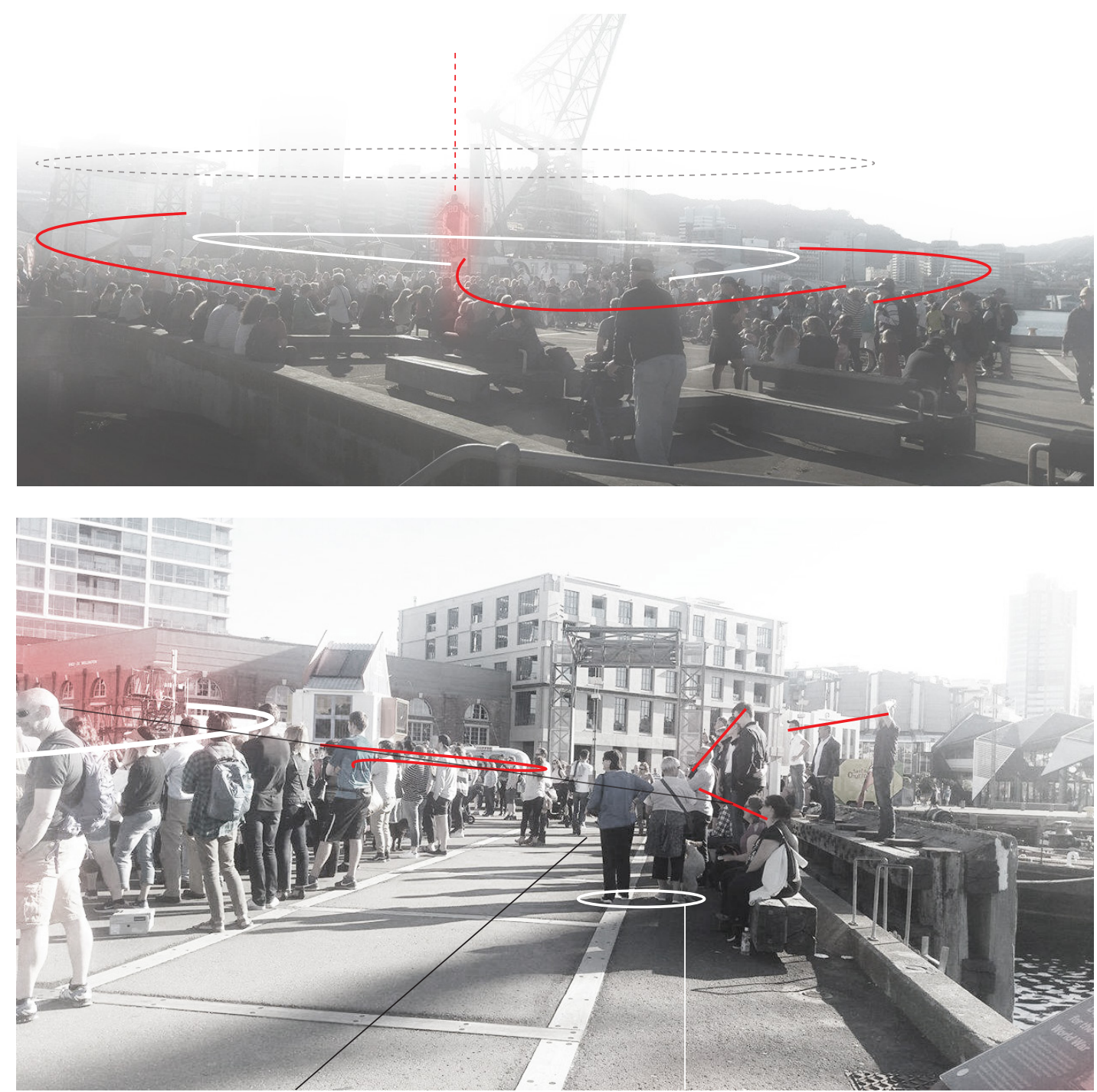

fig. 2.4: people on the periphery 


\section{Performance 3: Violinist}

This performance formed an intimate atmosphere within a public space. The violinist was adept to inviting a crowd and what resulted was a small gathering who were transfixed. His violin was unenhanced so this performance didn't have the luxury of volume. Therefore, only a few people occupied the periphery and music cognition was activated at close proximities. The audience's radius was small but invested. The rhythm in the area is quick, with a lot of people exercising or walking past quickly. The importance of being in the same time space to enjoy and engage with the performance was evident.

The musical style offers a point of interest too. The exotically festive genre caught people's attention, which harkens back to Doumpa \& Doucet's investigation where different genres invigorate the imagination or "bring back memories... cognitive connections with stories heard, movies watched, and books read" (p.7). This genre seemed to be engaging for people as they were willing to openly show interest in the performance; the musician's passionate playing can also be linked to this. The intimacy was produced through the small performance radius, and the performance encouraged people to come closer. It was noticeable that the few people on the periphery got created a connection with the intimate crowd and shared in their enjoyment.

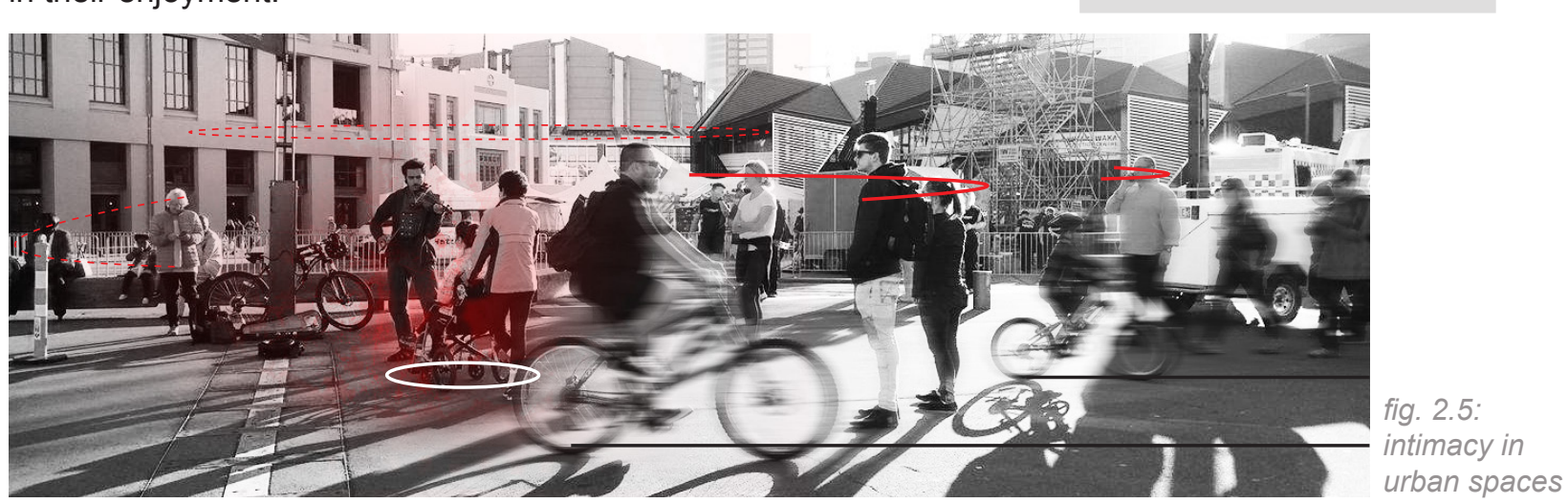

Triangulation

Music cognition

People on the periphery

Same time space

People attract people

Mixing Trajectories 


\section{LUX light festival}

The waterfront is a great location for the festival due to the combination of lights, walkways and water. Subtle lighting elements are littered throughout the waterfront, pushing people into usually unoccupied areas. One could say the ideal atmosphere of Wellington is exposed.

The amount of people who journeyed to Frank Kitts Park to see the installations predicts how the popularity of the park would increase if there was significant redesign. It was apparent that there were plenty of tourists attending adding to the diversity of the waterfront. People were constantly engaged so the argument for public spaces delivering affecting, sensory and meaningful experiences in Wellington holds merit. The increase in people inhabiting was another indication of an improved urban fabric.

The problems of the park discussed earlier still surfaced, however some were lessened or shifted. The obstructive wall of the park made it difficult for spontaneous engagement to initiate from the promenade. Inside, the structures blocked vision through the park, something that would have aided engagement at large distances. Several large areas, alcoves and spaces without any installations were left as empty, dark areas while other areas were vibrant and popular. While this could have been done to emphasise the installations, what resulted were avoided, unsafe and isolated areas that could have been utilized in some capacity.
The installations primarily used light and sound to portray a variety of atmospheres and effects, integrating several interior architectural qualities. The power of light and sound to invoke meaningful experiences for the everyday person was shown. It has been proven lighting can improve public spaces but the aspect that sets these installations apart is sound design, playfulness and manipulability. Each installation had an element of user interaction that blurred the line of participant, audience and intervention. Elements of manipulation develops spontaneity, anticipation, excitement and realisation - which was particularly effective with children. The use of sound generally intrigued and grabbed people's attention even from afar, expanding the installations' range of engagement and presenting an exhilarating contrast to the everyday sounds of the city. 


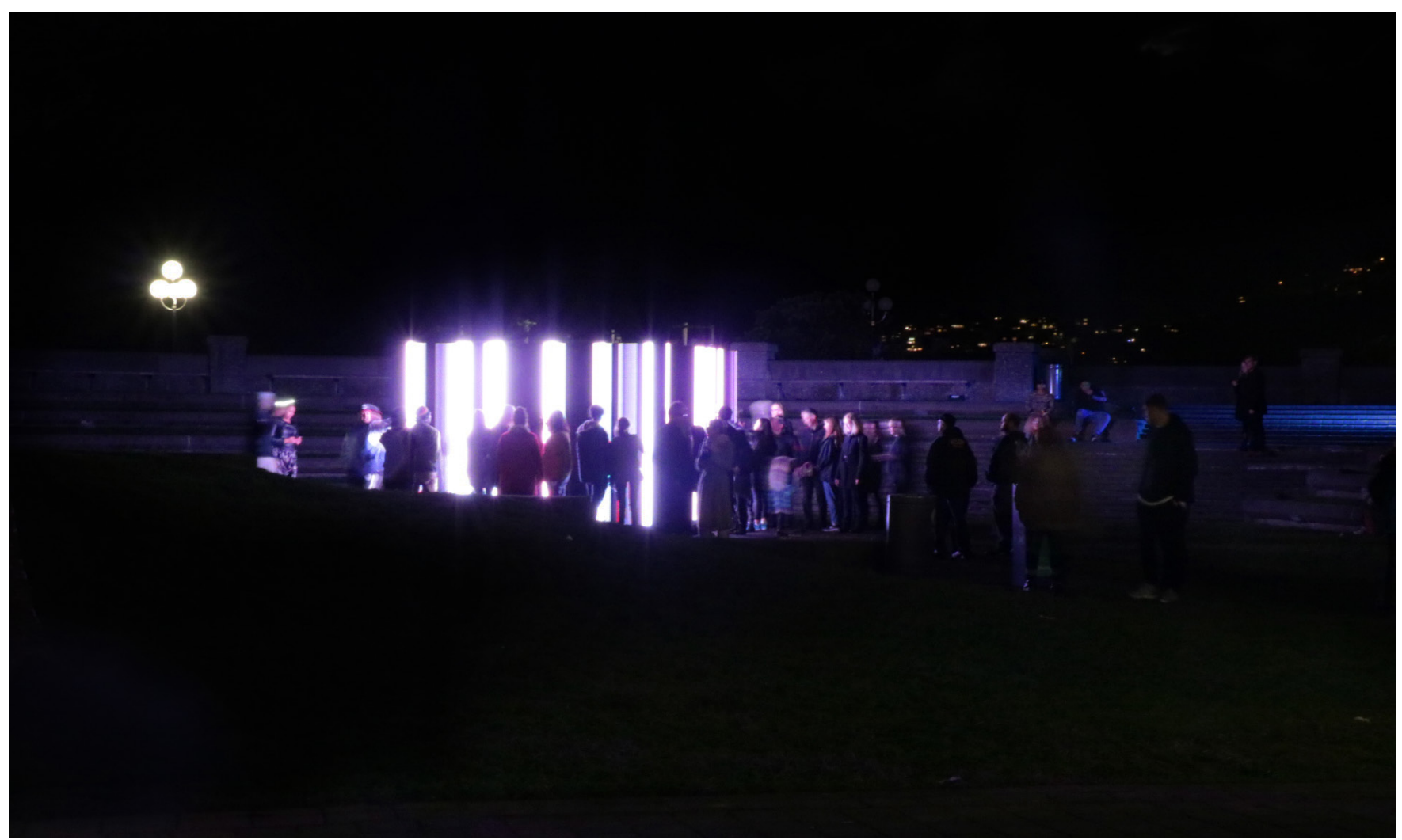

fig. 2.6: engagment with public

Using sound, interaction and kinetic design encourages people to stop, fully inhabit and experience the performance presented. Whether it is the crowd's size or a lone interior set upon a large empty space, intrigue also plays a part in creating meaningful experiences. 

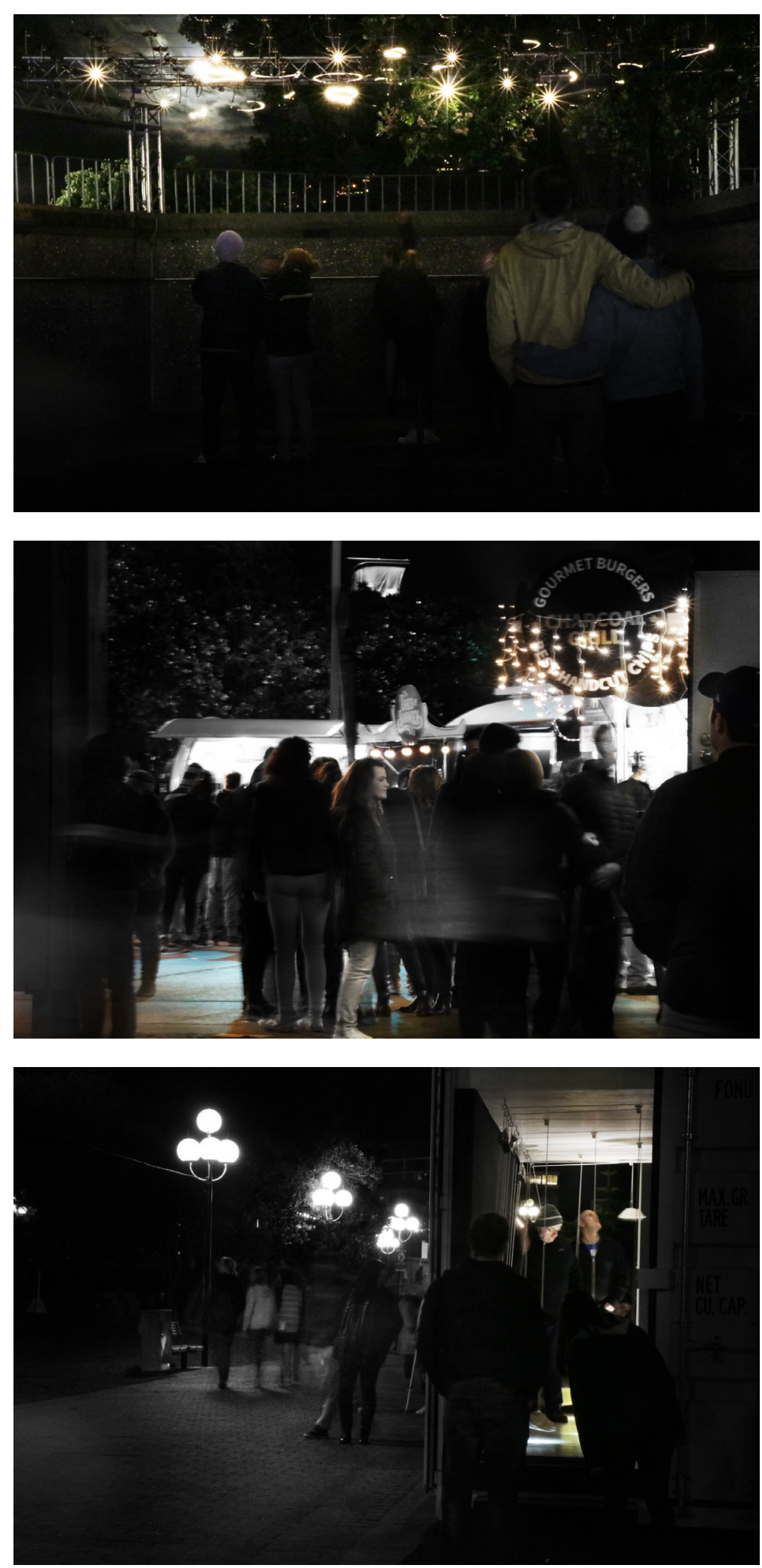

fig. 2.7:

LUX light festival -

sound + interactive

installations 


\section{Conclusions City + Performance}

Much like the previous chapter the literature has refined understanding of urban spaces and people's behaviour in response to performance. Analysing performances along Wellington's waterfront then supported these ideas. It also developed methods to observe the urban spaces. Being experientially aware of social patterns and the implications of the crowds and performers' strategies allowed a deeper understanding of the research topic.

It was evident through this stage how performance can change an urban space. Even within an already successful area the presence of performance transformed how people travelled through or occupied the space. People walking slowed and visibly engaged, this moment disrupted their set rhythm to connect with the environment. Those who sought longer occupation found a nice spot to sit or stand to be stimulated by the performance. The connection made between the audience members created a collective through the mutual appreciation for the event.

Comparing the same areas at different times, with and without performances, reveals the differences in people's behaviours- similar to Doumpa \& Doucet's experiment. Although, by walking in and out of multiple performances transpiring along the promenade one understands the effect in real time and more intensely. When approaching performances there was a noticeable shift in the overall atmosphere, cognitive focus was adjusted, initiated by sound and music. This was able to occur far from the source of the sound, therefore activating the process of music/ sound cognition and letting that mature through excitement, intrigue, annoyance, tranquillity etc.
This was only achieved because sound is not restrained by architecture; installations at the LUX light festival transmitted sound to sonically lure people throughout the Park. Additionally, the festival depicted the spectrum of interaction: some would run up to the installations eager to discover and participate, some people would rather watch and get enjoyment over observing this play, others would amble to the installation and act within the two states.

Sound, human interaction, and play + leisure were observed in all performances, albeit in different capacities; these elements themselves contributed to the experience and production of the performance. Moreover, the success of musical or sound performances is that freedom is still upheld. Freedom to talk, move and even lose focus temporarily without missing a crucial moment of the performance. Sound performances transcend time and shift focus from the visual while invoking emotions and atmosphere without governance. This could lead to the idea that play, sound and purposeful consideration of everyday performances together could provide a more profound escape into the urban realm away from constraints. The analyses and experiments have been concentrating on people and their experience, but they have revealed that sound is a core element to be considered. This leads the research to develop in the field of performance and the sensory within the urban context. 


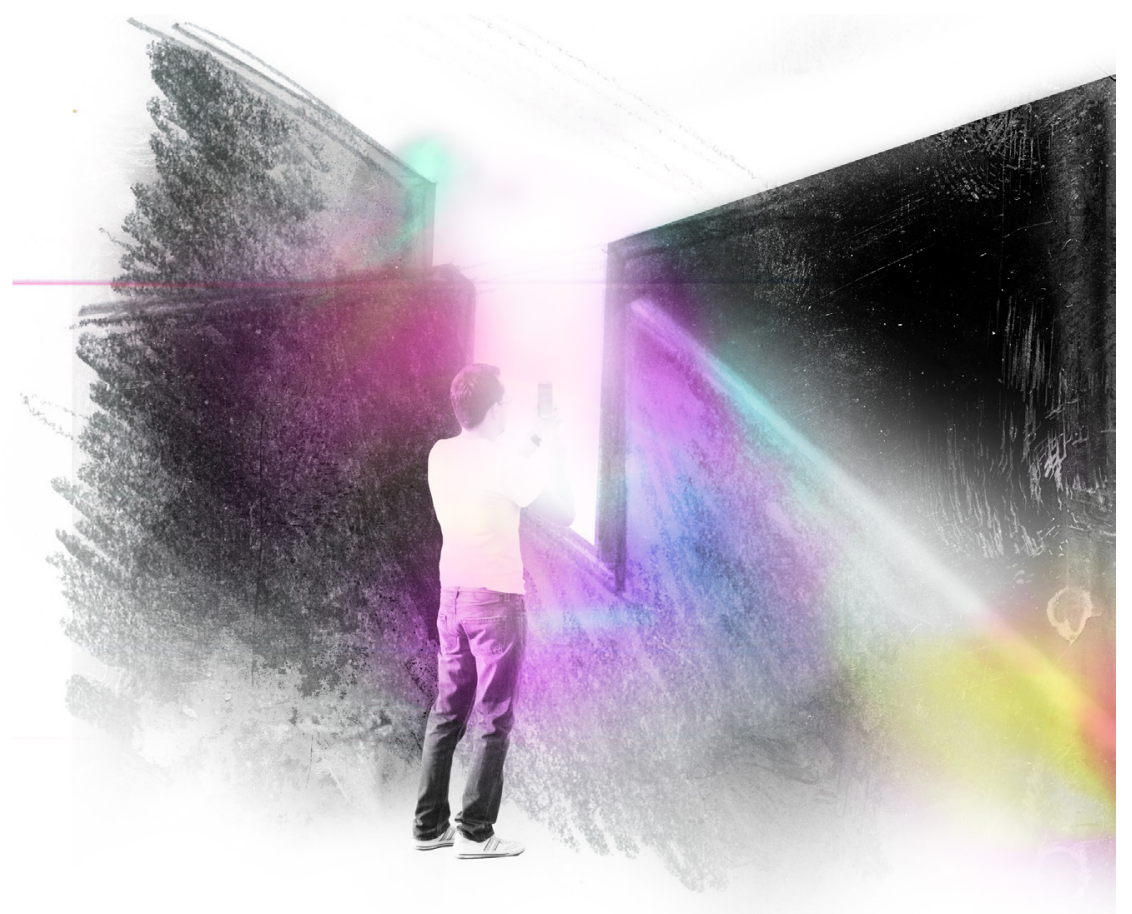


PERFORMANCE + Interior Architecture 


\section{Introduction}

The first chapter facilitated the understanding of urban and public spaces in an in-depth, experientially-led method, while the second chapter explored performance in the city and provided the tools to thoroughly analyse and experience performances along Wellington's waterfront. Conclusions of the literature and the several analyses found Quentin Stevens' idea of everyday performances, play + leisure as crucial characteristics of the urban realm. The importance of successful urban and spatial rhythms were also discussed. In chapter 2, it was established that performance can produce meaningful moments of engagement in the urban context. Importantly, it was also established that sound has potency in the urban context to create connections and surpass the restrictions of architecture to create a meaningful experience and invoke emotions.

The senses are an aspect of the lived world that are inseparable from the concerns in the interior discipline. As previously identified, sound installations and performances attract people, provide atmosphere, invoke emotions and mindstates, and uphold the freedom of public spaces. Sound installations, based off observation and participation, can connect people and encourage contribution to the space. Therefore, it can posited that the urban context is affected by the sound installation but also by the people it is affecting.
These statements and ideas hold significant impact and are key strategies in developing urban spaces. However, sound installations are additive elements to the urban realm; the beauty of Quentin Stevens' play + leisure, Wunderlich's Urban Rhythms and Lefebvre's conceptual triad lies within the idea that they are intrinsic to urban spaces. Finding methodologies and literature that can contain a similar beauty is imperative otherwise the design response will stray from context/ experience specific research. 


\section{Soundtrack of the City}

While attempting to integrate the senses and sound in a more intrinsic manner, the book Urban Interior came into focus. In particular, Malte Wagenfeld's work "The porous-city: atmospheric conversations of the Urban | Interior" and his notion of the soundtrack of the city. He argues that fleeting, everyday urban sounds can be reimagined or redefined in the design world to become crucial parts of the spatial experience. Wagenfeld uses ideas by Juhani Pallasmaa and Diedrich Diederichen, to introduce 'peripheral hearing': an un-concentrated state of listening and processing that is typical in modern cities. There is a need to hear these sounds for they are "indeed the soundtrack of the city" and contribute to the urban context (Wagenfeld, p.150-151). The semantic reflected in this notion lies closely within music; Meklit Hadero suggests a shift can be made in interpreting sounds in everyday life, although she uses this to promote a new wave of musical composition. Hadero discusses John Cage, an American composer and music theorist, and his observations that there is no such thing as 'true silence'. Much like Wagenfeld, Hadero and Cage consider the world is alive with sound. "We are already immersed" (Hadero) but we are not opening ourselves to experience and be affected by this performance;

"We can add to the soundtrack, but it is already playing." (Hadero)
The concentration or filtration of urban sounds could focus hearing and invoke experiences aurally, leading to natural, emotionally cognitive responses. "Sound has the ability to simultaneously integrate and unfold space, the interior with the exterior, and the interior into the exterior" (Wagenfled, p.151). Much of the article talks about sound from within an interior space but discloses the way people hear and respond to sound is of importance. He identifies Murray Schafer and Barry Truax's explorations of soundscapes and their desire to "increase sonic awareness of soundscapes that are as much as part of our daily lives as our visual world, but are often neglected" (p.151-152). This opens up the sentiment that urban sounds are often left out as an experiential contributor for designers and reaffirms that sound constitutes a powerful sensory element that has been left latent in the urban realm.

"Being simultaneously aware of and perceptually immersed in both the inside and outside, and slipping in between is the poetic moment of connection." (Wagenfeld, p.151) 


\section{Soundscape}

The mention of Murray Schafer's Soundscape from Wagenfeld prompted research of this domain of urban design. Schafer is regarded as the godfather of soundscape. Soundscape can be seen as the orchestration of sounds in an urban or public space. Using sound to create an identity of a space is a strong objective in soundscape as Michael D. Fowler explains, strategies were "developed as a means to understand the particular sensory experiences that meaningfully connect an auditor to a site". If sound and urban rhythms can be considered together the musical, rhythmic composition of a space can invoke experiences, feelings and associations inherently. The need for thoughtful consideration of sounds in the city arises in Schafer's argument: "Modern man is beginning to inhabit a world with an acoustic environment radically different from any he has hitherto known... world soundscape has reached an apex of vulgarity in our time" (Schafer, p.3). Much research has been deliberated over the psychological health effect of noise pollution as well as discussions and actions to mitigate noise in urban spaces. But urban planners and architects' acoustic designs "purely focused on the attenuation or amelioration of sound sources" (Fowler,2013), there is room for more thoughtful consideration for sound in urban spaces.
Schafer interprets sounds as 'events' that are heard, and proposes designers harness existing natural sounds and add 'electro-acoustic' sounds to create a composition of sonic events, a sonic environment (Fowler, 2013). If sounds are isolated, manipulated and interpreted comprehensively by the designer this sensory experience can become part of the urban fabric. Moreover, comprehensive analysis of the existing urban sounds in the site is crucial. The site must be experienced and responded to personally, the dominating sound, the rhythm over time must be considered. Schafer states "a writer is trustworthy only when writing about sounds directly experienced and intimately known" (1994), paralleling the analyses undertaken in the previous chapters. The study and practices of soundscape can aid coming design stages. 


\section{DIVERSE USERS THUDDER}

\author{
SONICALLY EXPOSED : CONNECTION
}

redefinition

fig. 3.1: sonic moments on the waterfront
These paths gives existing examples along the waterfront where sound makes an impact on the space and experience. The path in the top image produces a thuddering sound when cyclists or skateboarders ride over but also rattles underneath the foot. This communicates when others are nearby and often re-engages one's sensory awareness.

The bottom image presents a pathway that sonically exposes the water underneath, this connection is surprising. It redefines the water element and offers an interesting juxtaposition to the open free ocean water adjacent.

"All of a sudden out interior dimension enlarges as the interior aurally unfolds and opens itself up to the city." (Wagenfeld, p.151) 


\section{Sonic Analysis}

Michael D. Fowler presents an interesting study into the practise and design of soundscapes. Similar to this research project, Fowler argues there is a "pressing contemporary need to look beyond a reading of the landscape in purely aesthetic form". Alternatively, the sensation of listening can be nurtured by the urban and sound, the "mediator between human and environment" (Fowler, 2013). Fowler's article focusses on analysis techniques when trying to gain deep understanding of a site's sonic qualities, the primary technique used here was based off Hildegard Westerkamp's soundwalk:

"A soundwalk is any excursion whose main purpose is listening to the environment. It is exposing our ears to every sound around us no matter where we are."

Re-analysing Frank Kitts Park in this manner will allow for site specific qualities to emerge in the sonic realm. The sonic analyses will allow the initial design explorations to be focussed on key sonic aspects of the site. Listening and experiencing rhythmic qualities will also further provide a greater understanding of the site.
The analysis will be completed by walking through the space in sections: firstly through the promenade, from the city to Sea Bridge, then by following people's journey through the pathsthrough the middle section, from the promenade into the elevated walkway, up the steps into the elevated area and along the sidewalk.

fig. 3.2: main sonic contributors + route mapped 


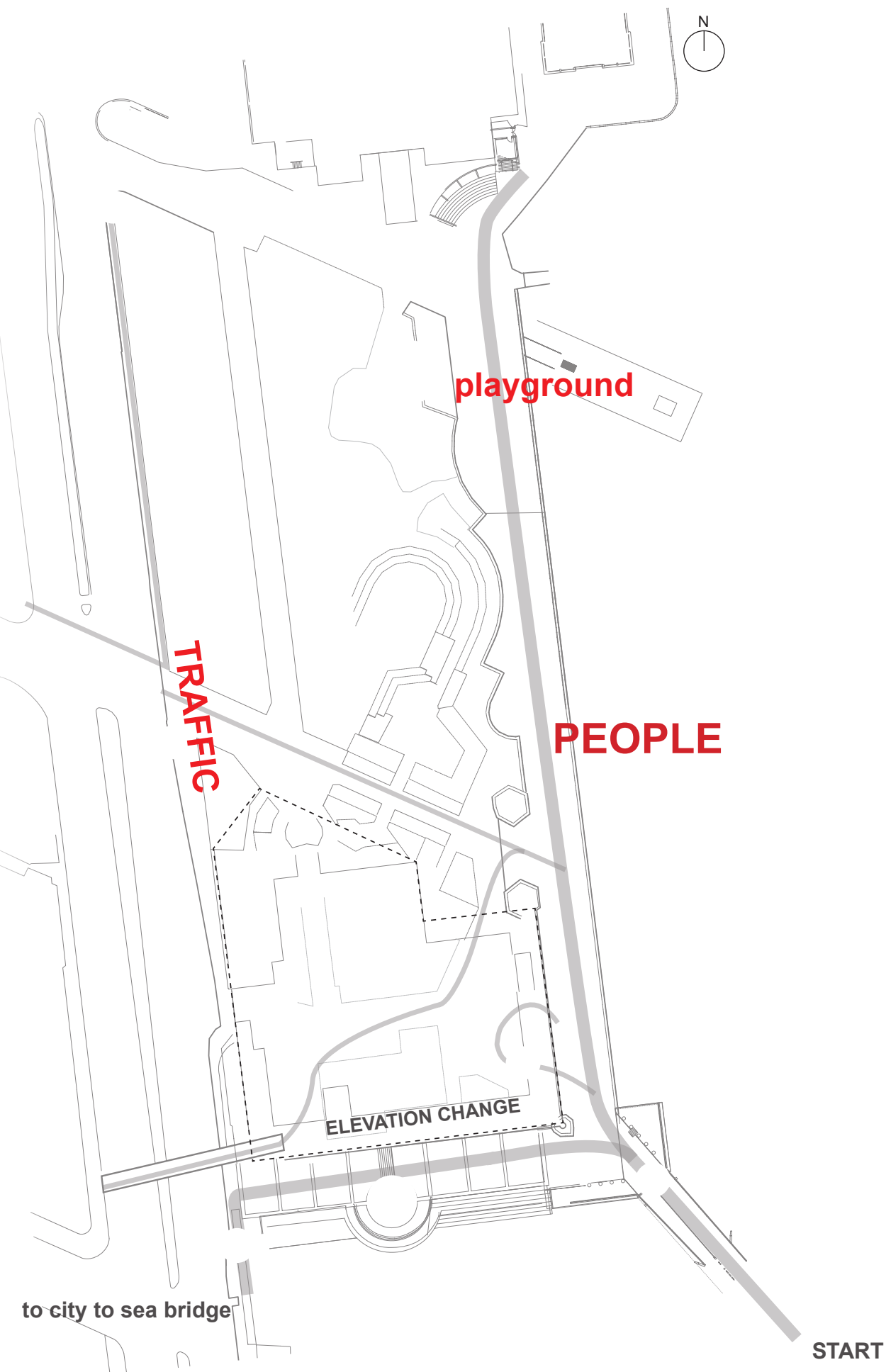




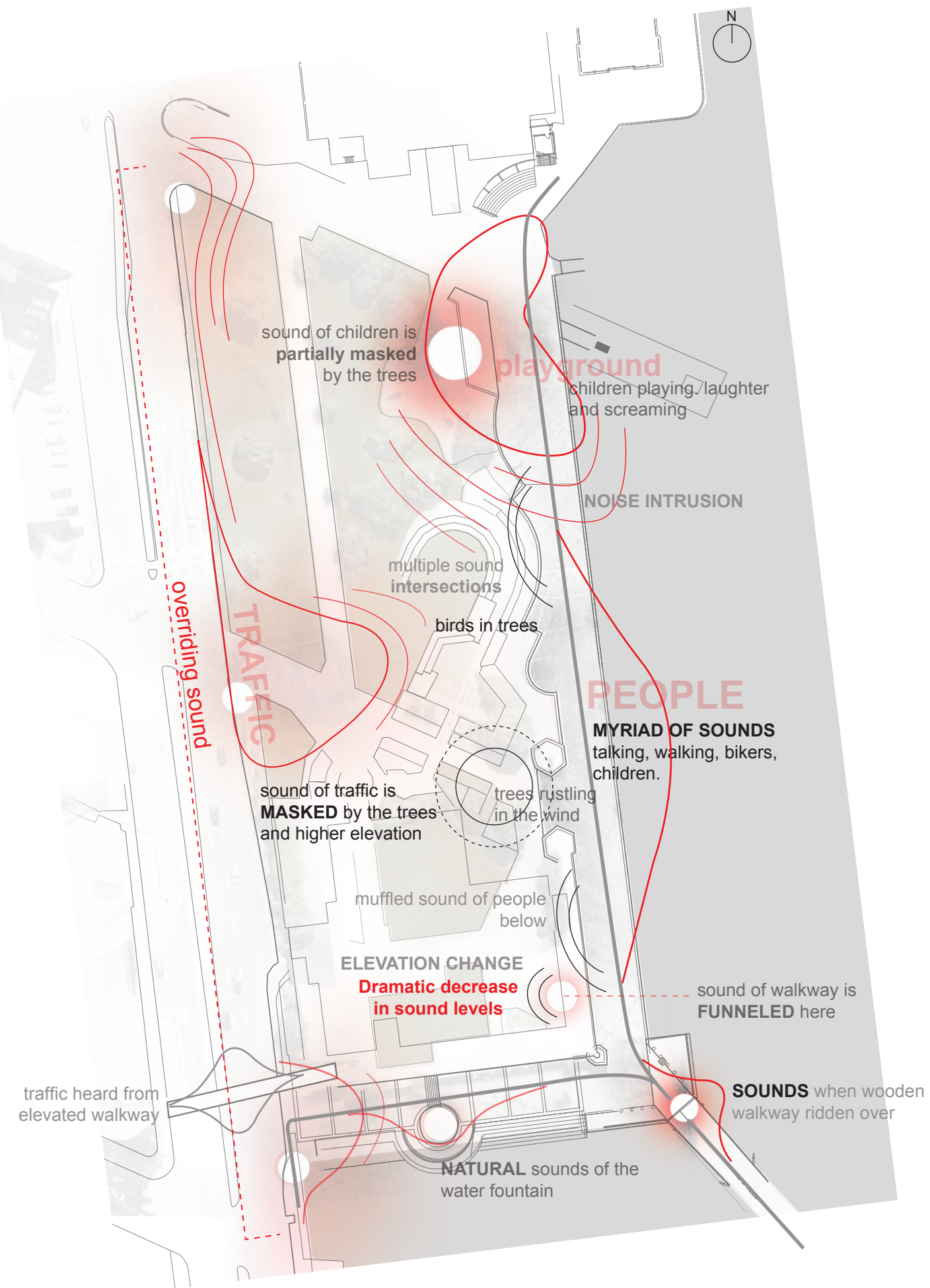

fig. 3.3: Soundwalk 1: sonic overview 
Sound walk 1: sonic overview

Three sound sources dominate the experience of Frank Kitts Park: people, children at the playground and the traffic.

Along the promenade the sound of many people blur into a blanket of sound. This blurring is experientially constricting and one is pushed into their own private sphere of inhabitation. This significantly reduces the opportunity for engagement with the space and other people. There is a lack of distinct sonic events along the stretch of concrete until the playground comes closer.

Within the Park there is always a presence of the adjacent traffic. In the elevated area the sound levels decrease dramatically, at ground level the traffic's sound penetrate far into the Park. A consistent sound rumbles, a few large vehicles or horns sometimes grab attention. Along the sidewalk the traffic is obviously the primary sound heard, it can become irritating as it hinders conversation and overwhelms thoughts.

The playground is an interesting sonic contributor. The concrete wall blocks transmission of sound but when it abruptly ends the sound of children quickly comes into consciousness. Its irregularity maintains stimulation without overwhelming. Inside the Park, the mixing of the traffic, children and trees opens up a strange intersection of sounds. While the traffic prevails over the others, once the vehicles stop at the traffic lights the other sounds fold into the space. 


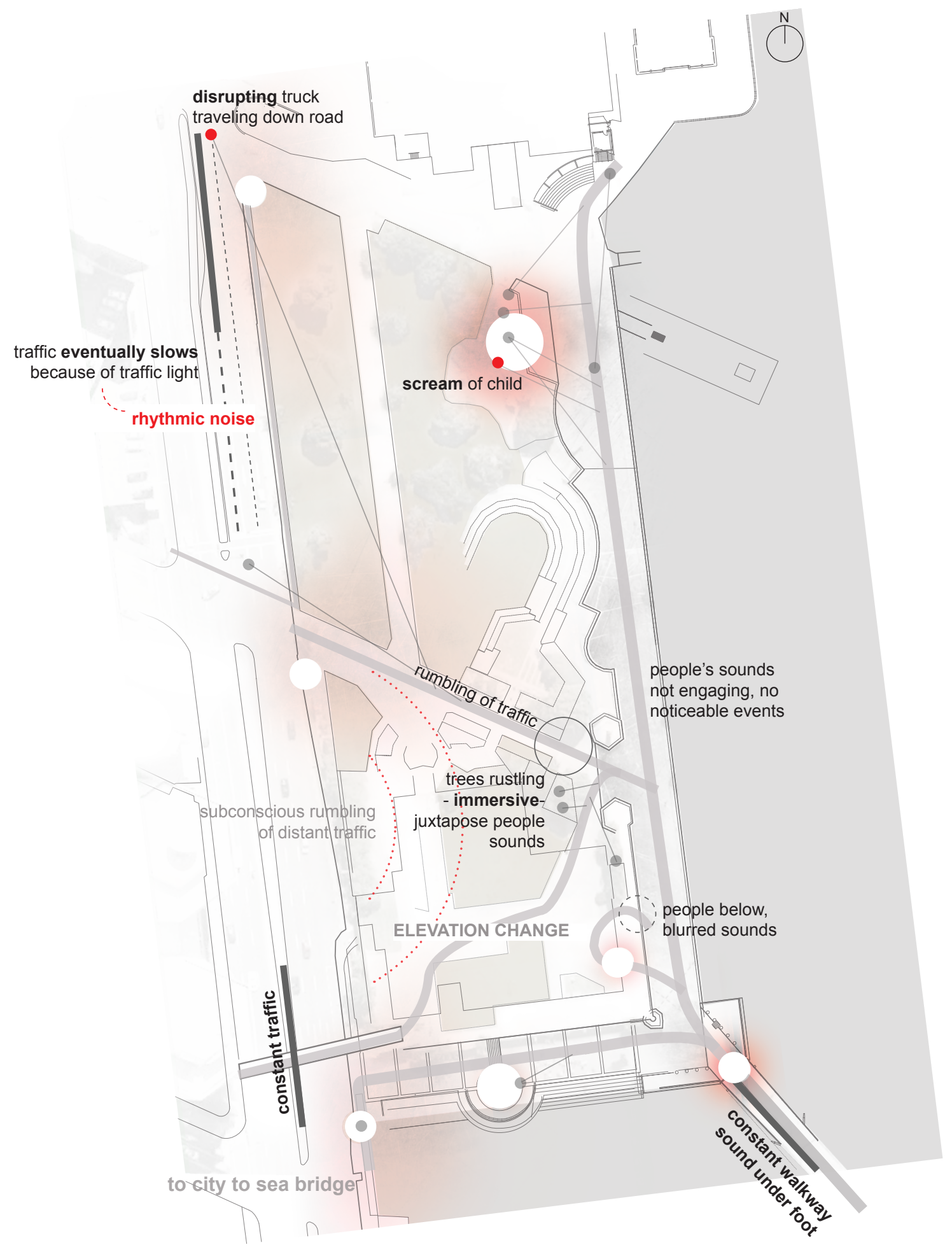

fig. 3.4: Soundwalk 2: sonic perception 
Soundwalk 2: sonic perception

In this soundwalk the sonic experience, the point of conscious perception of sound and the sound source were documented. This was repeated several times before its records were averaged; this repetition did not alter experiences significantly as there was no major sonic change.

The main finding from this experiment was about the traffic's rhythmic sounds. When travelling through the middle of the Park towards the sidewalk hearing was concentrated on the traffic, the traffic as one large sonic entity. It was not until a disrupting truck came by where the perception was narrowed, this truck was now in attentionshowing the shift from peripheral hearing into focussed hearing. As it slowed and stopped due to the traffic lights, it rested at a mere grumble. Focus then left the truck until it started to accelerate again. This transference of attention back and forth occurred over several minutes and shows the experiential power sound can have on the occupier over time. The shifts of the attention was evident as this occurred several times, and caused a clear urban rhythm. The traffic lights caused the sonic dynamics in the area.

There was no noticeable sound (or engaging) event along the promenade. This is another factor that leaves the experience monotonous. The wooden walkway on the southern bridge was under constant sonic activation, as discussed in Existing experiential + sonic moments. 


\section{SOUND AS DESIGN}

\section{Introduction}

This section will firstly discuss Aural architecture, an experientially focused domain of architecture. Unlike soundscape, there is literature that explores how various people have integrated sonic qualities into spaces. Following this, precedents will be investigated. The precedents will bring examples of sound, play and leisure into the discussion.

\section{Aural architecture}

Designing with sound at the forefront is not a wholly new idea. Many designers and architects have used sound in the creation as a mean to provide varied experiences from security and comfort to obscuration or unease. When researching the topic, three prevalent areas appear: acoustic design, urban soundscape and aural architecture. The former takes a predominantly scientific route that leads to an acoustically 'correct' space. Soundscape was discussed earlier in Chapter 2. Aural architecture, however, can further offer interesting insight into this project.

Design professionals and theorists are increasingly considering the domain of aural architecture. Pallasmaa is renowned to engage the senses, he "rejected the assumption of visual dominance, considered sensory architecture as an umbrella theme that explicitly included aural architecture" (Blesser and Salter, p.7). His critique of the modern city reflects that of Schafer's, and while its eloquence lessens immediate impact, its sentiment is compelling: "We stroke the boundaries of space with our ears... but our cities and have lost their echo altogether... our ears have been blinded" (Pallasmaa, p.51). The need for aural architecture and soundscape design principles is evident. In William L. Hamilton's article "the World of Sound" several examples of architecture with meaningful considerations to sound are identified. As early as 1949, Philip Johnson's Glass House uses sound to nurture the experience. It uses a gravel entry path that "crushes loudly underfoot" (Hamilton, 2012) to indicate an approach, similar to many urban parks around the world. The silence of the open interior creates a moment of suffocation that awakens the visuals that are continuously on show through the glass. Peter Zumthor's commonly integrates sounds and sonic qualities into his designs. Zumthor warped the floor in his small chapel in Switzerland creaks, this auditory cue, he insists, lies "just below your level of consciousness". Hamilton also mentions the Japanese Zen gardens that often use wind chimes to "keep the ear off balance, which prevents the eye from comprehension." These ideas define aural architecture as a way of designing with sound that purposefully and specifically affects experience. (Hamilton, 2012) 
Aural architecture can increase spatial awareness and increase our "aural connection to the space" (Blesser and Salter, p.8). This aural connection harkens back to the sentiment that spaces, particularly urban spaces, can provide an emotional or perceptive connection that exists beyond the visual. Maria Lorena Lehman explains that sound is used to stir emotions but also we "use our sense of hearing to bond with other people". Restaurants, churches, music halls are the most obvious but it is evident through the sheer number of instances that sound is an effective and efficient way to unite diverse people and enable them to share an experience (Lehman). According to Pallasmaa, using more poetic language to discuss and explain sound in architecture can lead to greater impact. A.S. Redman makes the distinction that both poetic and scientific language is relevant and valuable; it enables one to "conjure up a visual image of sound shape within the mind's eye. It seems that we must try to combine, like the study of aural architecture, the arts and science together to really understand and communicate the concept of the aural." (Redman, 2012).
Both of the design strategies, soundscapes and aural architecture, are interdisciplinary and incorporate thoughtful detail design. But employing and combining these two strategies falls directly into the interior realm of designing; understanding and considering people and their sensory experience is the primary role of interior architecture. Isolating particular sounds, understanding their effect on people and the performance of the area will help quell the barrage of the senses that produces discomfort. Intimacy elevated through sound can help improve the environment and enhance the sense of belonging one has to the space. The opportunity for contemplation of their experience, acceptance of the environment and reflection on their city marks an immensely important role within the urban fabric. 


\section{Project precedents}

Paprocany Lake shore redevelopment (2004), Poland

\section{Architects: RS+}

RS+ uses a winding wooden promenade to shift people from the lake edge into grass leisure areas, it "meanders out over the lake and back on the ground" (RS+). The wooden promenade also rises up into seating where a boundary is made. Grass then suggests a more tranquil mode of occupation.

Fig. 3.5 shows 'netting that is used for lying' as described by the architects. It cleverly blends play and leisure into one- the mere action of climbing on will create a small event; this reimagining of simple materials and forms creates meaningful engagement with the urban fabric. With more traditional seating surrounding the primary function of the promenade is not compromised.

The versatility of the elements provides multiple options for leisure and by adding in elements of play, the complexity and creativity of urban life can be seen.

$$
\text { play + leisure }
$$


fig. 3.6: Paprocany Lake shore redevelopment. 2004.

fig. 3.7: Ekko. 2012 
Ekko (2012), Hjallerup, Denmark

\section{Designer: Thilo Frank}

This public labyrinth-esque installation uses the wooden structure to confuse the perceptions of space and form. It also aims to amplify the presence one has when within it by disturbing the visual senses. The form and its shadows create confusion from the outside. The interior-exterior connection further pushes disorientation. The visual connection to the outside world fluctuates as the wooden structure overlaps, intertwines and folds in and out.

The use of sound is an added element to reorientate how one experiences the space:

"While moving through the installation - built-in microphones pick up the sound of the visitors and a computer sound system filters and remixes the recorded pitch... the project becomes an instrument and plays a constantly changing soundtrack." (Kortmann)

sound + pathway 
Pennisula Residence (2011), Hillsborough, CA

\section{Andrea Cochran Landscape Arch}

This precedent evokes a similar sense of leisure, privacy and tranquillity among nature that is sought for this project. Here, the importance of purposeful design is shown.

The $4 \mathrm{ft}$ height partitions provide overstated privacy and lift the view outwards to the trees. The smooth floating seats clash with the cor-ten steel texture and gravel ground. The large oak trees are part of the visual focus when placed against the orthogonal forms. It seems as if the trees are the visual key points, where the orthogonal forms are the experiential focusses. (ASLA, 2011)

The sensory implications are also inspiring. The high partitions warrant quiet in seclusion, yet the gravel grounding purposefully conflicts with this. Arriving or leaving the space abruptly severs any sense of solitude but this creates an experiential connection. This is an example of how sonic qualities can add a new layer of experience to a space.

privacy + leisure + sonic qualities

fig. 3.9: Pennisula Residence. 2011 
High Line (2009), NY

Architects: James Corner Field Operations

"The pleasure of walking along it - and of a visitor's sense of escaping the city while being in the middle of it - derives from its height... The rumble of traffic below the High Line physically assaults pedestrians at street level." (Kimmelman)

Michael Kimmelman describes High Line as a project that allows people to reflect on the city's barrage of noise. The height displacement works to separate people from the city but, unintentionally, it is the sound of this 'rumbling' that truly induces reflection. It is rare to find protection from the city's noise pollution whilst being in the city, making this moment noticeable.

$$
\text { sound + leisure + urban rhythm }
$$


Material: COR-TEN ; weathered steel

Cor-ten is a useful material as it has diverse applications, particularly in urban spaces. It is a durable material that can be perforated or structural. As seen in Pennisula Residence precedent, it combines well with concrete and plantation. The colour and weathering texture is an aesthetic that fits within Wellington's waterfront.

With its versatility, it could be a useful material to use for each of the design areas. Fig. 3.12 shows cor-ten can be used with concrete, wood and vegetation together; the combinations between the three materials can be transposed continually. 


\section{[7] INTUITIVE DRAWING-LED DESIGN}

\section{Introduction}

Following the sonic analyses and precedent analysis, it is apparent that the design brief's objectives and focusses are refined sufficiently to begin initial design responses. The importance of sound in the urban context has been discussed, as has the role of play + leisure and urban rhythms. The interrelations between these ideas will be explored in the initial design stages.

Primarily, the design process will be intuitive drawing-led. Design exploration is key and this method offers freedom and efficiency. The drawings below test simple ideas and aim to present them organically in an unconstrained manner; the communication of these early, sometimes unattractive, images is an important phase that is often ignored. The notion that raw thoughts can be depicted on the page is fascinating and is a consistent theme.

"Most architects still believe sketching to be a more natural and organic way of harnessing their creative thoughts."

(Bhartia ,2017) 


\section{Preliminary intuitive drawings}

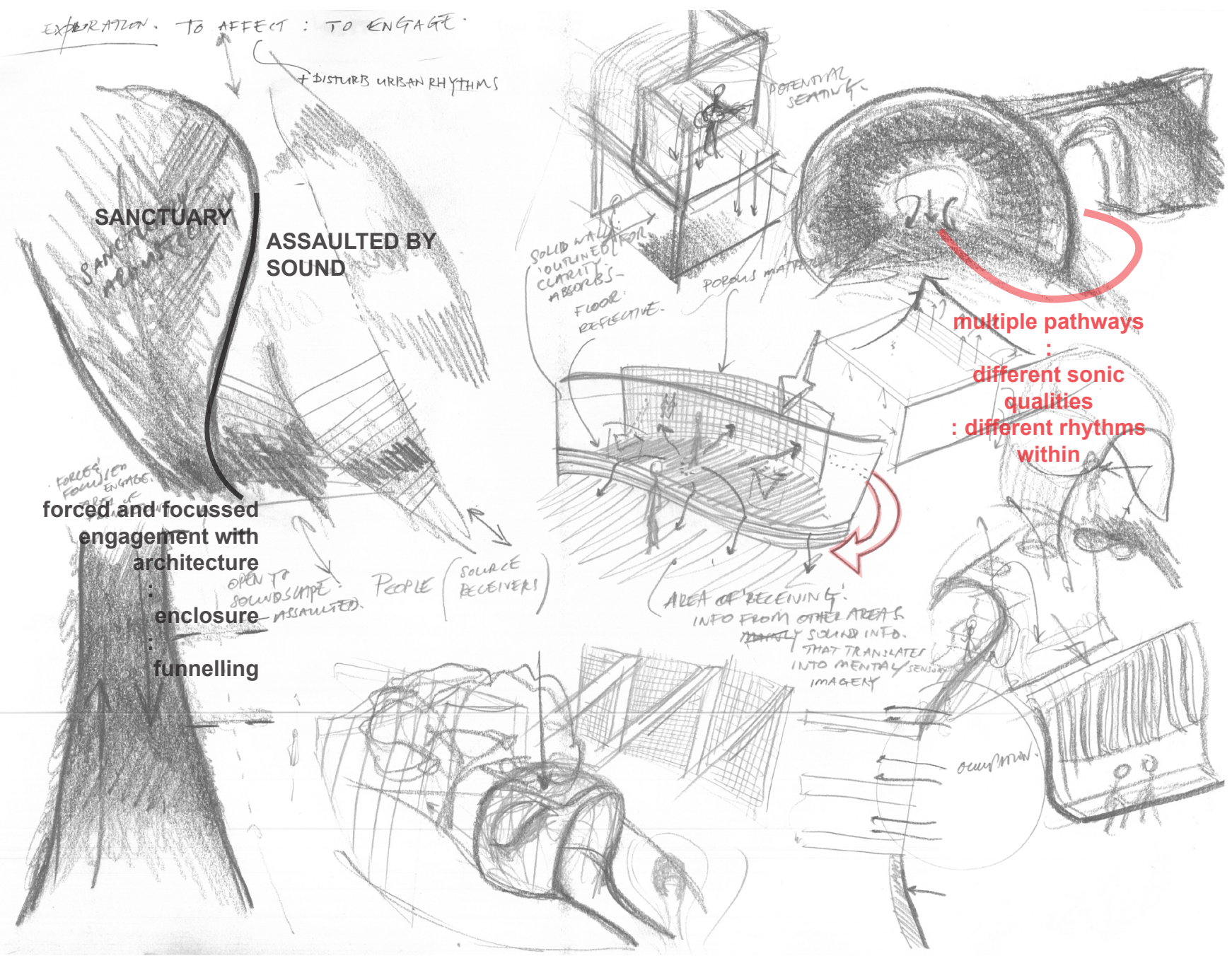




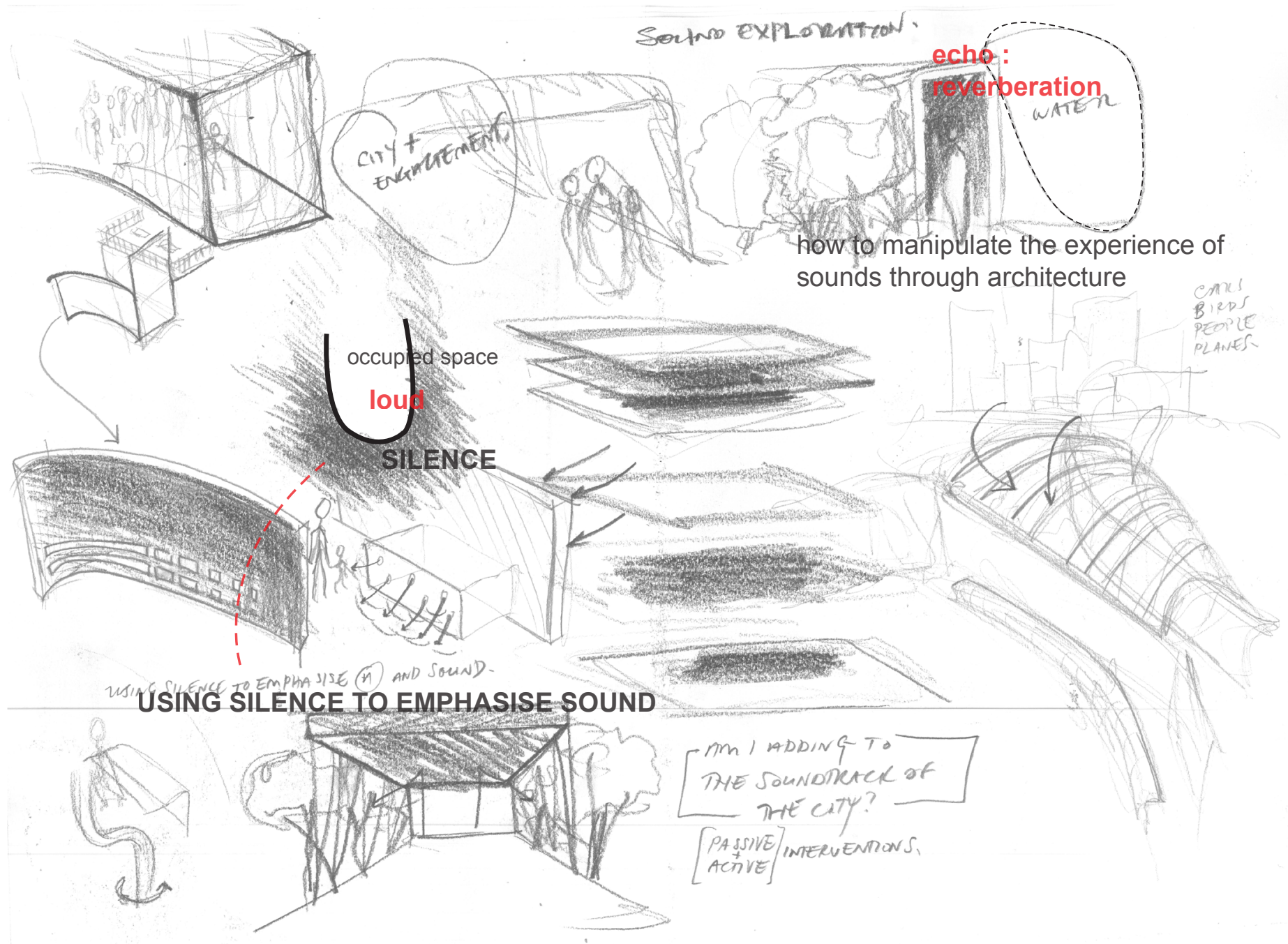




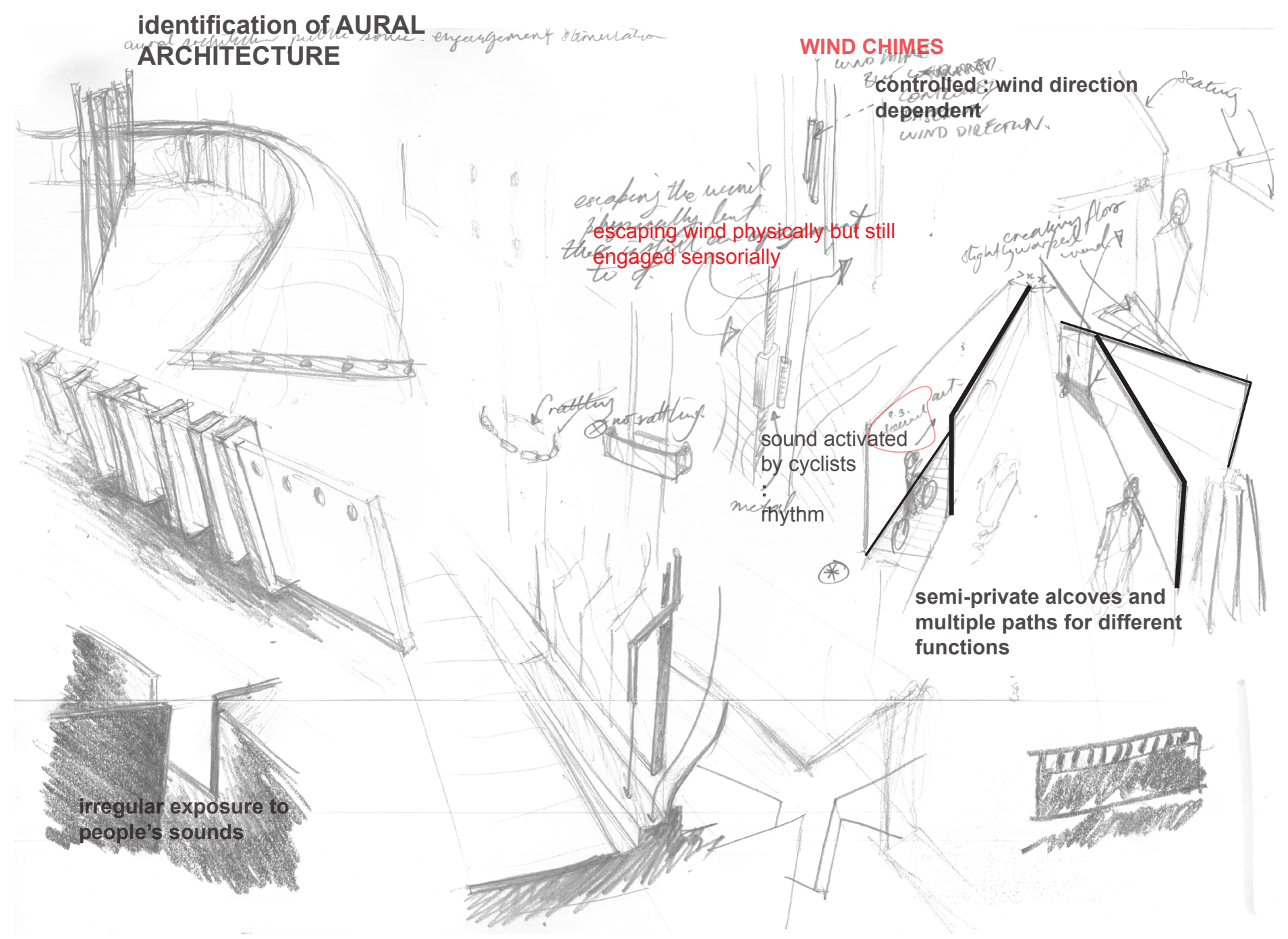




\section{Experiment 1: sound as visual}

In this experiment, sound as a design tool will be explored, Michael Kimmelman states that:

"Sound may be invisible, or only unconsciously perceived, but that doesn't make it any less an architectural material than wood, glass, concrete, stone or light."

(Kimmelman)

This sentiment reflects the need for designers to consider sound significantly. Sound's immateriality creates challenges in representation and conceptual exploration; in this visual orientated discipline "the ways in which one can experience a sense of the design outside of its 2-dimensional representation or 3-dimensional model is always difficult." (Fowler, p.123).

As a preliminary experiment, the spectrum of white to colour to grayscale will be used to denote loud sounds to silence. Successful images from above will be processed to explore this representation. 

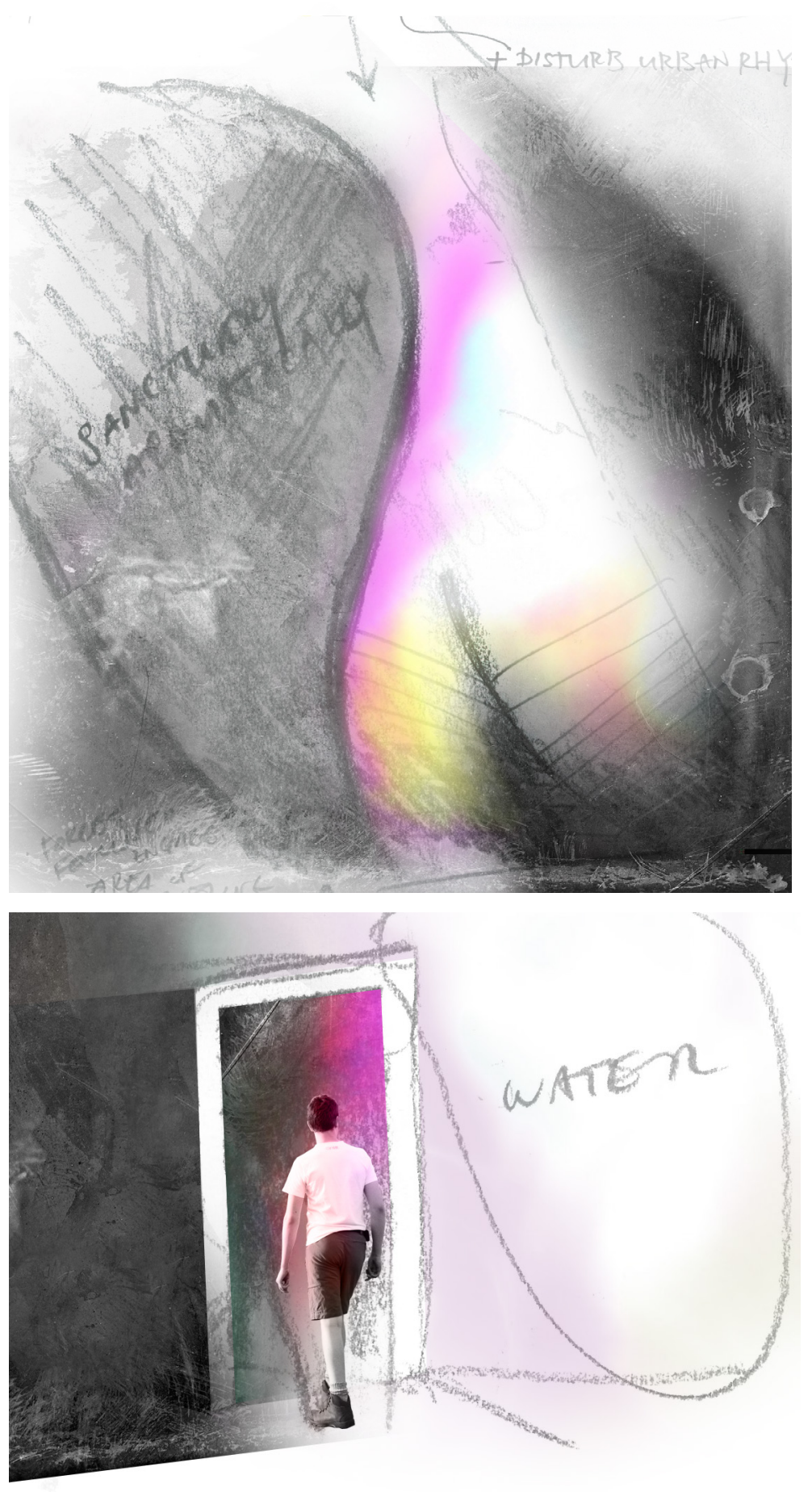

Performance + Interior Architecture - Intuitive drawing-led design 83 

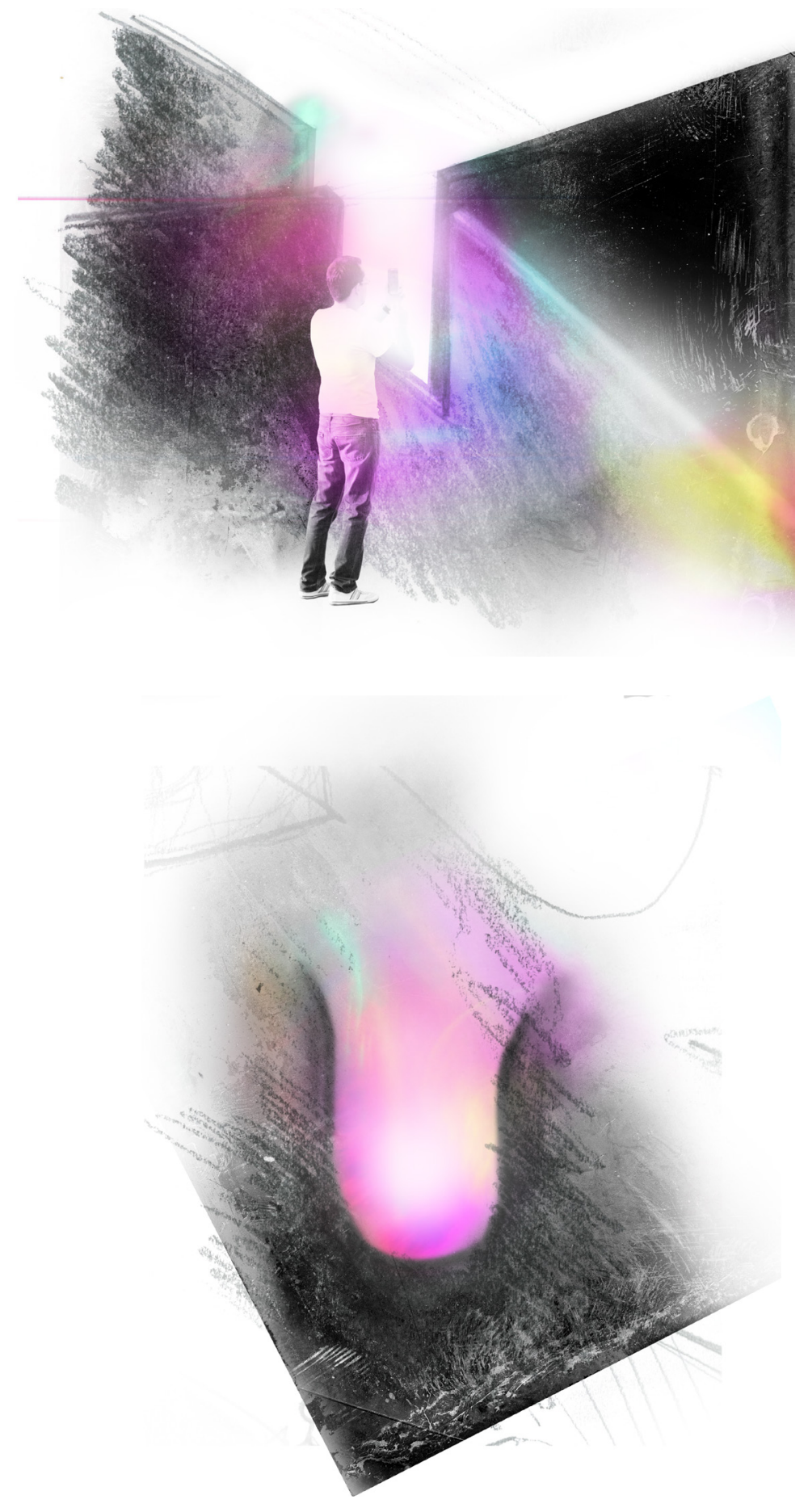

84 Performance + Interior Architecture - Intuitive drawing-led design 
Experiment 1a: sound + architecture

Experiment 1 produced evocative images that suggested structure and form with dynamic sonic qualities. To further explore this method, concepts with a more realised form and sound sources will be presented.

This set of experiments allowed for quick exploration of representational methods to depict sonic presence. The sonic qualities lying within these drawings can be identified and built upon in later stages. The first drawings were instinctive and efficient responses to the research, and in doing so successes arose in unforeseen places. For example, the sonic connection + visual separation notion recurred often. It offers a temporal mode to engage and affect people. Using sound to shift one's focus and momentarily slow movement can disrupt the rhythm of the site. It can help reduce the monotony of a straight path by diverting attention and engage people with sounds' sources. 

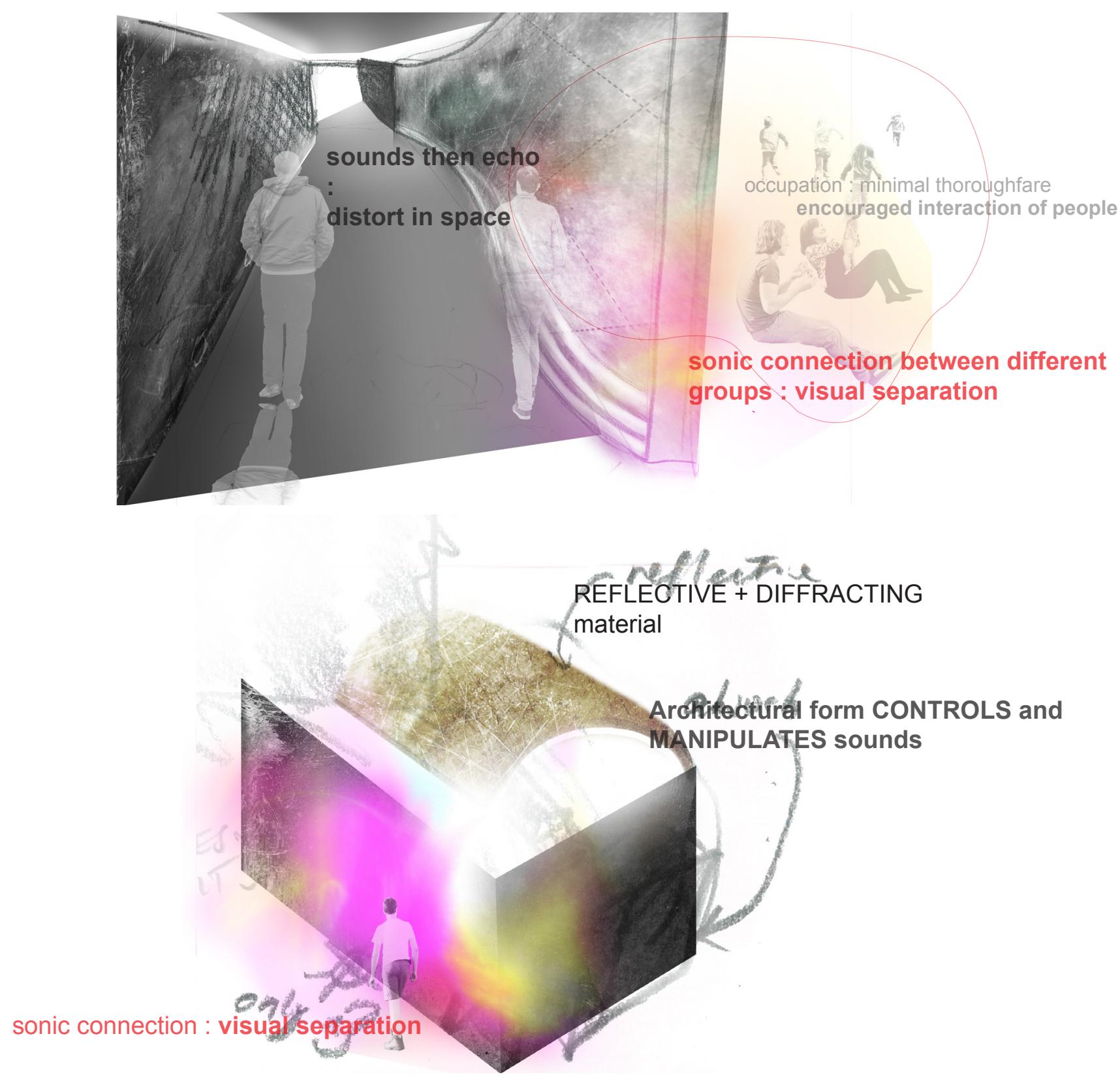


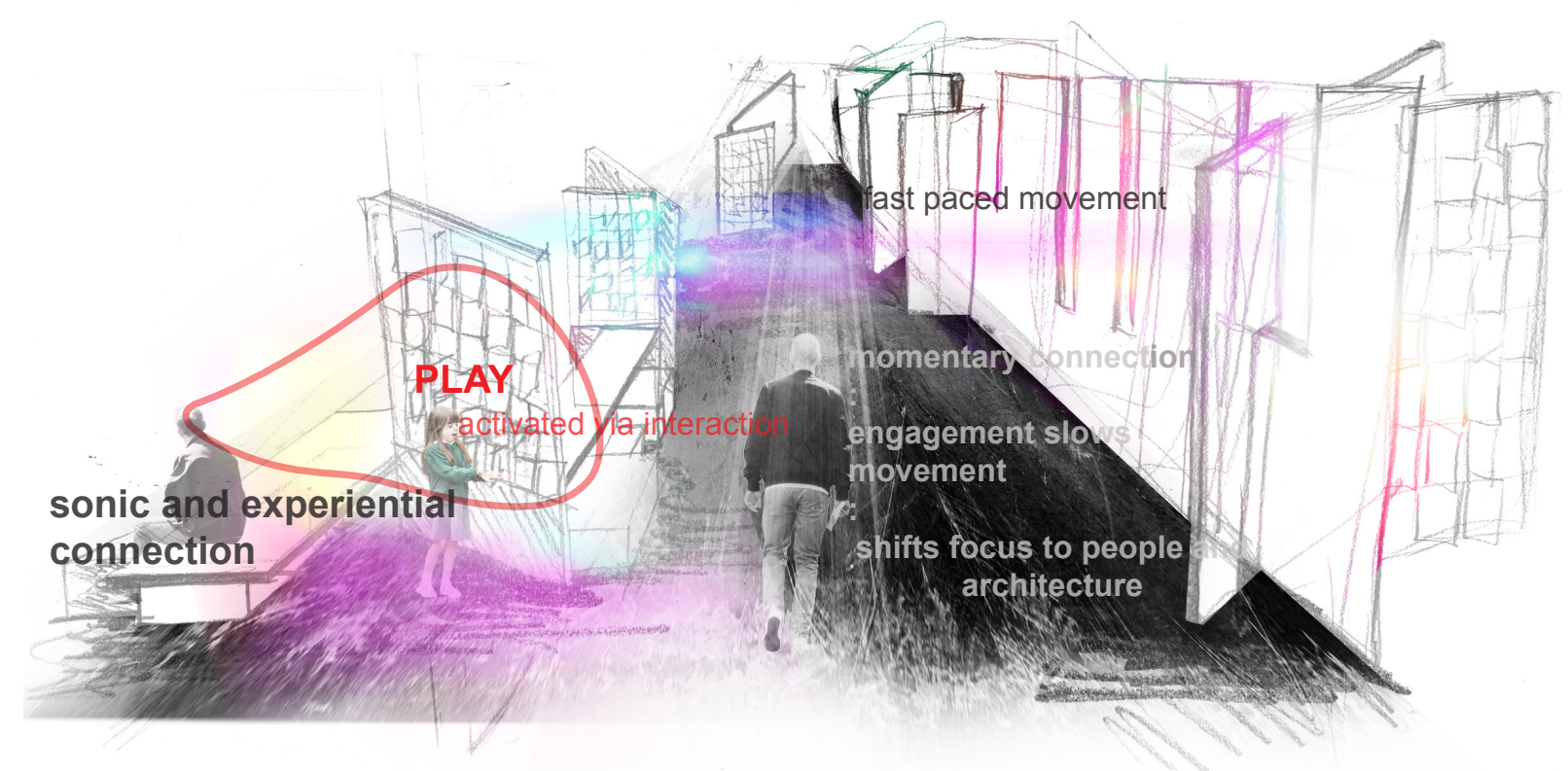

Again, swift gestures were made to produce the drawings, and the ideas unfolded on the page. Flirting with the idea of a space for musicians or places for melodic play with adjacent seating seemed a simple but pleasant way to emphasise a performer-audience dynamic. The following drawings depict potential installations and spaces but the need for experimentation at a larger scale is beginning to appear. The context and site need to be considered before these ideas grow larger. 

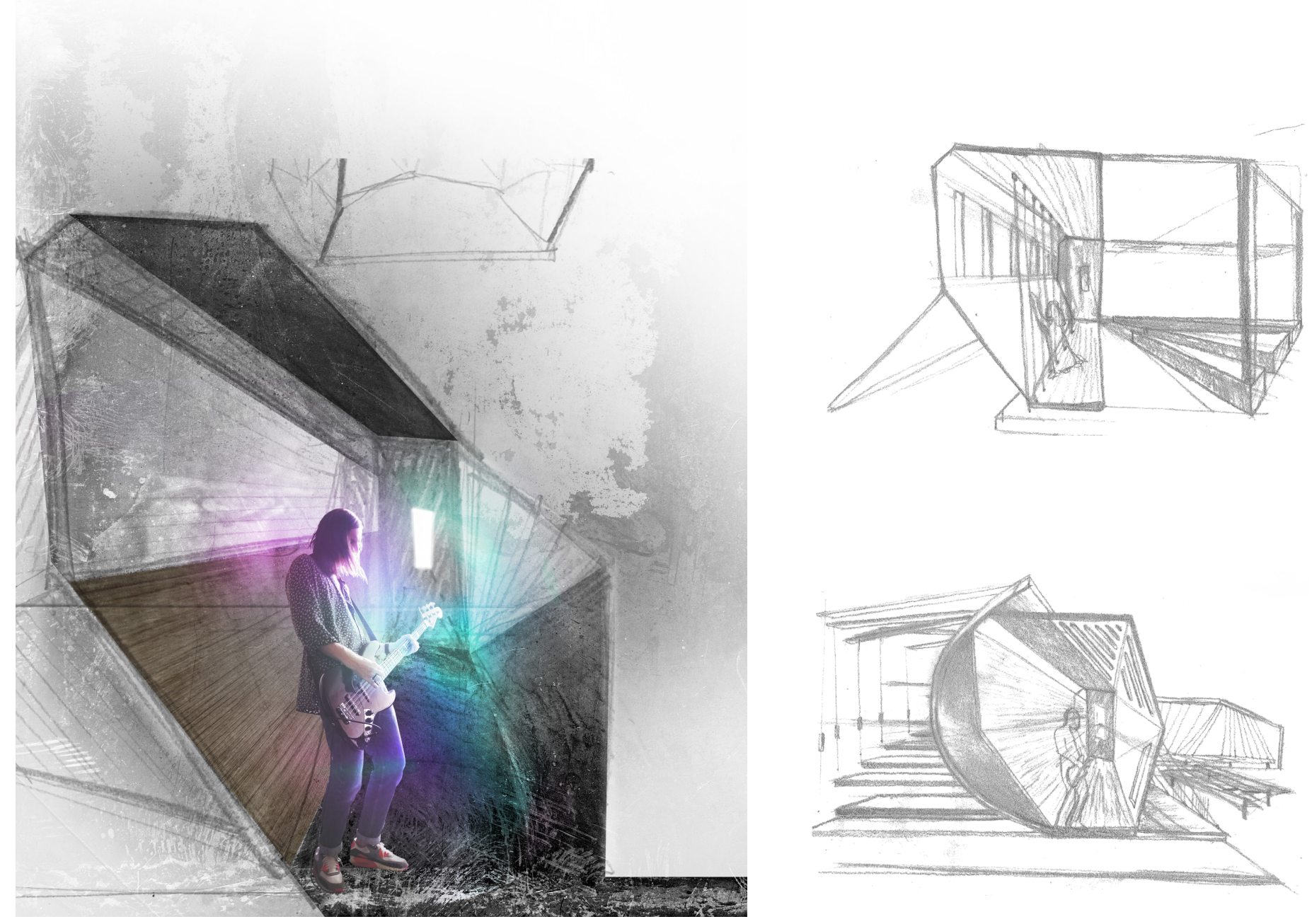


\section{Reflections}

These experiments are producing interesting images with meaningful implications and they communicate the idea of sound successfully. The logical way forward is to begin to reconsider site and spatial arrangements. The drawings, however, have all been produce within a 'void', while this is appropriate for this stage of the design process, the next stage: the reintegration of Frank Kitts Park and its scale, warrants a different approach. The size of the Park and the method of intuitive drawing in this manner do not marry naturally. To communicate the length of the Park through drawing is difficult and hinders the communication under the current process. To uphold the impulsivity sought another technique needs to be explored to form an initial spatial arrangement. Investigating alternative methods through precedents and perhaps applying the context into the drawings can mitigate this issue.

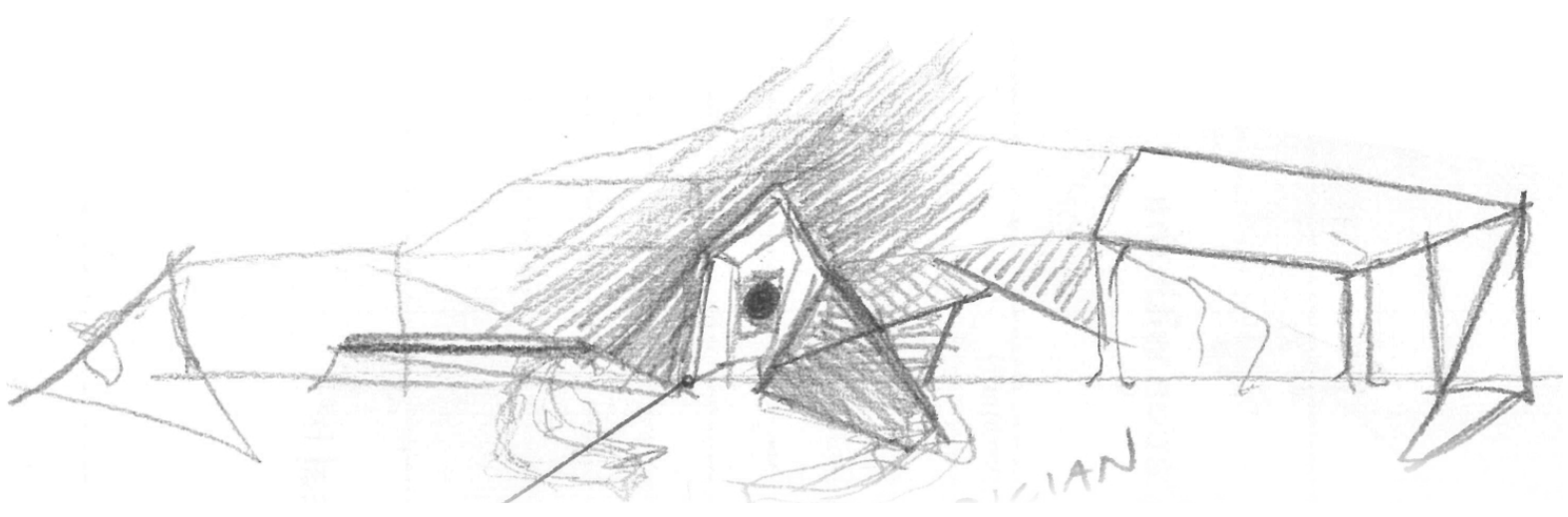




\section{Experiment 2: impulsivity as a design tool}

With the process revealing the complication of Frank Kitts Park's scale, another technique is needed. The precedents adjacent will be used to aid the coming experiment and will attempt to evolve the intuitive technique.

These specific precedents project impulsive and experiential qualities. But the fascination lies within the duality of control and freedom acting simultaneously. The association of certain lines into architectural forms is instant, yet with extended examination the illogicality of the image is revealed; that's where the captivation of this image lies.

The intertwining of control, freedom and impulsivity can propose a technique to push process drawings into the larger scale without constraints. With all the previous research and analyses completed, letting go of complete control and trusting the subconscious response and the experiential knowledge of the site could create a significant step forward. fig. 3.13: retrieved from <https://carlygertler. com/A-Building-in-Conversation>

fig. 3.14: retrieved from <http://ardezart. com/?attachment_id=198> 

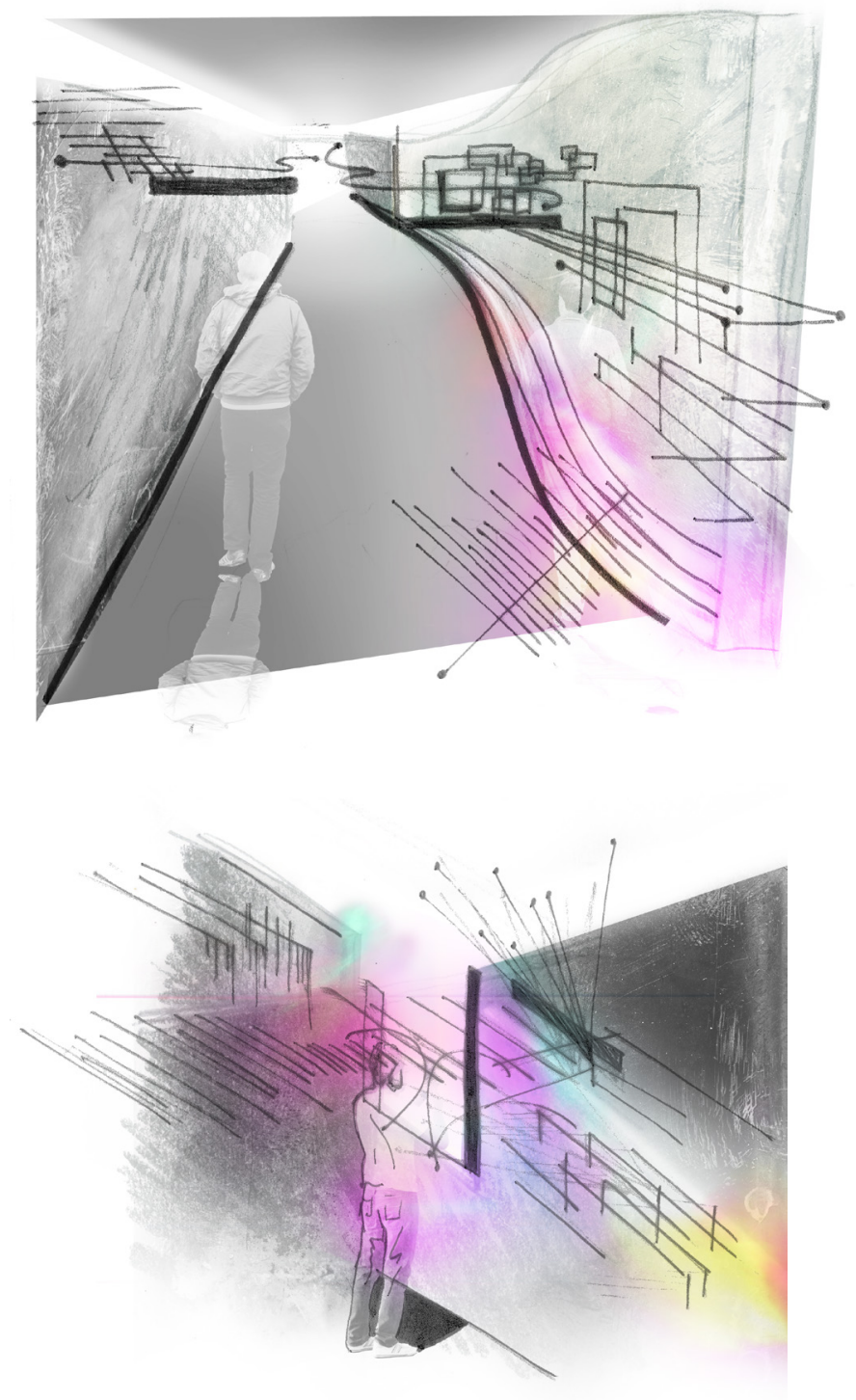

exploring impulsivity 

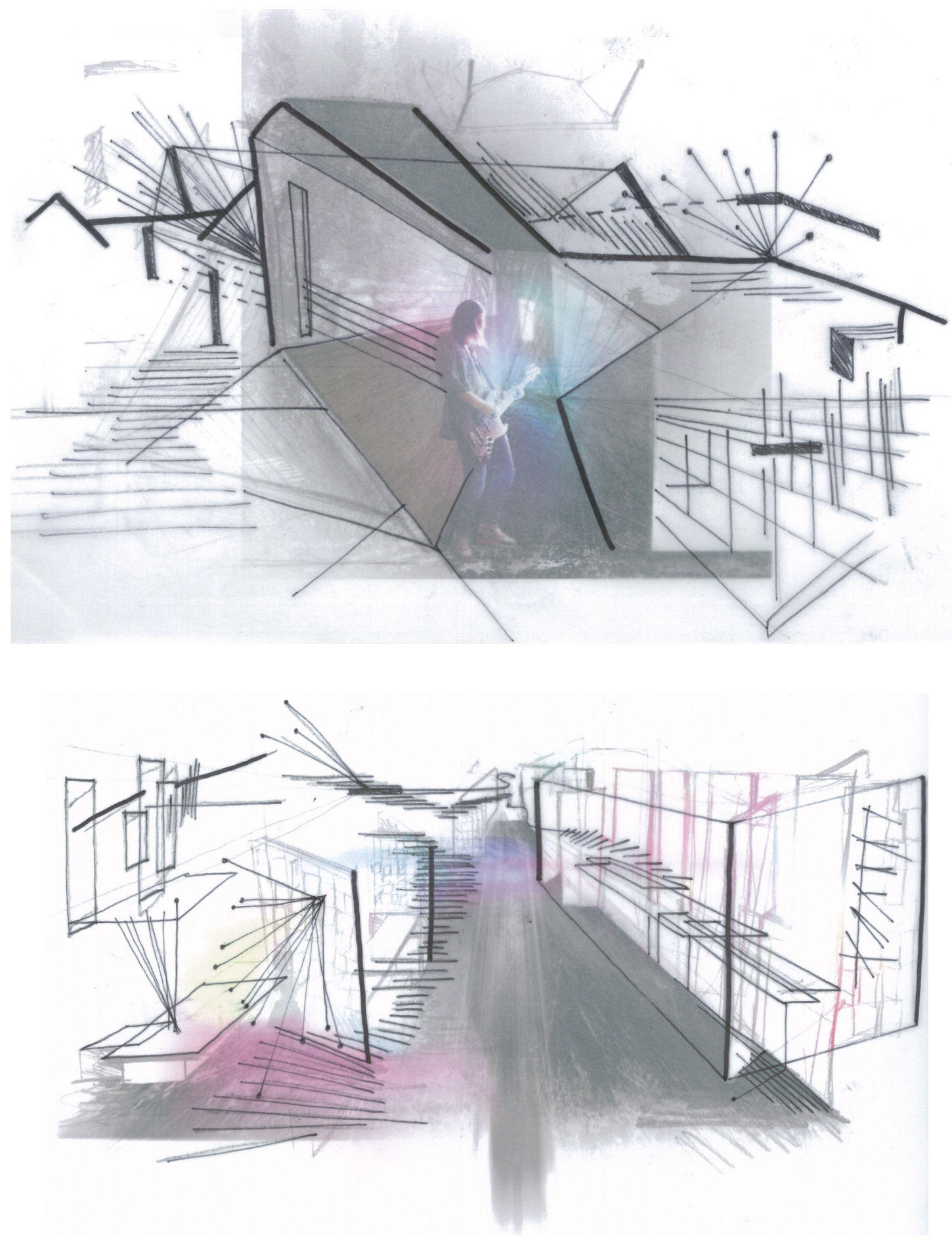


\section{Experiment 2a: impulsivity in context}

Manipulating and reinterpreting these drawings to sit within the site can separate the lines and gestures from the original concepts. The testing and growth of these ideas between experiments helps ensure creative exploration. It is imperative aspects of these drawings are not being constrained by forced decisions or desires.

The drawings will be processed digitally to integrate with photos of the site, the areas depicted will be suggested by the processed drawing. The labelling will communicate personal interpretation of the drawings, which will lead to a preliminary spatial arrangement. 

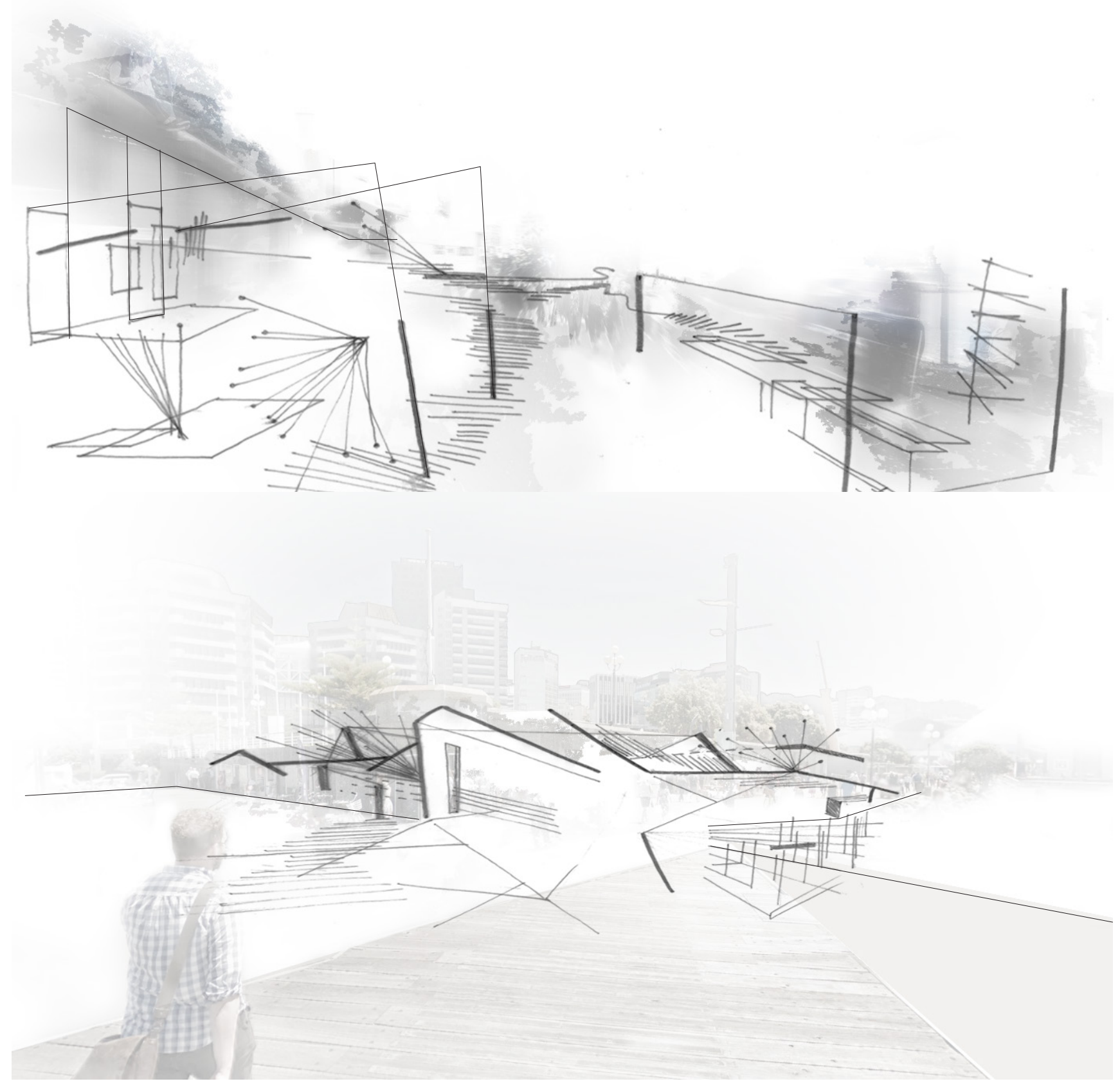

fig. 3.16:

manipulated impulses within context 


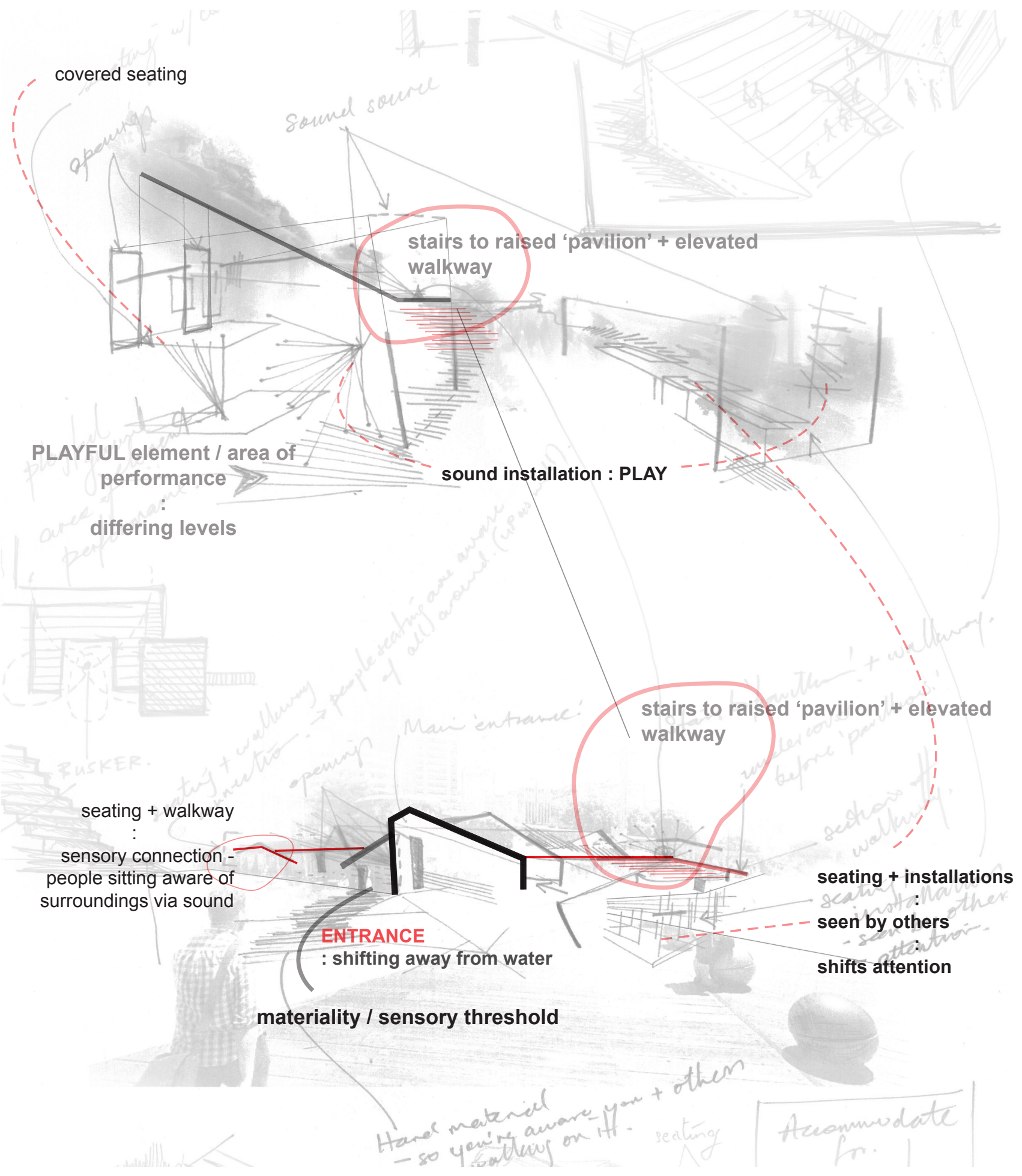




\section{Reflections}

The direction implied in fig. 3.16 can shift the rhythm and lead people past a threshold that envelopes the senses through sound events. Shifting the main circulation and its dominating rhythm away from the water makes it possible to introduce a separate leisure area near the water that is not rhythmically dominated. The water will attract people to this separate space where they will be able to experience an area that is unique along the waterfront.

Pushing people further into the Park can also create an interiority of sorts that uses urban sounds and focusses on play + leisure. Additionally, the sounds of nature and people can be emphasised easier. Spatially, the proposed intervention can distribute people to several different areas.

Fig. 3.16 suggests a rising staircase in both images, this can connect to a potential elevated walkway. This idea, while unintentional, holds merit especially considering people currently use the existing elevated walkway. This walkway could offer interesting sound installations that engage people on the ground with others above. An area of elevated seating could integrate with the walkway and could become a pavilion that acts as the climax of the entire site.
The subconscious unrestrained gestures seemed to present and suggested unforeseen ideas that could be successful with further development. The technique allows scale to be interpretable, and this helped ease the problems found in the early experiments. Moving forward, this abstract technique has fulfilled its role; an initial spatial arrangement can now be explored.

Key Points in summary :

-Shift rhythm through sensory threshold.

- Push people further into the Park, away from water.

- Water can then be used as appeal and a focussed space for play and/or leisure.

- Rising staircase/ elevated seating connects to an elevated walkway.

fig. 3.17: (opposite) initial spatial arrangement 
Spatial arrangement explorations 


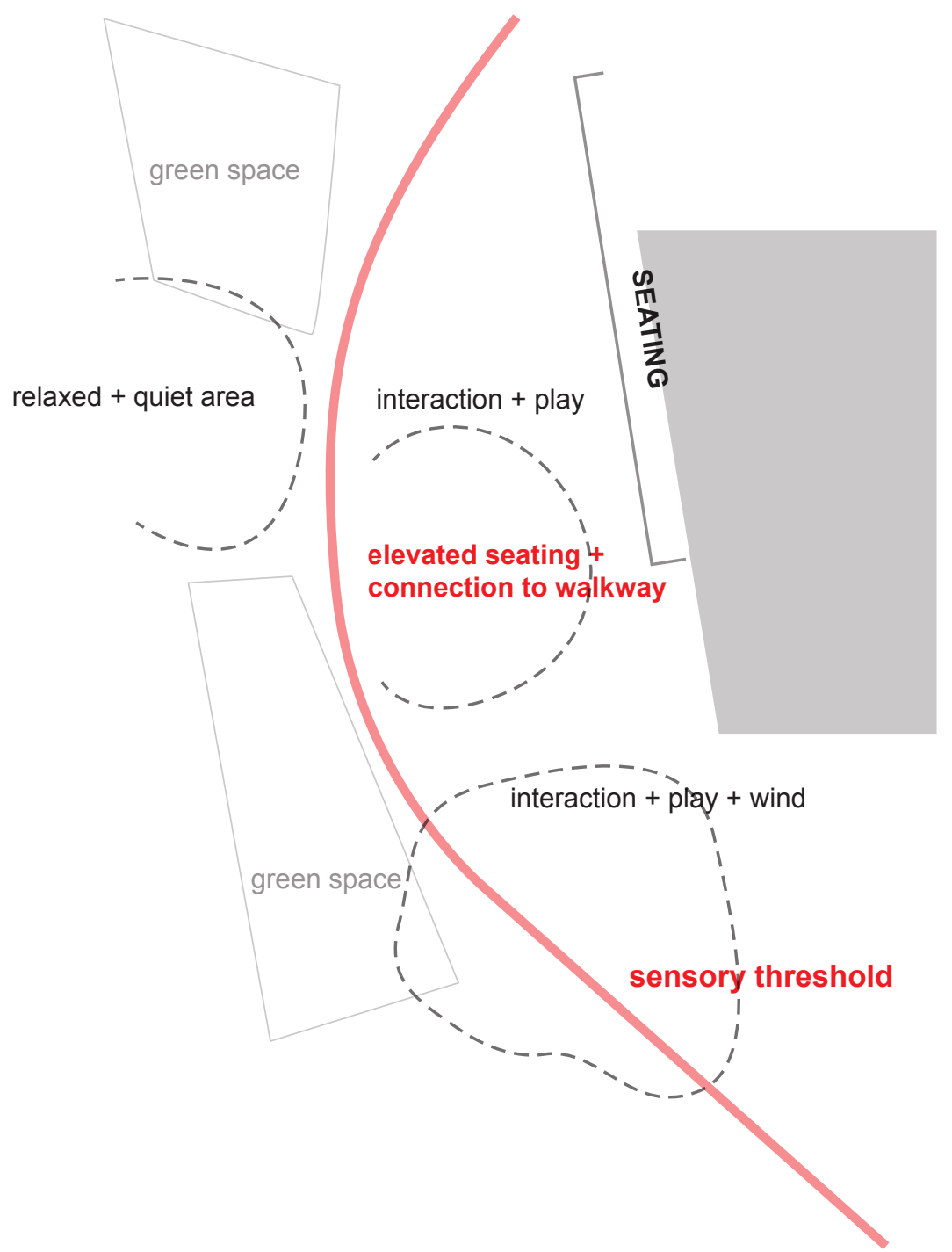

fig. 3.18: experiential aspects 


\section{[8] INTO THE ABSTRACT}

\section{Introduction}

In this section the spatial arrangements and concepts will be pushed into more detail. Still in the conceptual stages, several preliminary details will be explored: roles within the site, soundscape intentions and possible materiality. This will be completed through a mix of iterative drawings, spontaneous gestures or rigorous investigation. The resultant conceptual sketches will then be taken into the abstract realm once again, this will evoke and evolve the impulsive technique used earlier. The use of perspective viewpoints and the abstract method together will aim to produce readable spaces that are evocative and thoughtprovoking. At the end of this section, the concepts will be critiqued rationally and dissected as one sonic journey. This is to facilitate the focus on the soundscape as the driver for decisions.

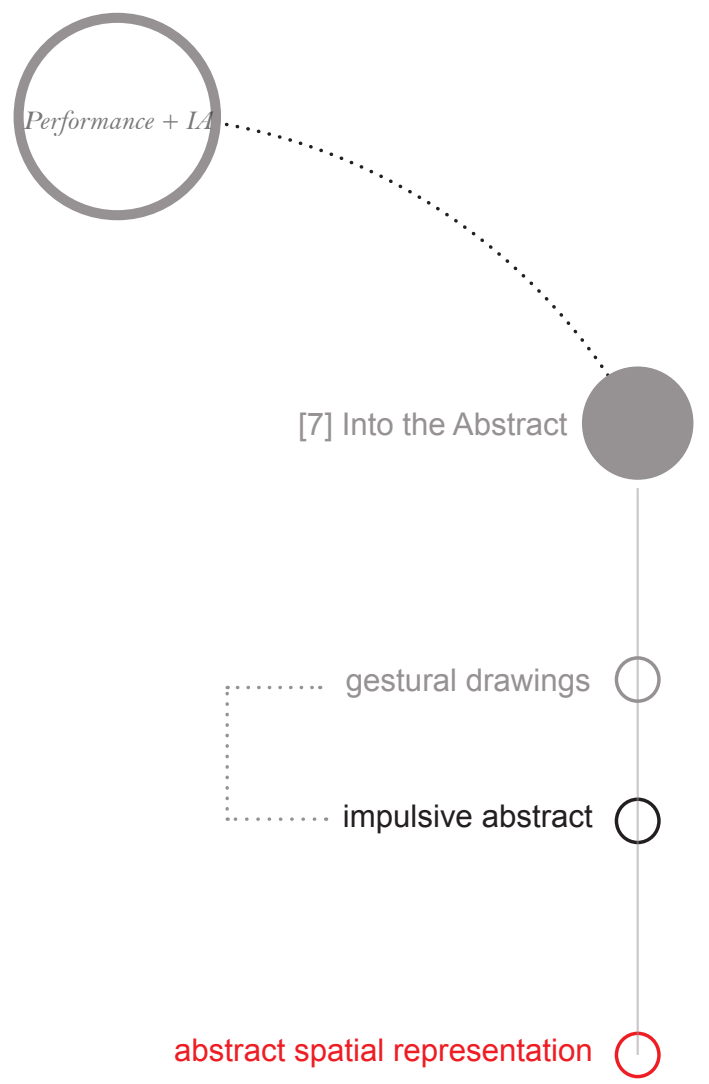




\section{Refined spatial arrangement}

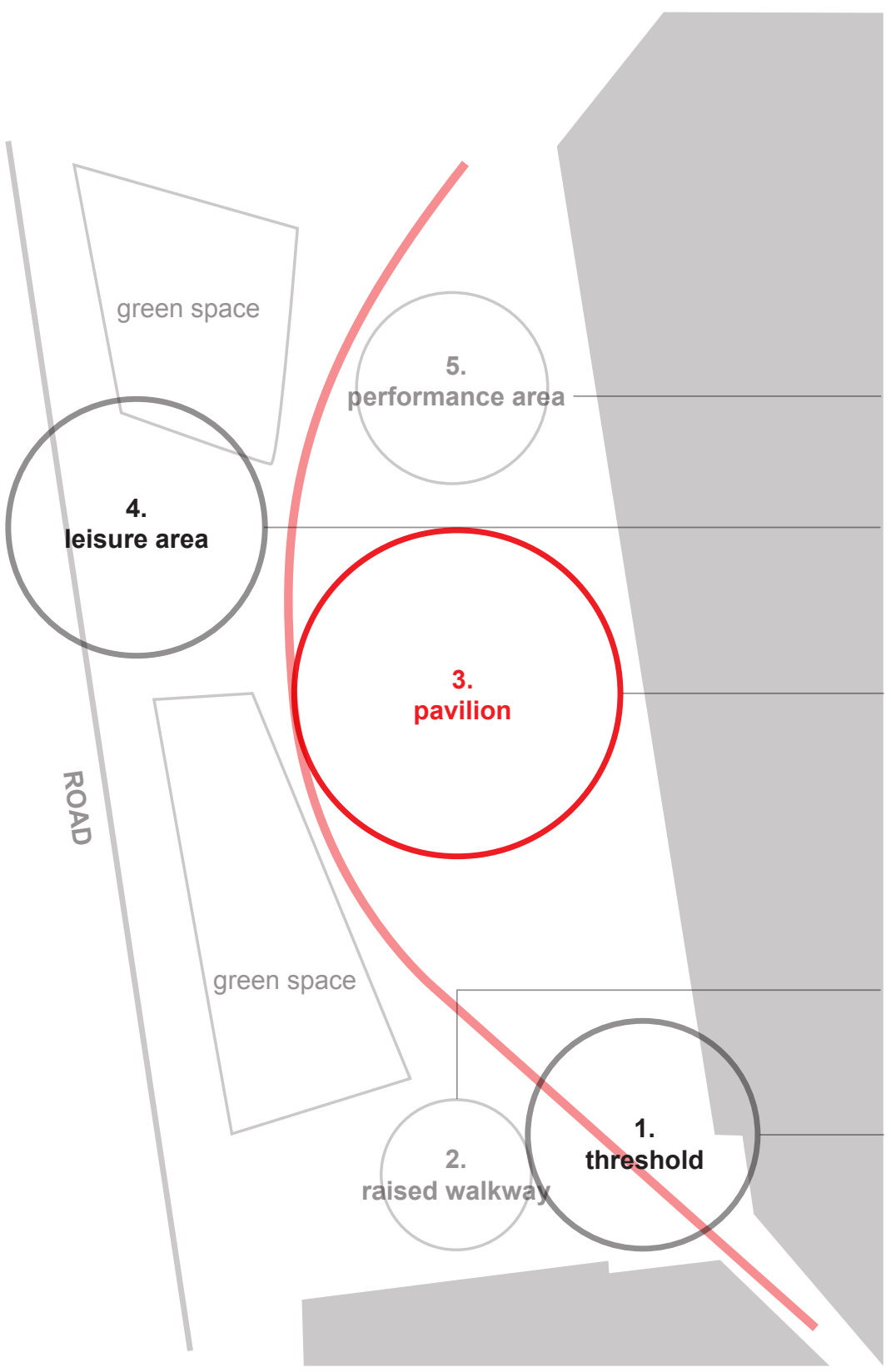

Acting as a connection point, the soundtrack can encourage play and lead people into/ out of the space.

The sound of the traffic will be integrated and manipulated appropriately. This is where quiet leisure will be the main attraction.

The climax of the park where elevated seating, people, the soundtrack of the city and environment combine to create a focal point of engagement.

Interesting sound events from the two levels are offered. Creates opportunity for long distance appeal.

Major threshold that disturbs the rhythm of the waterfront, play will be emphasised. Space will invoke a sensory shift that engages people 


\section{Intuitive drawing as Abstract}

A constant theme in my explorative drawings is perspective viewpoints. Perspective drawings tend to draw out experiential qualities, implying space, scale and movement. Using the perspective technique in the early stages of the design process is not uncommon but encourages quick, creative production. Using perspective sketches to explore ideas has invited a gestural technique that promotes experimentation. There is a mask of evolving thought.

This section will aim to evolve the gestural, impulsive method of drawing into a more understandable image. Each proposed conceptual space will be layered with textures, with consideration to sonic qualities. Also structure will be intuitively integrated. The result is an abstract spatial representation. The form of the space will be interpretable, perhaps undefined. This ensures the form is not dictating the conceptual stages, but that sonic qualities and role within the overall site and soundscape are.

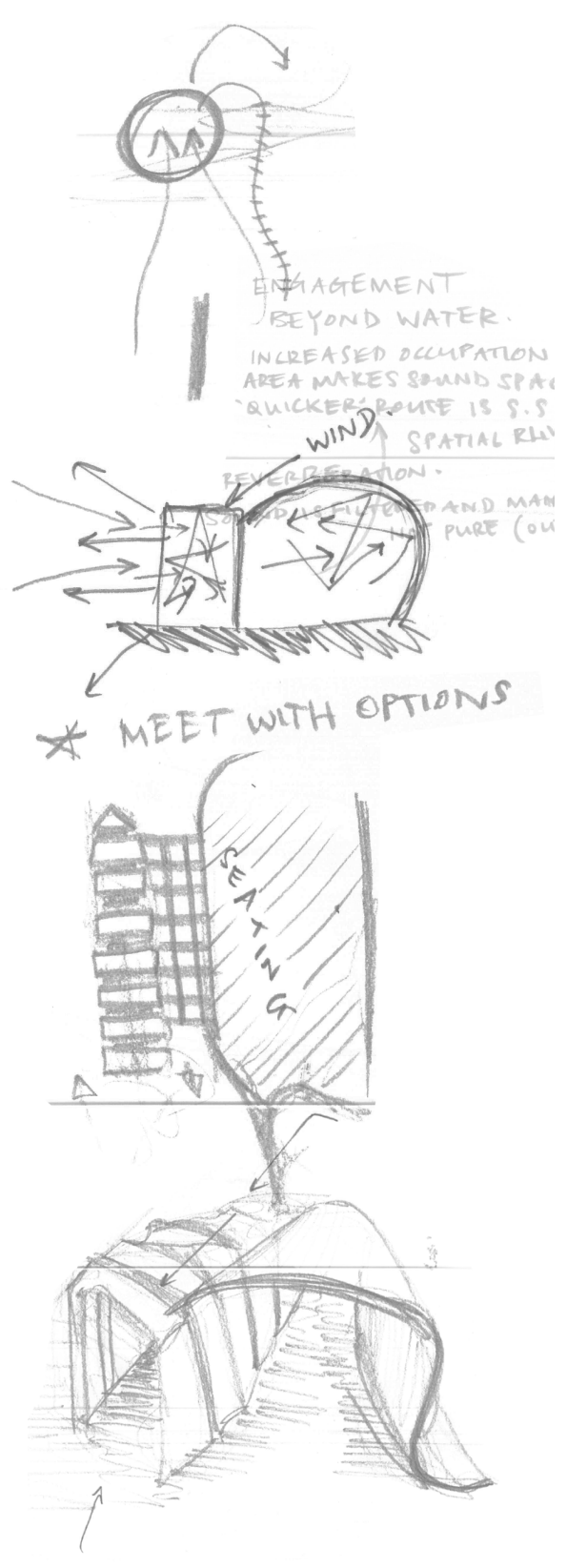

Performance + Interior Architecture - Into the abstract 101 


\section{Threshold}

The main threshold needs to incorporate two aspects: disruption and engagement. The Park can disrupt the set rhythm of the waterfront and people's tendency to travel along the water. By drawing people away from the water and towards a green space a point of difference can be made. The sounds of people, of wind and rain are magnified inside this enclosed space. Manipulating these sound will produce spontaneous moments and raise awareness of one's immediate surroundings.
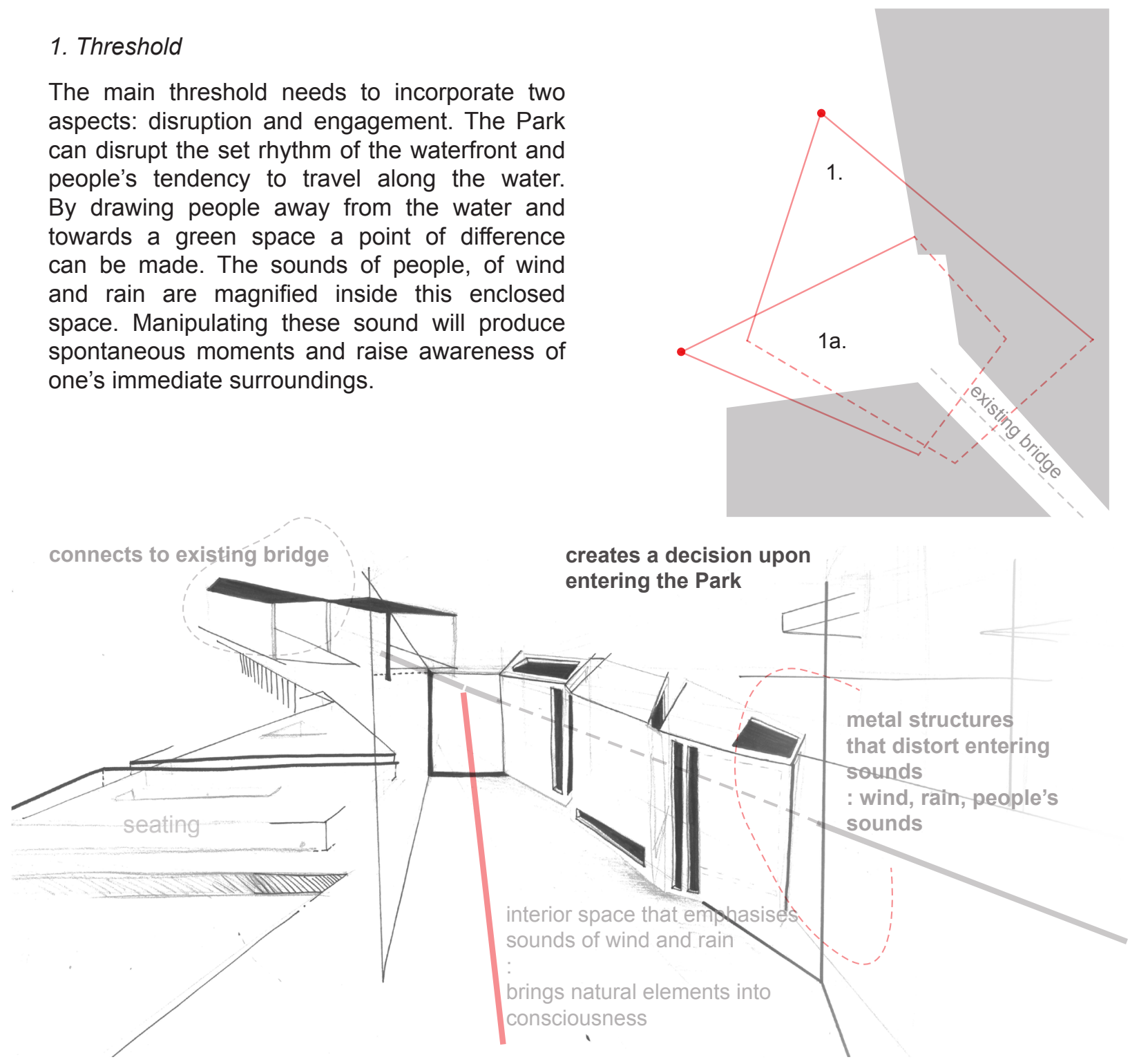


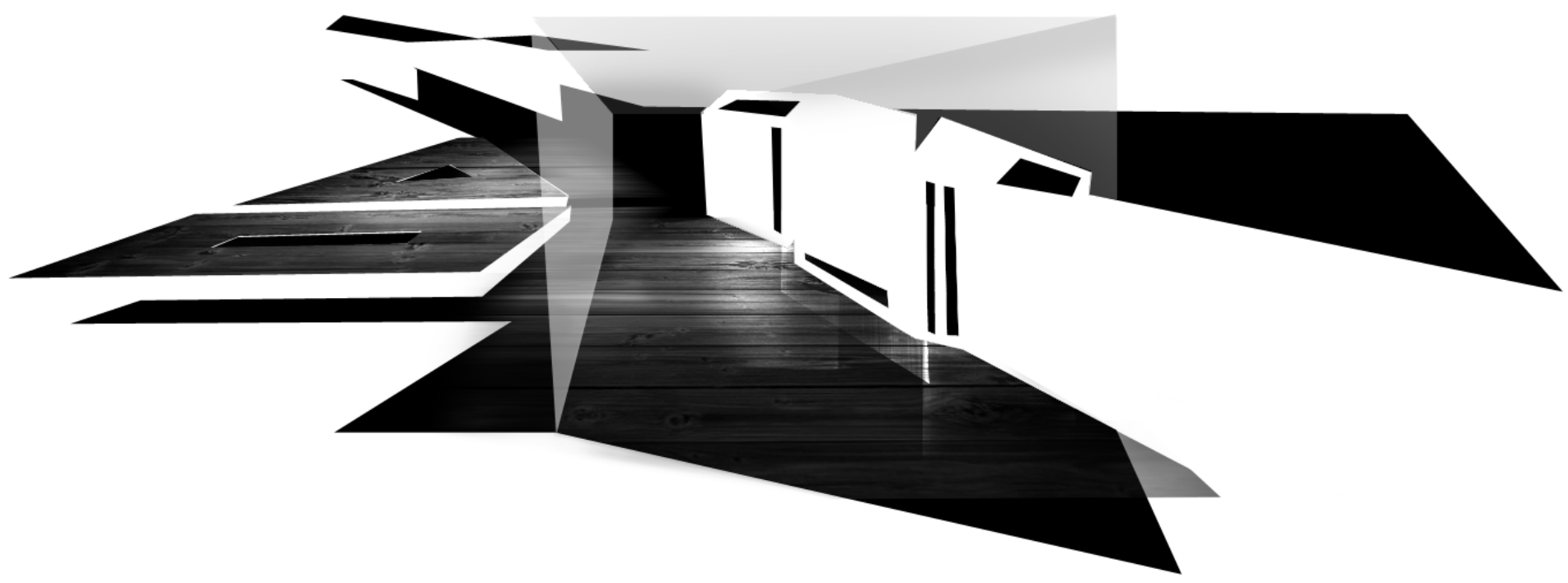

\section{Threshold}

sensory experience + diverging paths + emphasise environmental sounds 
This secondary area can work in tandem with the adjacent space [1]. As the space looks over the lagoon area leisure could be emphasised here. By preserving the existing pathway and bridge, the funnelling of people and the wooden path's sounds can be harnessed. This space is visually hidden from the main path but provides moments of leisure and interactive play.

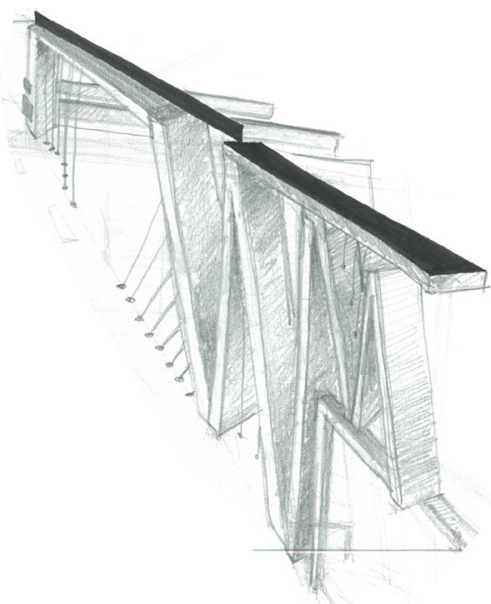

existing wooden pathway activates when ridden over

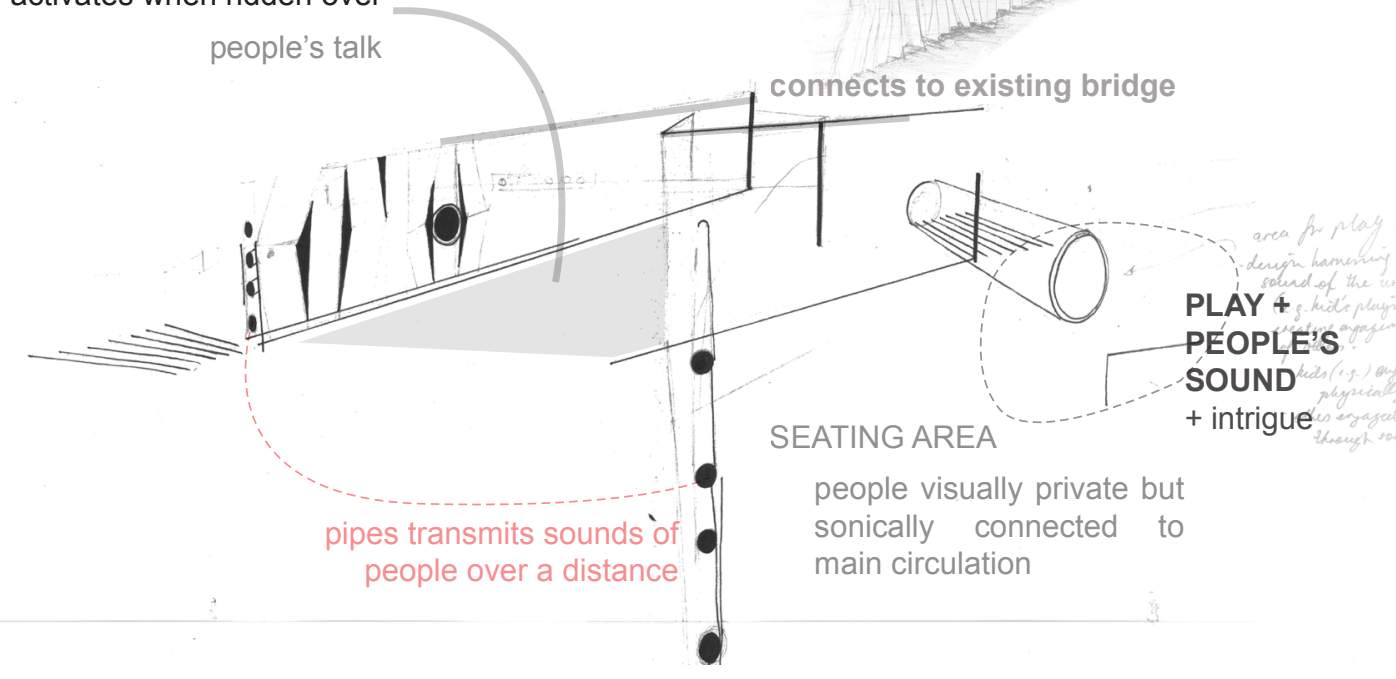




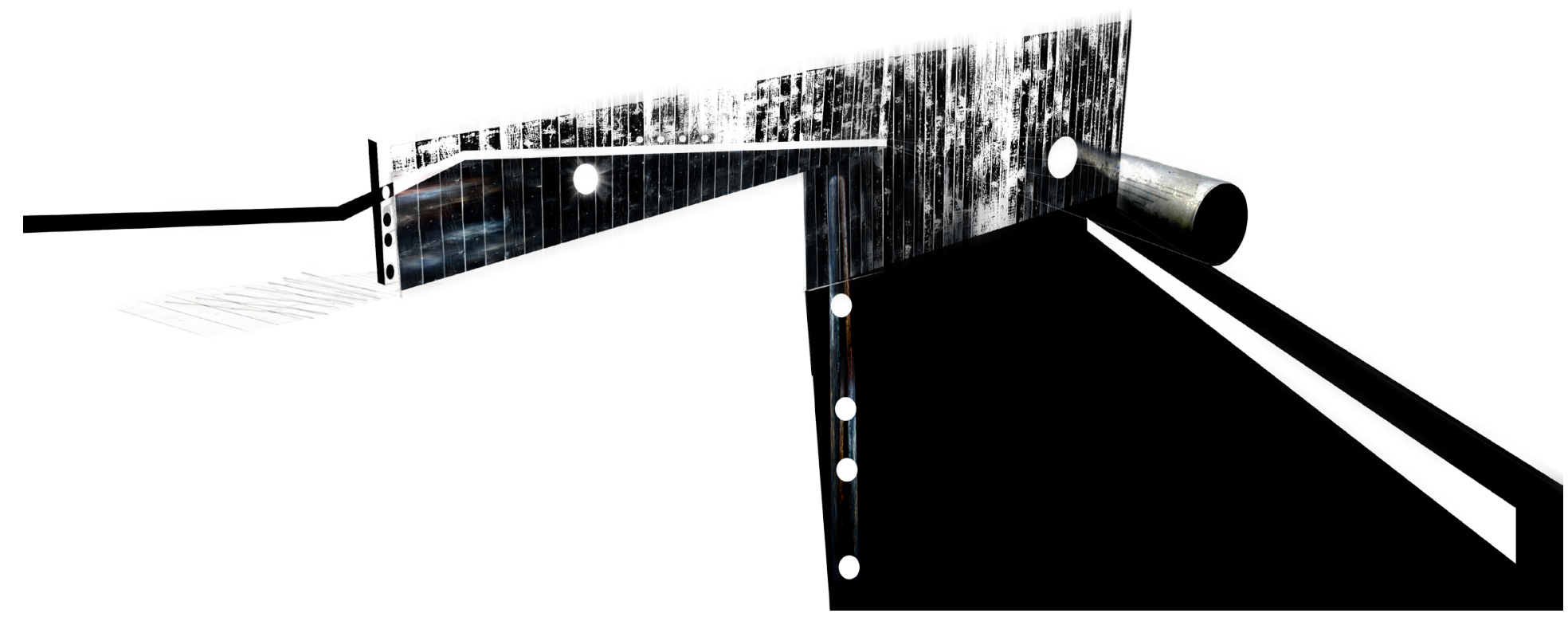

1a. Threshold

leisure + sonic connection + emphasise people's sounds 

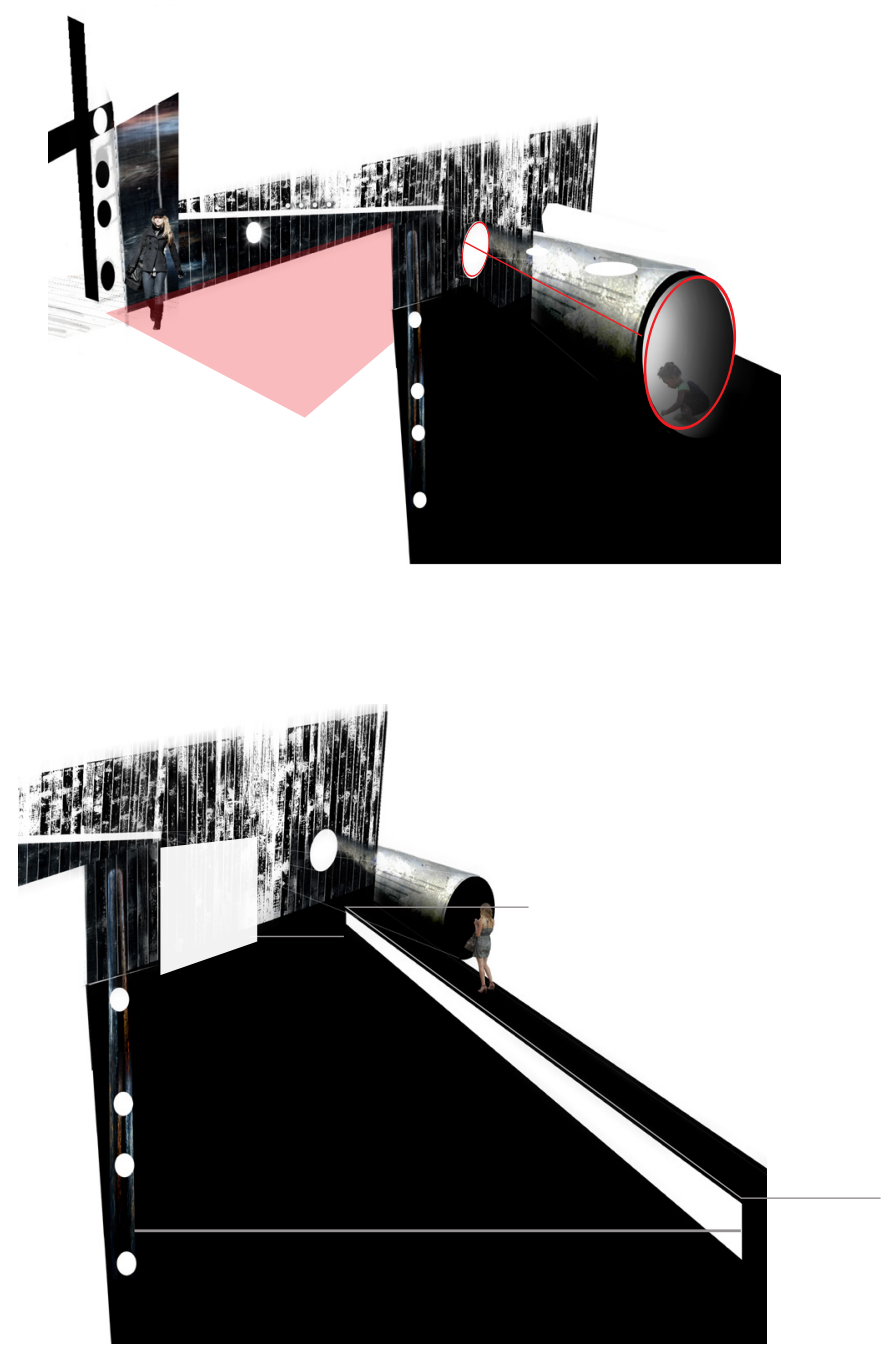

exploring changing scales with regard to interaction and occupation 


\section{Elevated walkway}

The elevated walkway will stimulate engagement between people and their city. The walkway can be an attraction from other areas of the waterfront. There is opportunity for people above and below through sound events. As the existing walkway is generally used by work commuters there will be a regular circulation that can be increased. Incorporating seating and look outs above which integrate into the rest of the intervention can create some extra occupation.

Improving engagement between people also includes raising awareness of others around, suggested here through voids and use of mesh. Disrupting the rhythm of the area can be orchestrated via disruptive sounds.

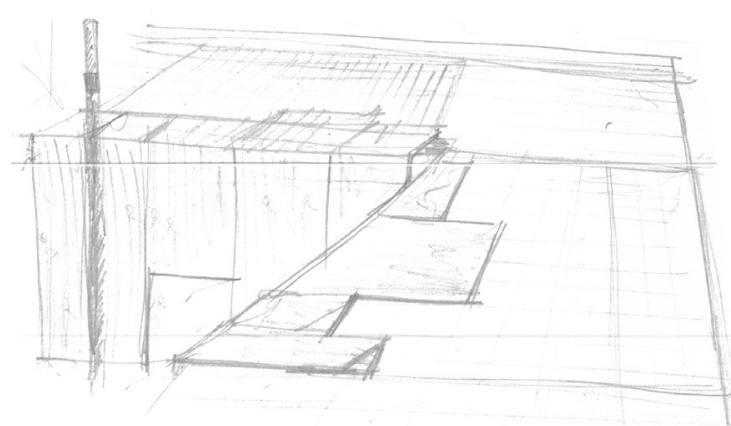

voids control movement through walkway

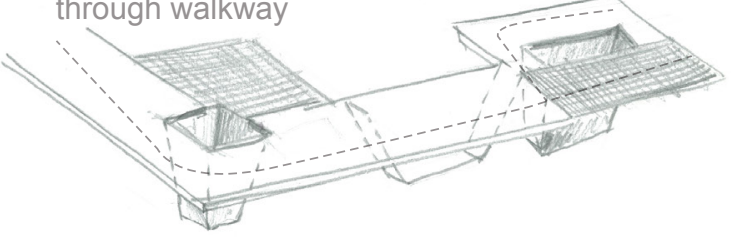

OID

visual, sonic and light exposed

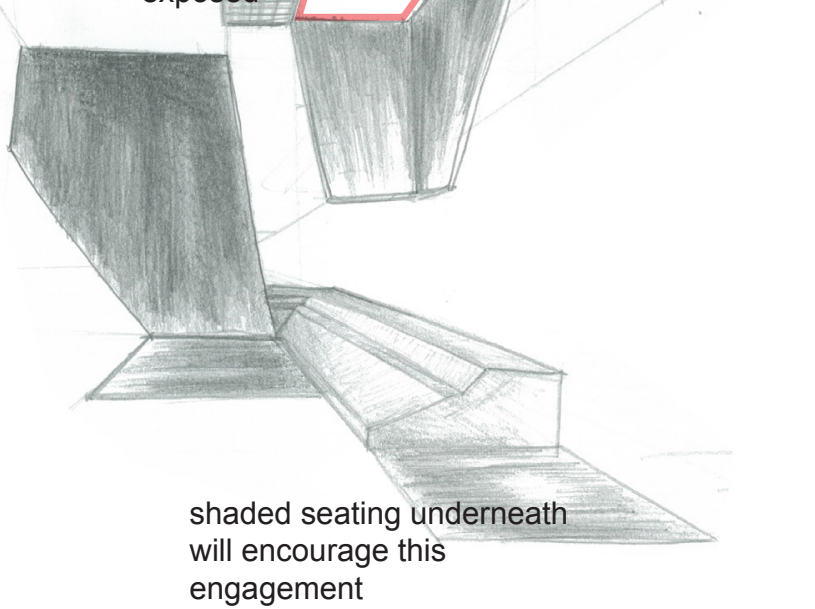



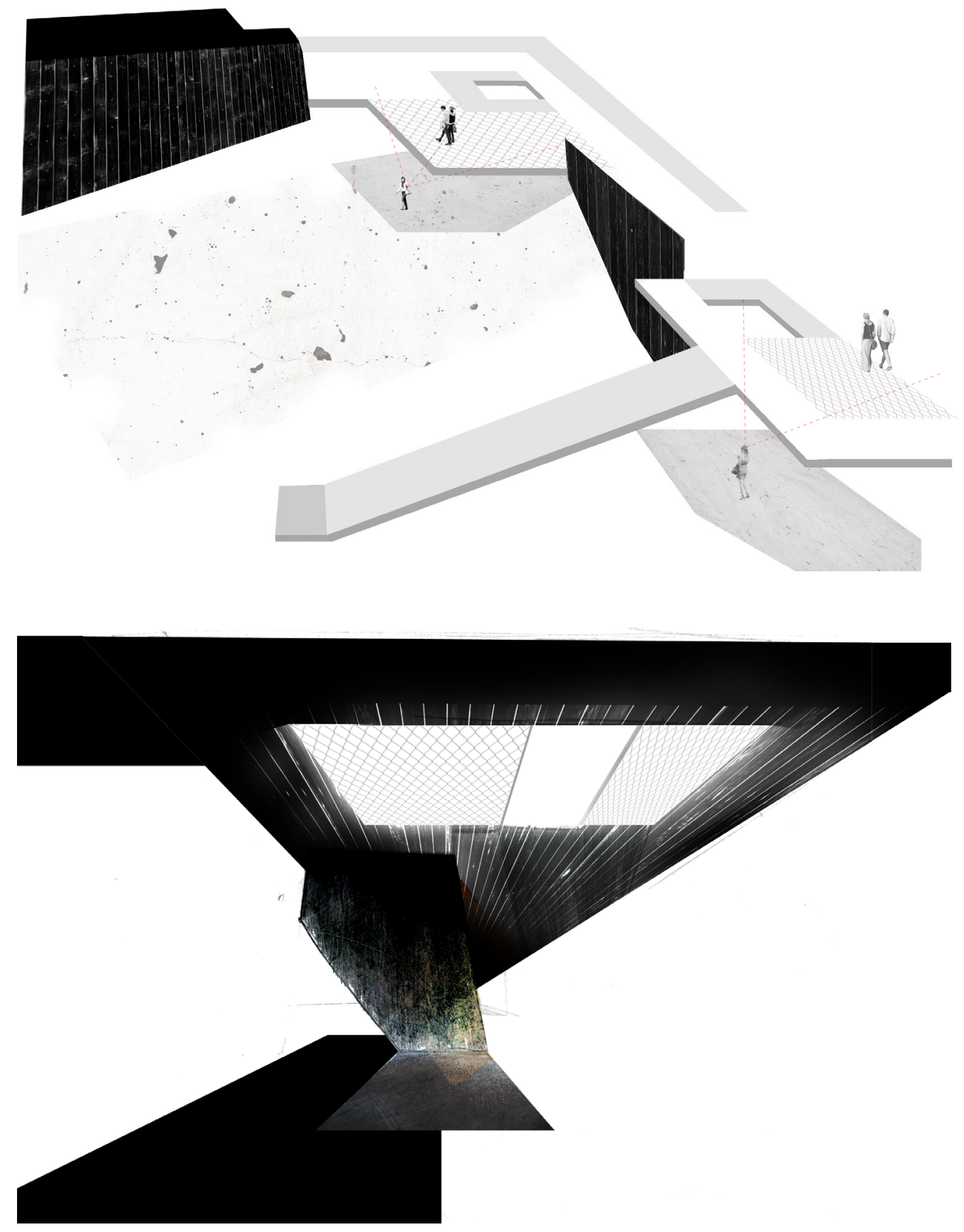

2. Elevated walkway

sonic connection between elevations + long distance attraction + circulation 


\section{Pavilion}

This area will be the climax of the interventionthe leisure centre point. Engagement with the water, leisure and the views will be the primary appeal.

An enclosing arrangement creates a determined space for diverse leisure. The intervention can also act as the connective centre; the raised walkway will be met by rising stairs and seating. This creates opportunity for leisure and circulation to blend together.
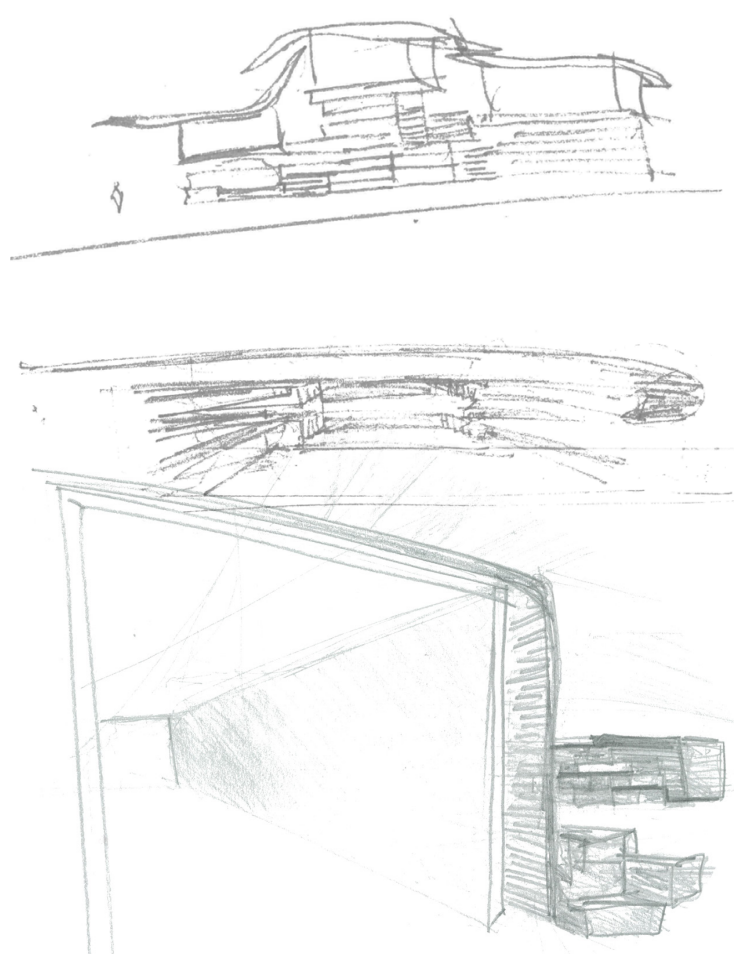
Sound can dictate experiences when it is suddenly dampened in such an open environment; an enclosed, visually limiting space that focuses on the present sound qualities creates momentary isolation and contemplation. This moment of sensorial focussing can be potent in urban spaces.
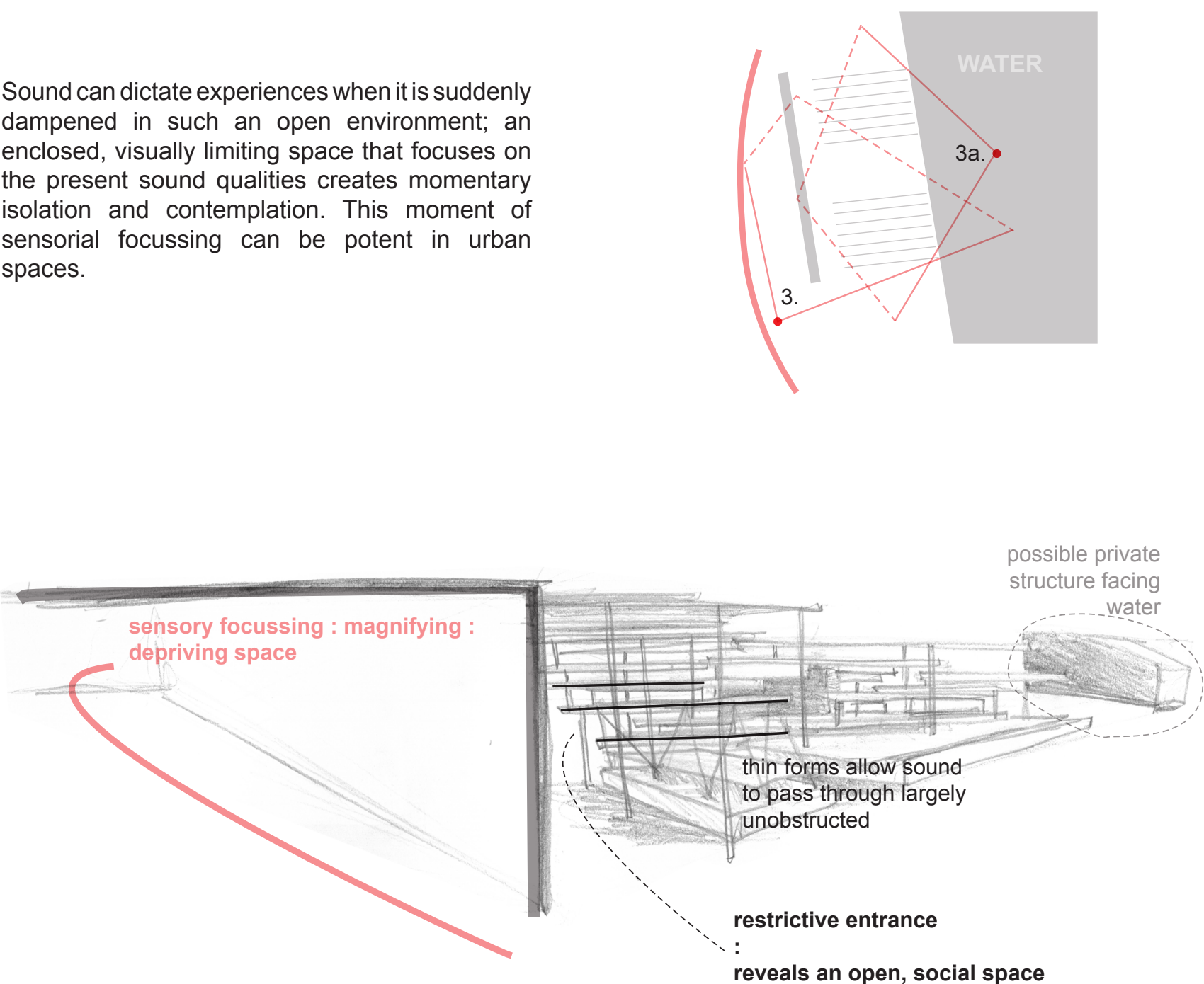

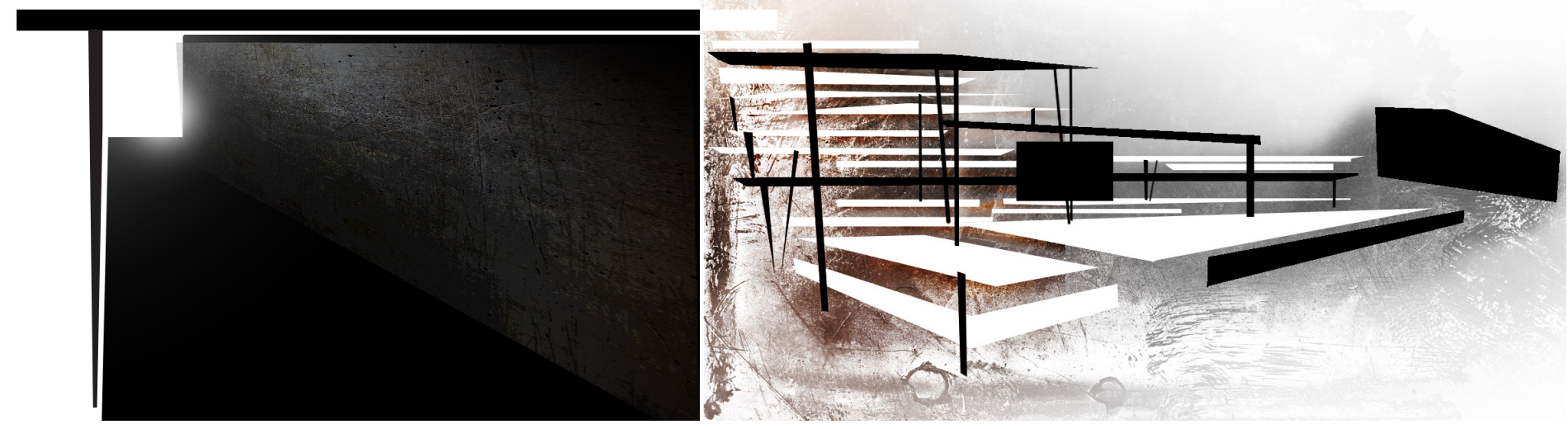

3. Pavilion

diverging paths + people's sound + sensorial focussing + water as an attraction 3a. Pavilion

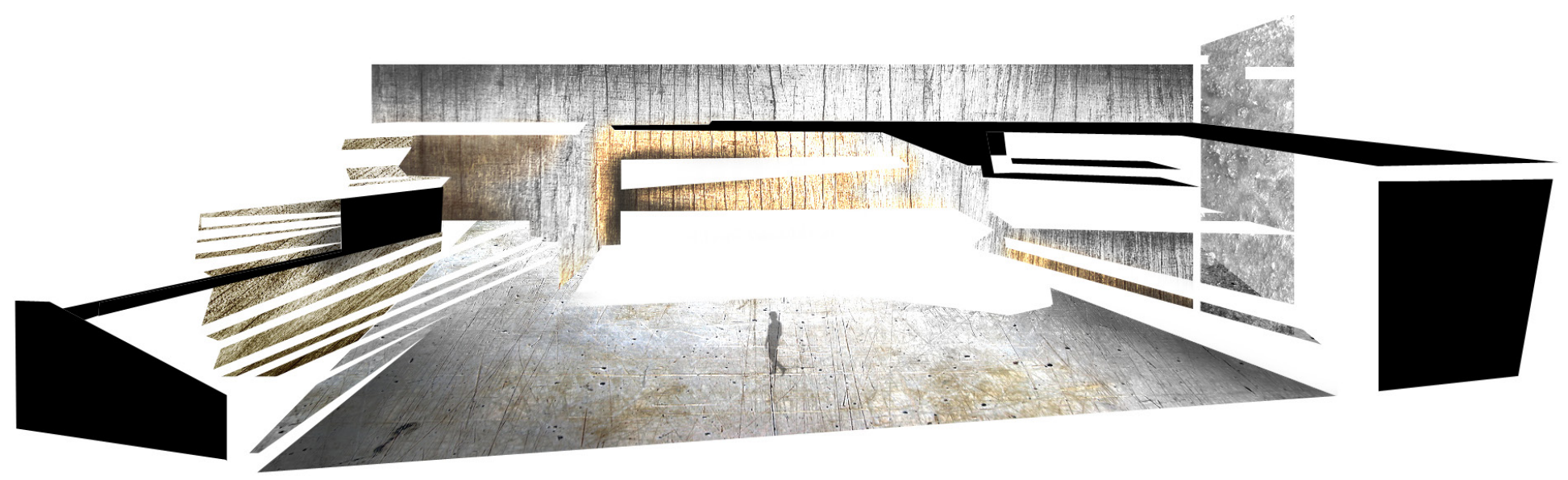




\section{Leisure Area}

Located furthest from the water and closest to the traffic 'noise', the leisure area will harness the sounds of the city. Solitary and relaxation caused by exposure to nature's sounds will attract people and evoke tranquillity. The traffic sounds present an interesting antithesis to the sought quiet atmosphere, yet it opens up the chance to reimagine how the traffic's sounds can be experienced.

This area is currently being used by people wanting a direct route from the waterfront to the city. Therefore, the proposed intervention could provide a direct passageway where the manipulation of traffic sounds are emphasised.

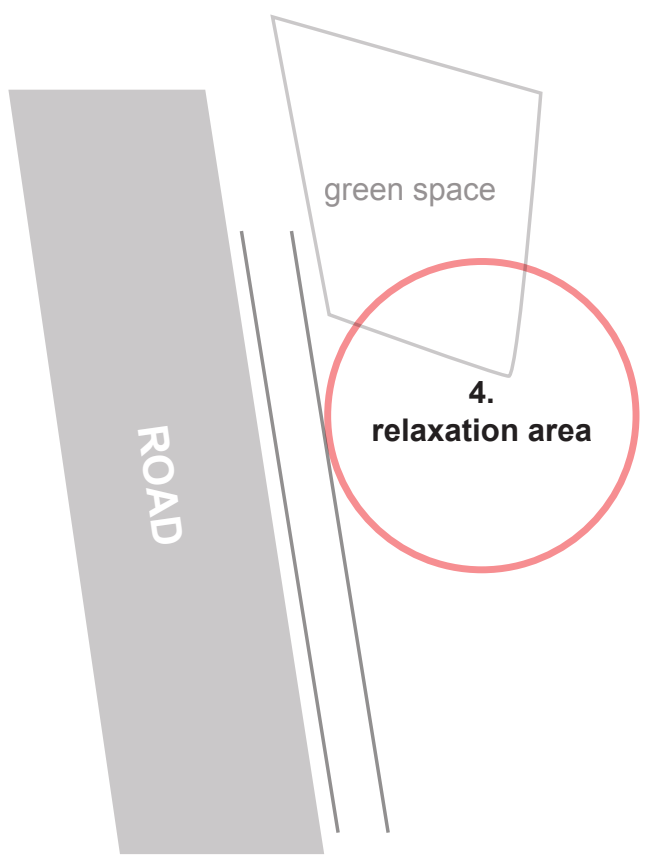


Along the length of the passageway, people will experience a dampened sound that subtly builds, climaxing in the centre. The narrow design focusses attention onto other people within and the filtered traffic sounds.

The seating area uses spatial isolation and natural sounds to achieve a sense of tranquillity. Smaller enclosed 'pods' promote acoustically dampened private space within open spaces. Careful use of natural materials can enrich the sonic experience.

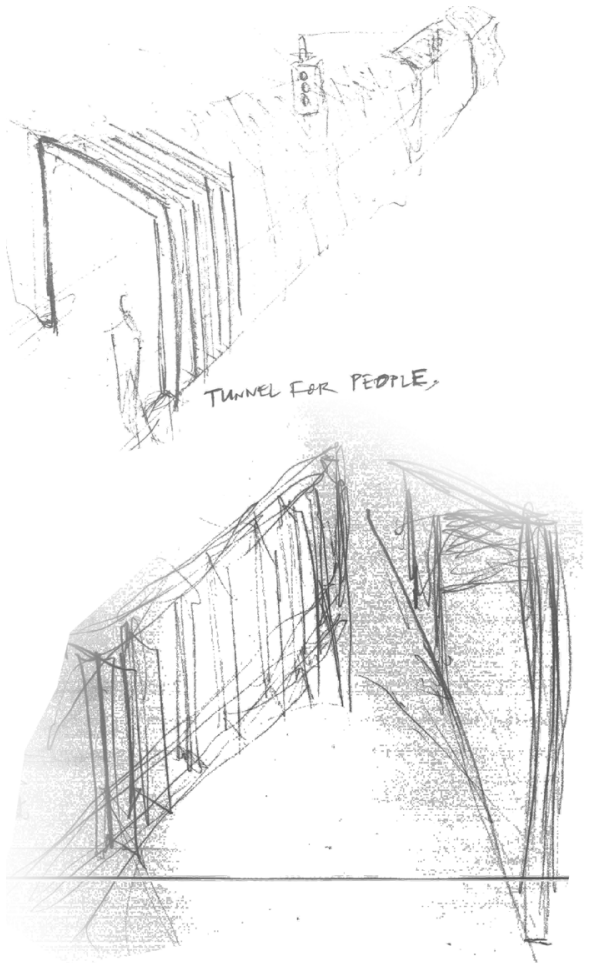

traffic sounds manipulation + circulation

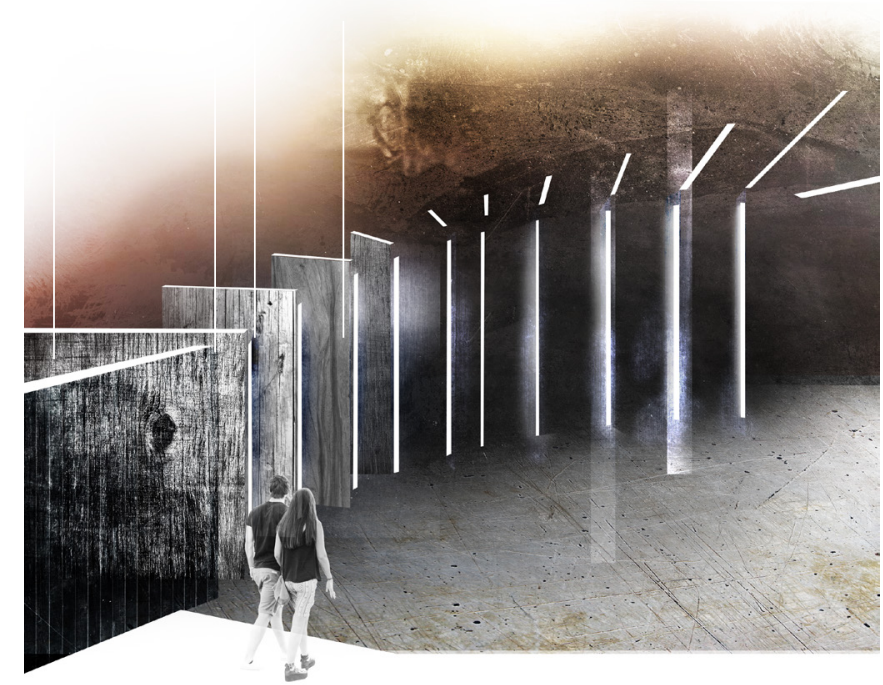




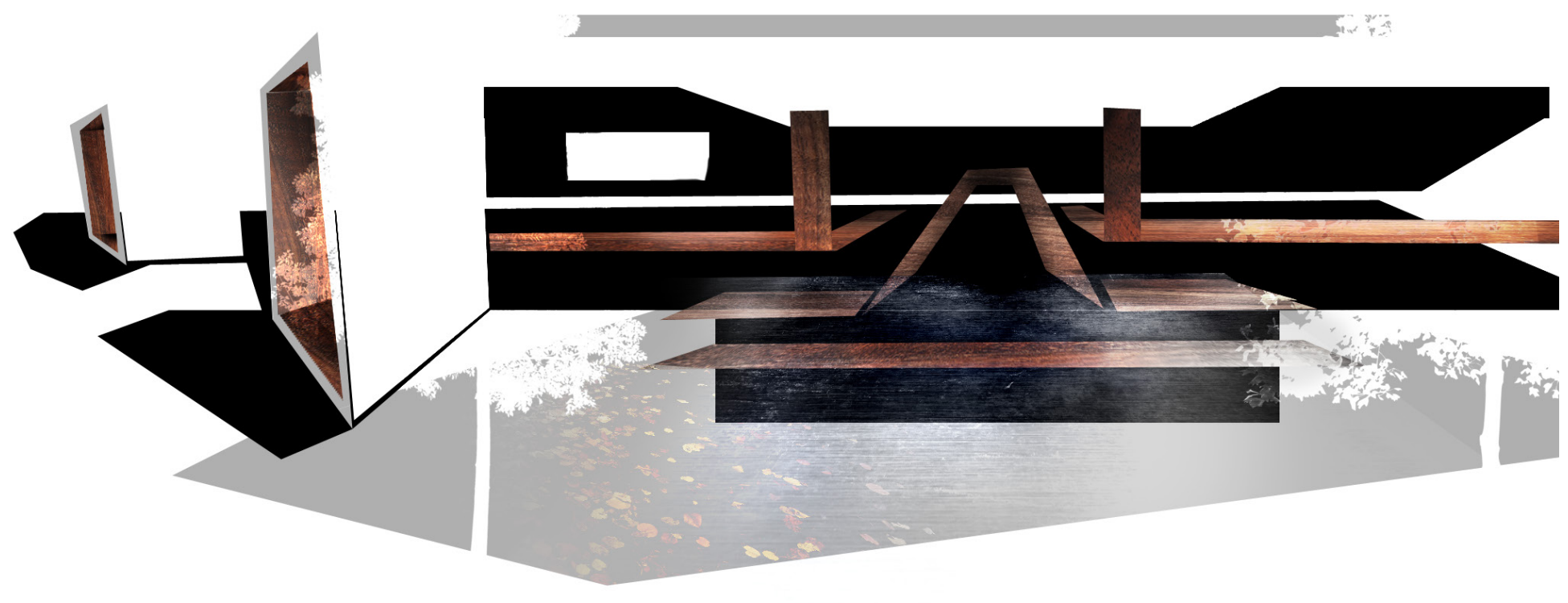

4. Leisure Area

tranquillity + natural sounds + leisure + isolation of differing scales 


\section{Performance space}

This space can frame and advertise both the pavilion and the leisure area. People who seek exploration and stimulation versus those who desire solitude among nature. This space can distribute in a way that completely affects the experience one has in the Park.

This area could also harness an 'active' sound event via play. The performer / audience notion suggested earlier can be brought to the forefront here.

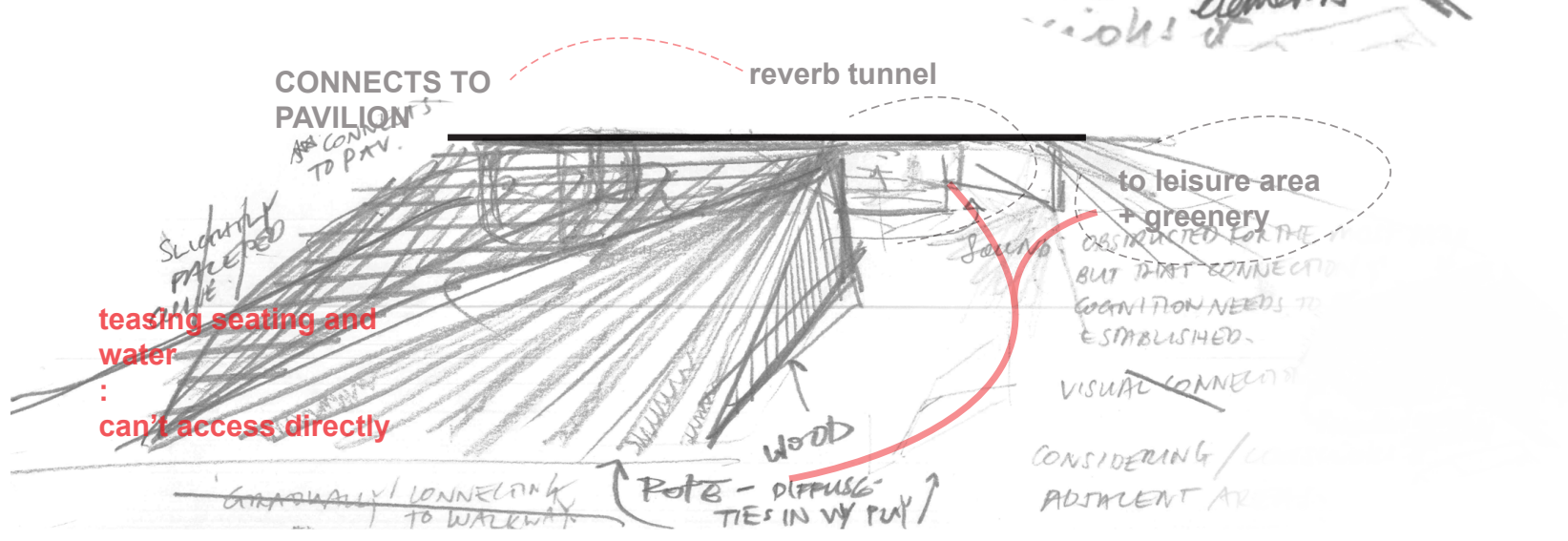




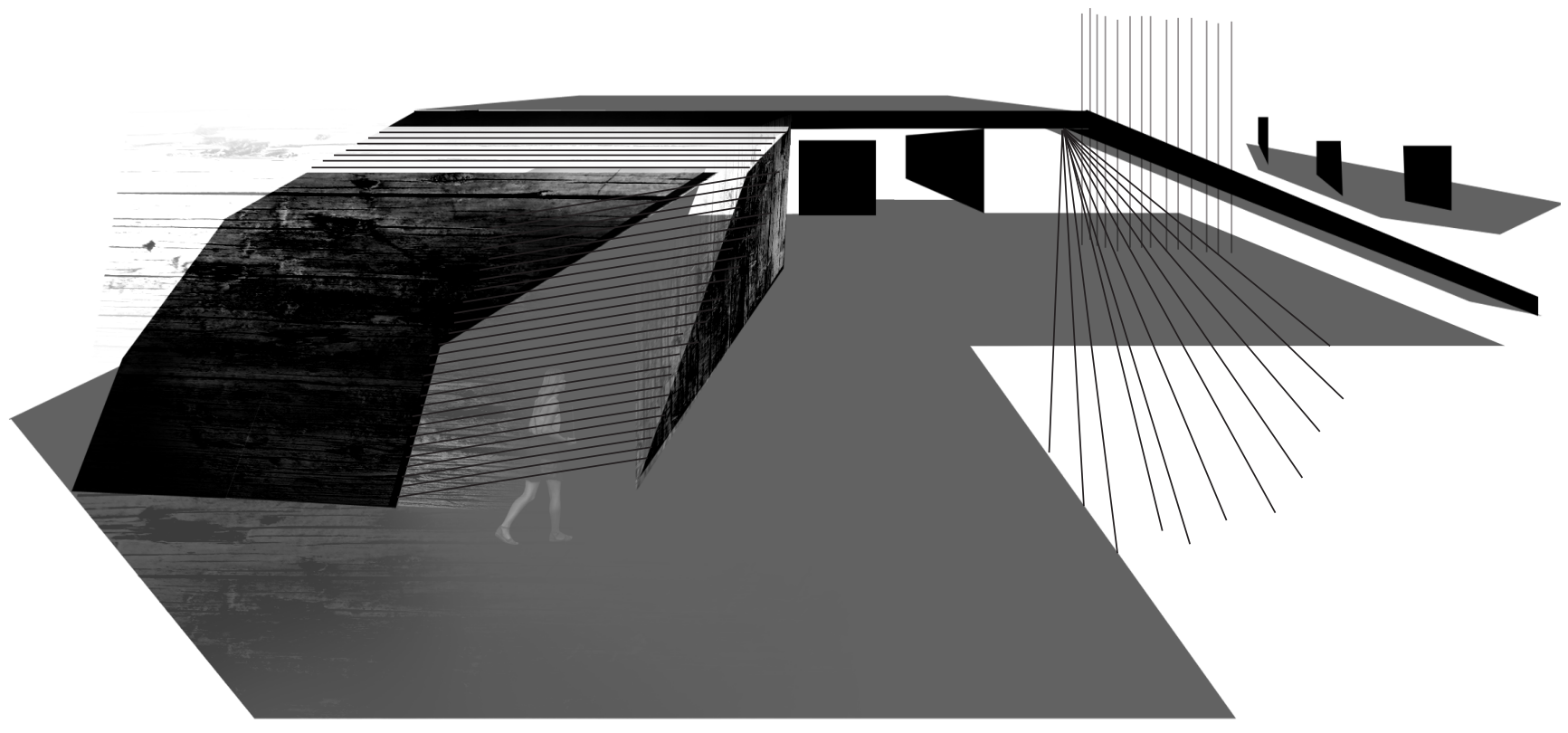

5. Performance area

inviting connection point + diverging pathways + teasing attraction of water 


\section{Rationalising the concepts}

The concepts will now shift from the abstract and be dissected and explained through diagrams. This will help firstly, to communicate what conclusions were made through the various phases of concepts, but also unresolved aspects can be identified.

The allocation of colour to specific sound sources will be introduced as followed, this will help determine the balance and complexity of the soundscape.

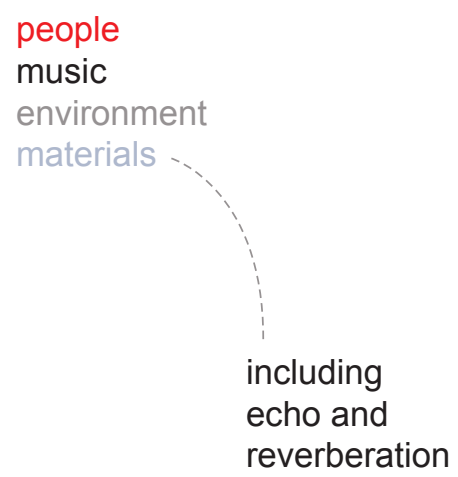


people

music

environment

materials
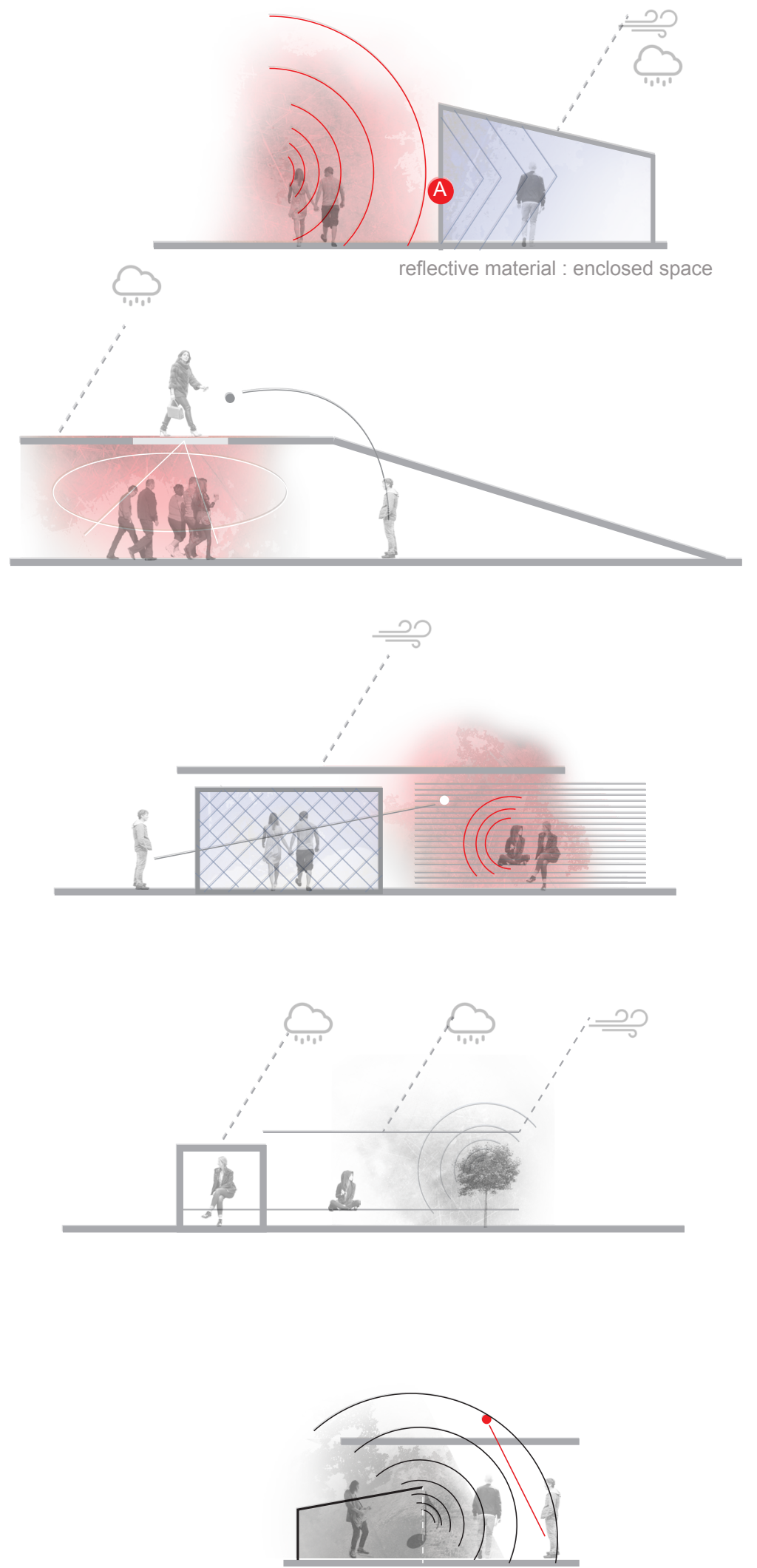

1.

Manipulation

of people's +

environmental

sounds

2.

Awareness of others + appeal of the space + circulation

\section{3.}

Appeal of space + circulation connection + sensory focus

4.

Leisure + nature's sound emphasis + privacy

5.

Music engagement + circulation + appeal of space 


\section{Soundscape analysis}

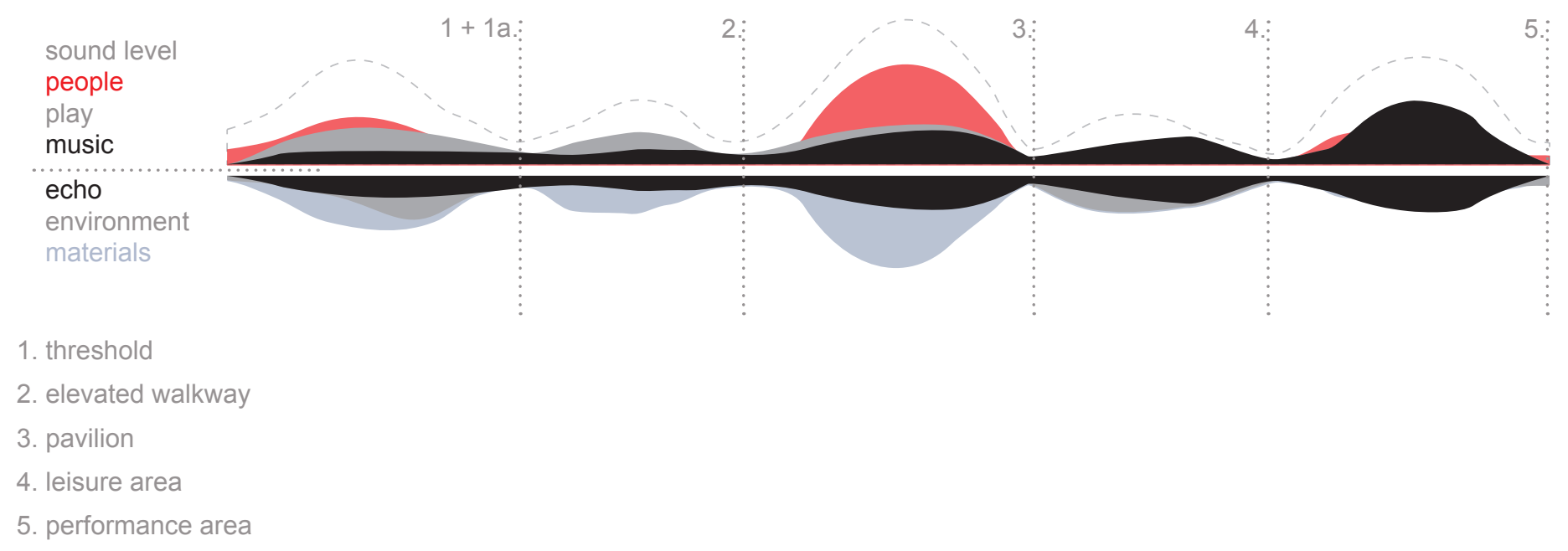

The journey through sound and estimated sound levels are represented above. The soundscape is divided into 6 main sound components that fluctuate throughout the site. Ultimately, the balance of the intervention's sound levels looks promising (dotted line): sonically stimulating entrances / exits (1 \& 5) that decrescendo into quieter areas $(2 \& 4)$ that then climax around the pavilion (3).

This diagram and the breakdowns adjacent describe the emphasis on people and material's sonic qualities. For example, both areas 1 \& 3 use enclosed spaces and sonically reflective materials but in various ways. 1 uses these qualities to increase engagement with environmental conditions, while 3 uses the qualities to focus on people and their sounds away from stimulating visuals. 1 also incorporates play as a main source of stimulation, while 3 uses people and leisure. The juxtaposition of the two spaces could be important to produce a holistic intervention.

The quietest area (4) harnesses the sounds of the context, including traffic. In this space the plants and trees, and the materiality of the ground and seating will be crucial- the influence and effect of these need more emphasis. This area is crucial to the overall experience and usage of the Park- this will need to be carefully considered in the coming stages. 


\section{Conclusions}

The role of spaces within the site and intentional soundscape have now been narrowed. The next stage is where developed design begins. Using intuitive drawings to formulate initial ideas, then reinterpreting the ideas via impulsive responses ensured the design drawings creatively and organically refined. The technique involved was surprisingly successful, particularly the impulsive gestures that subconsciously captured insightful and thought-provoking design ideas. The impulsive drawing technique helped to address the problem of scale within Frank Kitts Park.

Evocative concepts were produced by evolving the impulsive technique and integrating textures in the digital realm. These images offer ideas that can be development, but where the main success lies is in the process. Through rigorous iterations, the sonic and experiential qualities of each space were refined to their specific location and role within the Park. This means the coming stages of design have a solid foundation built on sensory and experiential qualities.

The development and testing of varying representational techniques throughout these stages was also a focus. The use of colour was a notable realisation, the intensity and colour designation began to communicate different sound levels and sounds- though this needs to be developed. It is a concern that the amount of information communicated could be saturated when sensory and experiential qualities are included. Also, colour may help communicate over-complexity or a lack of sonic influence.
The sheer size of the Park opens up a difficult task: to design each space to a standard that showcases the latent power of sound and play + leisure. The attention to materiality, forms, scales, and sensory, experiential and sonic qualities is imperative. Each of the five spaces contain significant importance to the entire Park, however, there is an increasing need to reduce the scope of work. In the Soundscape analysis, three spaces were identified (1, 3 and 4$)$, the combination of the three offer an intriguing and thorough look into how soundscape and sensory design can better the urban context. Therefore, to produce substantial conclusions about this proposal three areas will be concentrated on and taken into detailed design:

- Threshold area (1)

- Pavilion (3)

- Leisure area (4). 


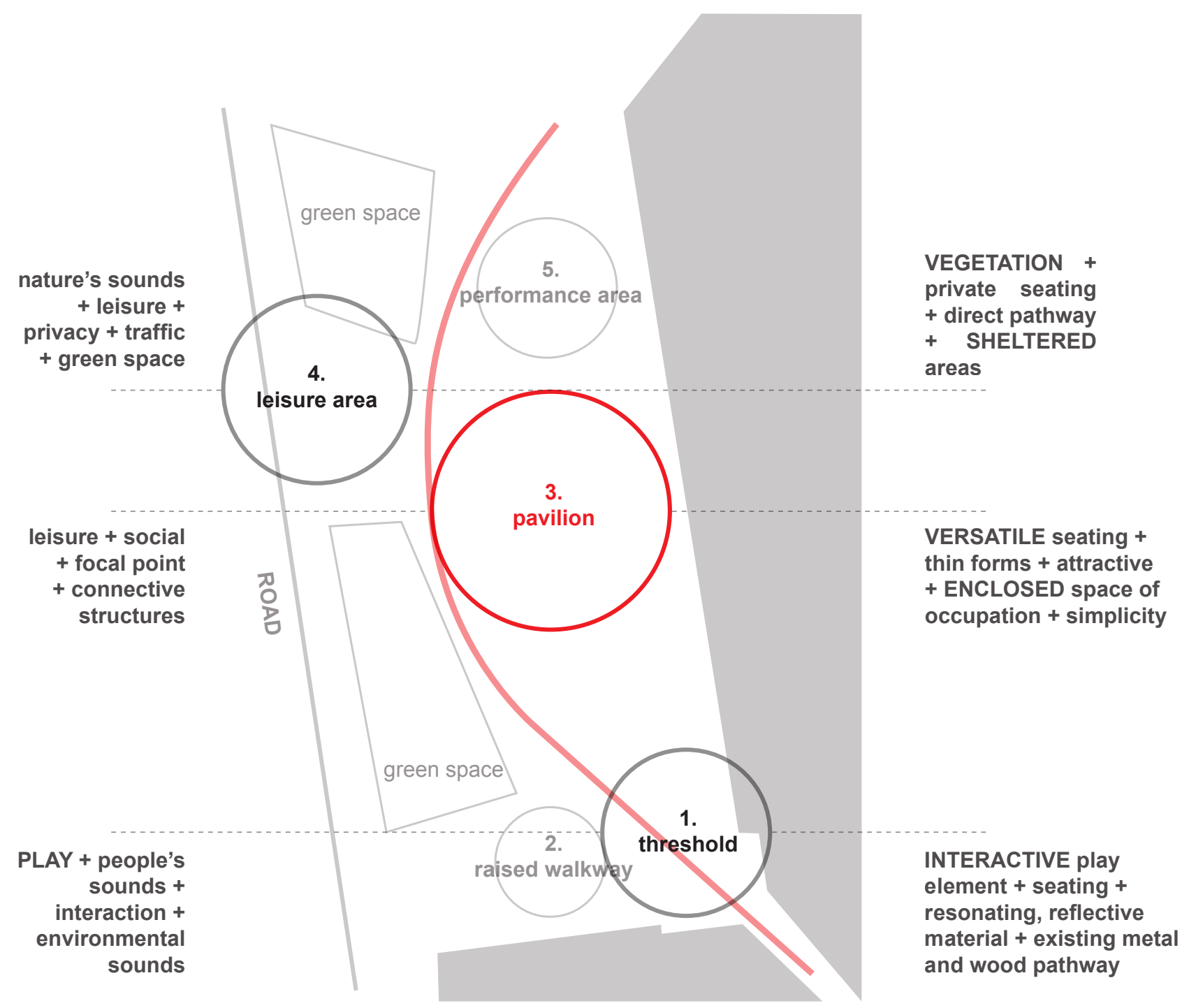




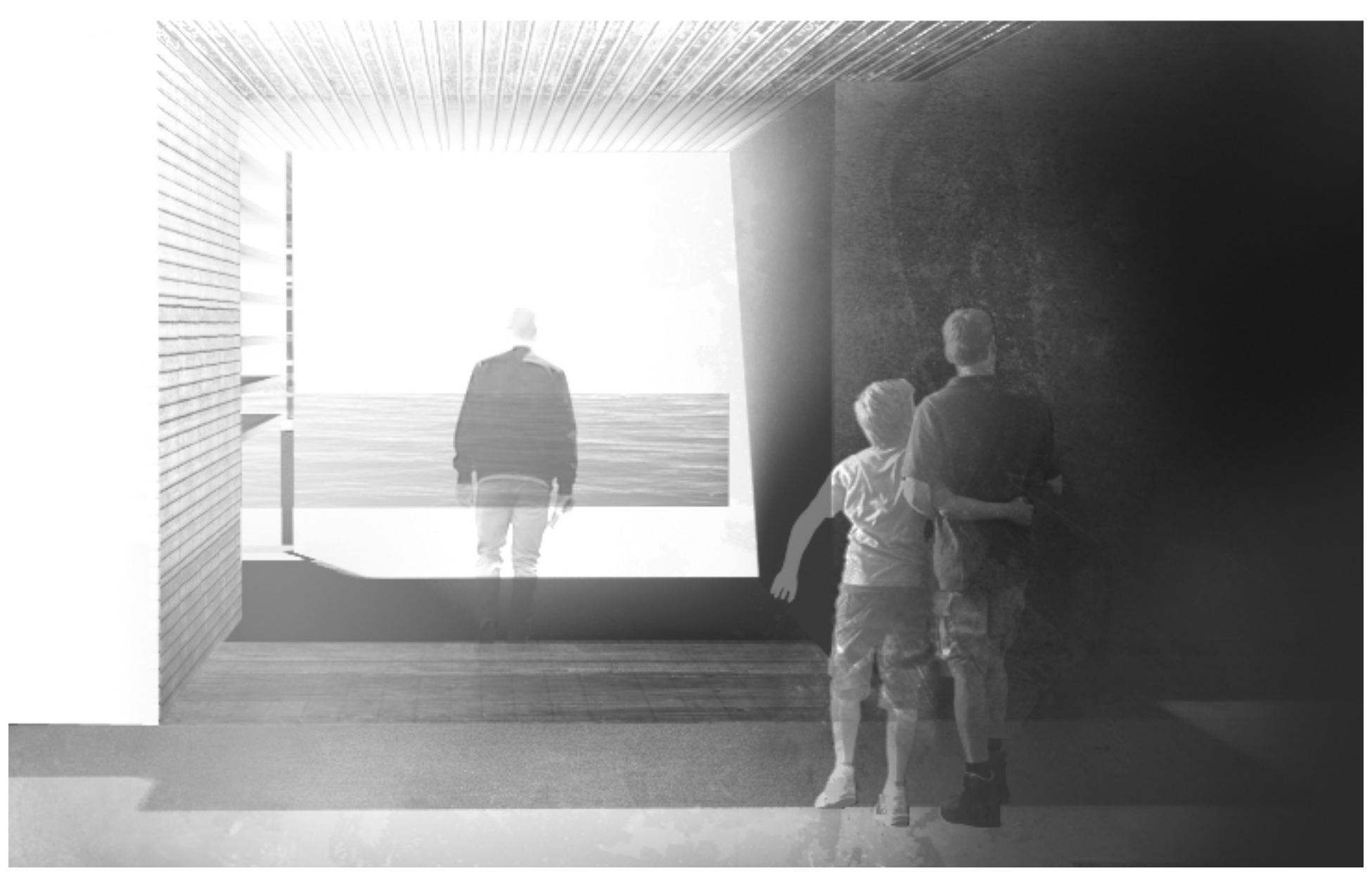




\section{[9] DEVELOPED DESIGN}

The following sections will apply all the research, analyses and precedents into developed design. The concepts produced will be taken further separately, first the threshold area, then pavilion and leisure area (renamed below).

Hand-drawing will be used in tandem with digital modelling. The aim is to use the digital realm mainly as a communication, refining tool. Development sketches' raw nature will be maintained throughout.

Threshold area

Pavilion

Leisure area
Threshold of Sound

p.124

Convergence Area

p.145

Rhythmic Seclusions 
THRESHOLD OF SOUND

PLAY + people's sounds +

$1 a$ interaction + environmental sounds

INTERACTIVE play element + seating + resonating, reflective material + existing metal and wood pathway

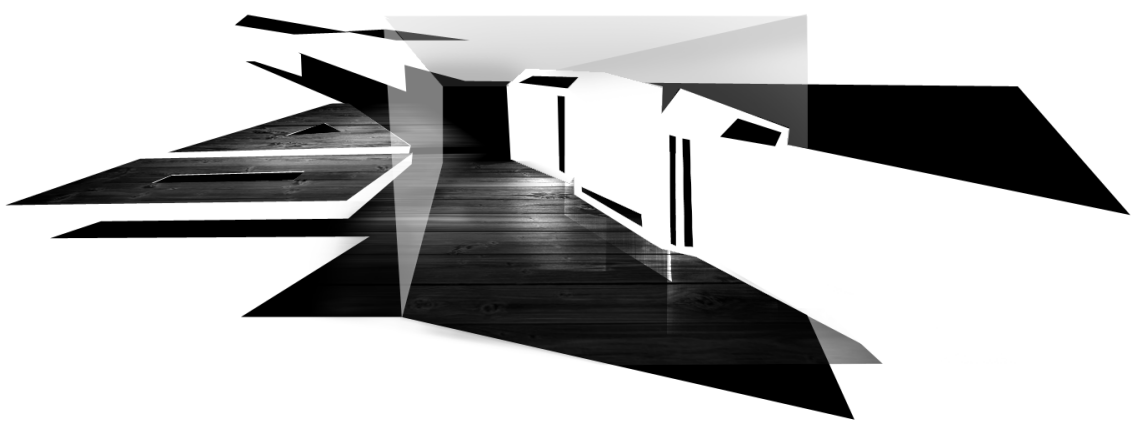




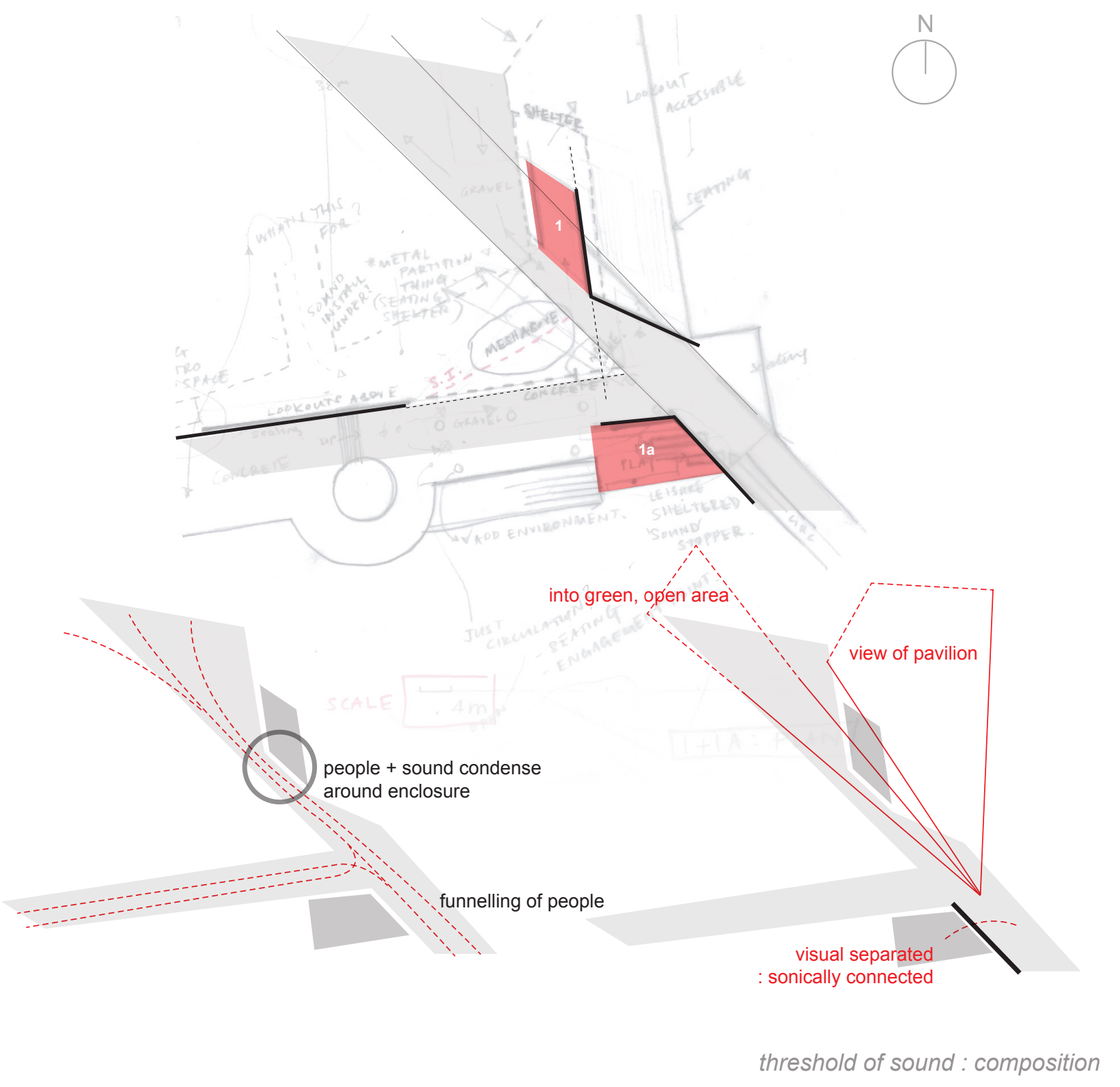

Performance + Interior Architecture - Threshold of Sound 125 
1a. Entrance and sonic connection

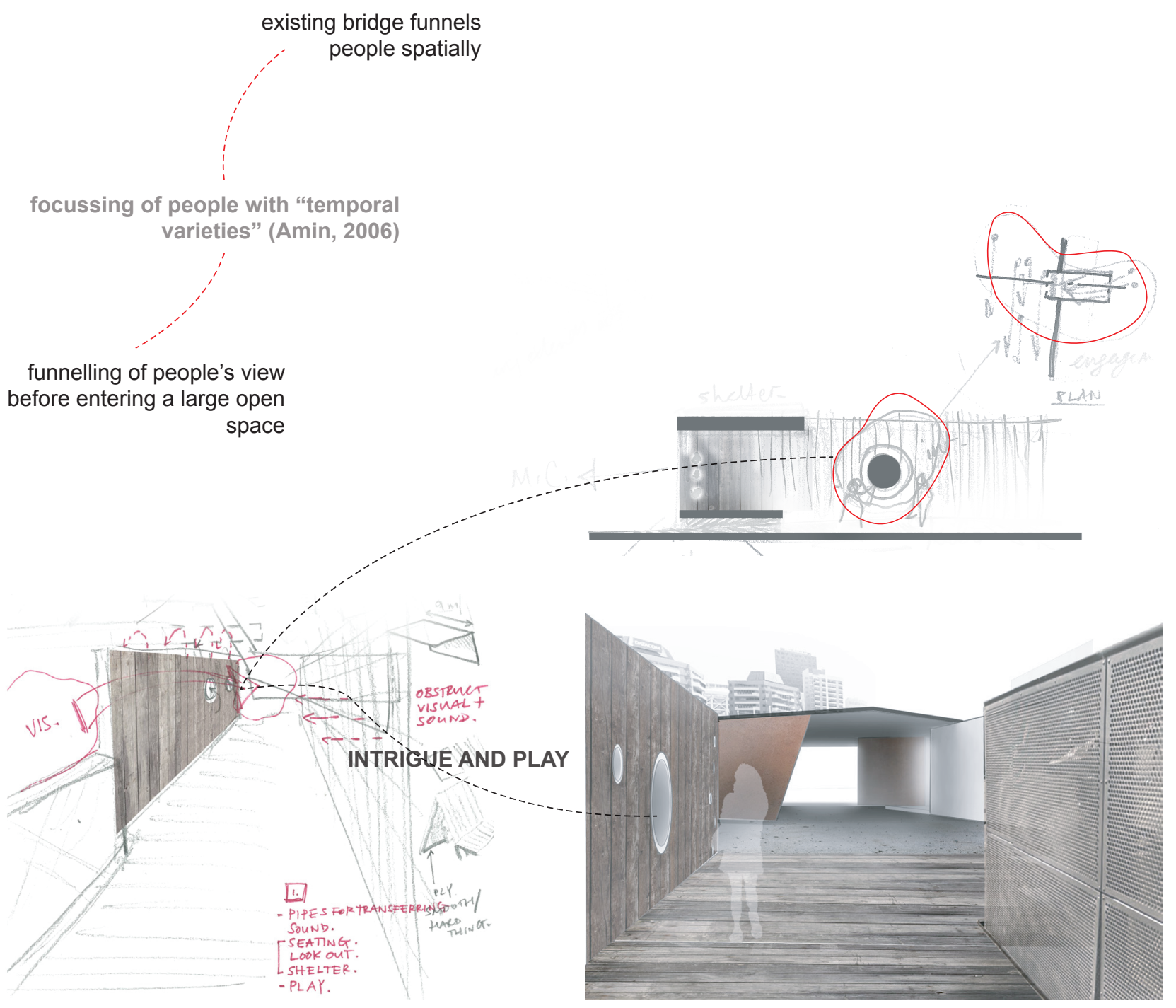

fig. 3.19: threshold entrance 


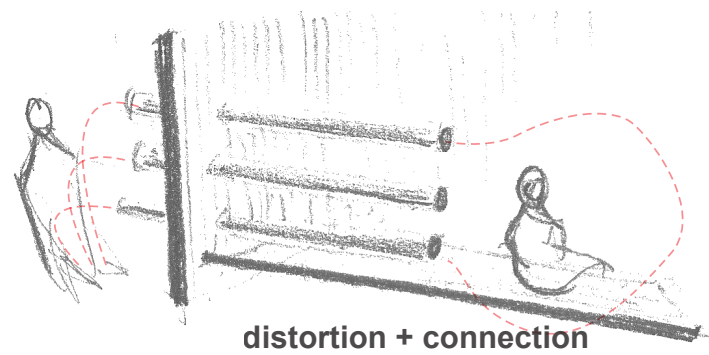

as visual privacy increases, the sonic connection increase as

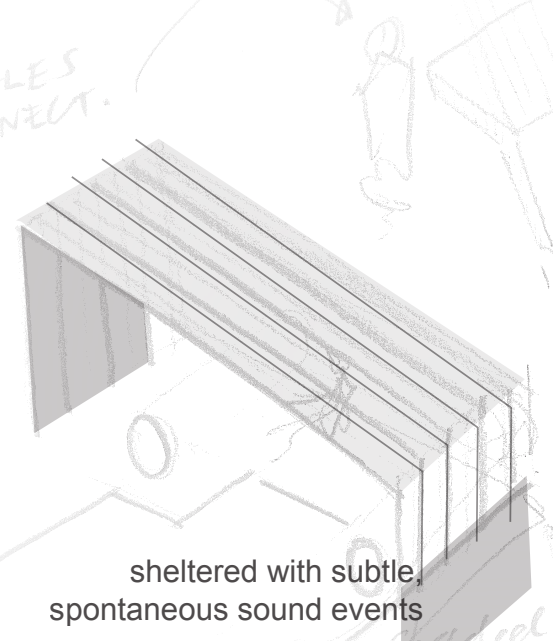
well spontaneous sound events simple forms are used as to enable versatile occupation 
While it is difficult to test and communicate the sonic qualities through visuals, interesting ideas emerge such as when privacy increase so does the sonic connection - these concepts merit further exploration.

fig. 3.20:

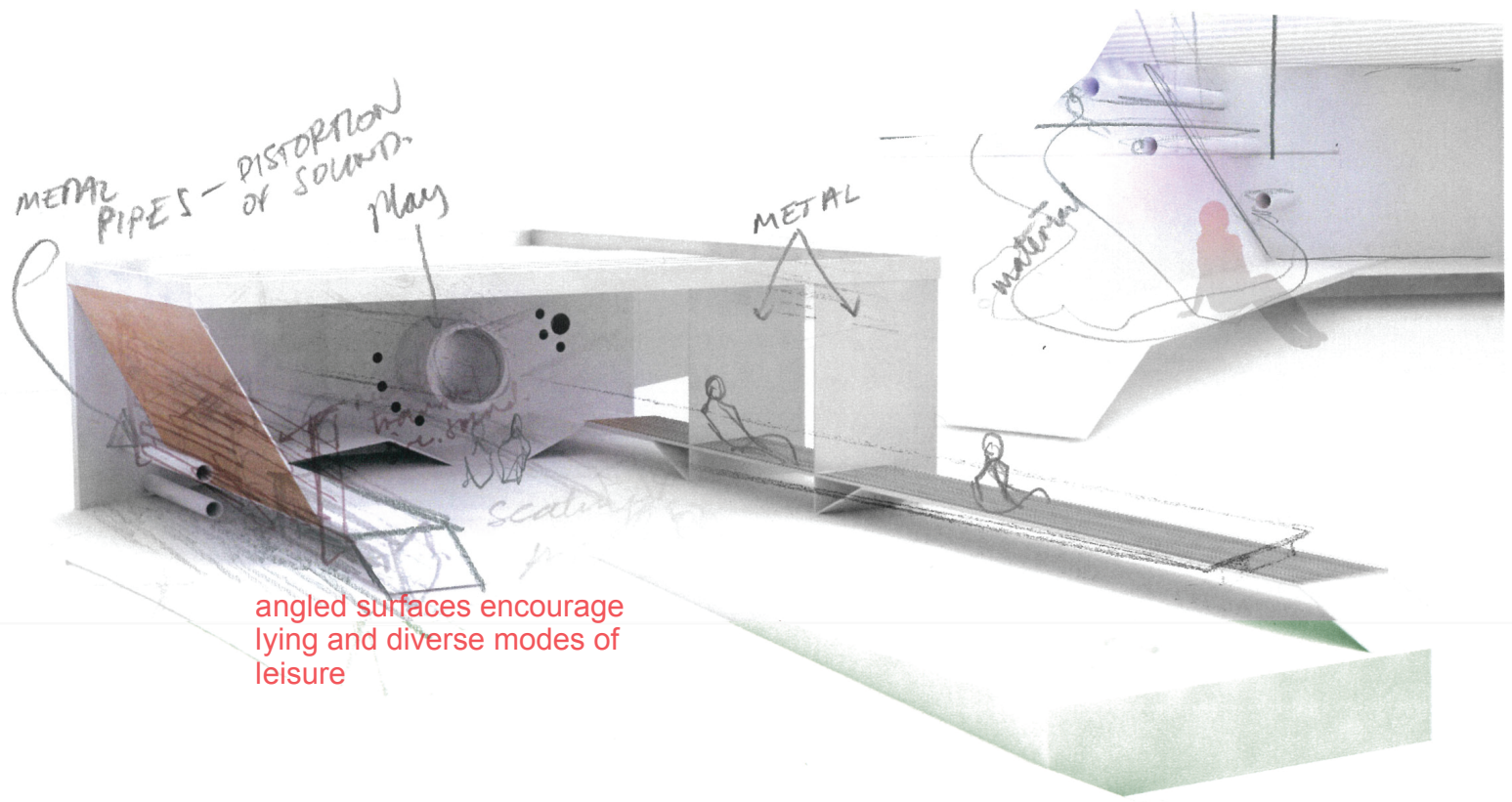




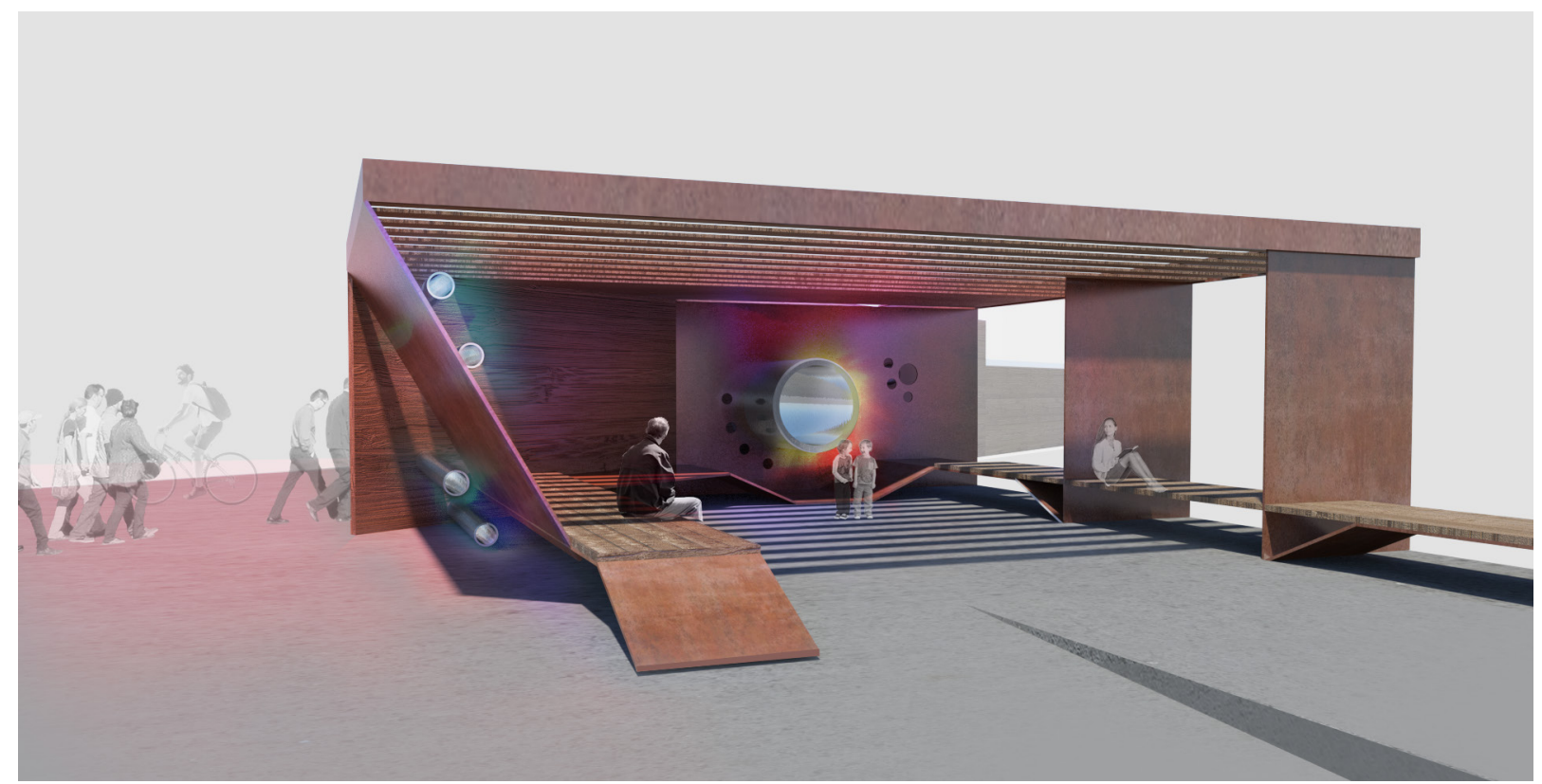

iteration one- exploring representational technqiues

using colour to denote different sound sources

people

materials

$\{$ leisure+

circulation\} 

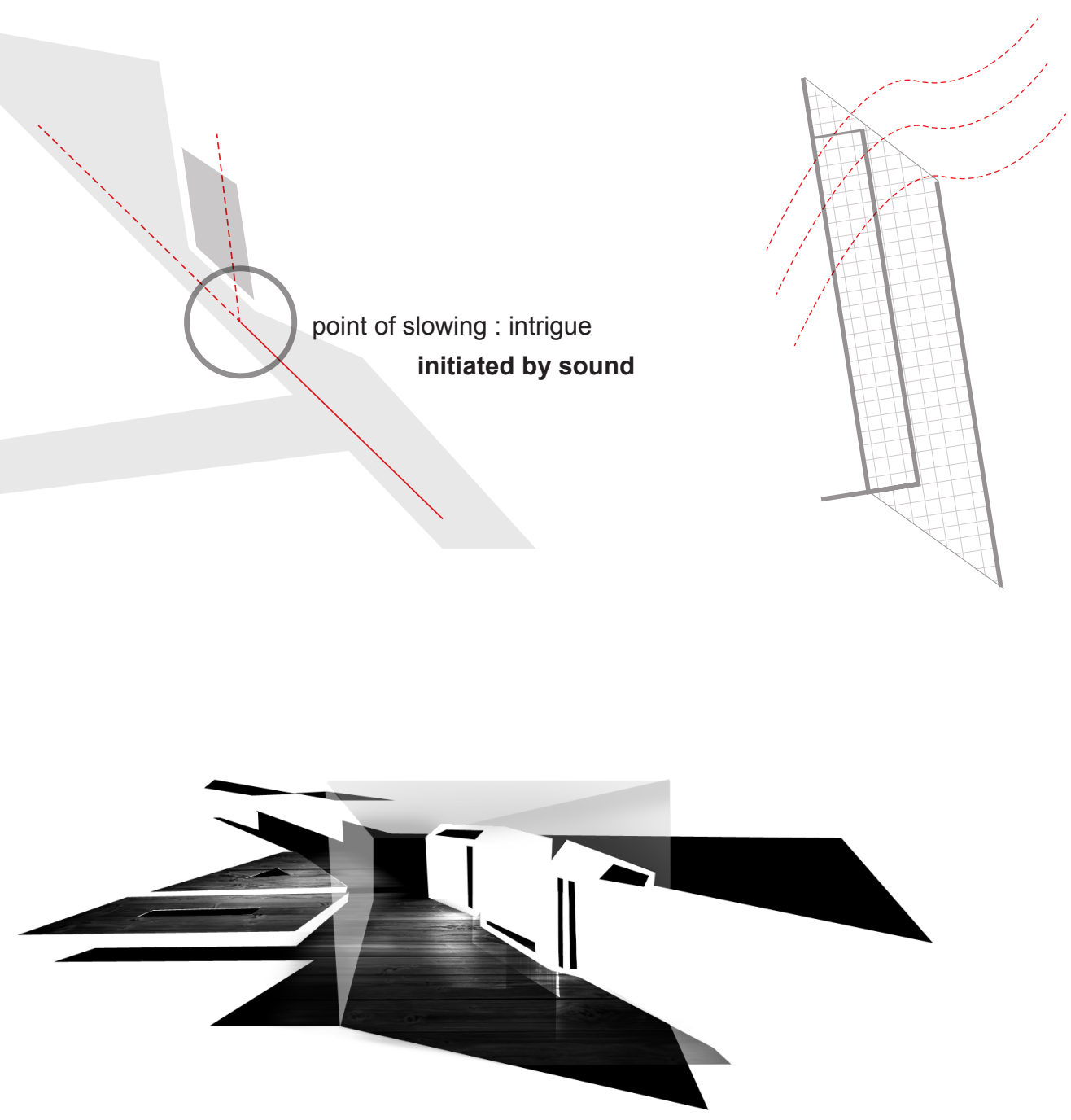


\section{Original concept into digital model:}

The way in which sound is used needs to rely on tested and realistic methods. To design a distinct interior space could create a more engaging space.

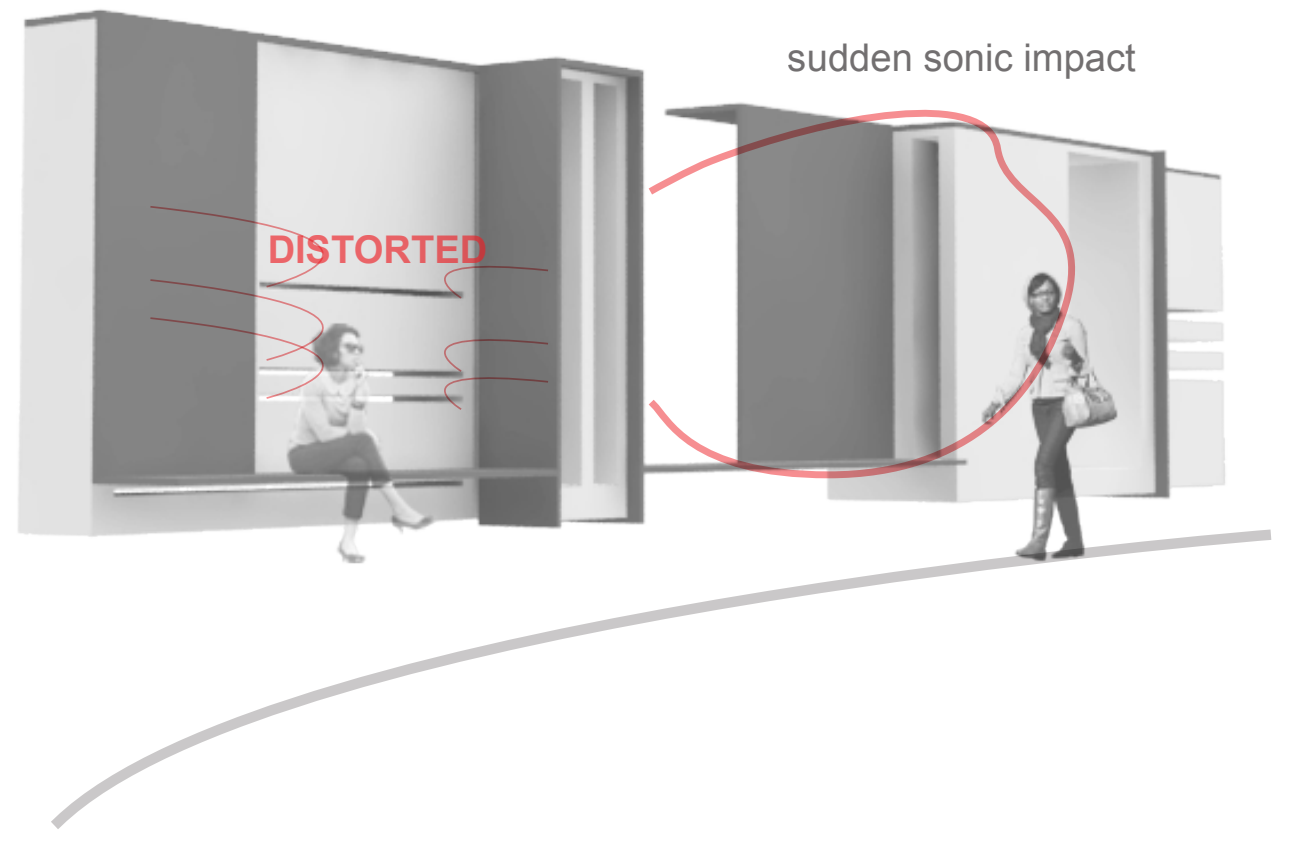




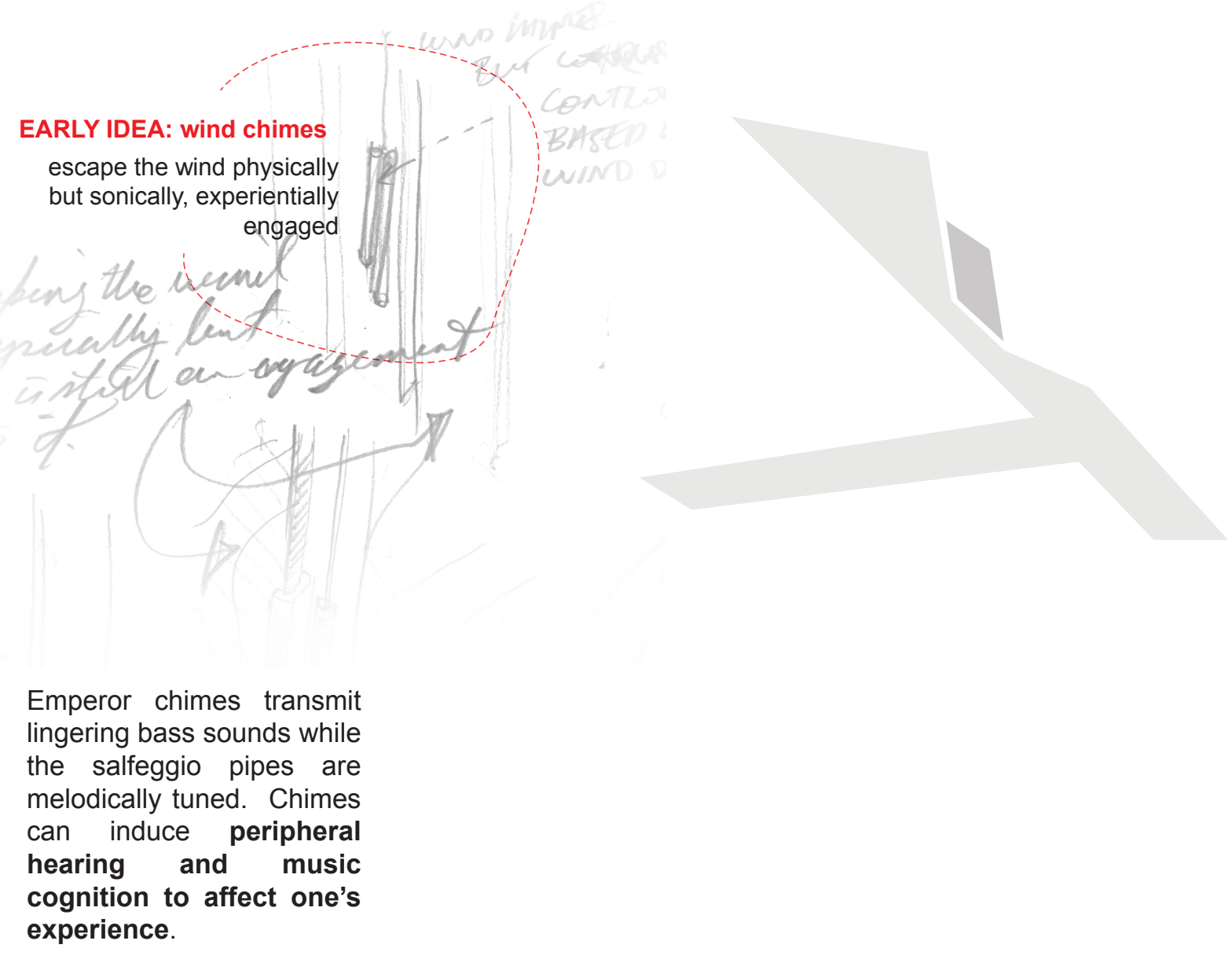

fig. 3.21: (left) emperor chimes. fig. 3.22: (right) salfeggio pipes. 


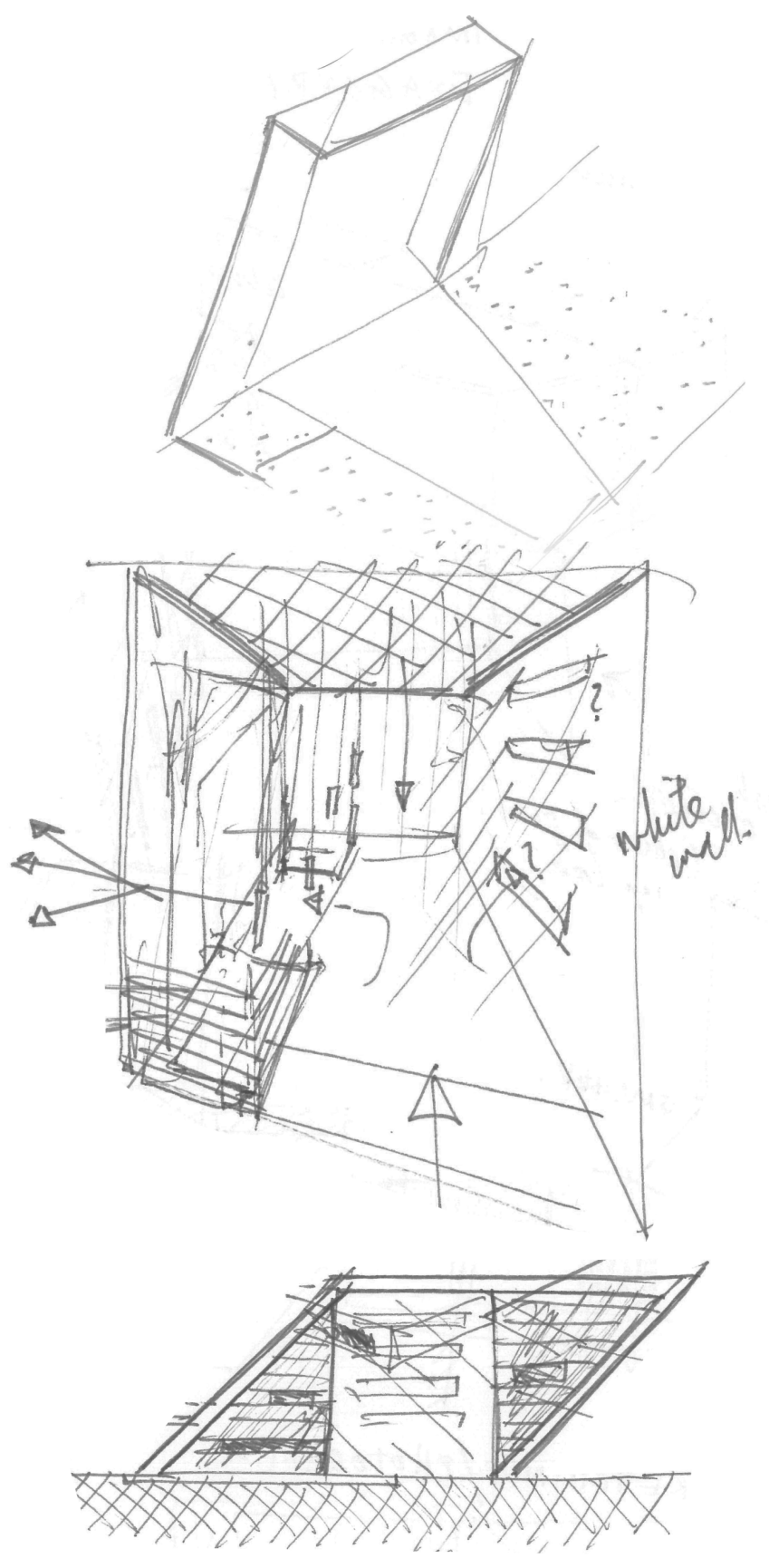

Performance + Interior Architecture - Threshold of Sound 133 


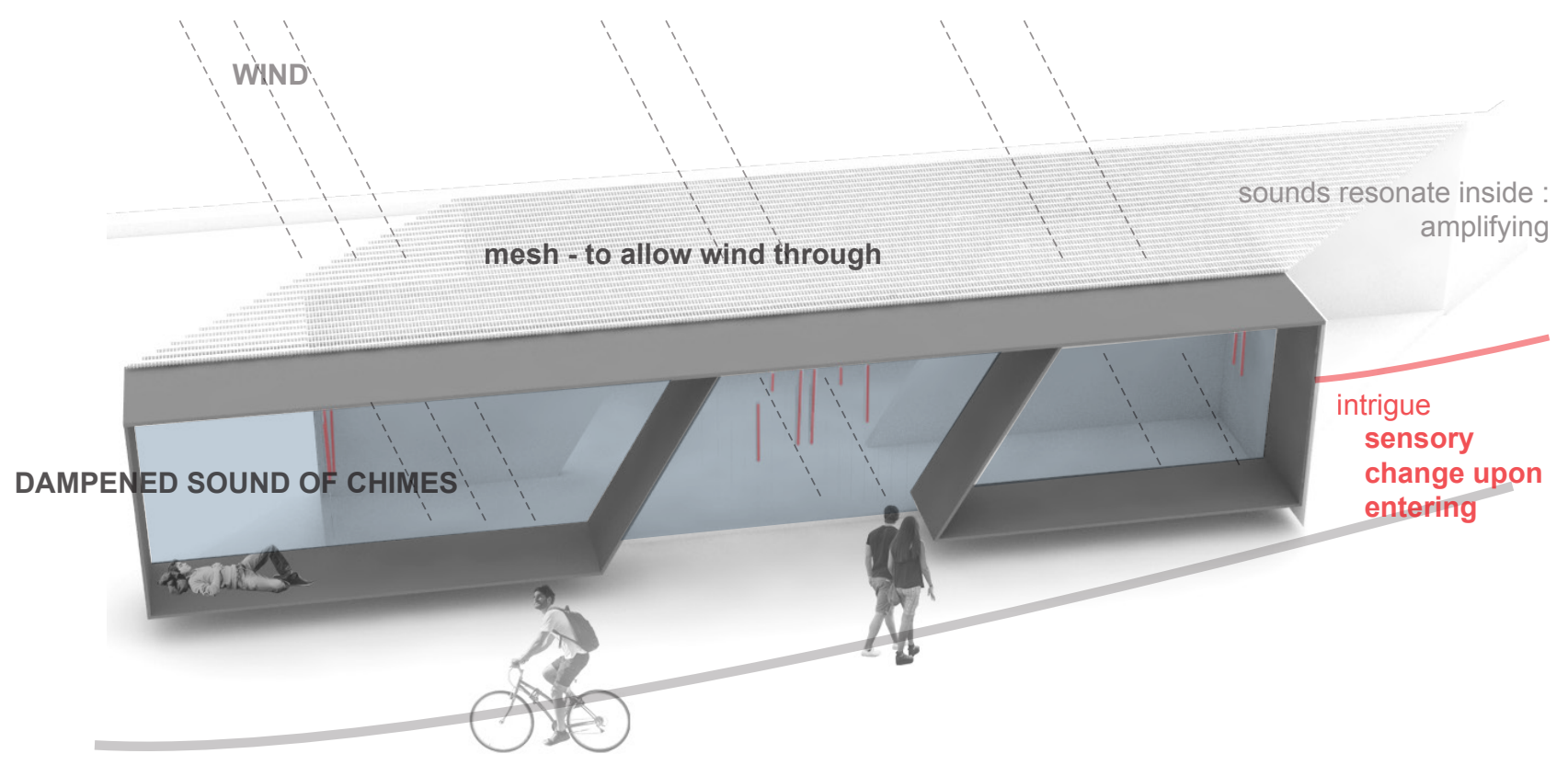

people

materials

environment

\{leisure+

circulation\}
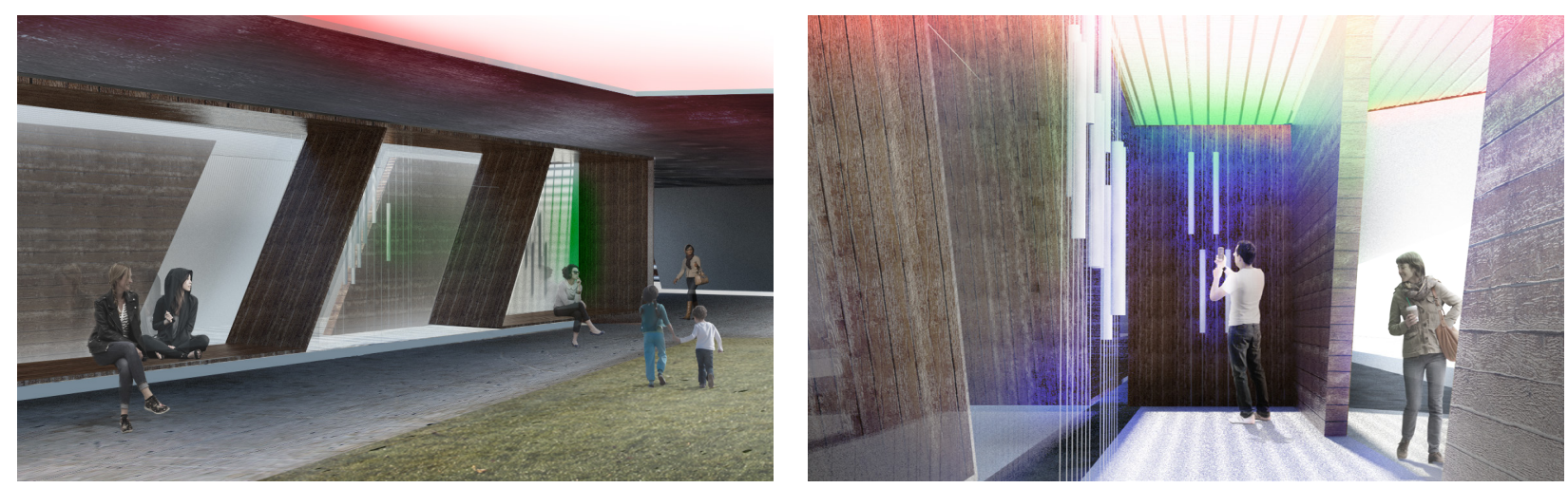

iteration one: exploring representational technqiues 


\section{Threshold of sound: Reflection}

The two objectives for this area were to disrupt and engage. The engagement aspect seems to be developing, but disruption- sensory or rhythmic is more difficult to achieve.

- The use of the outdoor chimes seems to have potential; they are activated both by wind and via play

- Play needs to be increased to disruption, engagement and everyday performances within the space.

The use of colour to denote sounds has led to evocative and fairly successful images. However, there is a sense of confusion that needs to be addressed. In order to bring clarity, two representational techniques will be used: the traditional rendered image and an abstract, sensory-driven technique.

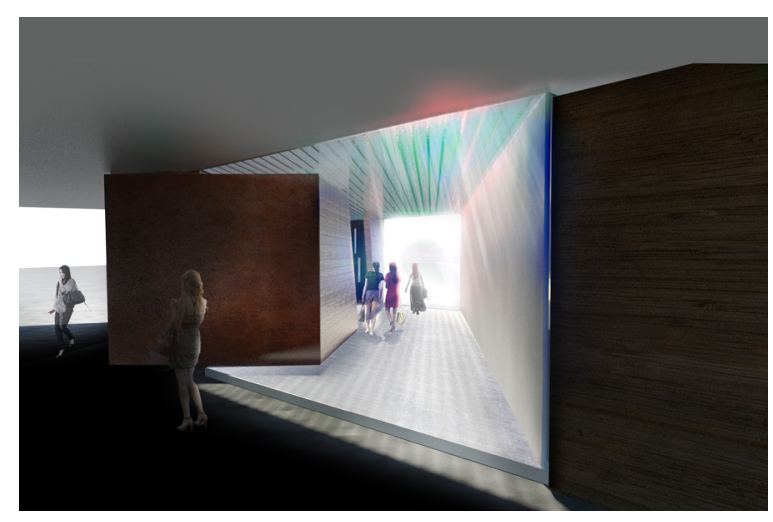

USING CHIMES AS

INTERACTIVE PLAY DEVICES

attracts children especially

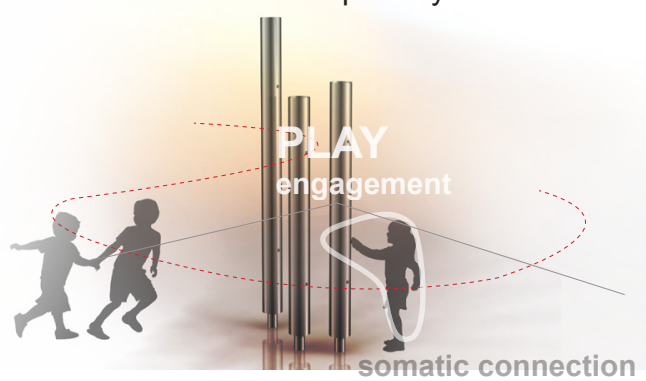




\section{Threshold of sound: development}

Playful chimes will be integrated in two concentrated areas to encourage mixing and bonding of diverse people.

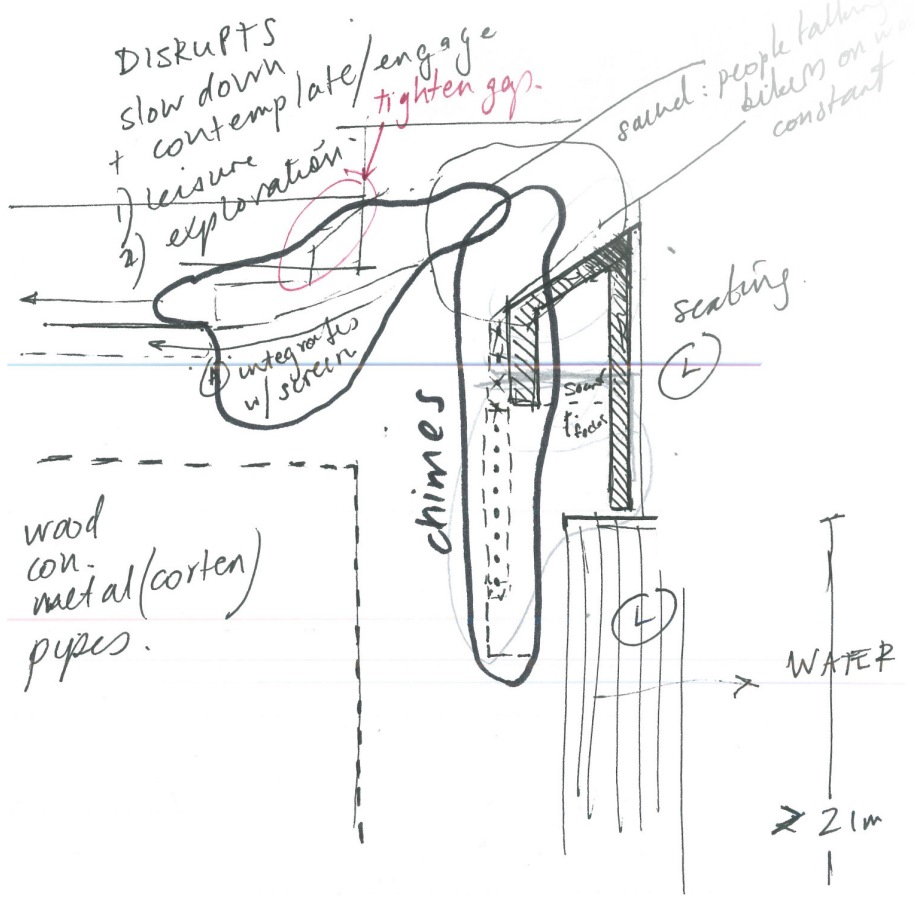




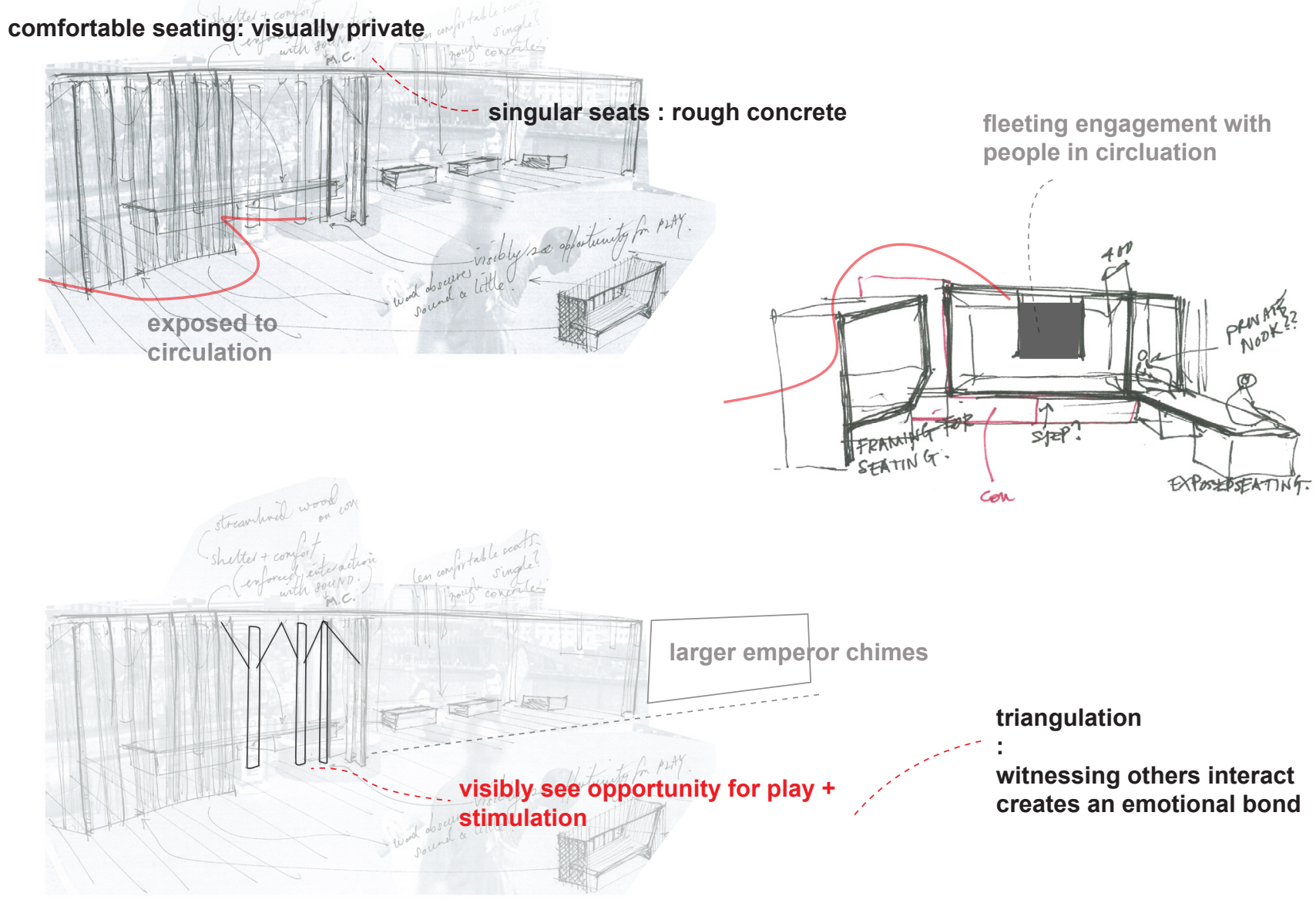




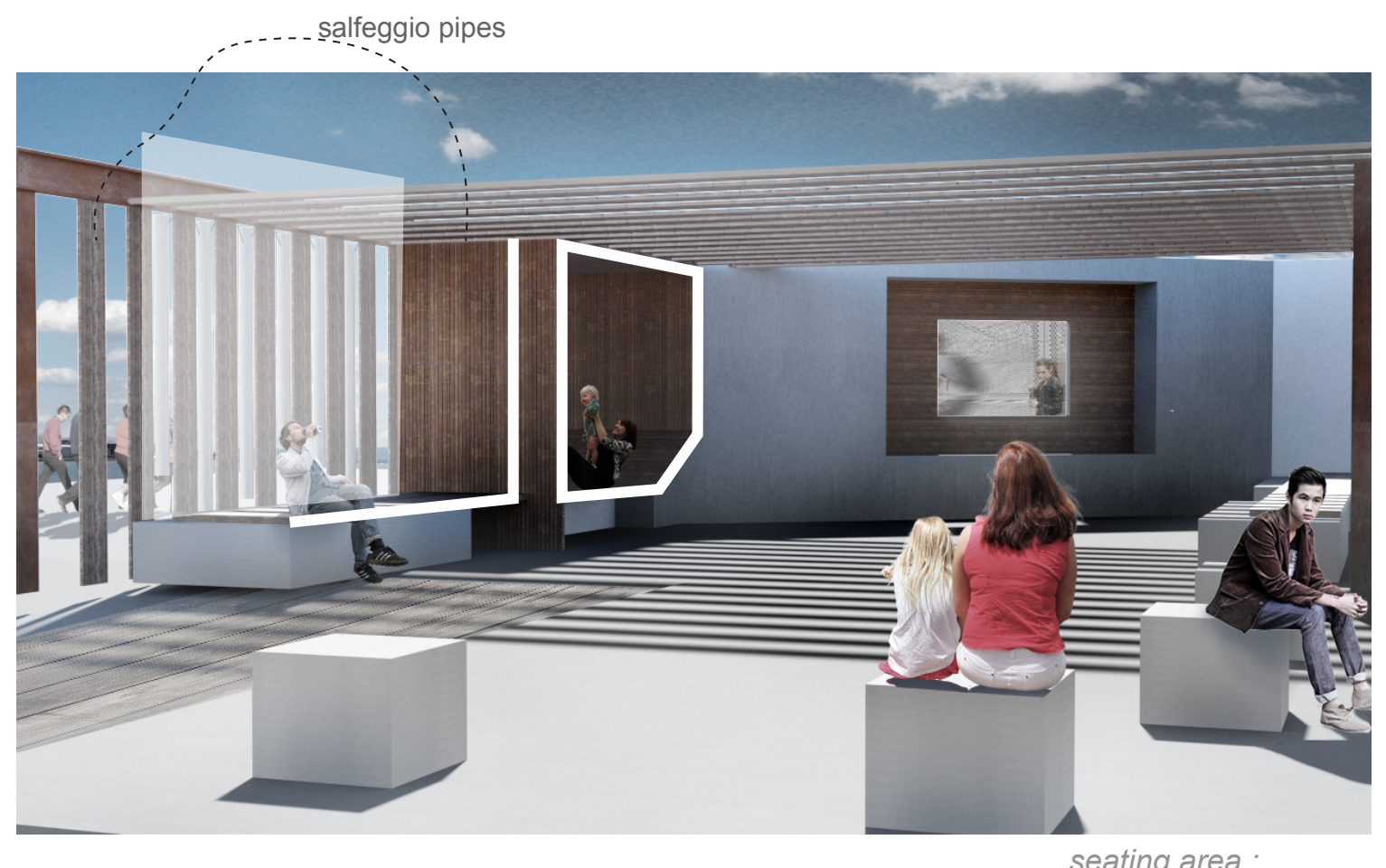

the difference in the seating opportunites 


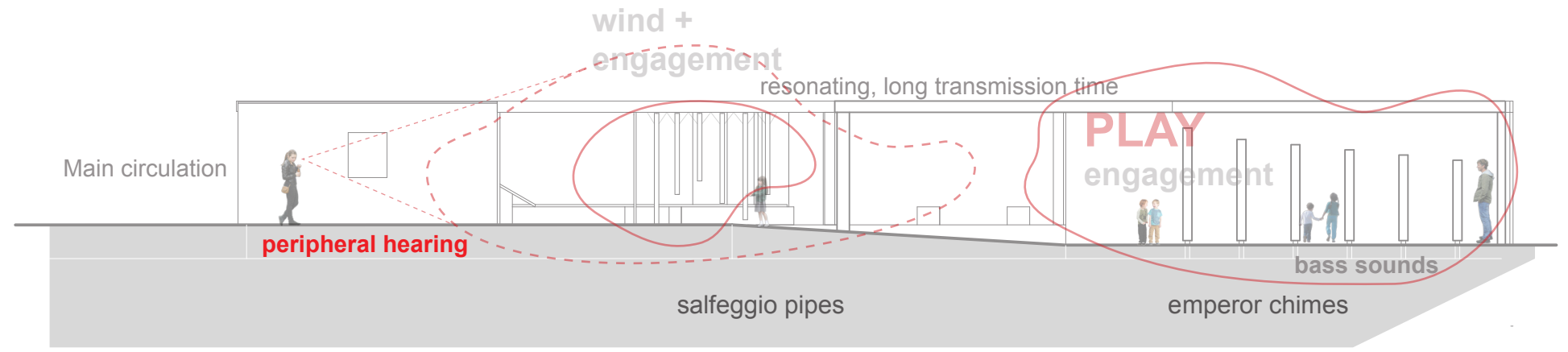

section :

showing chimes and experience influences

The outdoor chimes transform this seating area into a connective, melodic space. People can simultaneously engage with everyday sound events, witness and perform play and undergo leisure. 


\section{Room of sound}

The sensory and contextual experience has reimagined this space as a 'Room of Sound'. The space will exaggerate the chimes and reverberation within. The theatrics of the interior will bleed out and induce peripheral hearing to outside people; this can lure people inside, or just offer a fleeting moment of wonder.

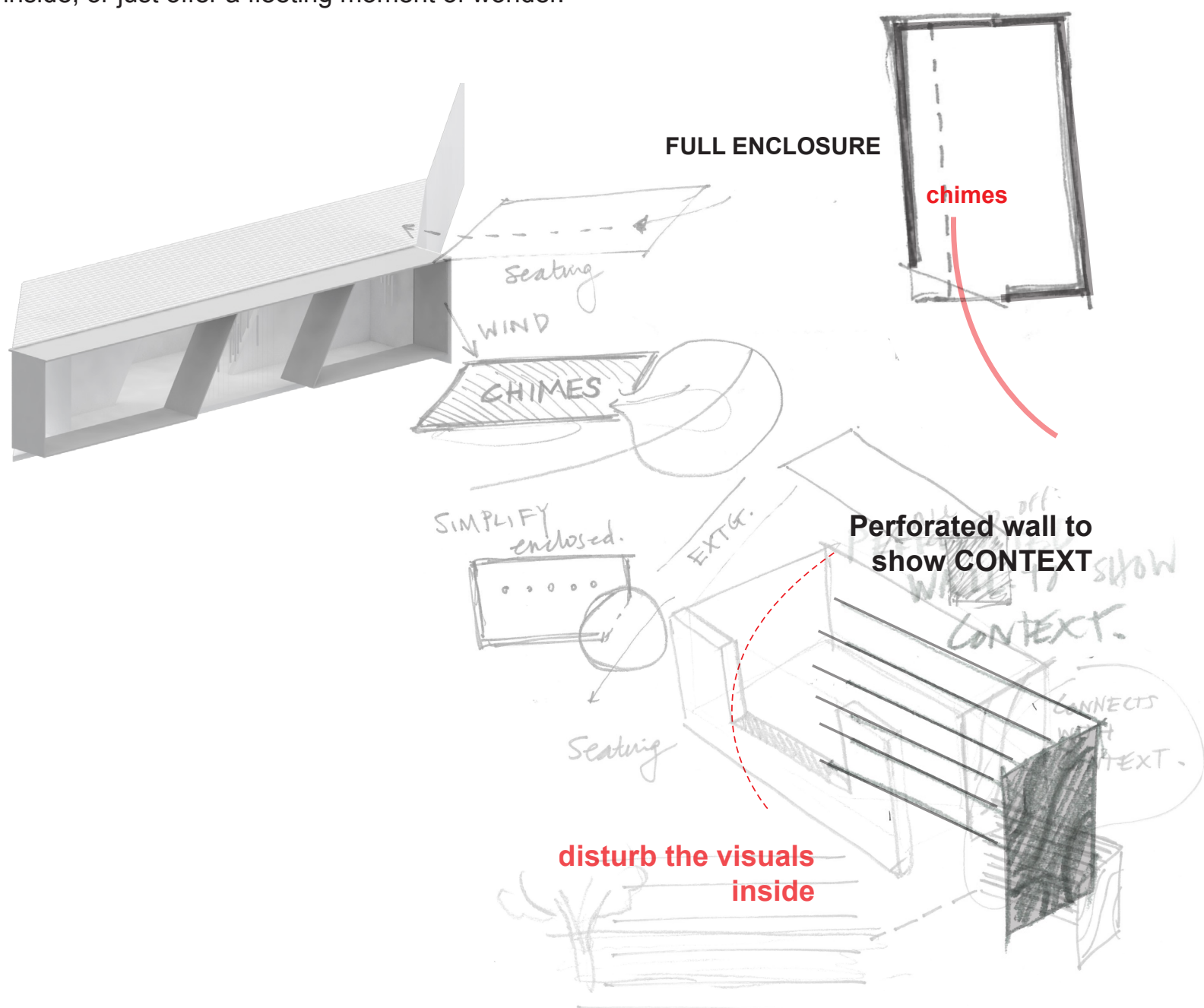




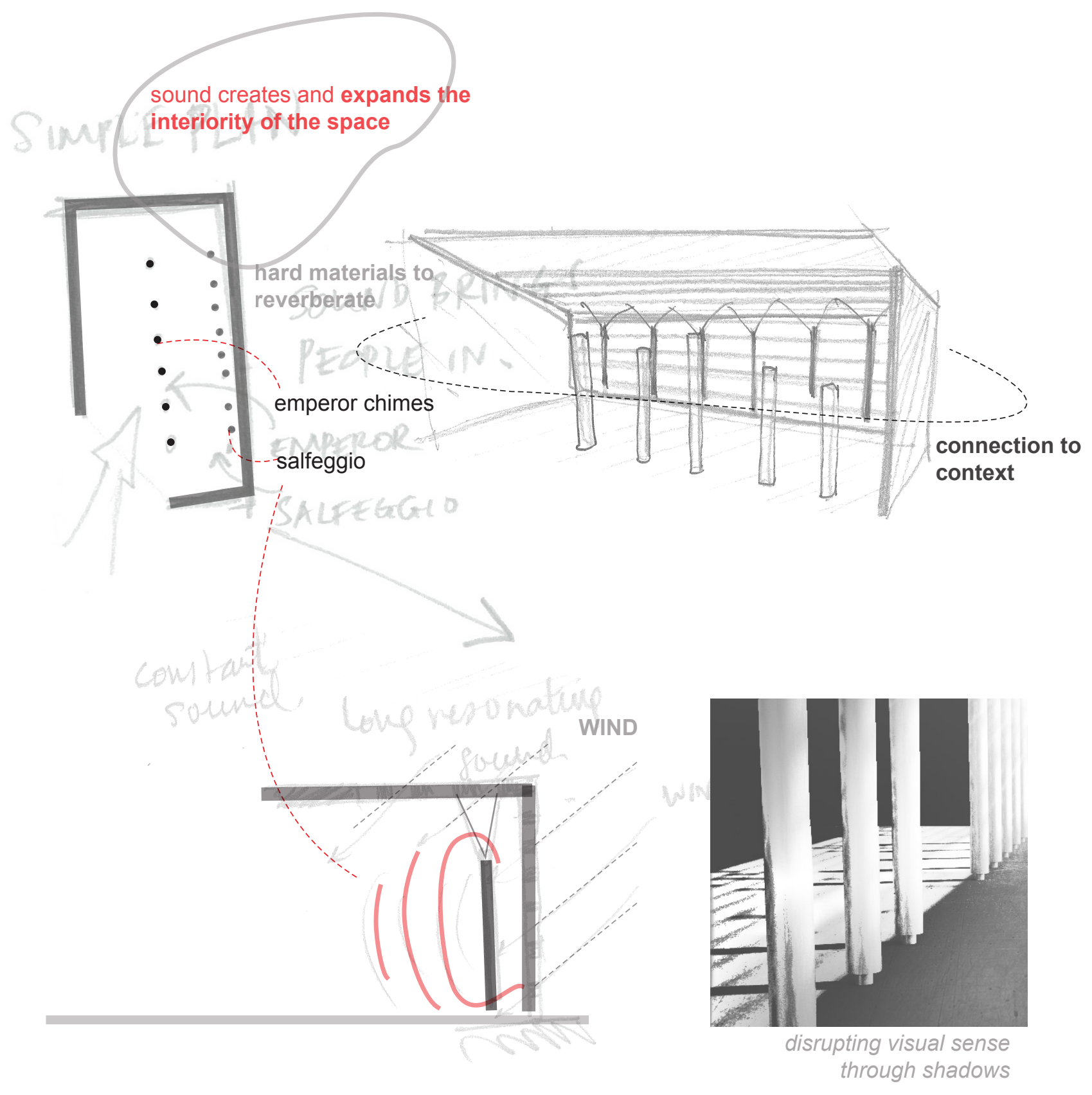




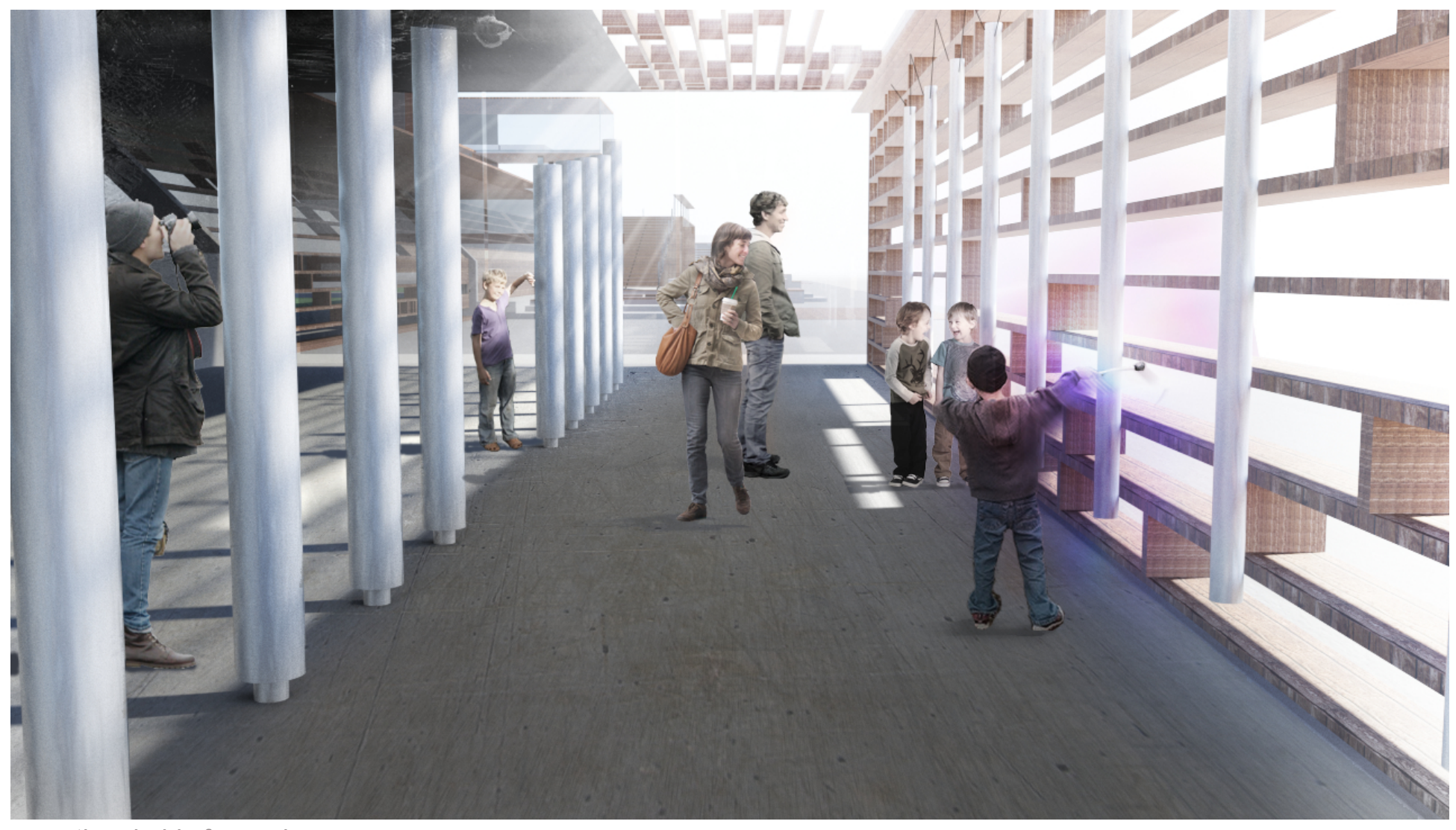

threshold of sound:

room of sound 


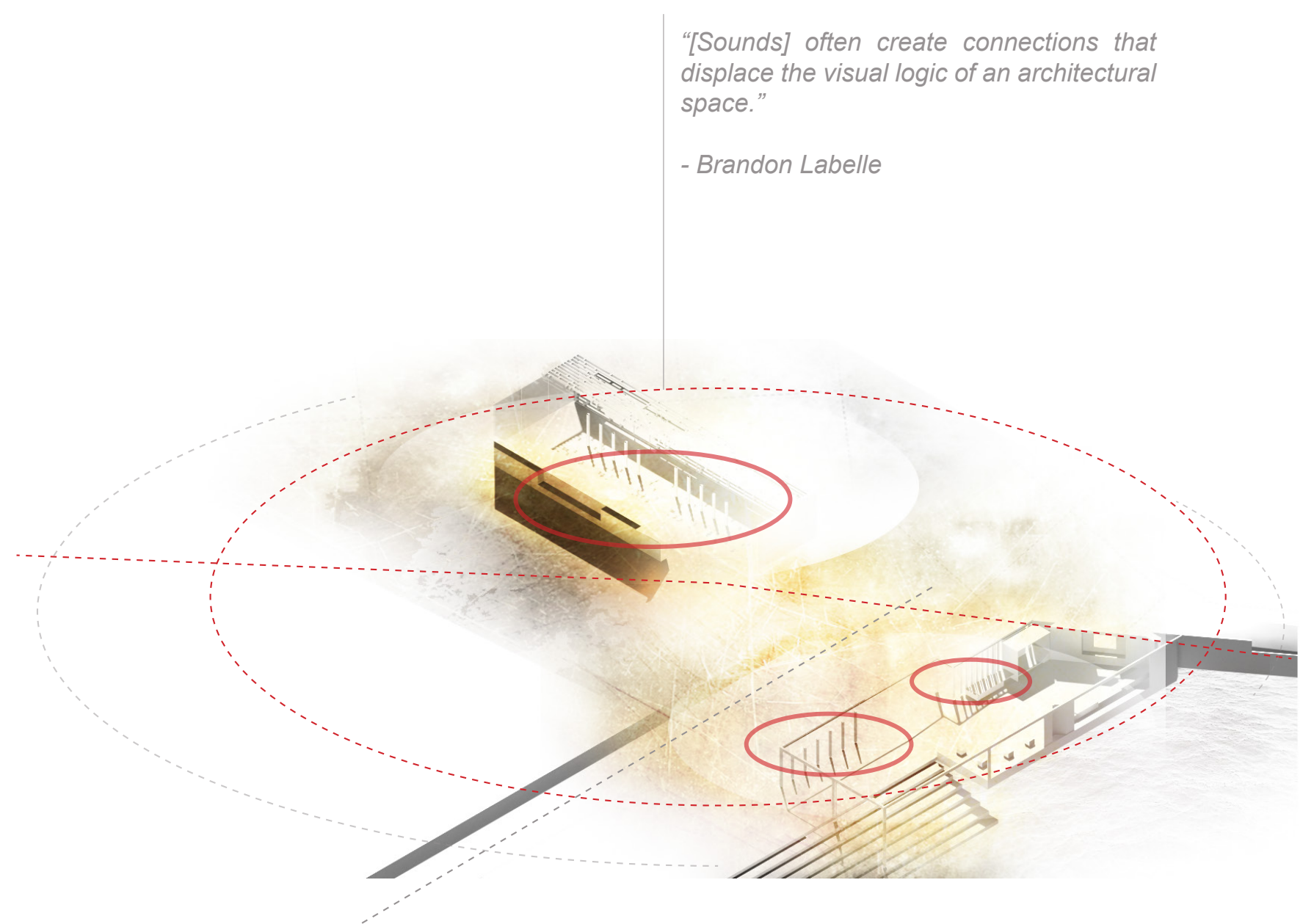

threshold of sound : expanded boundary 
The outdoor chimes creates a background/foreground dichotomy via sound.

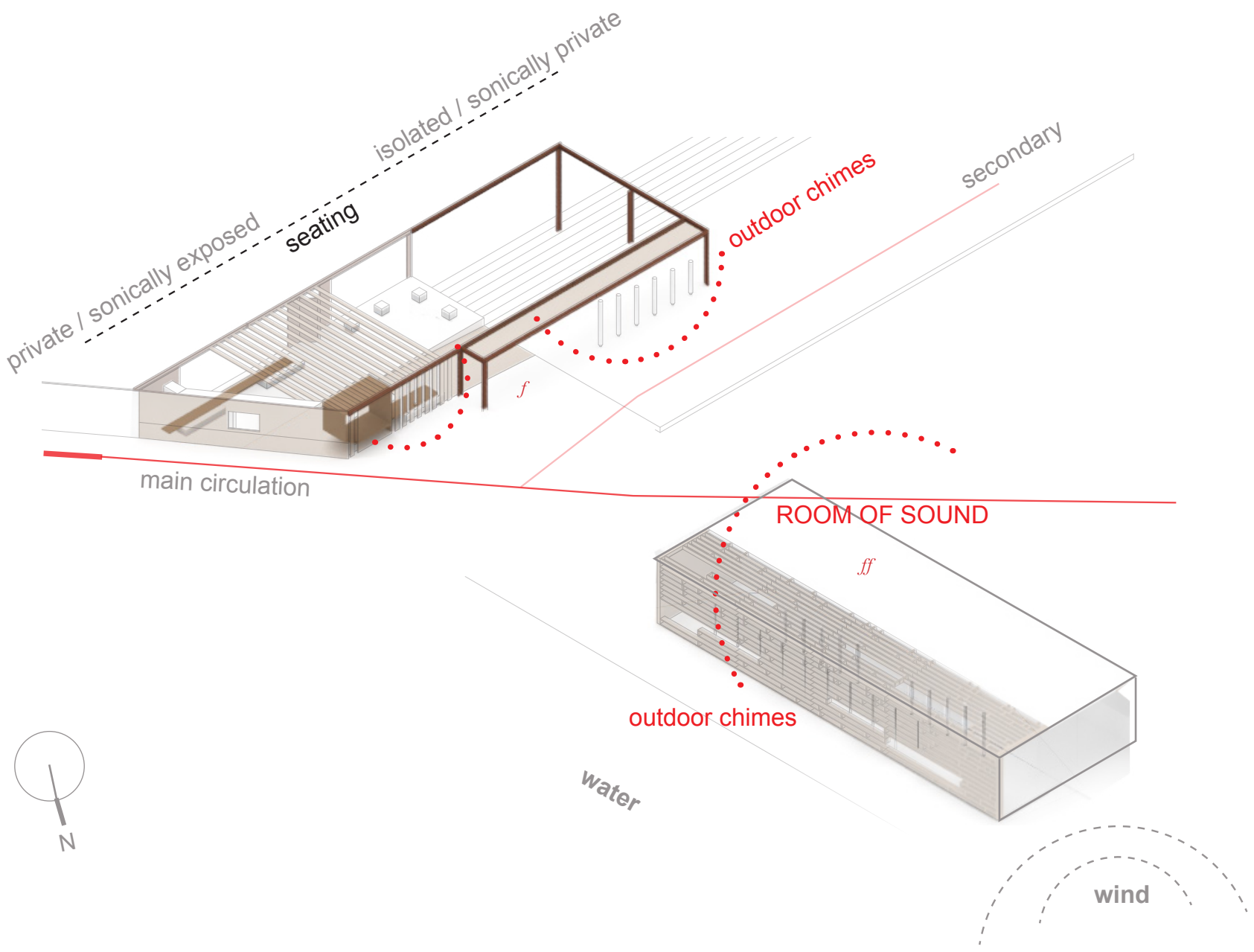

Threshold of sound: Final design 


\section{CONVERGENCE SPACE}
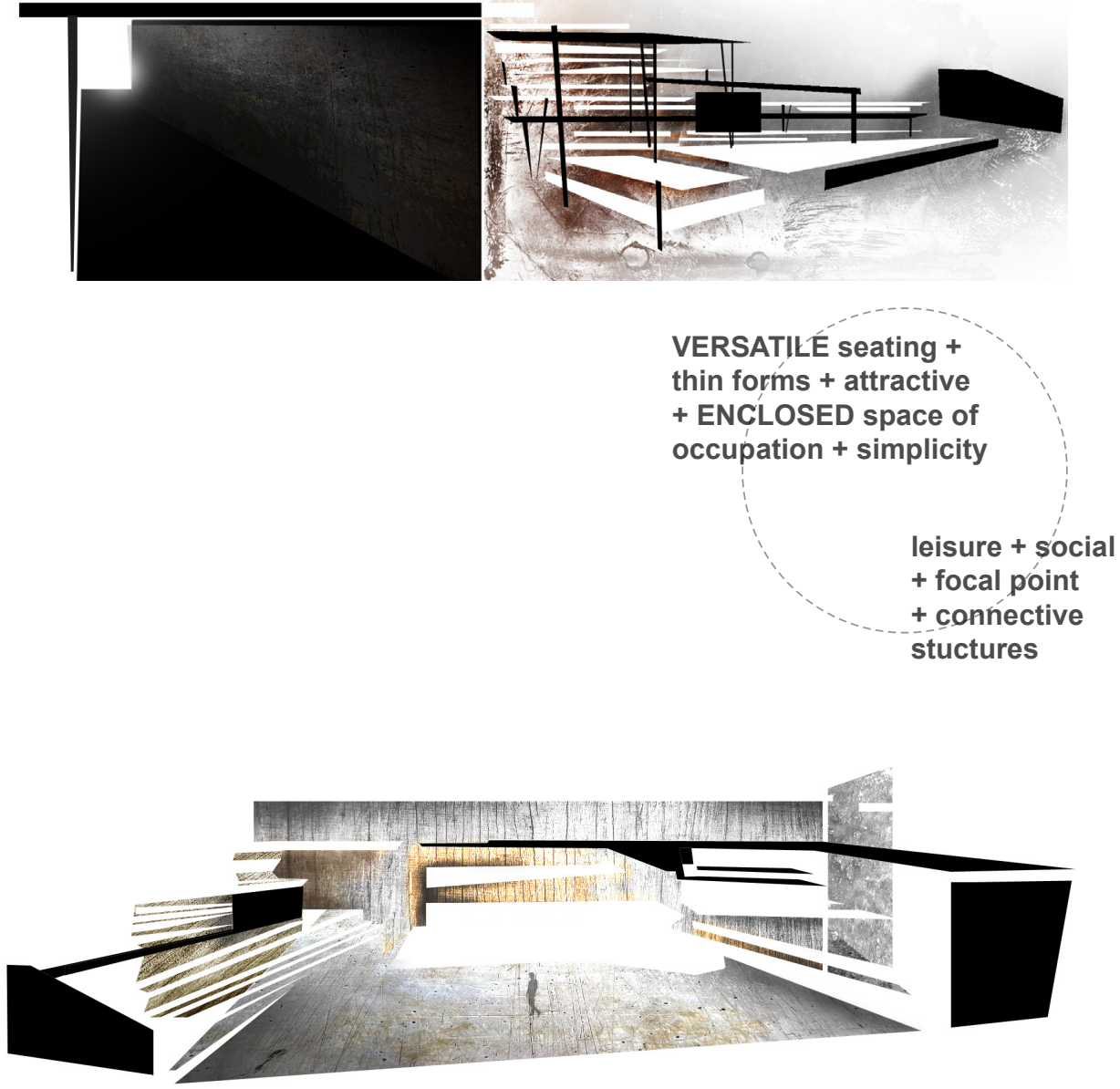


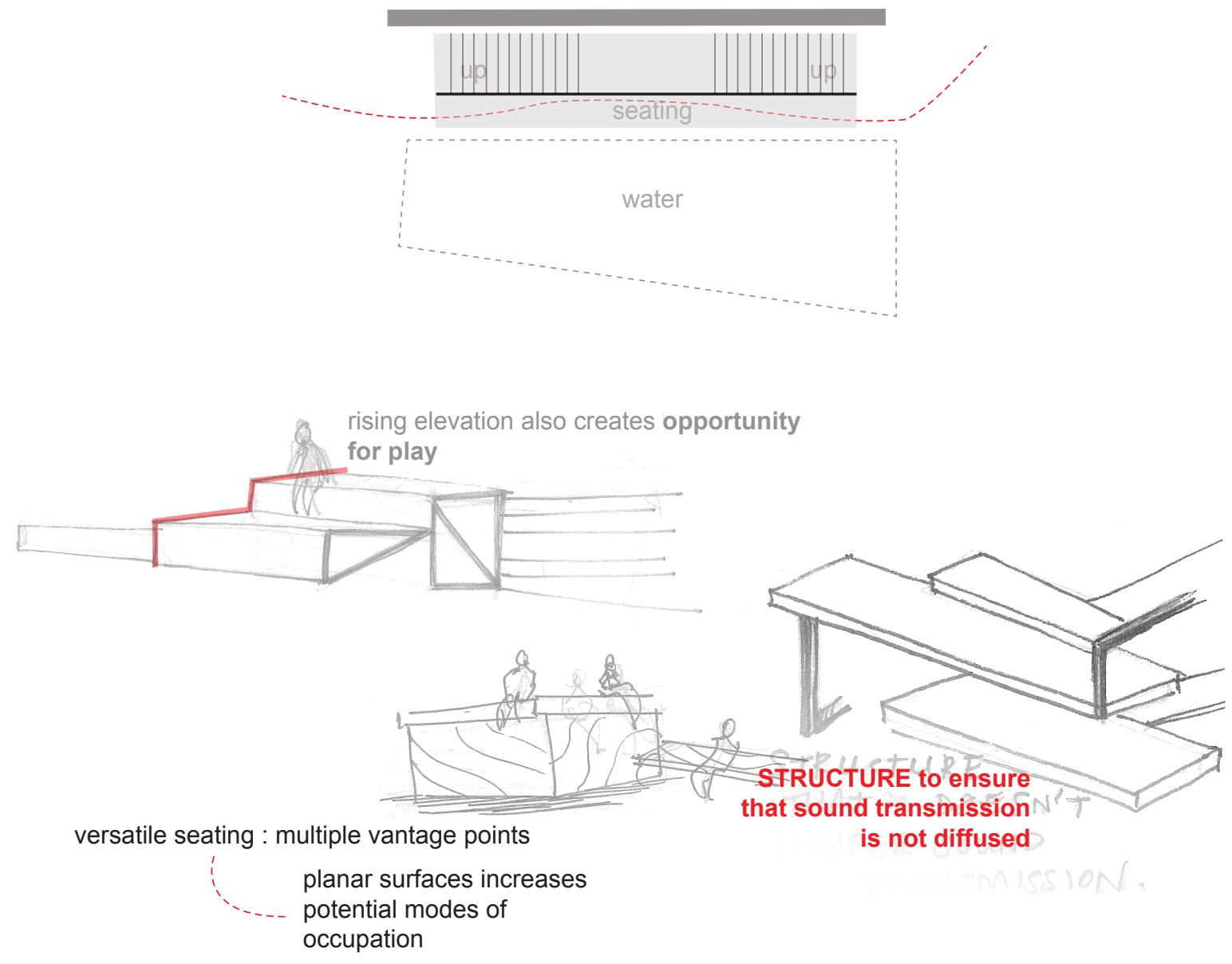

to room of sound

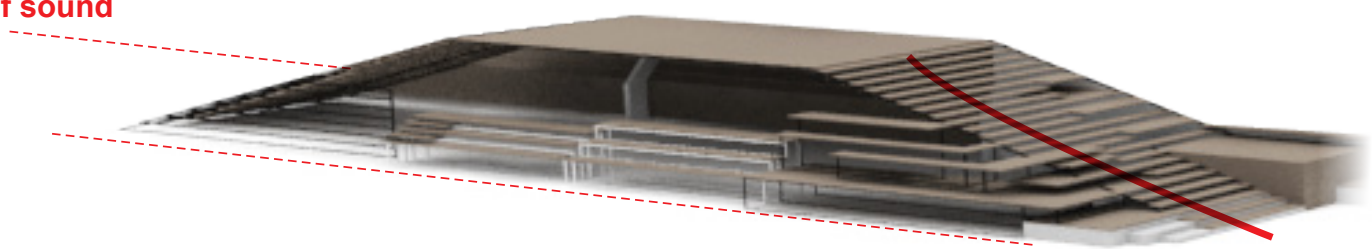

Convergence space: versatile seating + elevated seating 


\section{Composition}

The space will expand to allow versatility and accommodate for diverse people, the privacy will fluctuate along the length.

"Different orders of sensory experience, social interaction, regulation and movement" (Edensor, p.82) are free to be expressed.

The expansion also allows the possibility to emphasise the audience / performer dynamic introduced by Quentin Stevens.

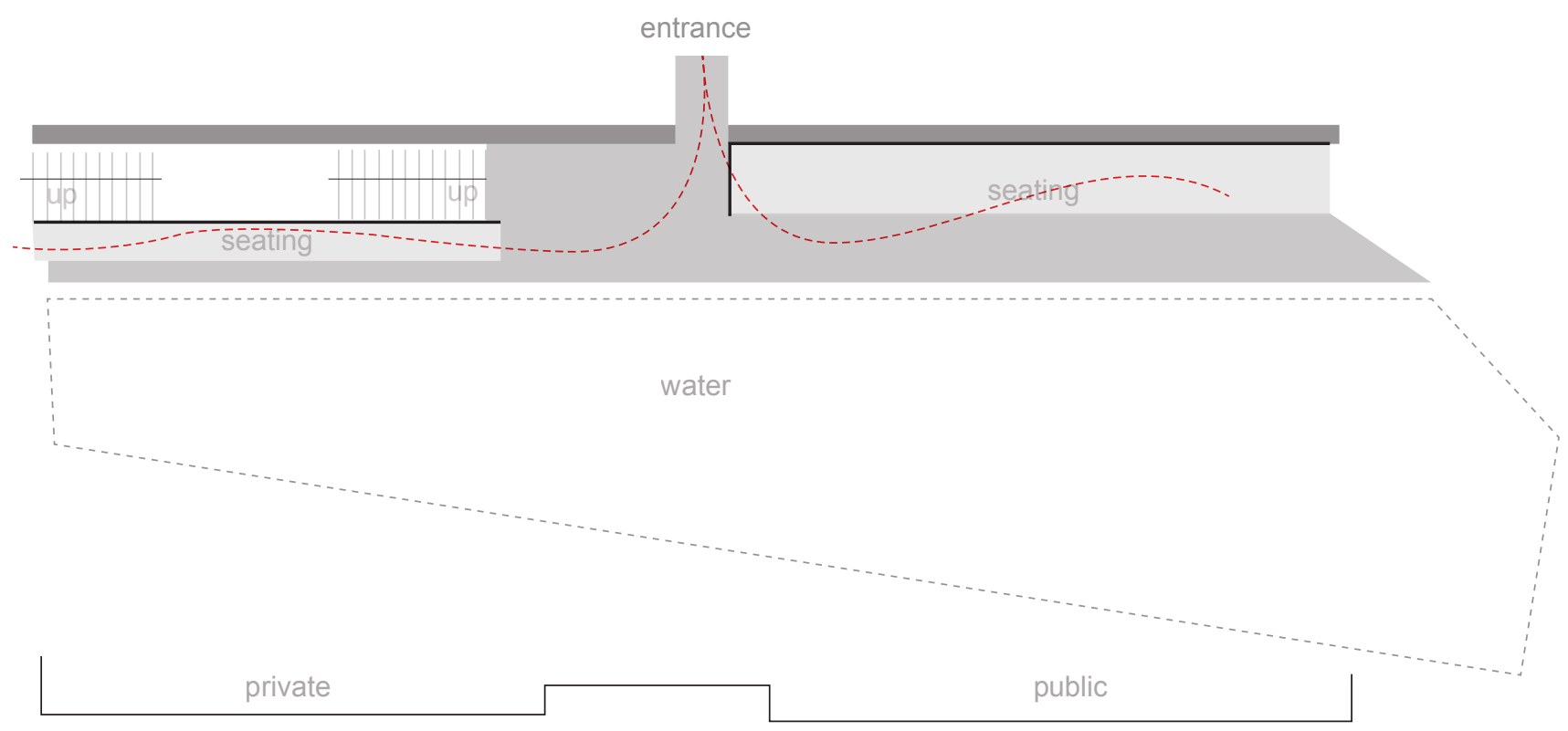



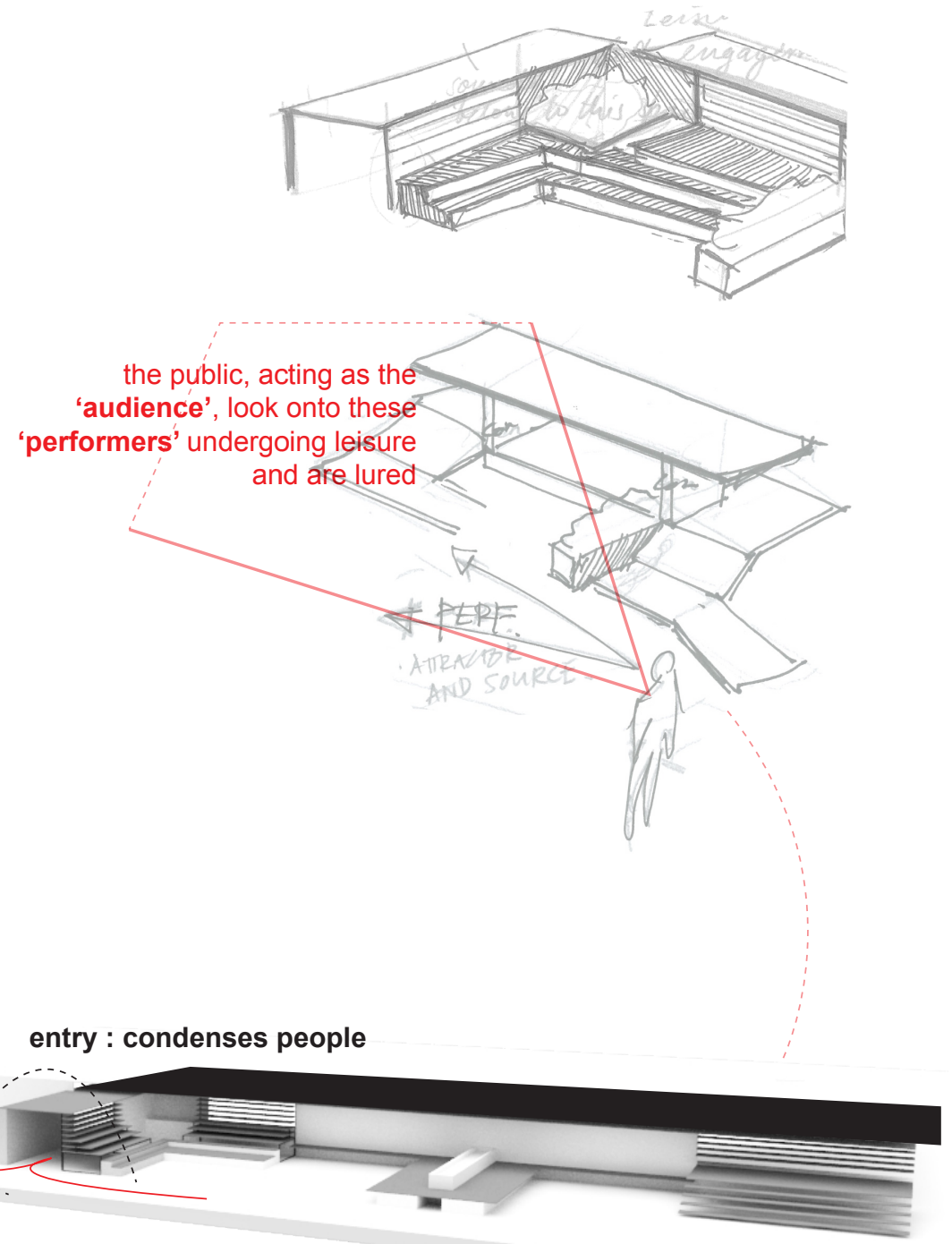


\section{Sensory focussing space}

In the earlier conceptual design stages, water was considered to be the main attractor of people to the Frank Kitts Park promenade. However, through the process, a decision to create an architectural element was made to further render the park alluring. Consequently, a lookout structure was explored to be the visual and experiential focal point.

Its interior space becomes a moment in the Park where the sounds of the city are severed and one's own sounds and silence are emphasised.

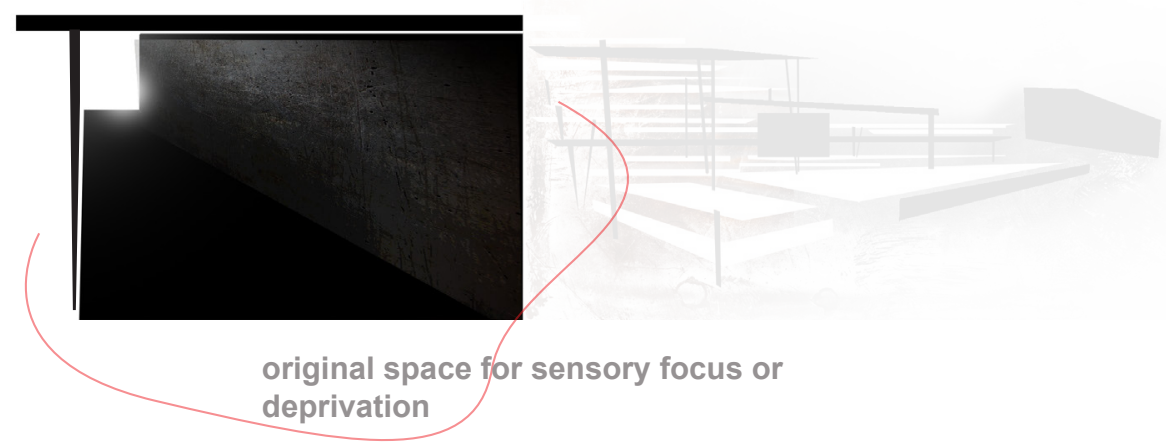


originally for seating, but becomes

a staircase to the structure
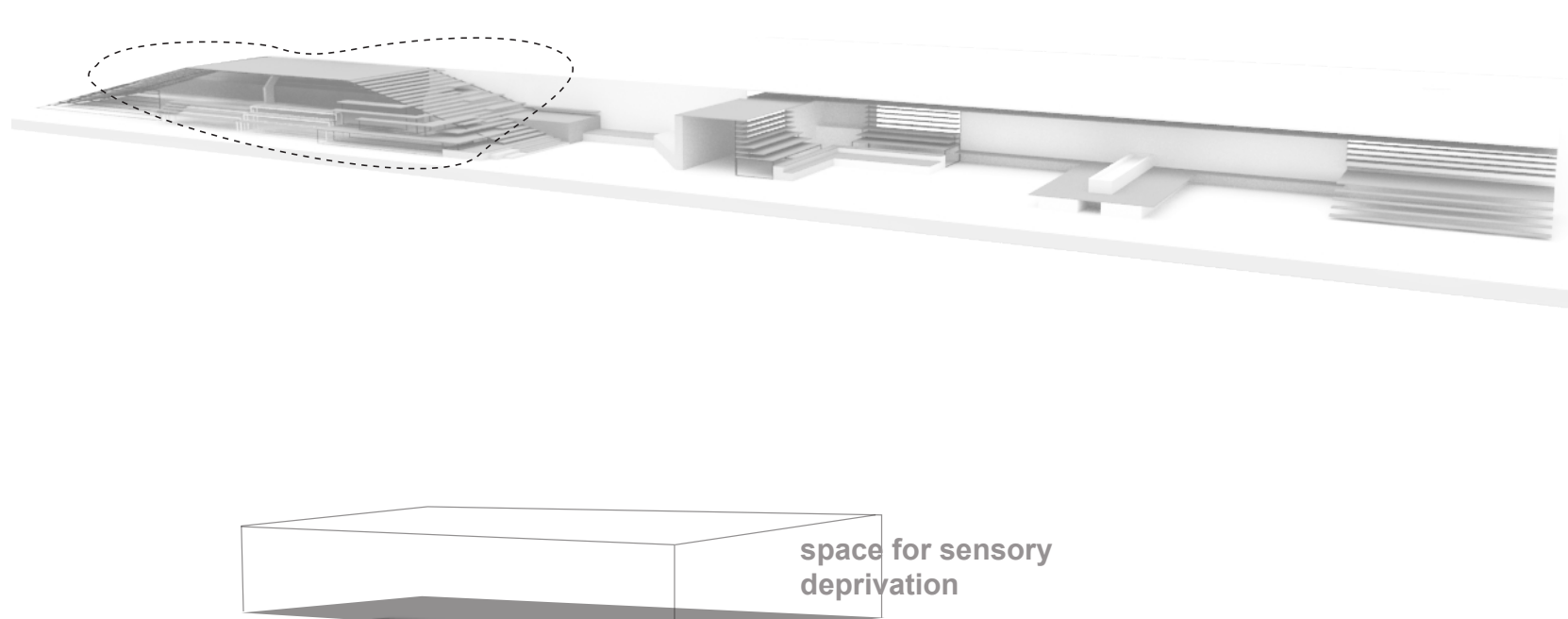
but dominating

CLIMAX point : attraction from afar

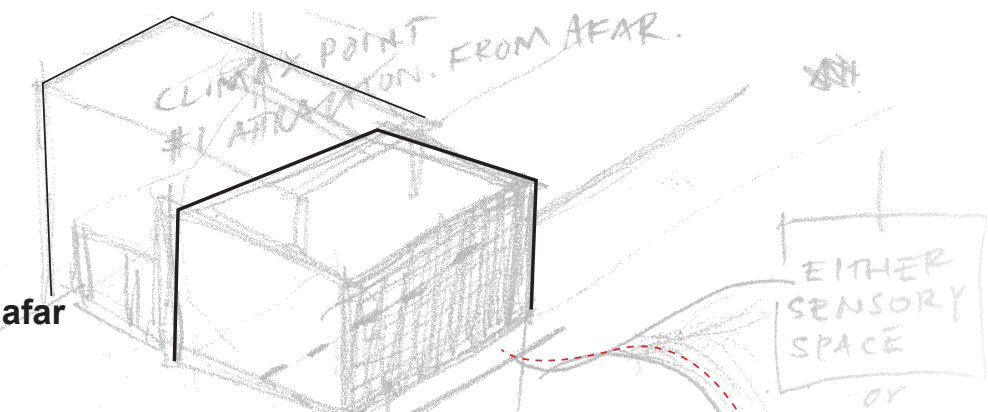

Lookout: Glass and reflective materials

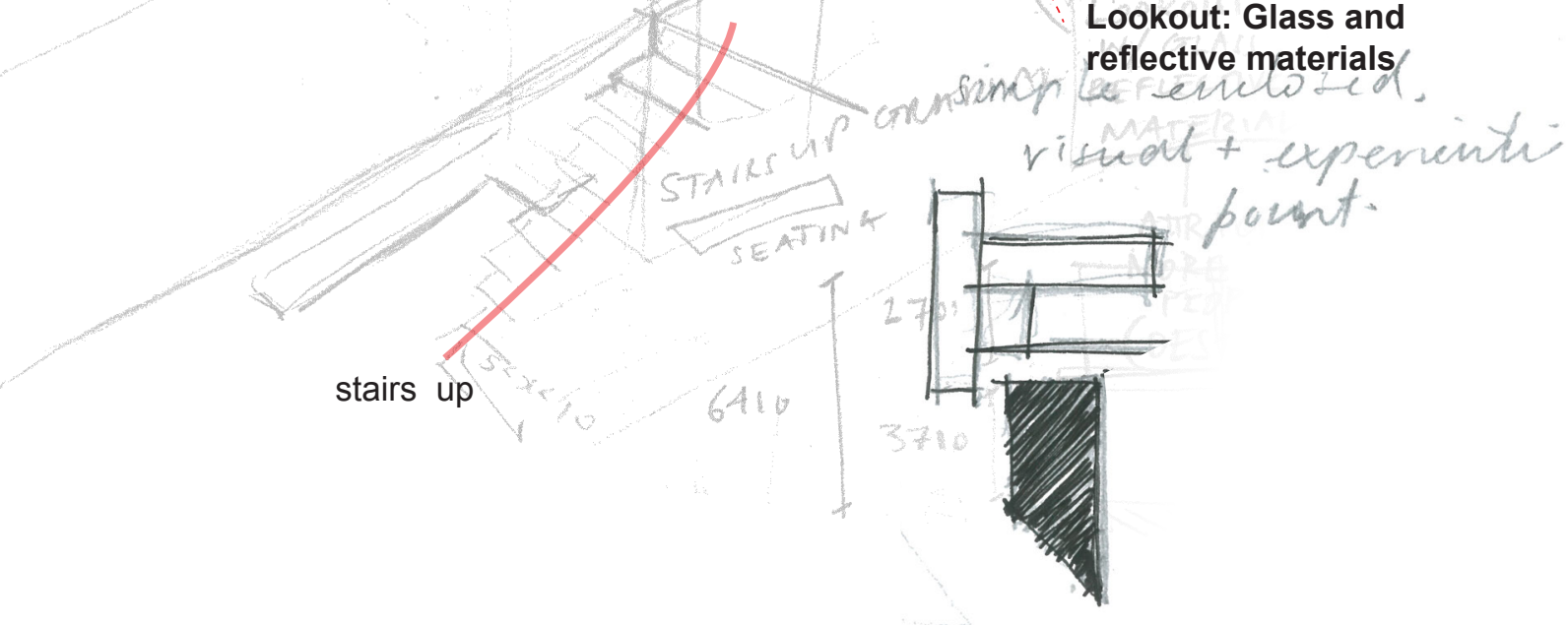

Exaggerated, simple forms to stand out in the Park
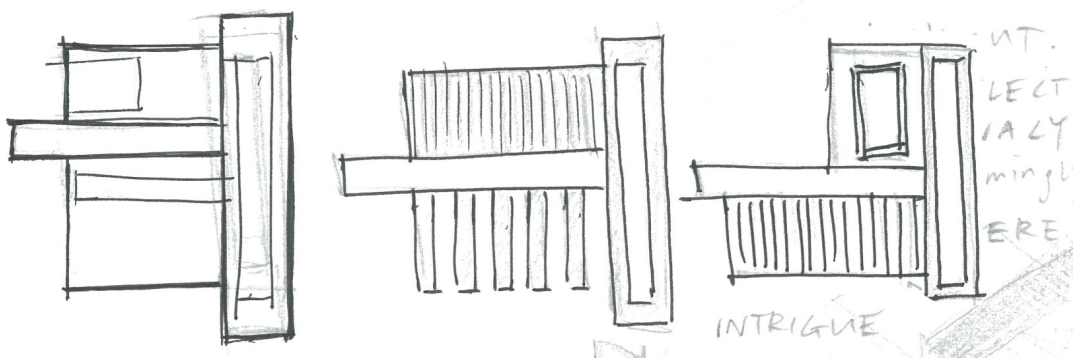

Developing the Lookout 

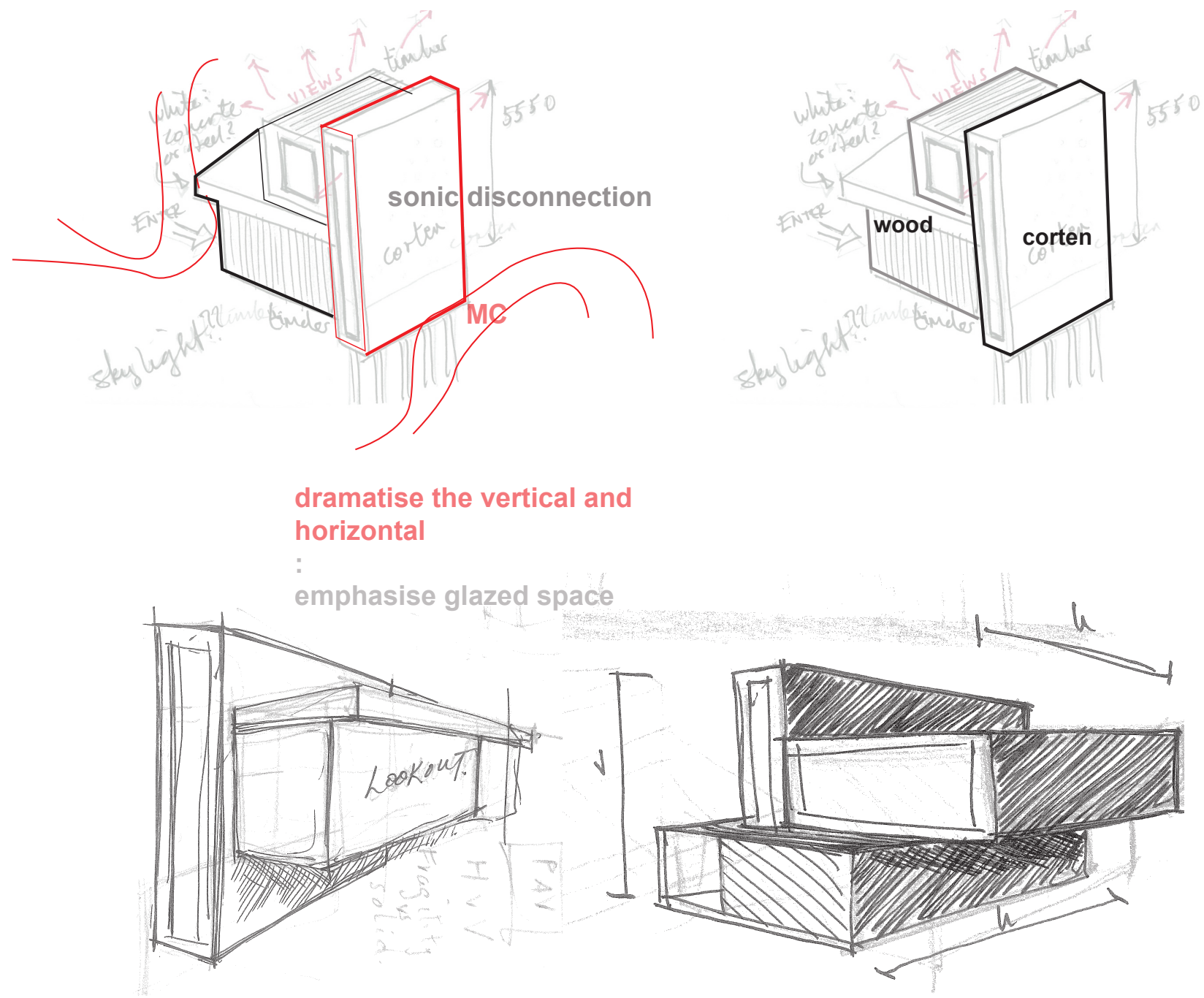

Developing the Lookout 

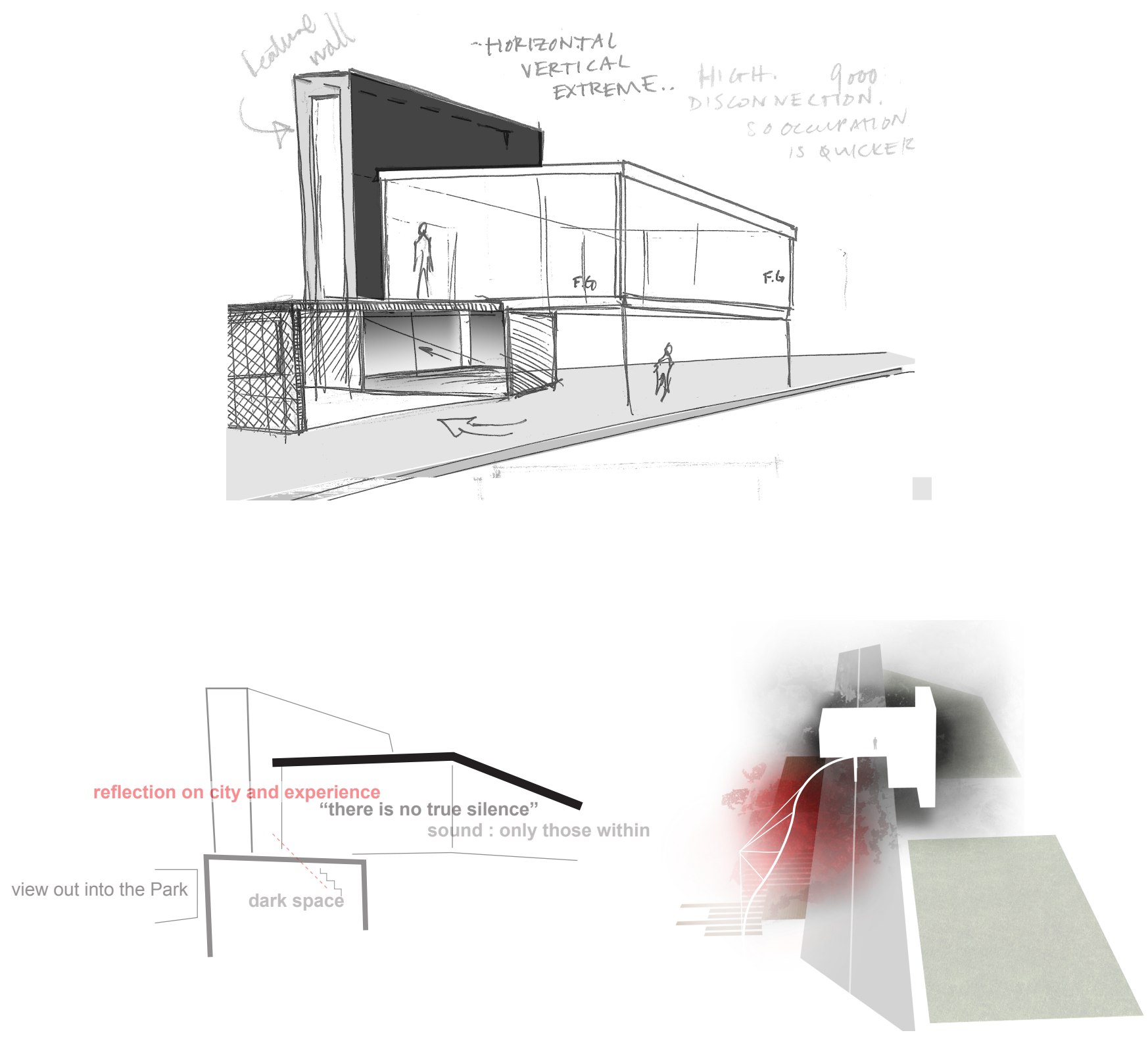

Lookout :

silence amidst sound 

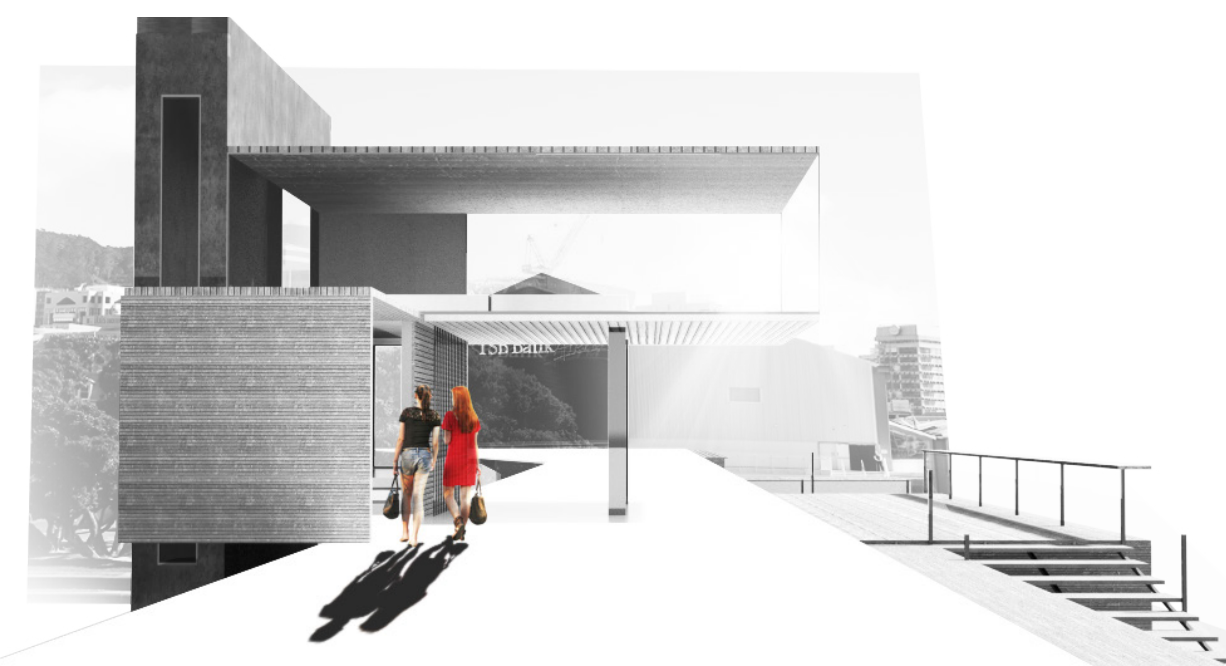

융

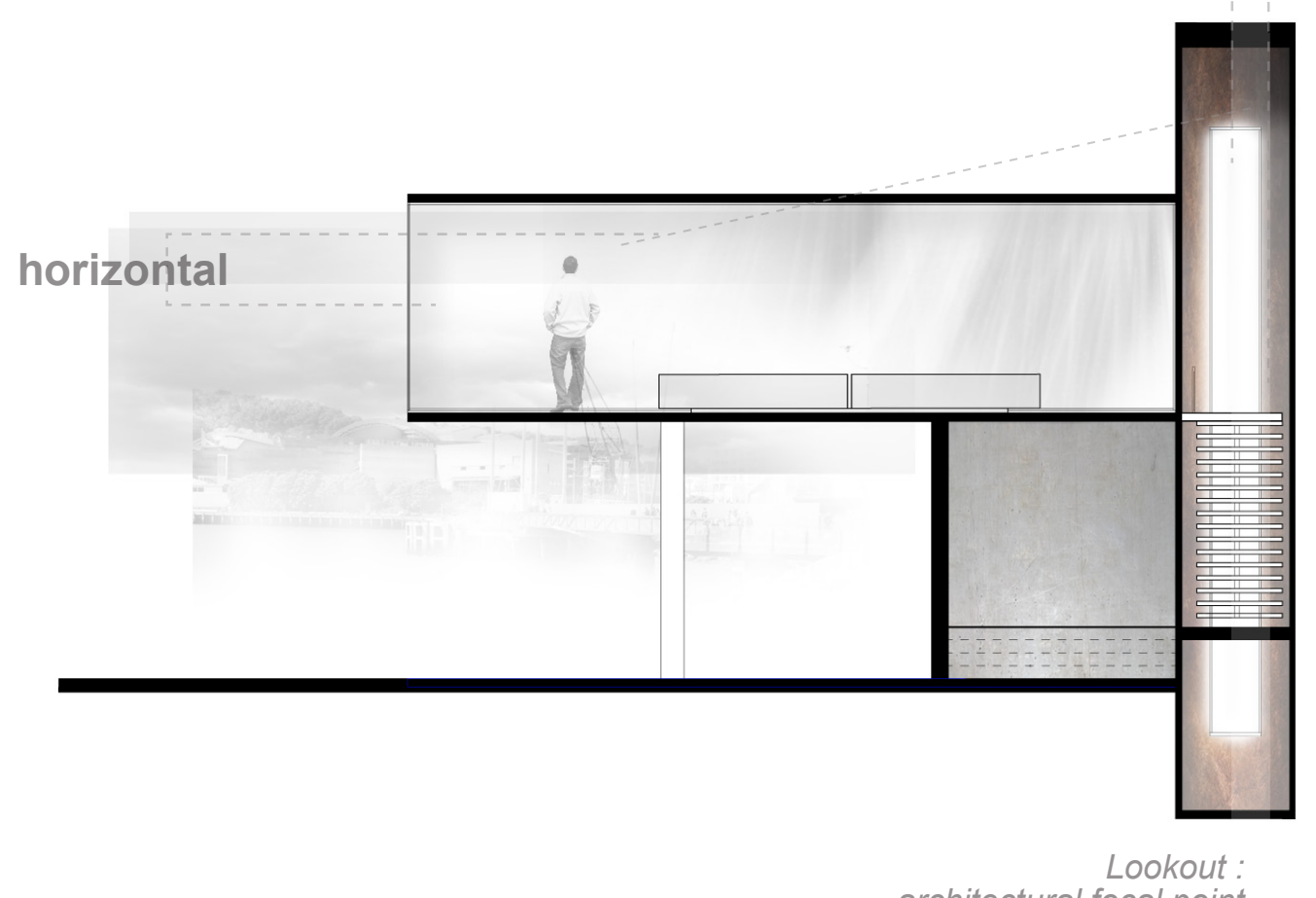

architectural focal point 


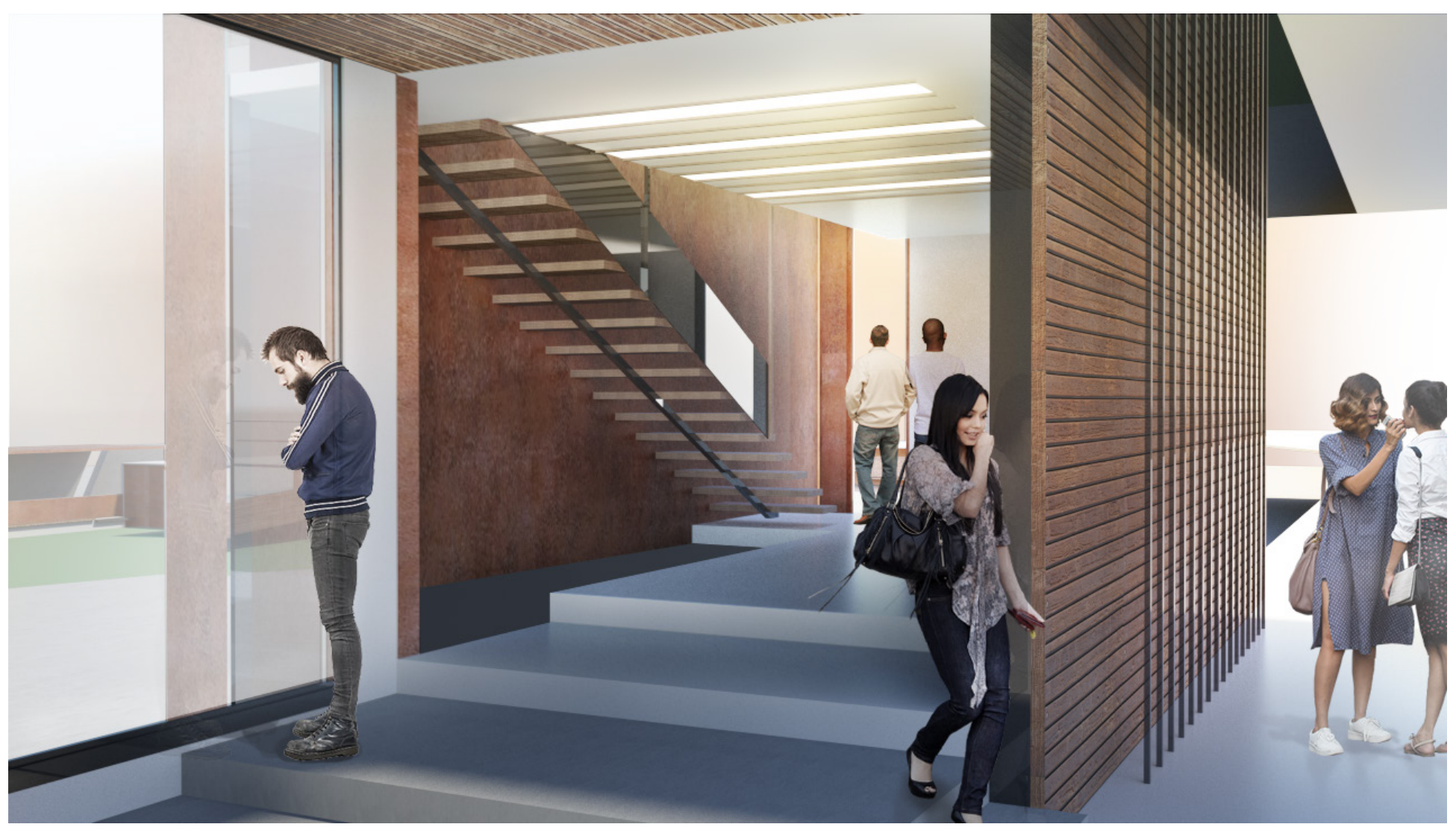

Lookout :

entrance to lookout 


\section{Convergence space: Reflection}

In reflection, several points need reconsideration to produce more opportunities for play and diverse leisure and to enable the mixing of different people.

- More aesthetic + experiential coherency

- Openness of spaces

- and seating design simplification

one final act of experiential restriction and concealment before ultimately releasing the expectations

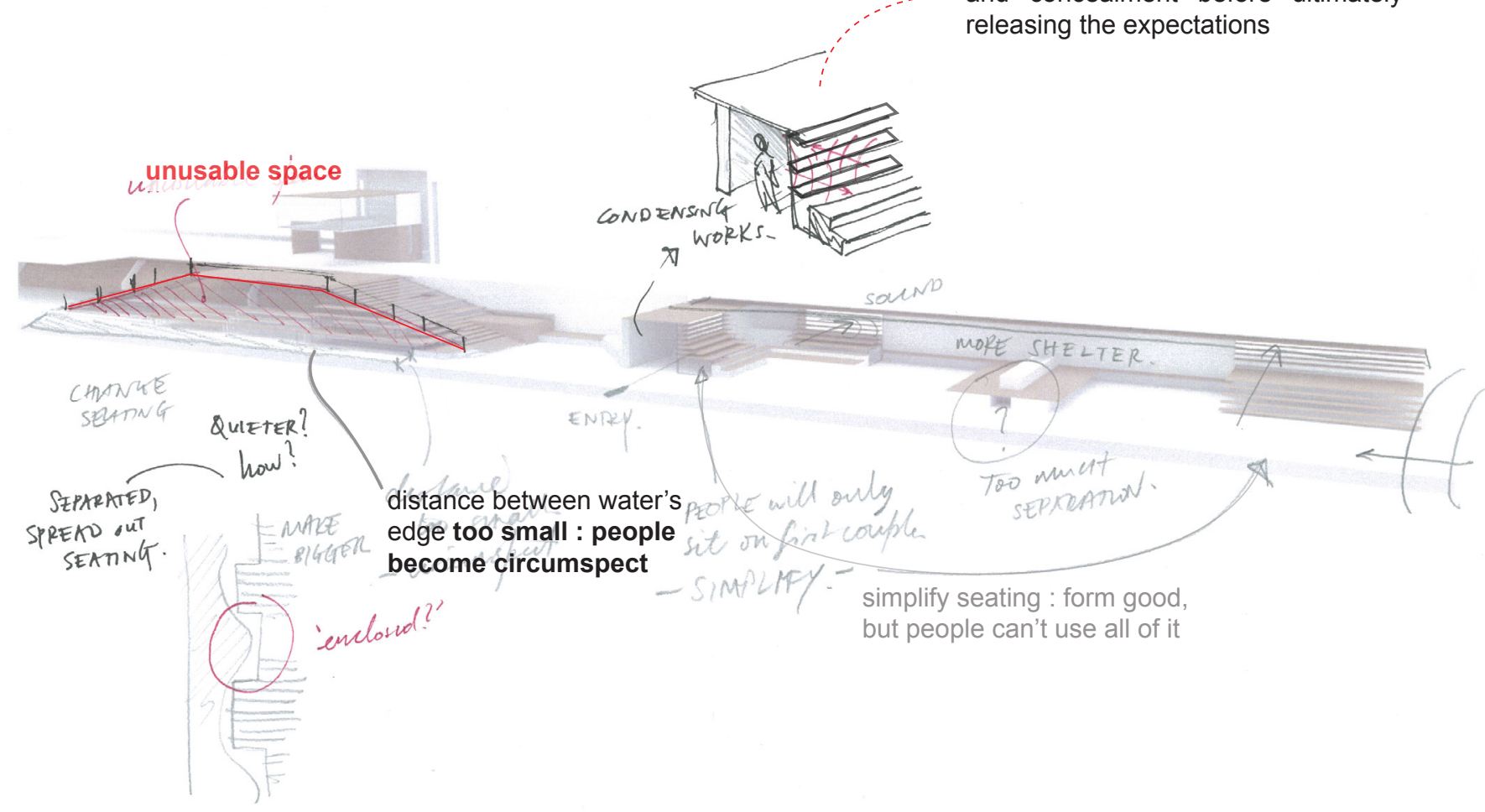


"Reducing public leisure activity to defined functions reduces what it means to be at leisure" (Lefebvre)
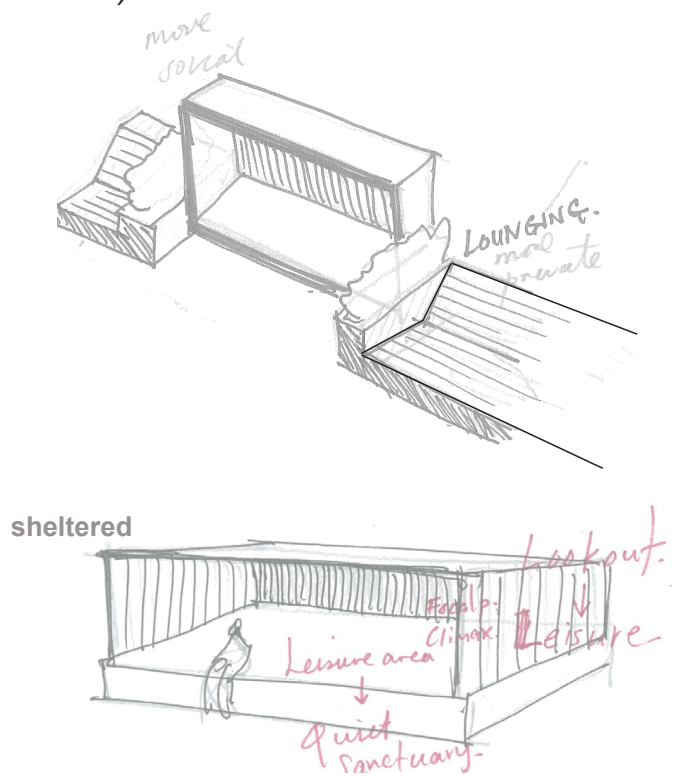

fig. 3.23: (top) Atlantique furniture

fig. 3.24: (bottom) The Jingumae residence

concrete warms over time in the Sun, while the constant shade combats the heat

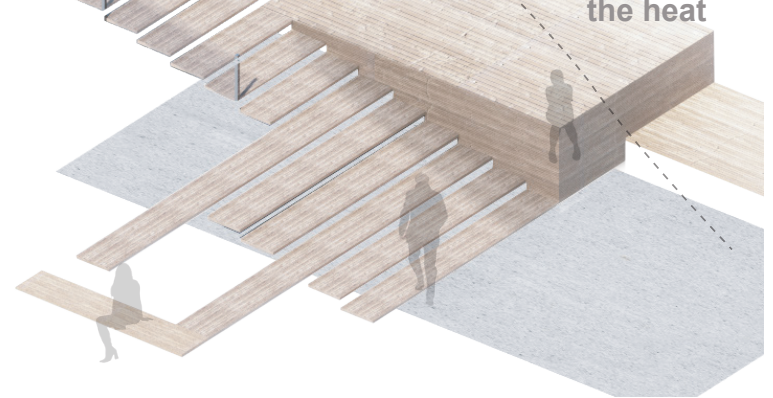

simplicity : accommodating for diverse people 


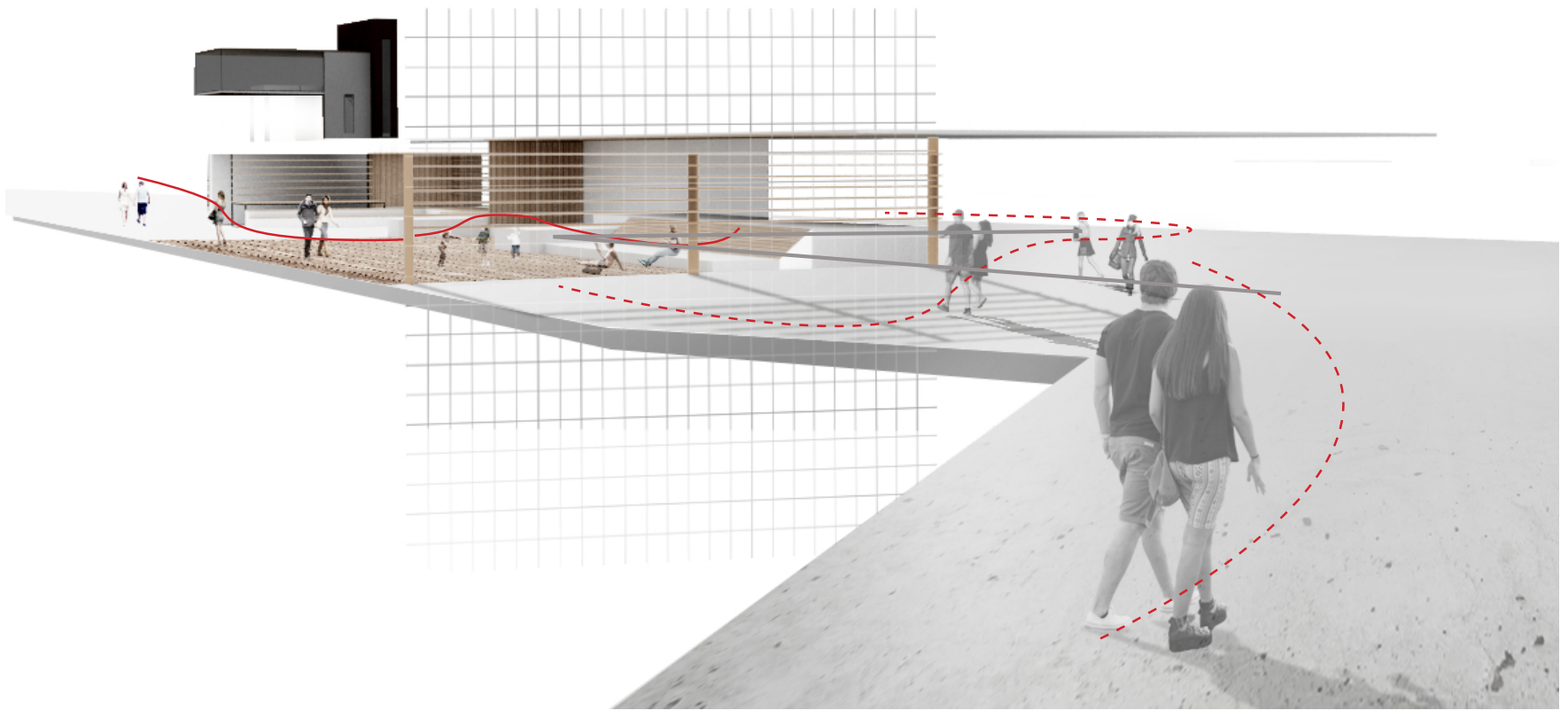

The positional relationship between the seating and steps up to the lookout adds a temporal rhythmic variance to the space. An underlying performance exists where the convergence space rhythmically transforms. This is enabled by the quicker, intrigued wanderers .

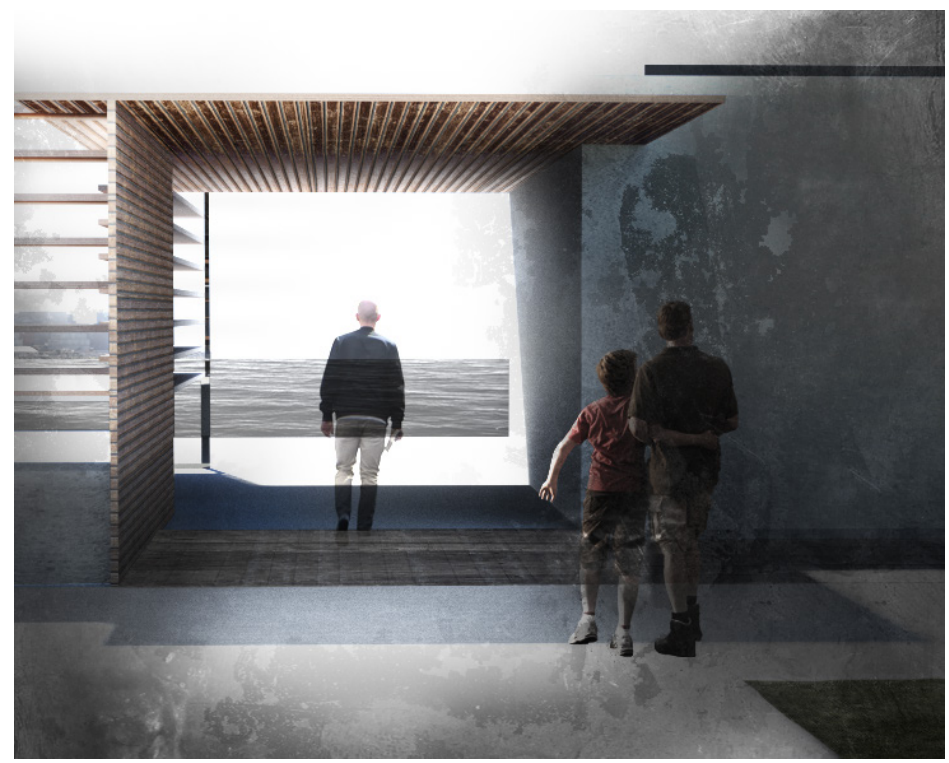

Convergence area spectators becoming the performers 
"[Humans] do not merely enjoy a vision, a contemplation, a spectacle- they act and situate themselves in space as active participants."

(Lefebvre, p.294)

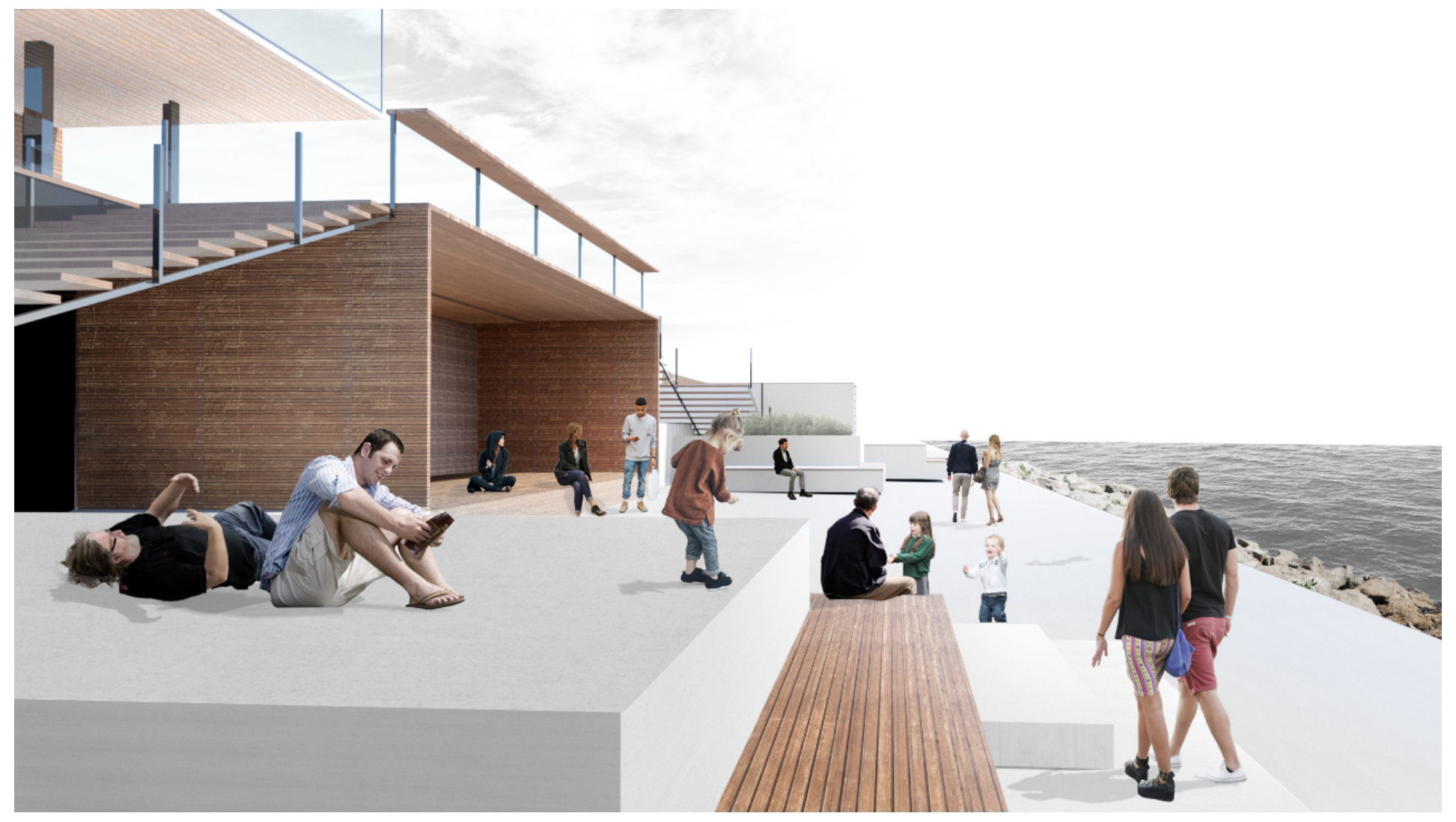

Promenade :

diverse occupation + convergence 


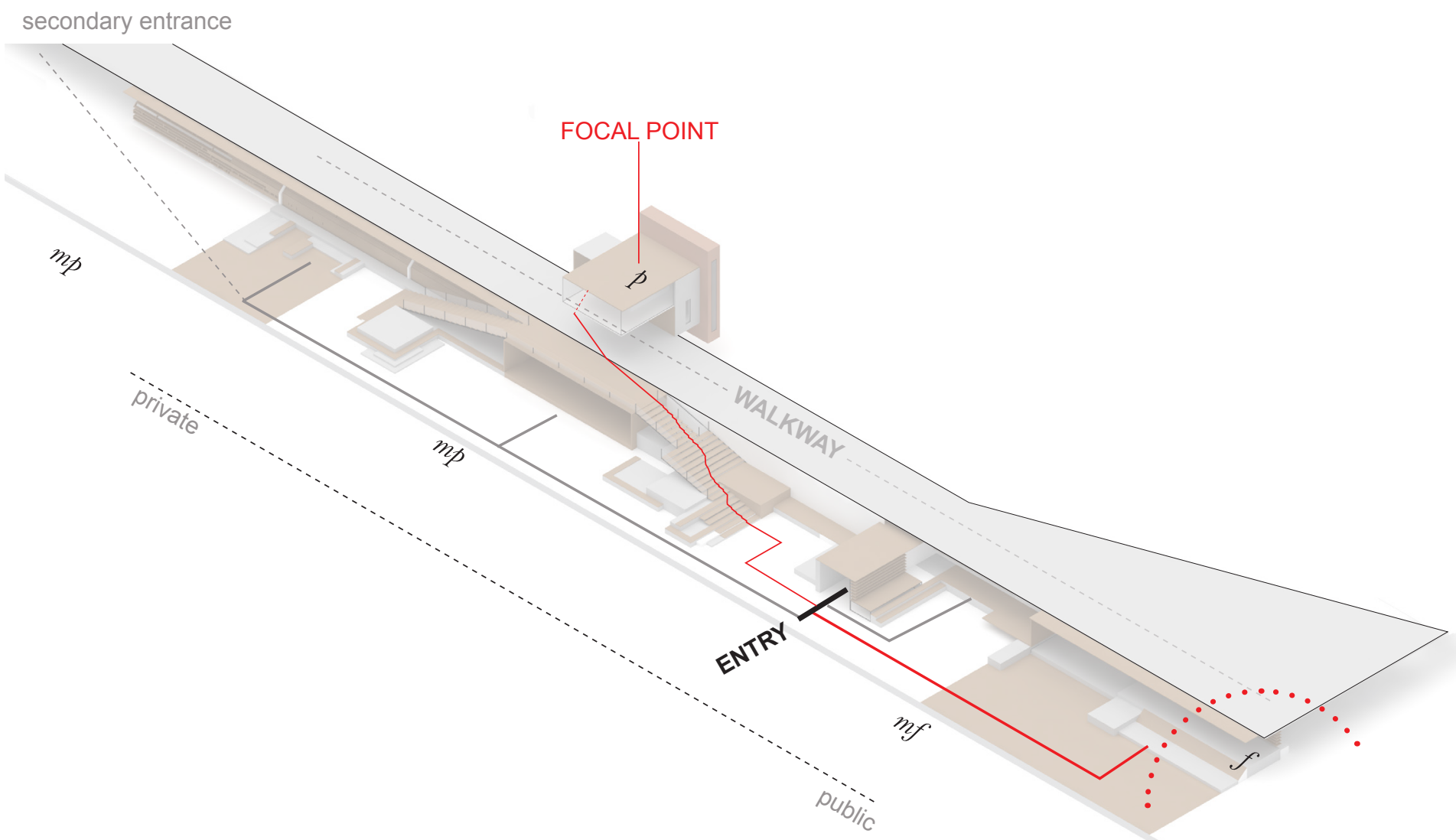

Convergence space: Final design 


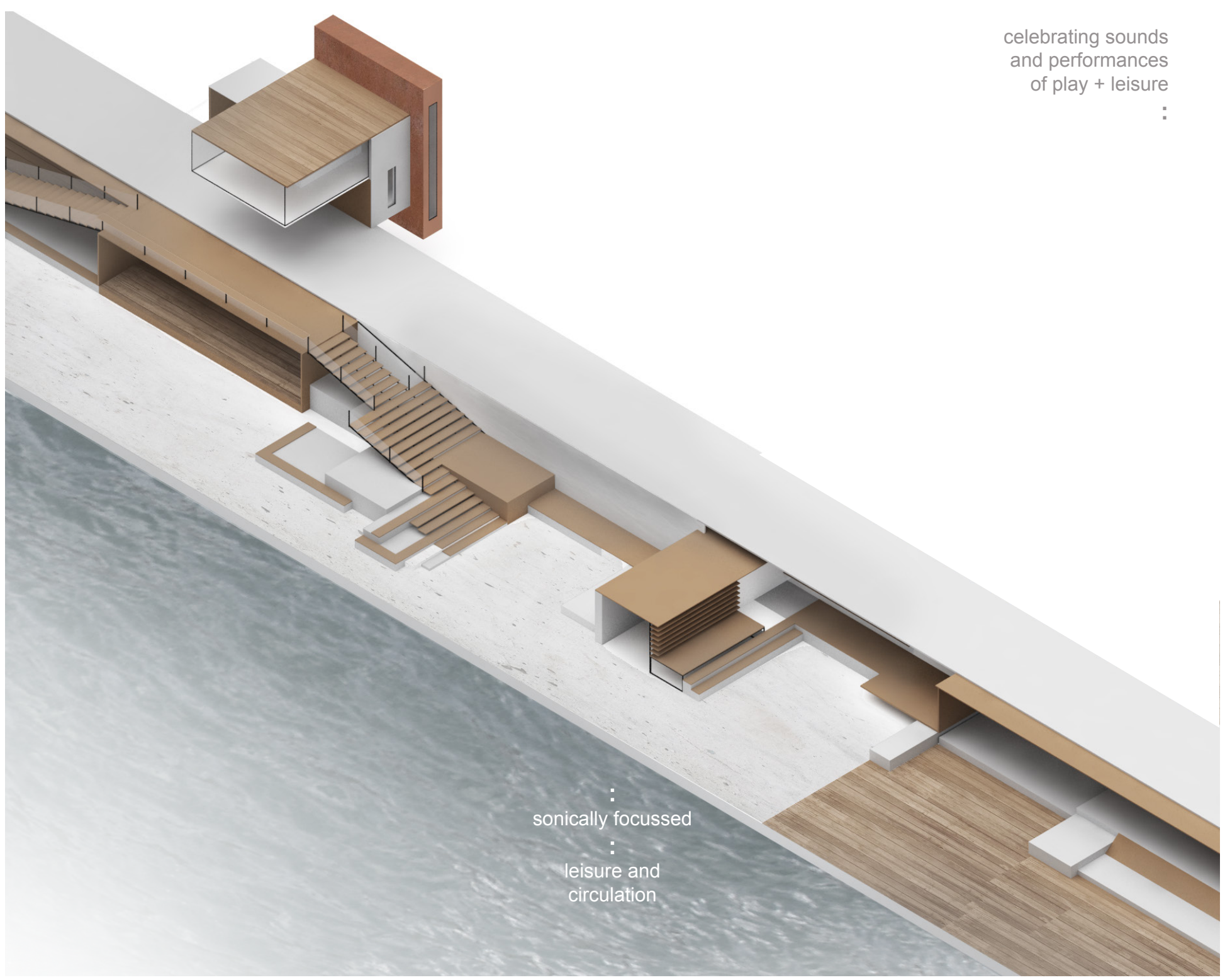




\section{RHYTHMIC SECLUSION}
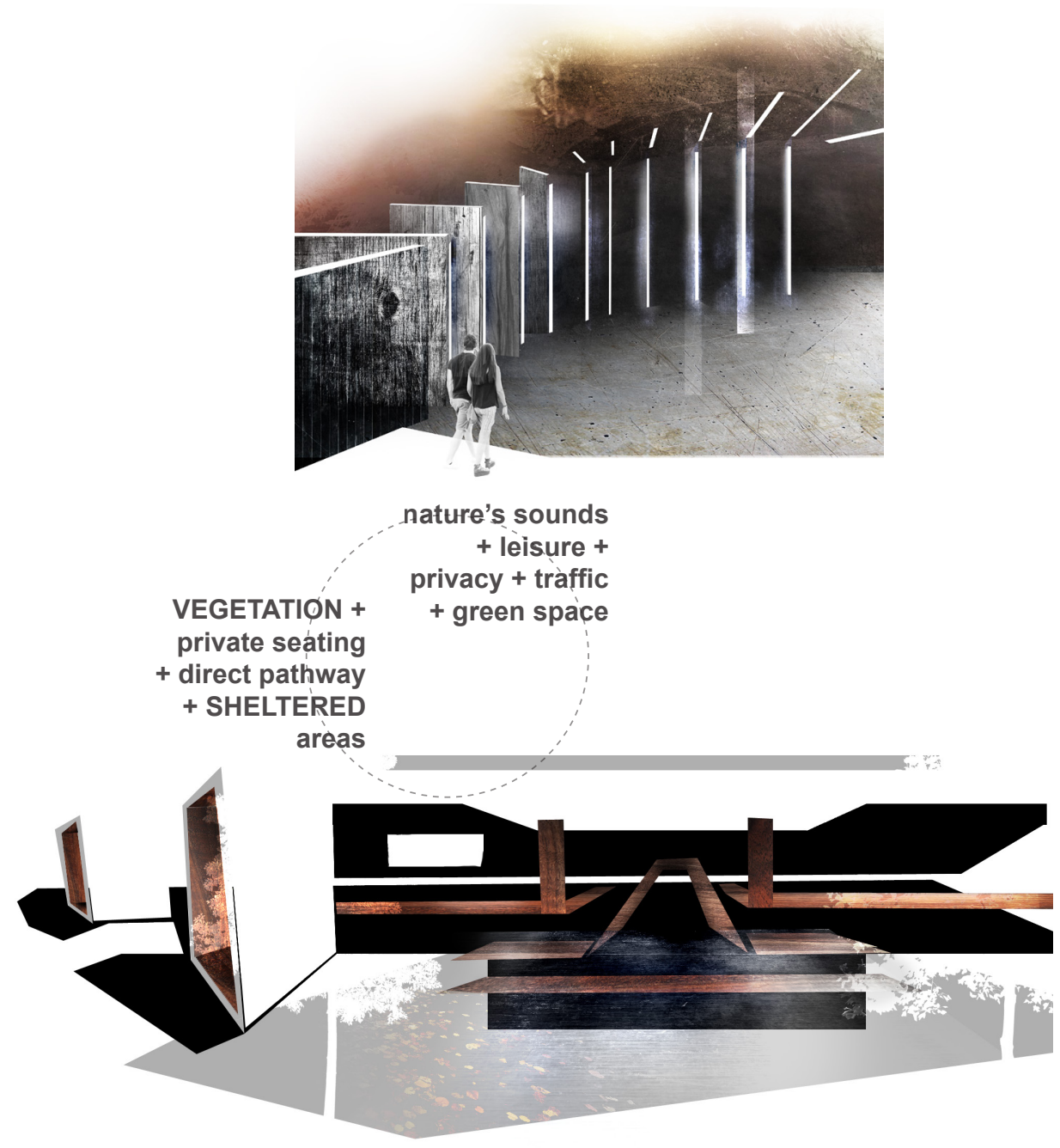

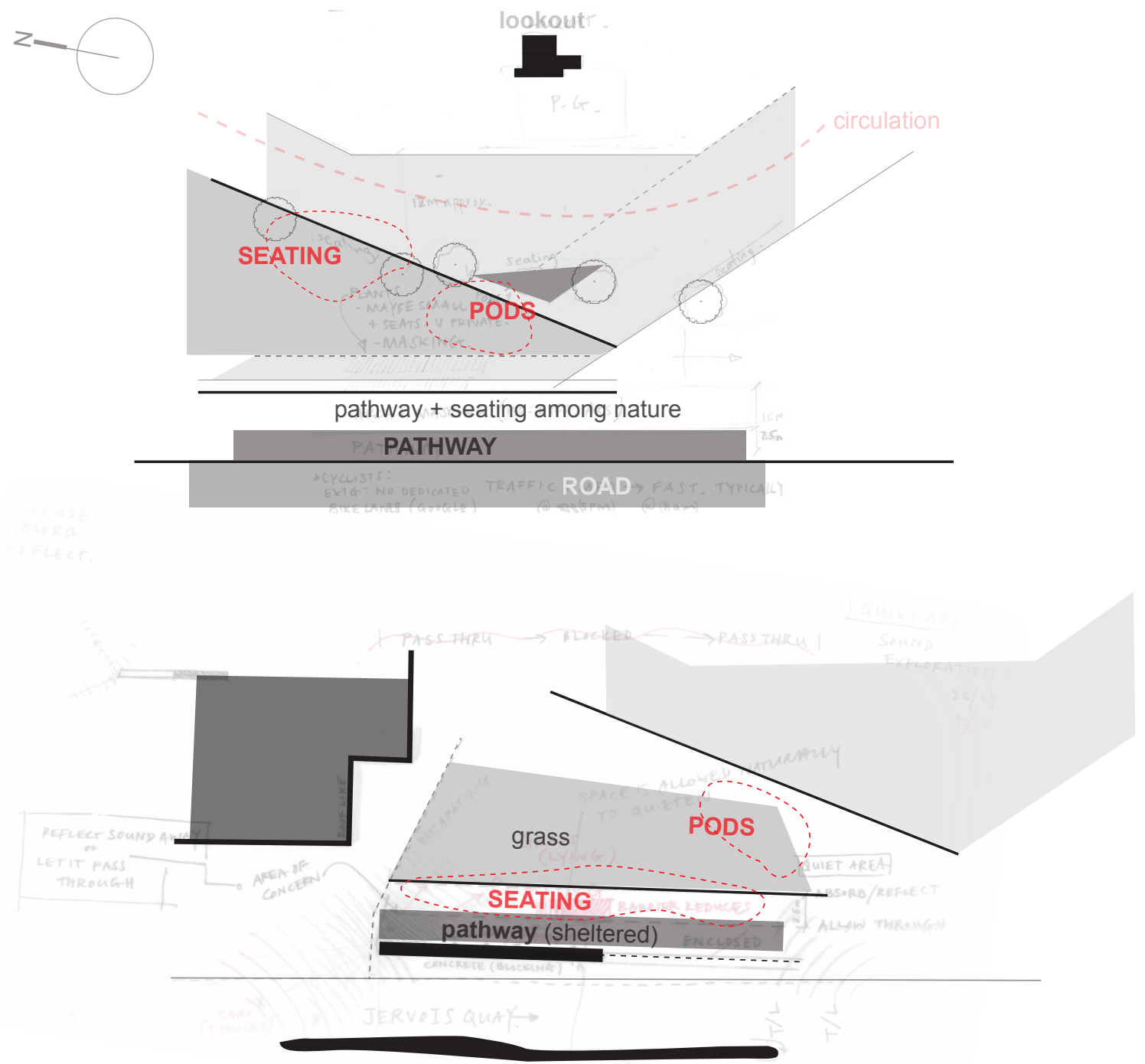


\section{Leisure seating}

fig. 3.11: (left) Klopfer Martin Design Group. 2009 fig. 3.9: Pennisula Residence. 2011

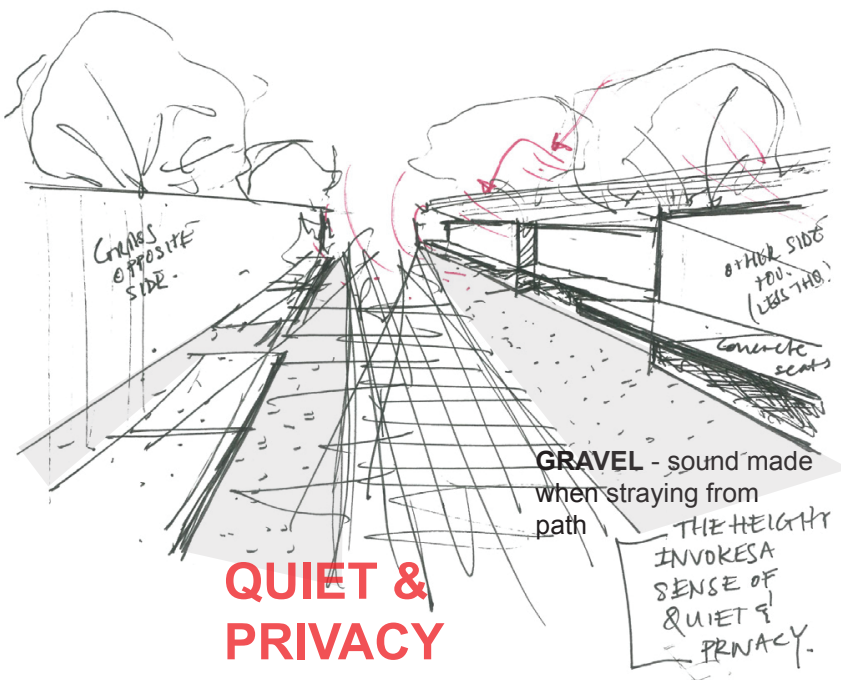

$27 \% 9$

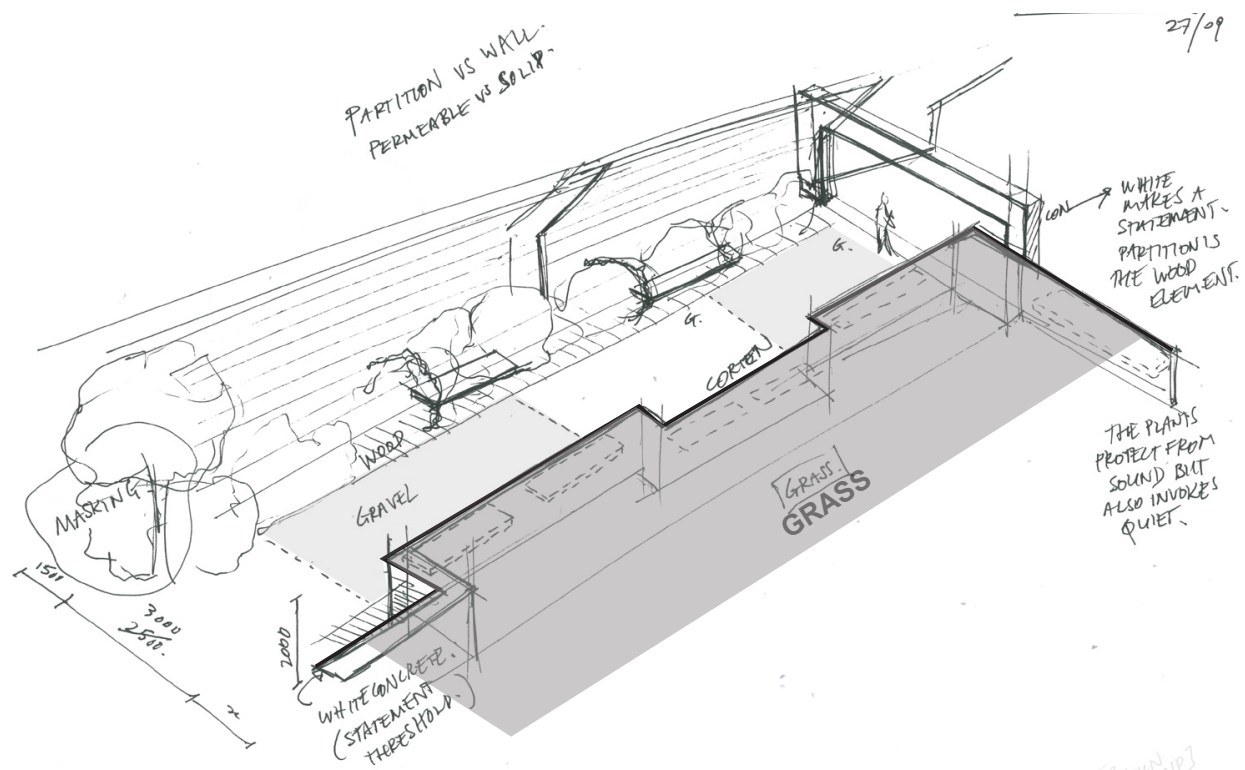




\section{Traffic sound barrier + pathway}

The idea of manipulating the sounds of traffic was considered earlier. It was noted that in experiencing the area the traffic's sounds penetrated far into the park. Therefore, the role of the pathway/leisure area will be carefully considered to diffuse or block the traffic's sound.

Looking back to Chapter two's Soundwalk 2: sonic perception a dominant experiential aspect was the rhythm of the traffic and how sounds fluidly came in and out of consciousness.

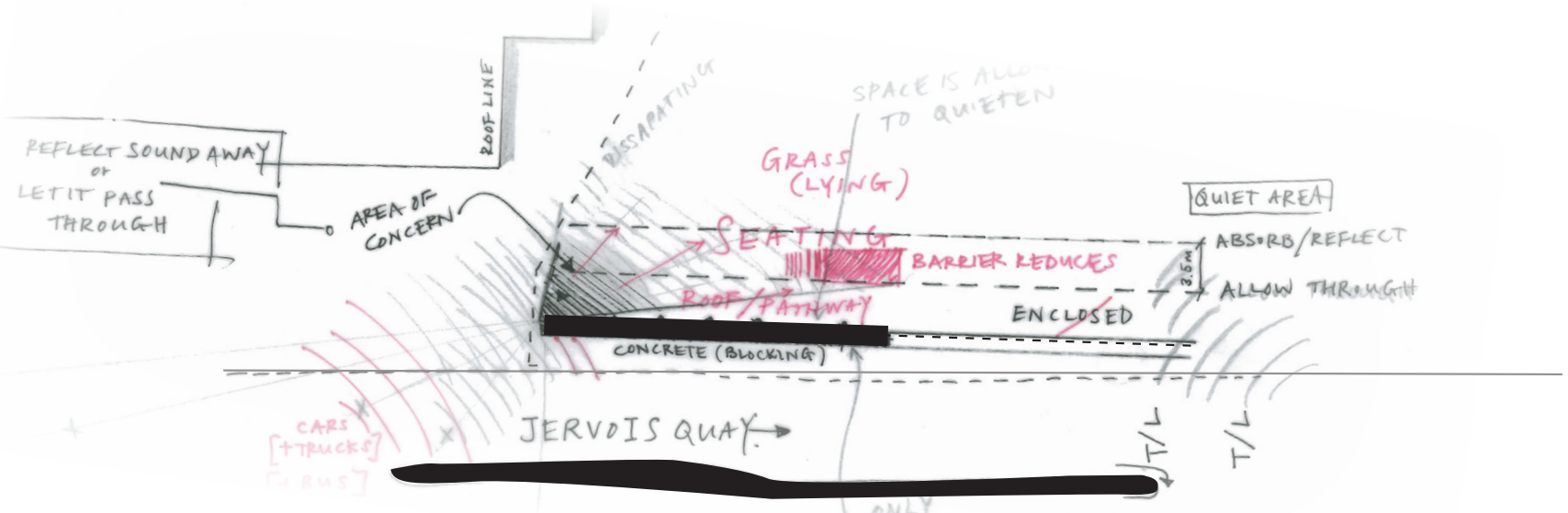




\section{Sound barrier}

Using the barrier to transmit sounds only sporadically can be an effective way to engage people with the traffic. This creates a rhythm in the experience of people walking through as well.

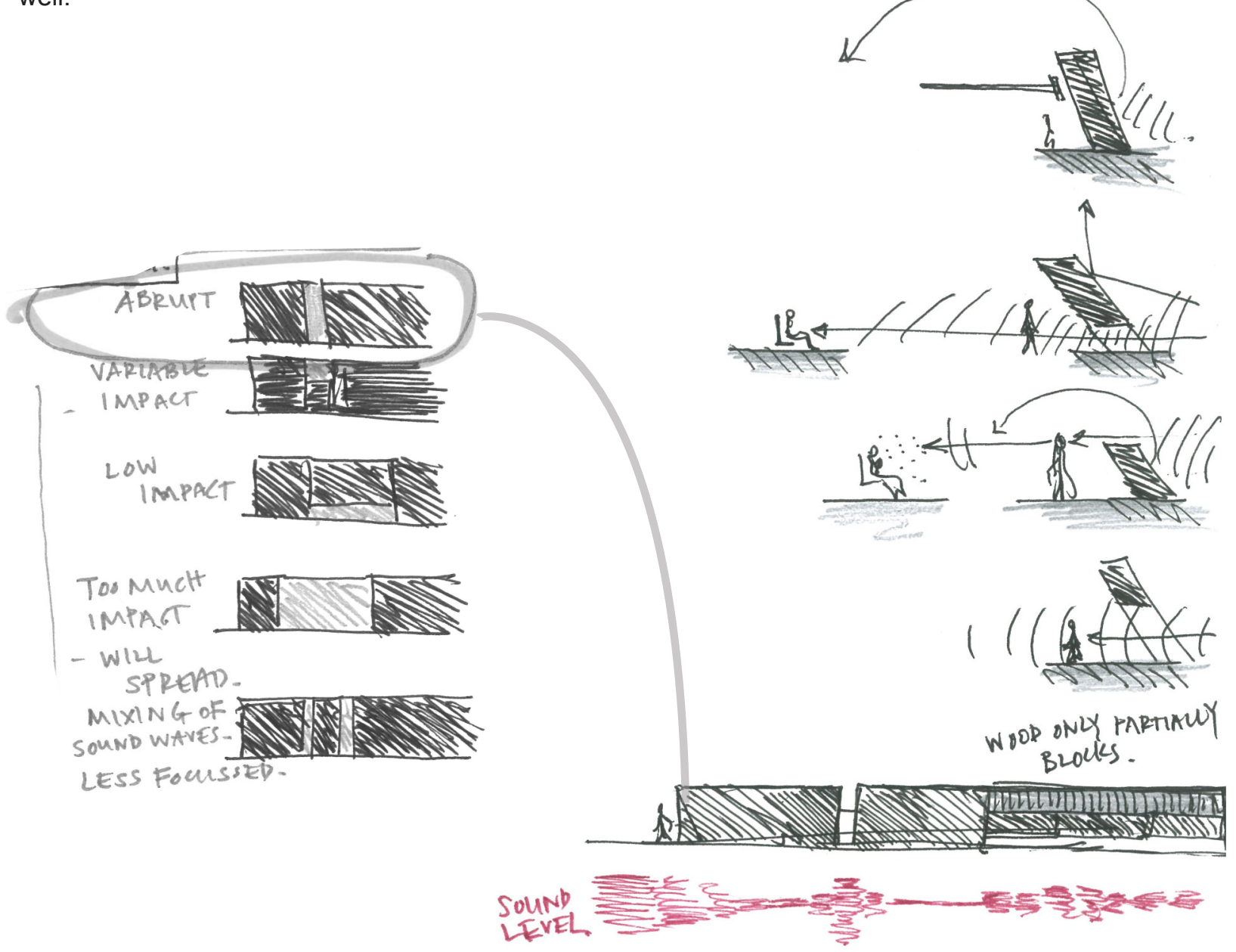



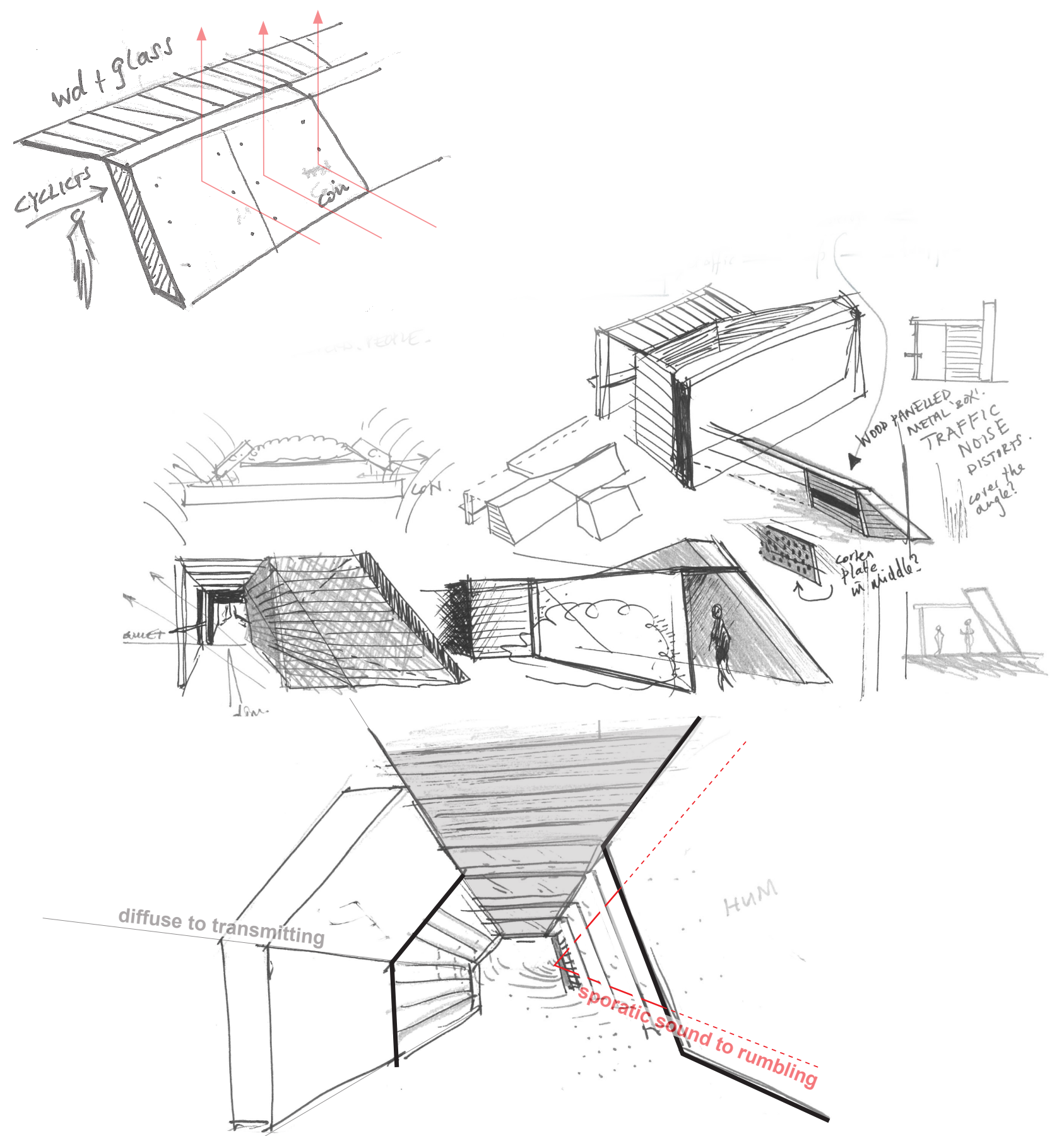


\section{Rhythmic seclusion: Reflection}

In such an important and dynamic area of the park the existing urban sounds need to be considered more comprehensively. The space needs to dictate experiences more holistically.

- The seating's design can be refined.

- The sound barrier and the logic behind that is successful.

- The reasoning for the forms of the passageway needs to be addressed to concentrate on sound and the experiential aspect.

- Exploring how this space can accommodate for diverse people needs to be considered too.
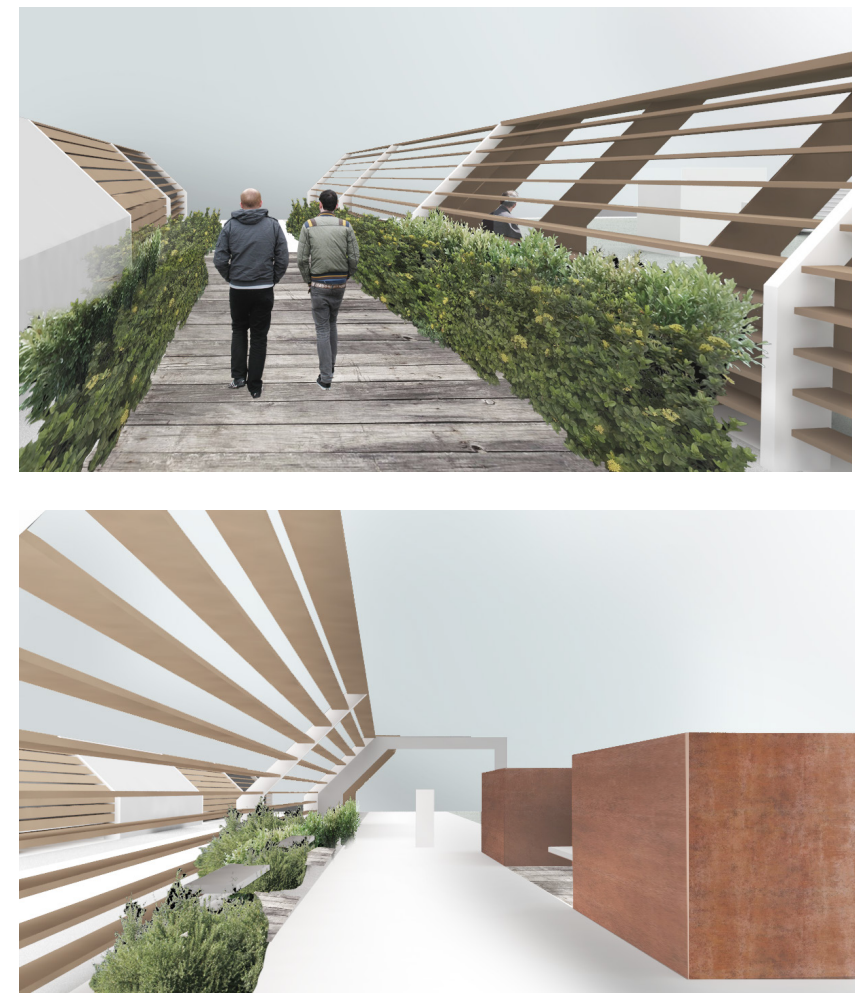


\section{Clarifying spatial + experiential elements}

One's focus rhythmically shifts from traffic to the sounds of trees, wind, people and the distant city in chorus; the duet produced is a fluid yet spontaneous reminder of the modern city of Wellington.

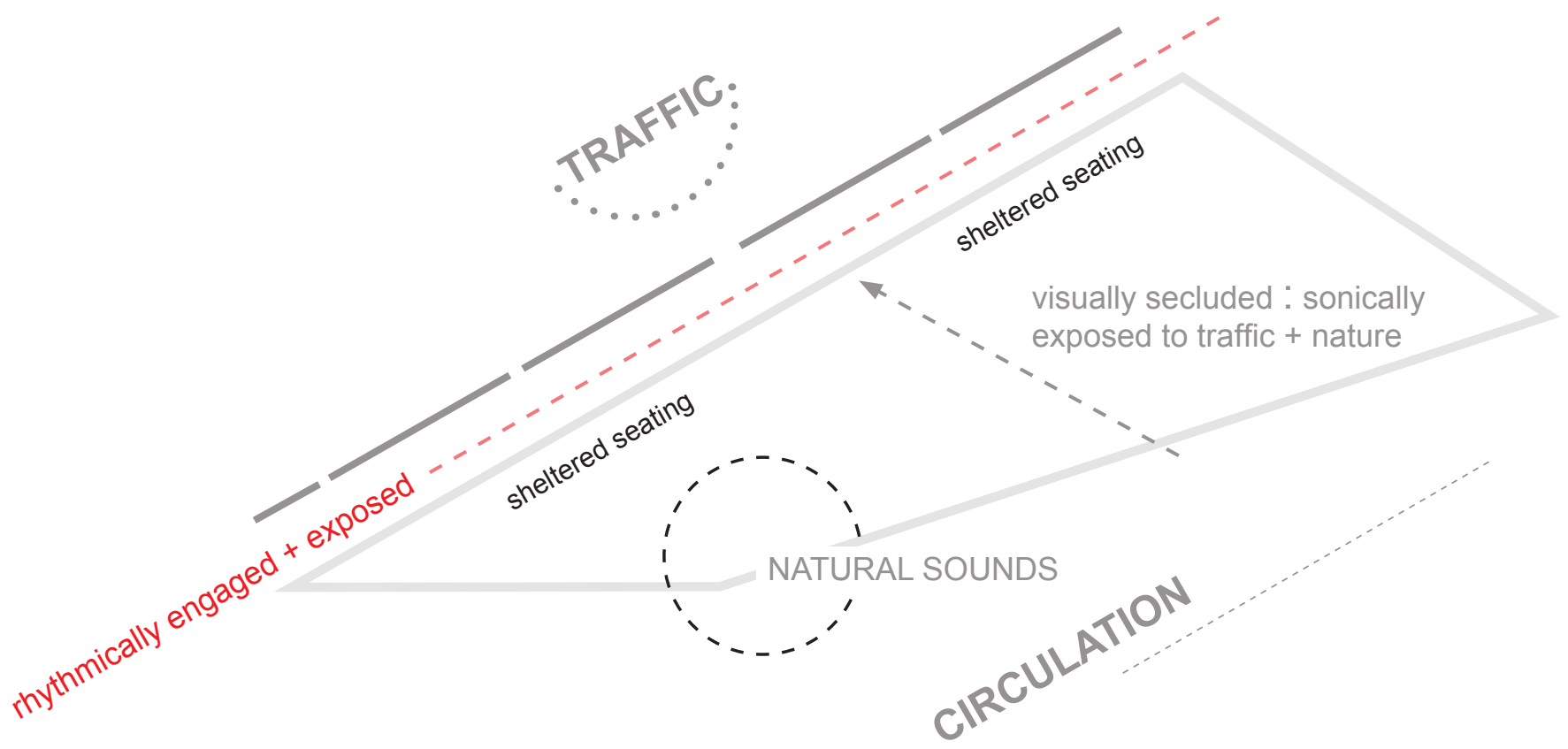


seating area iteration 2

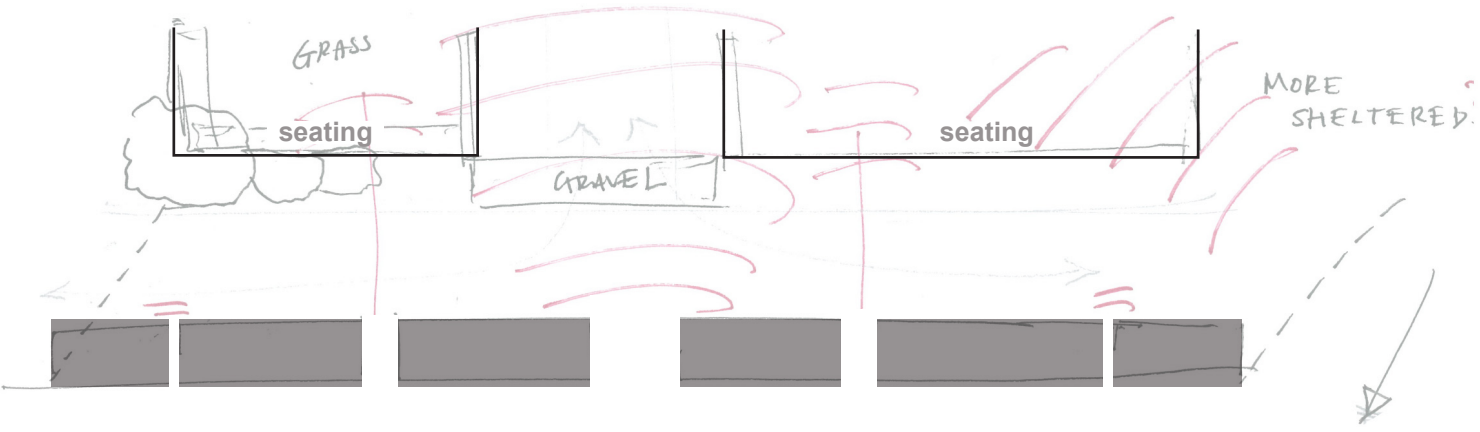

The seating should be dependent on the barrier's sonic influence. People sitting in the area will experience the rhythmic traffic- though differently from people walking through the passageway.

Providing shelter from the sun and rain must also be considered.

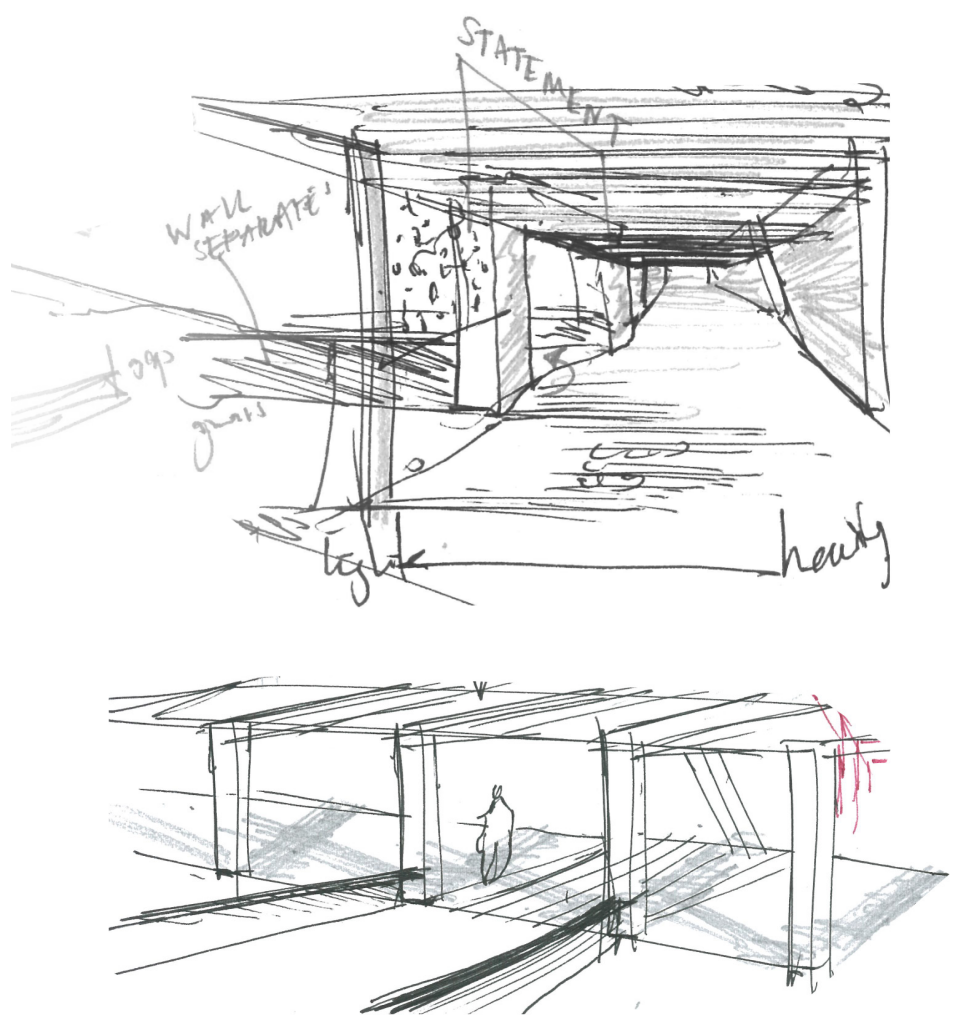



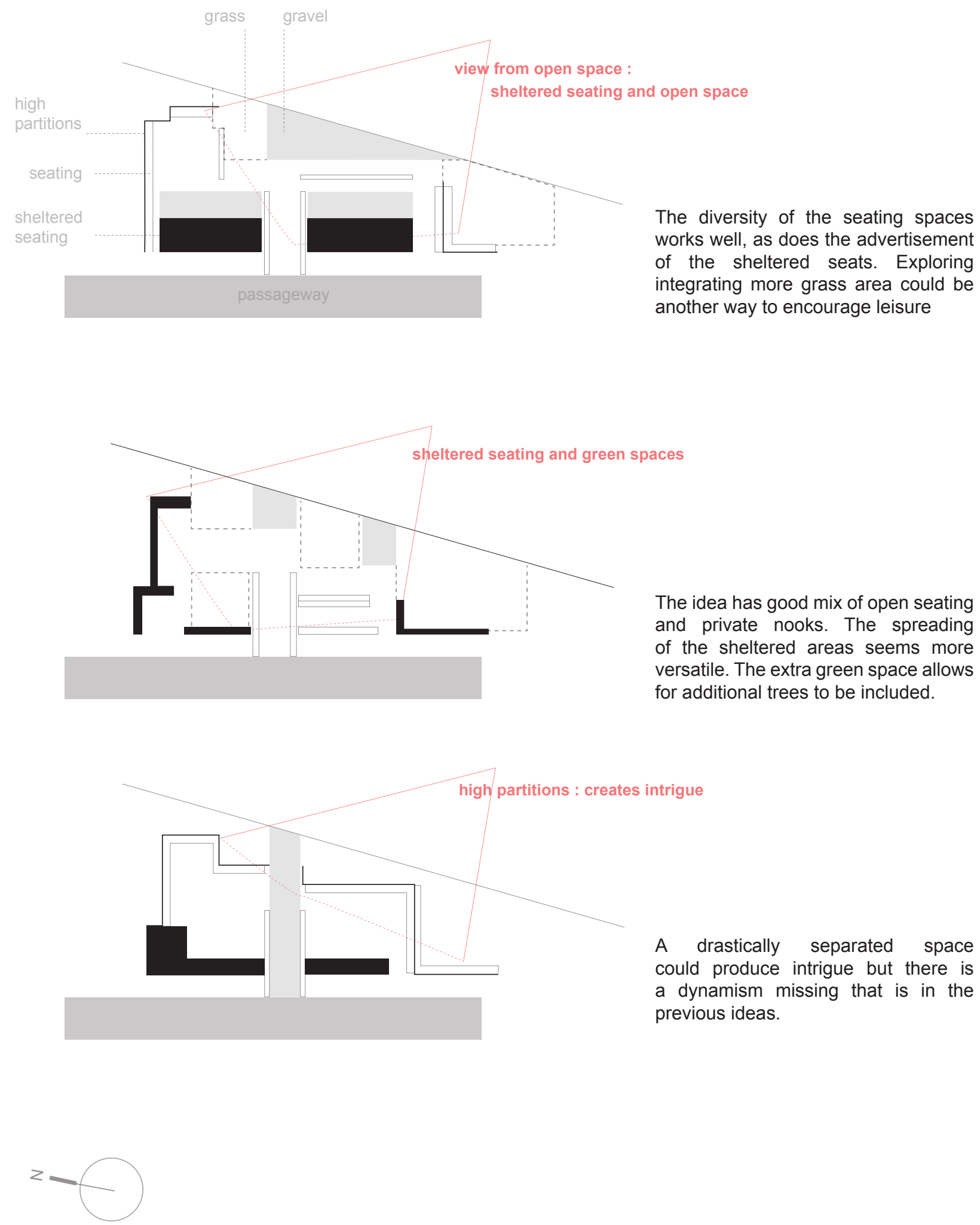


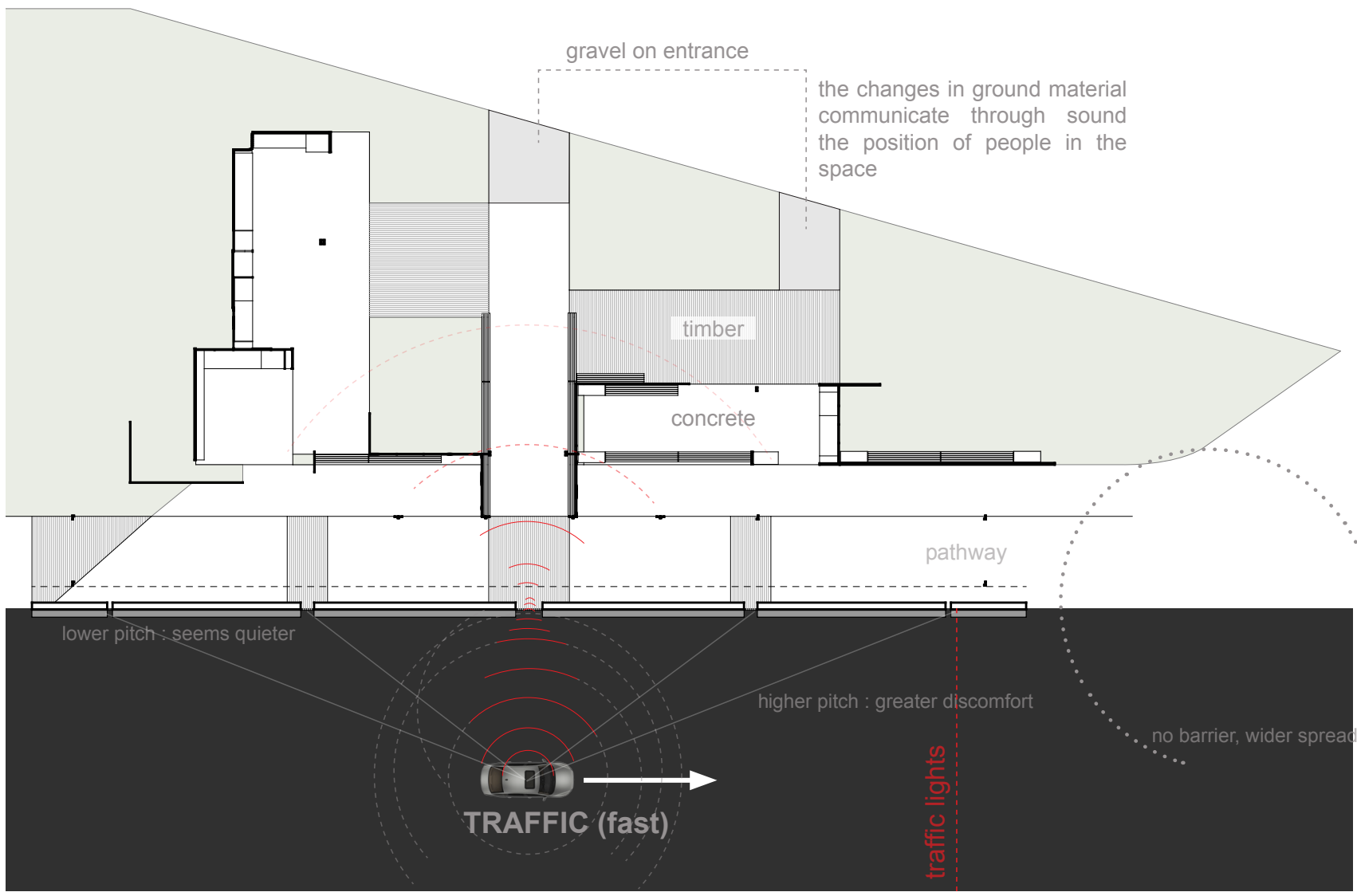




\section{Seating aesthetic}

The intervention offers varying degrees of privacy, though, people seeking solitude from people are more exposed to the sounds of the city.

The orthogonal forms work to encourage diverse occupation but also to attract people with the familiar. As public spaces need to challenge the everyday, the sonic qualities (caused by the city and nature intertwined) brings in unfamiliarity; the combination of rhythm, fluctuating sounds and seclusion will invite reflection on where they are and on the city they inhabit.
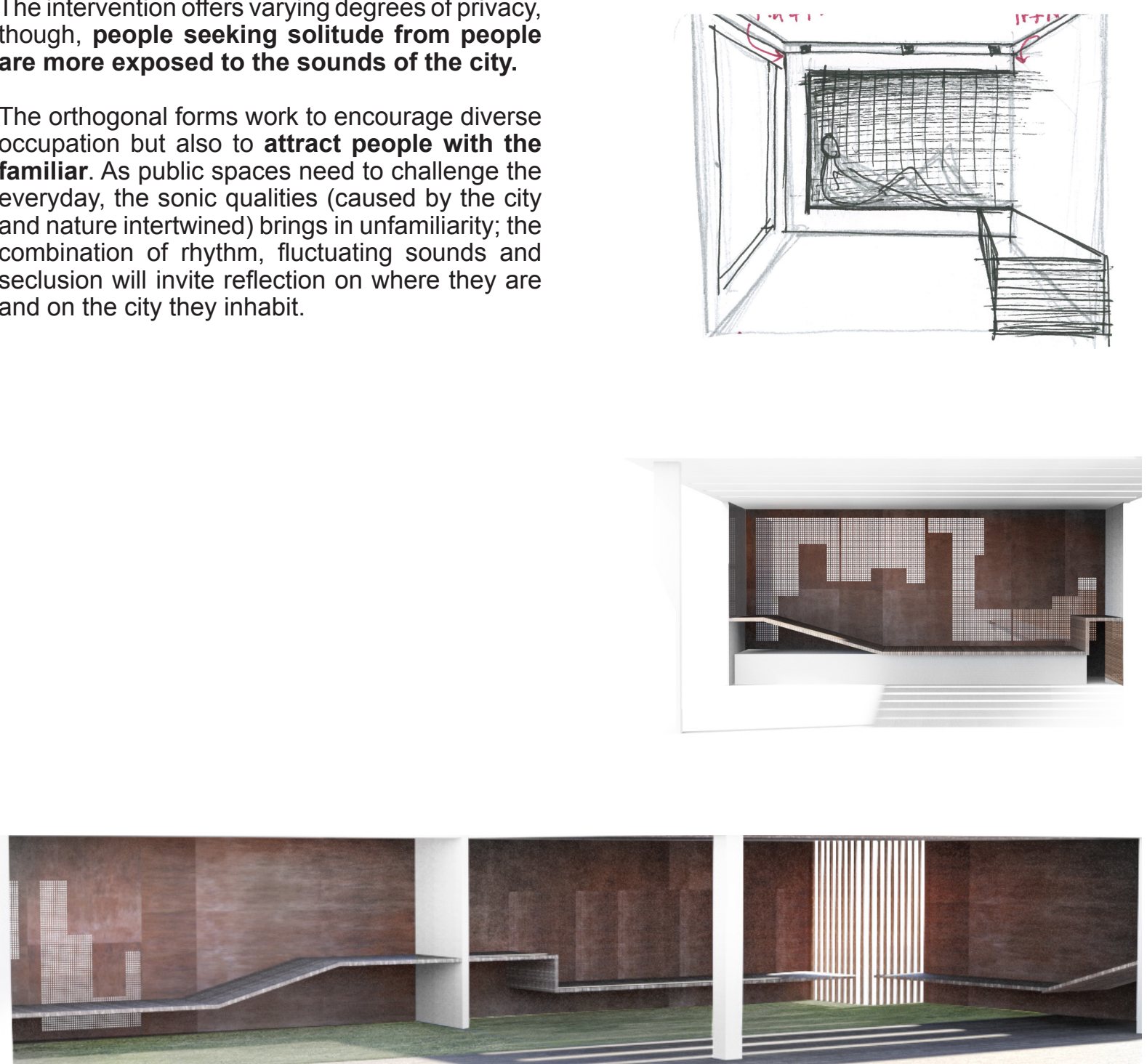
The rhythm is twofold: the sound through the barrier's breaches but also the periodic decrescendo of vehicles due to the traffic lights. In the quiet period, pleasant sounds of the vegetation folds into consciousness to emphasise the unaltered beauty of urban park spaces; faded sounds of the bustling city continue also. These sounds are eventually overtaken by engines and mechanical chaos.
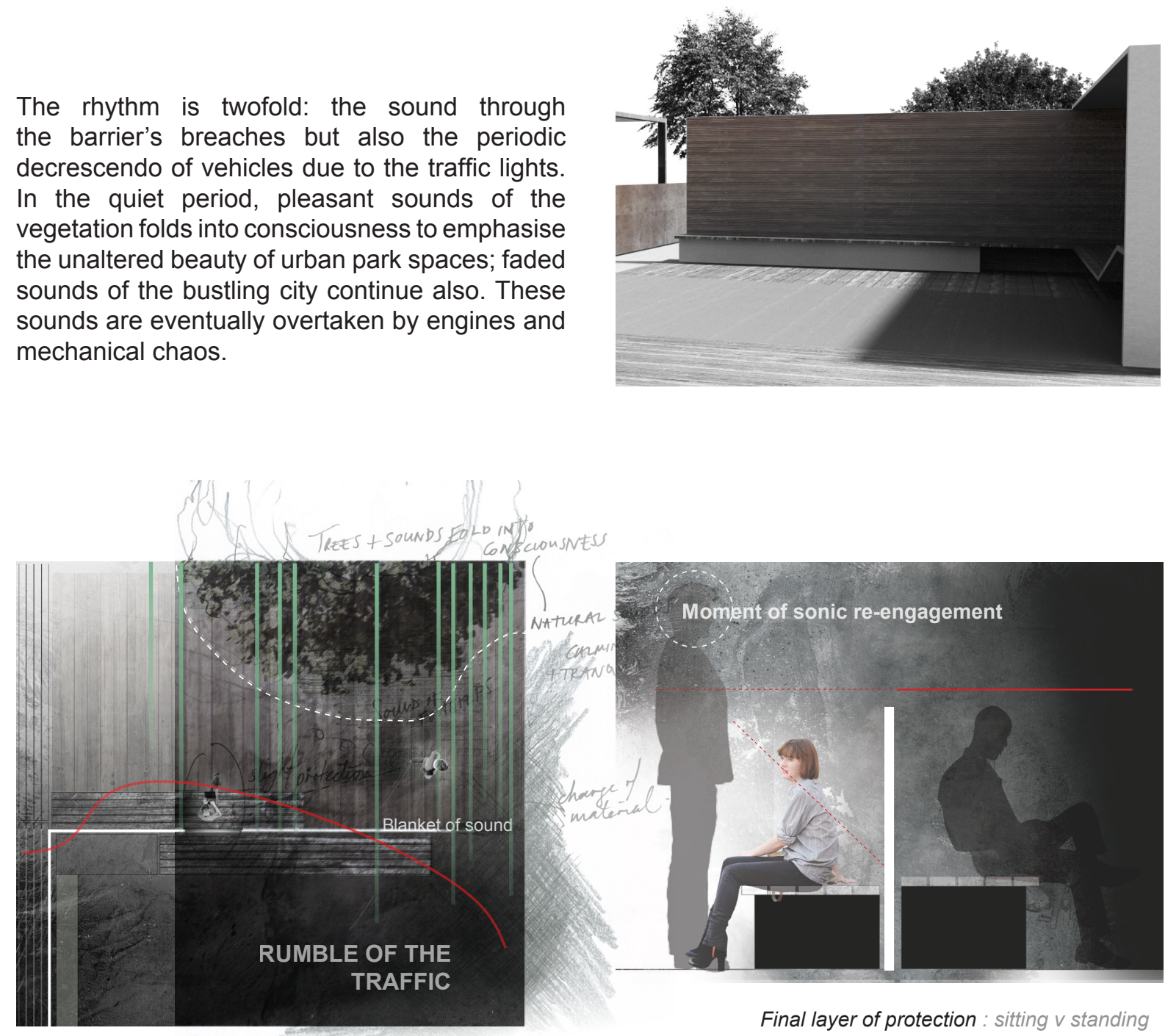

rhythm + fluctuating sounds 


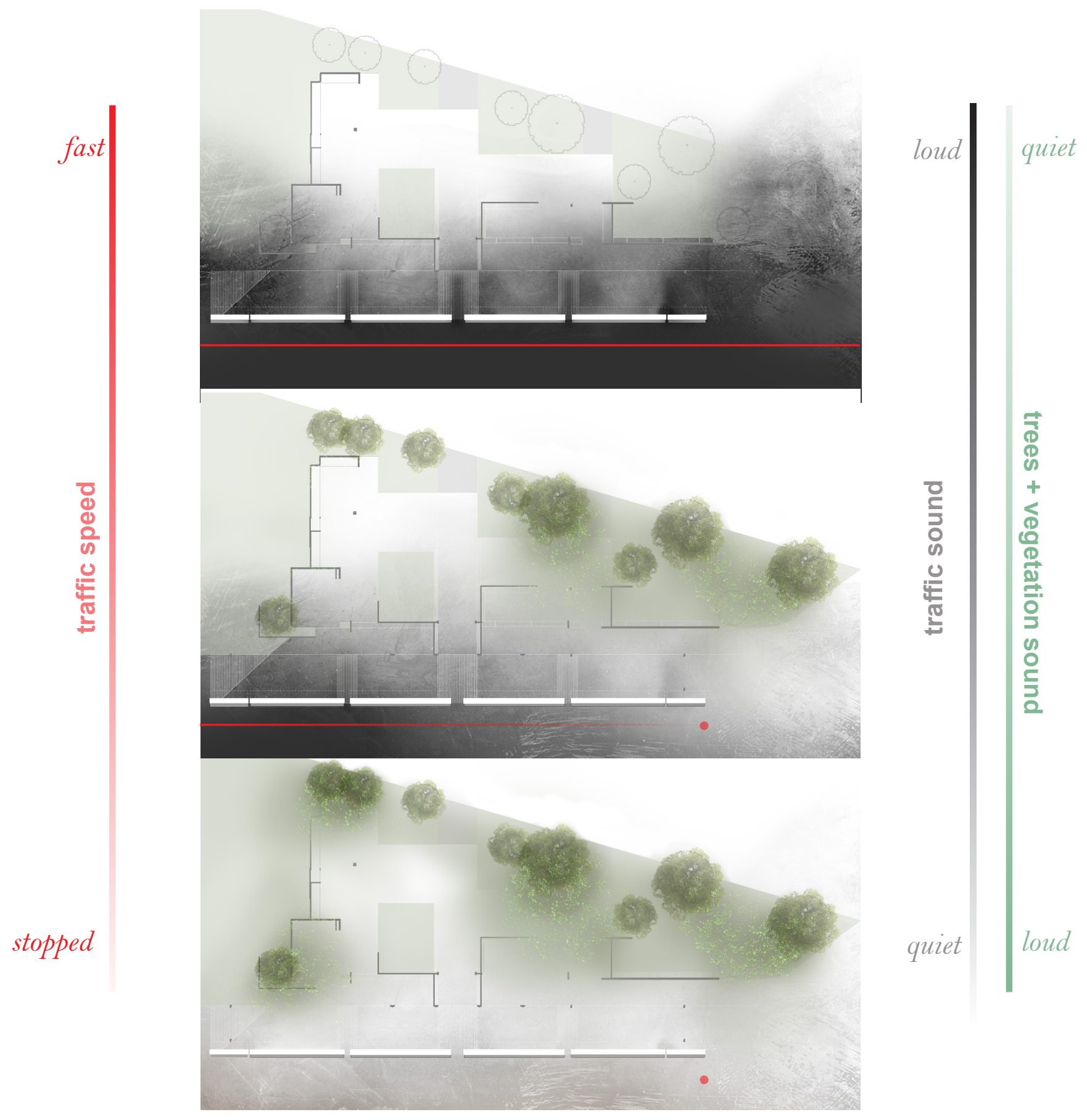

Performance + Interior Architecture - Rhythmic seclusion 175 


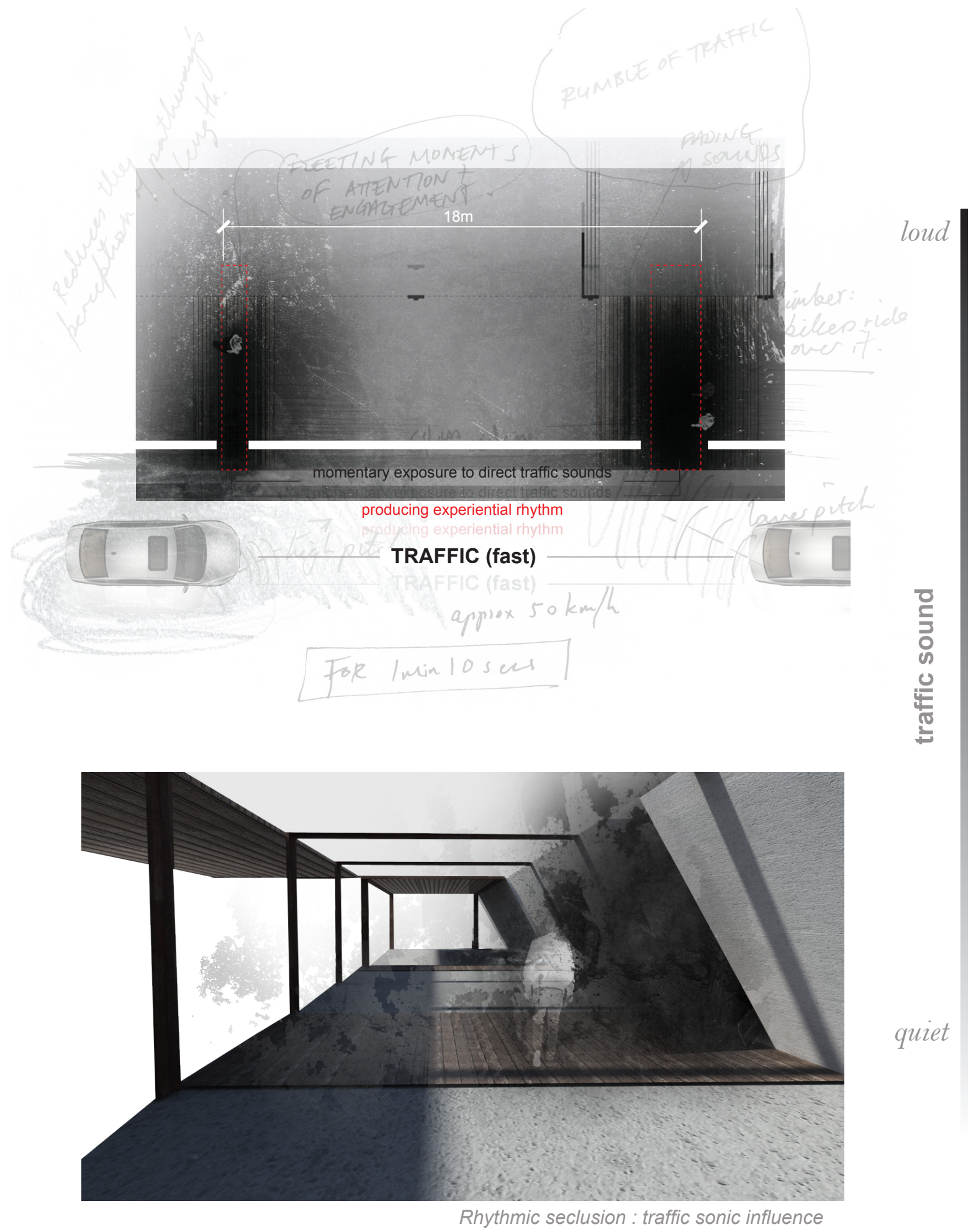

176 Performance + Interior Architecture - Rhythmic seclusion 
The three main materials used have been established since iteration one.

- Concrete: absorbtion and diffusion

- Wood: comfort and textural engagement

- and Cor-ten: texture, structure and slight diffusion.

These rigid materials respond to the vibrations of the traffic, increasing engagement between people and their city somatically; the vibrations will ebb and flow with the traffic.

In the passageway, people are able to engage aurally with the rain without being exposed. The shift from timber to glass roof varies the sound.
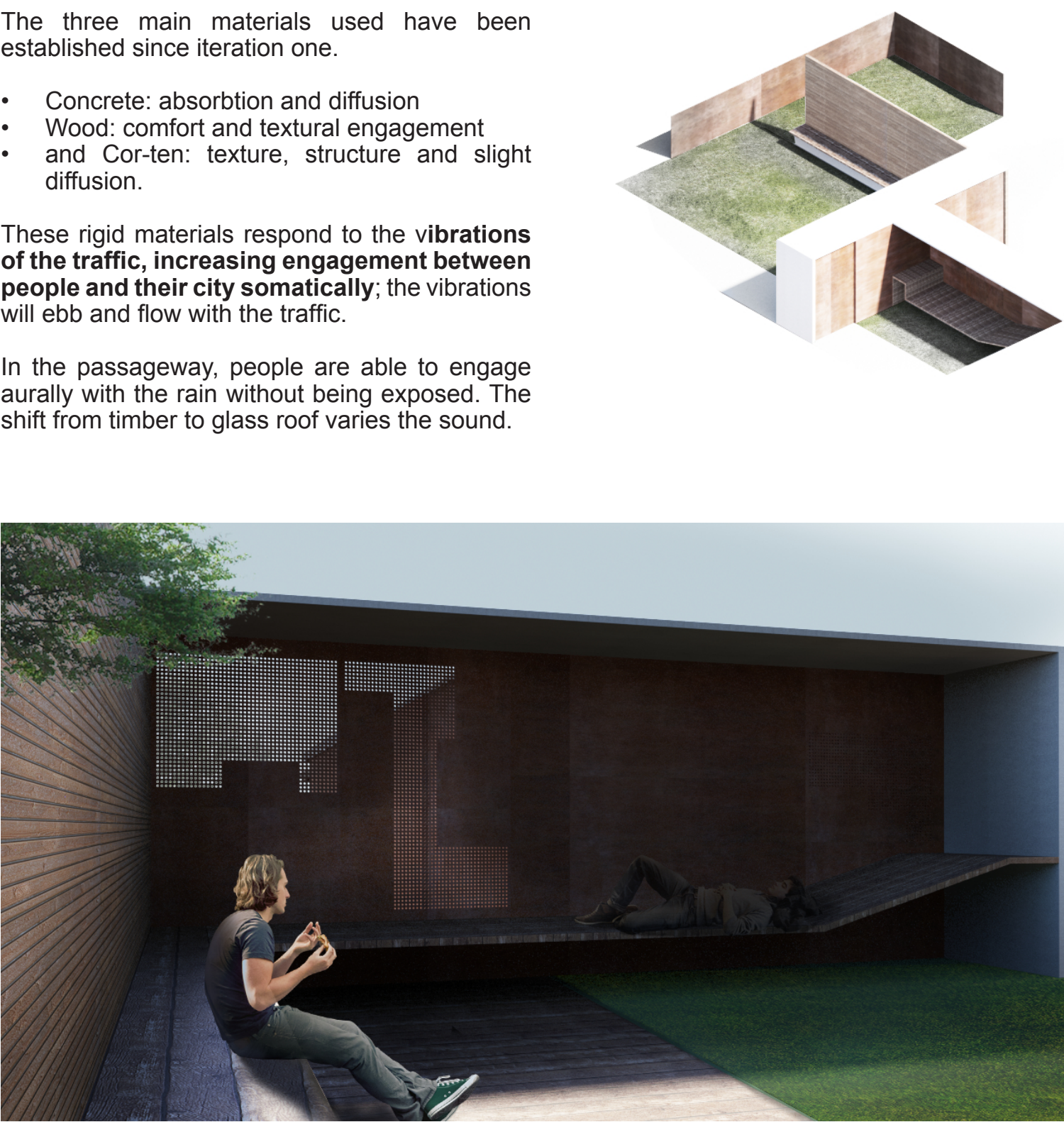

materiality 


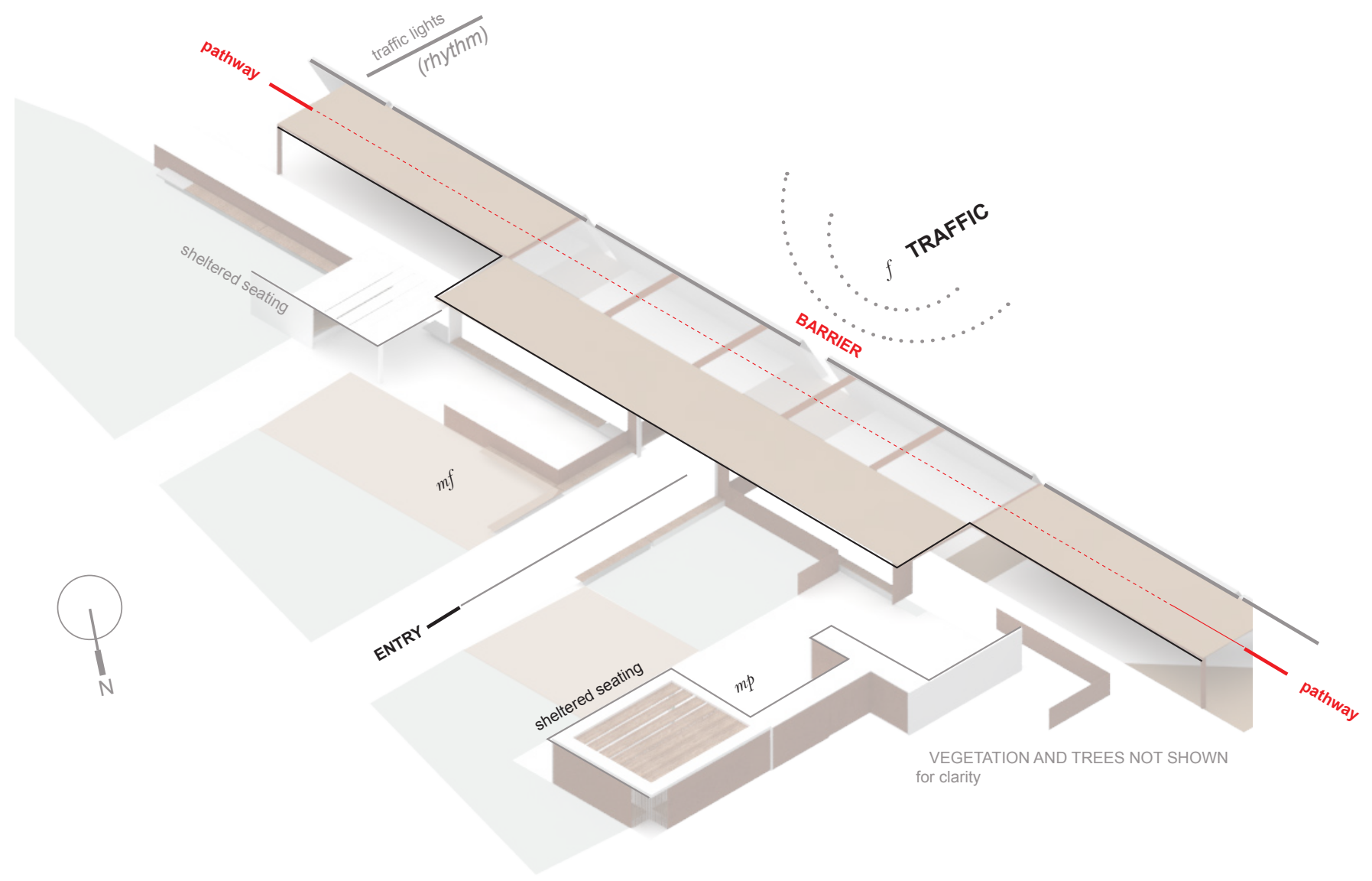

Rhythmic seclusion: Final design 


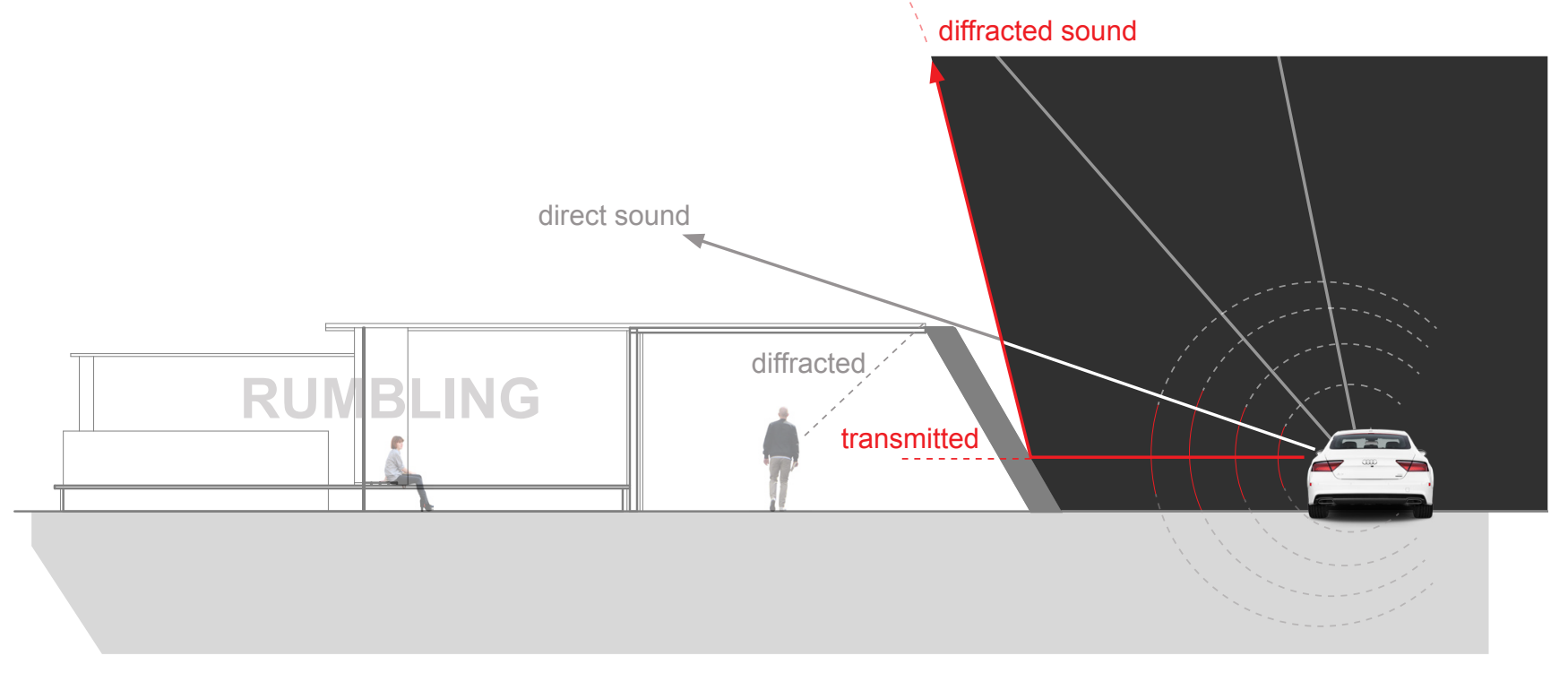




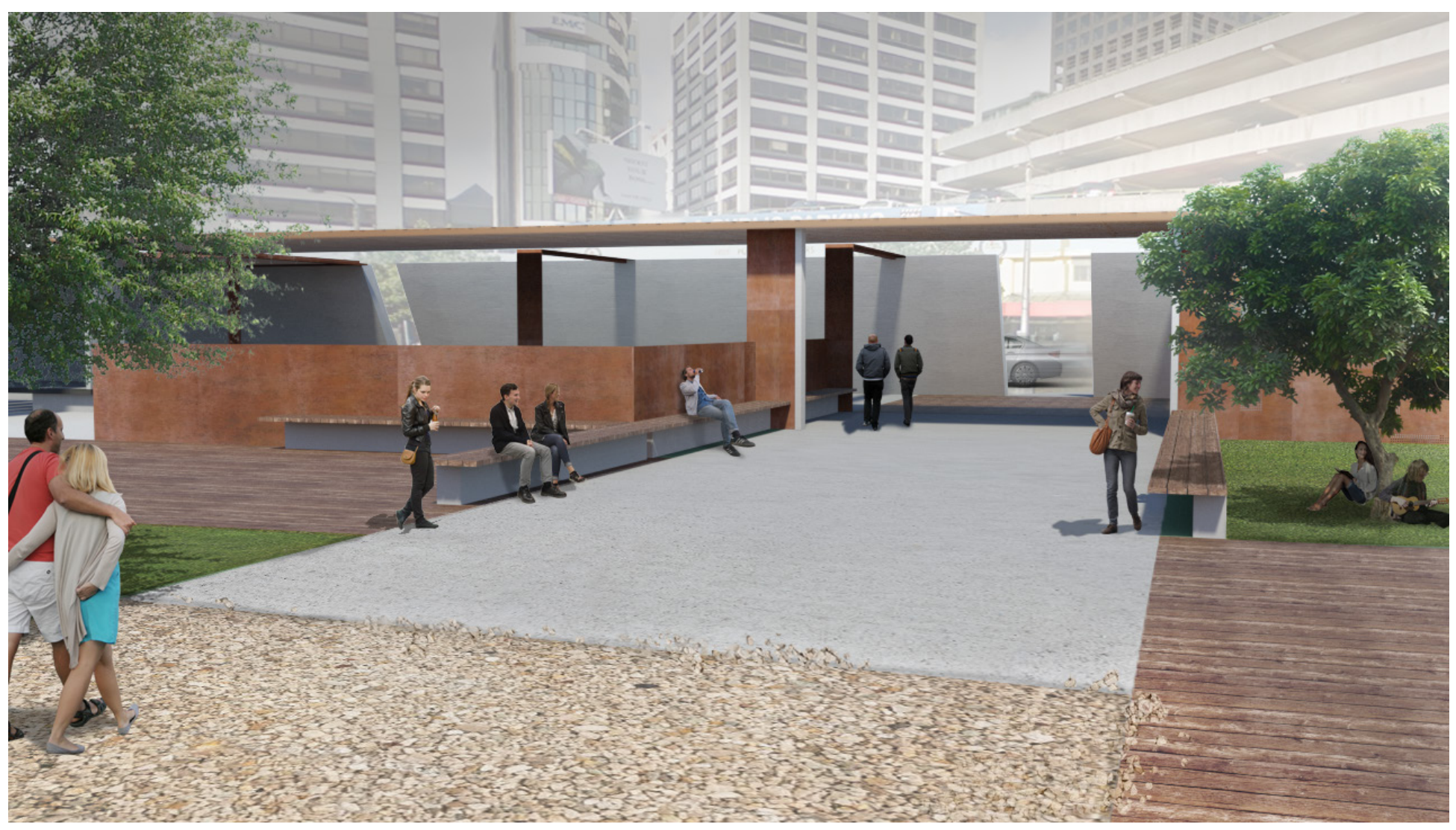

"The static landscape changes, it refuses to rest or to be one thing."

-William L. Hamilton 


\section{THE SENSORIAL LATENCY OF URBAN SPACES}




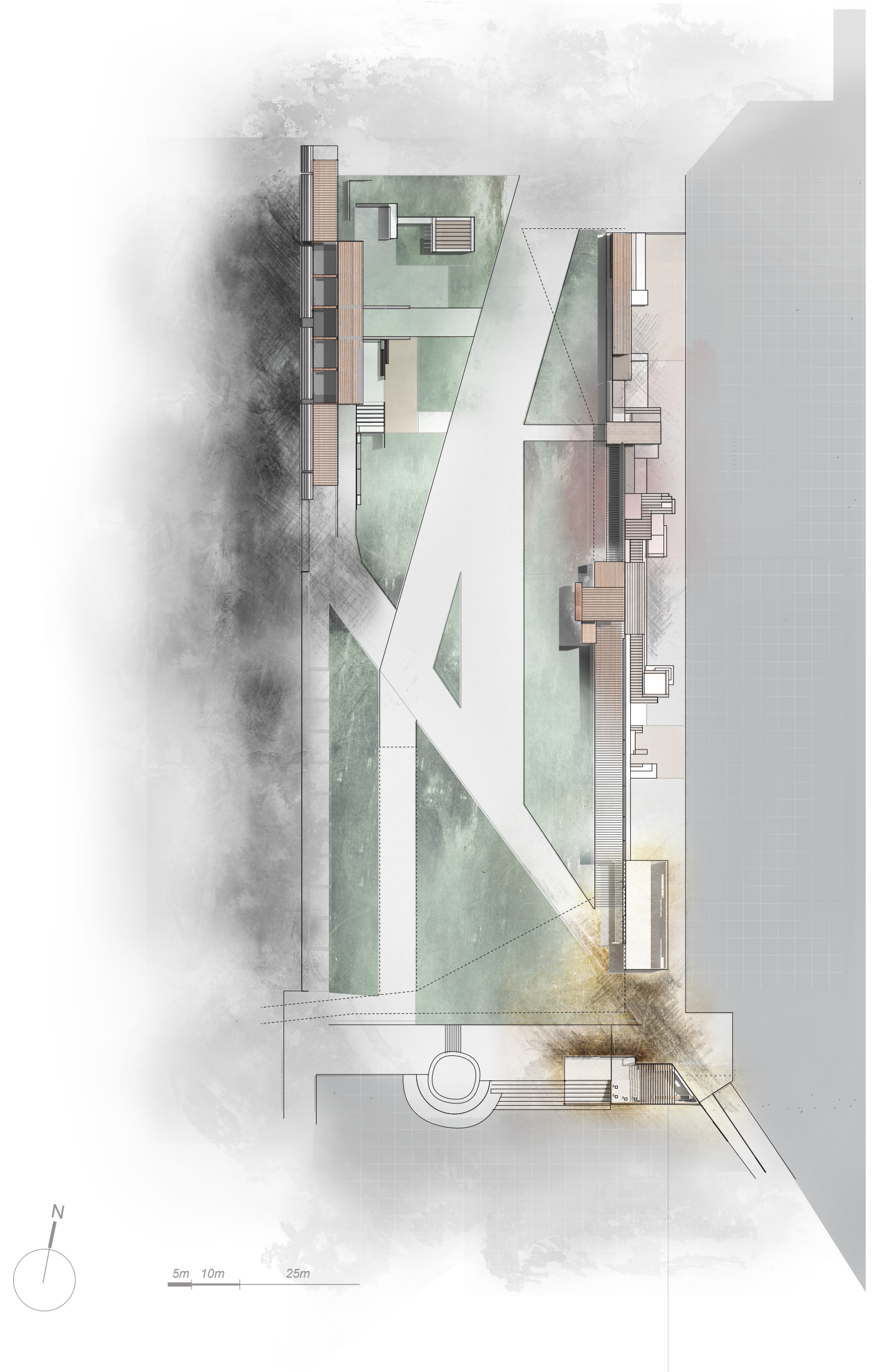




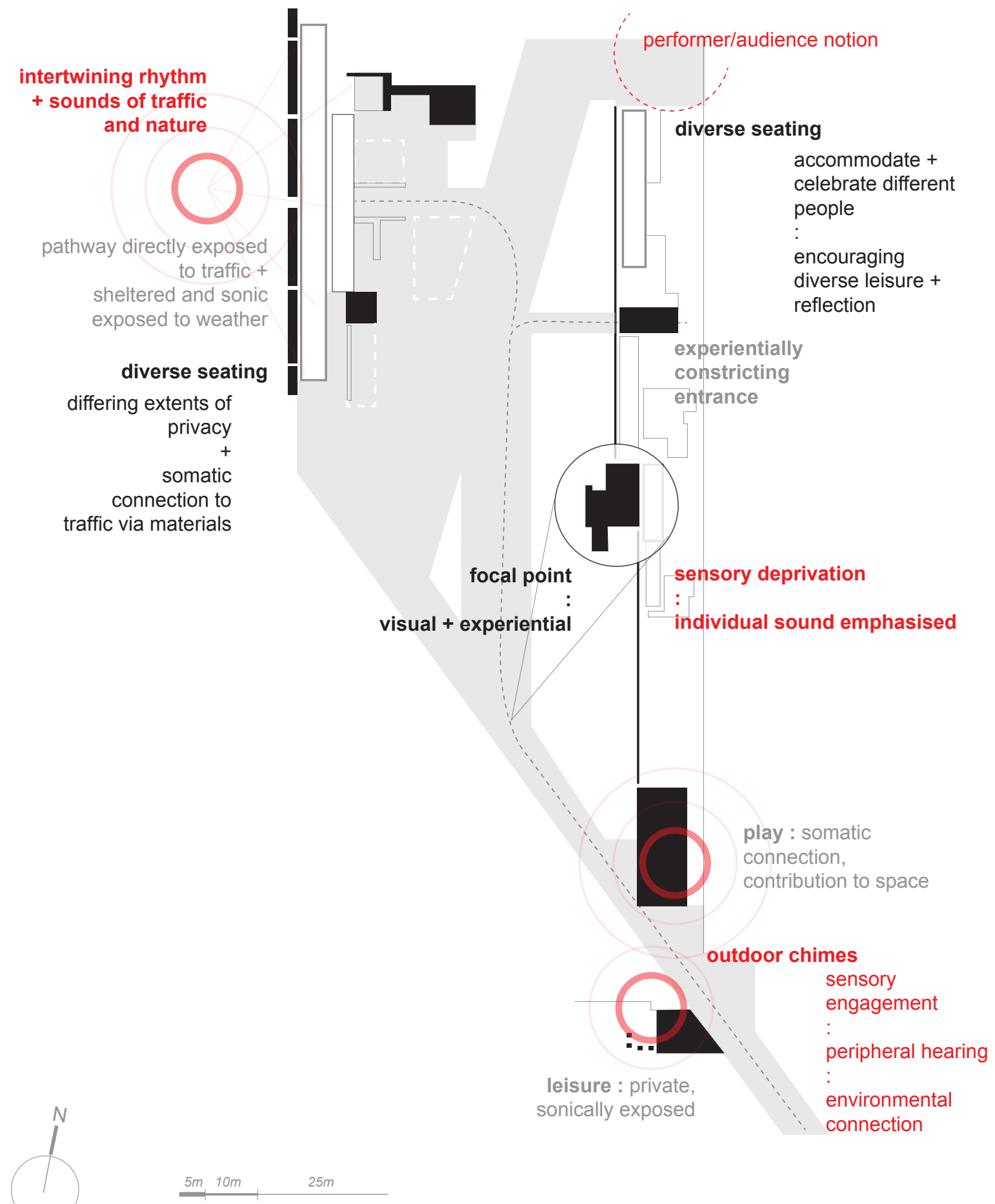




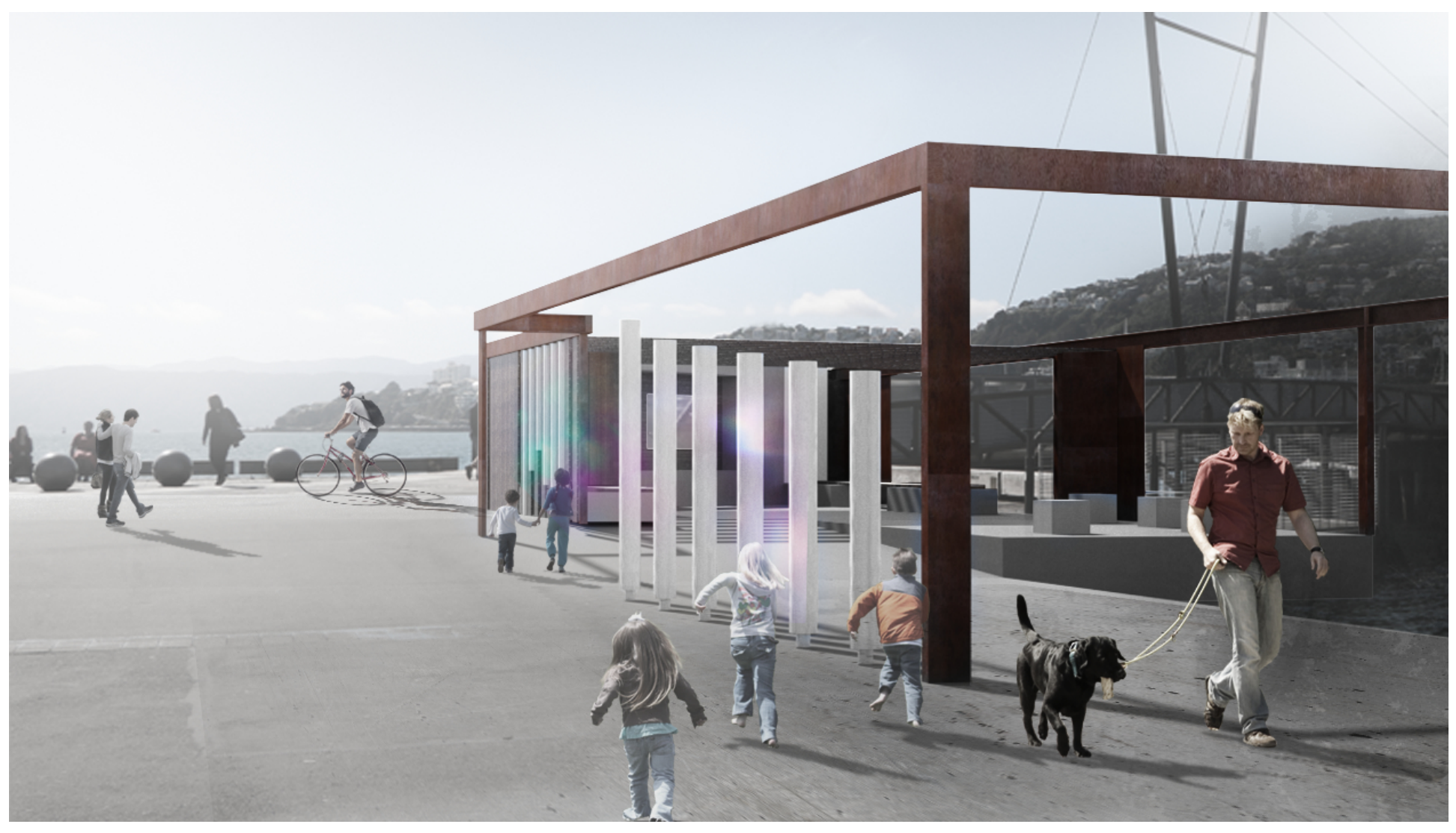

playful threshold of sound 


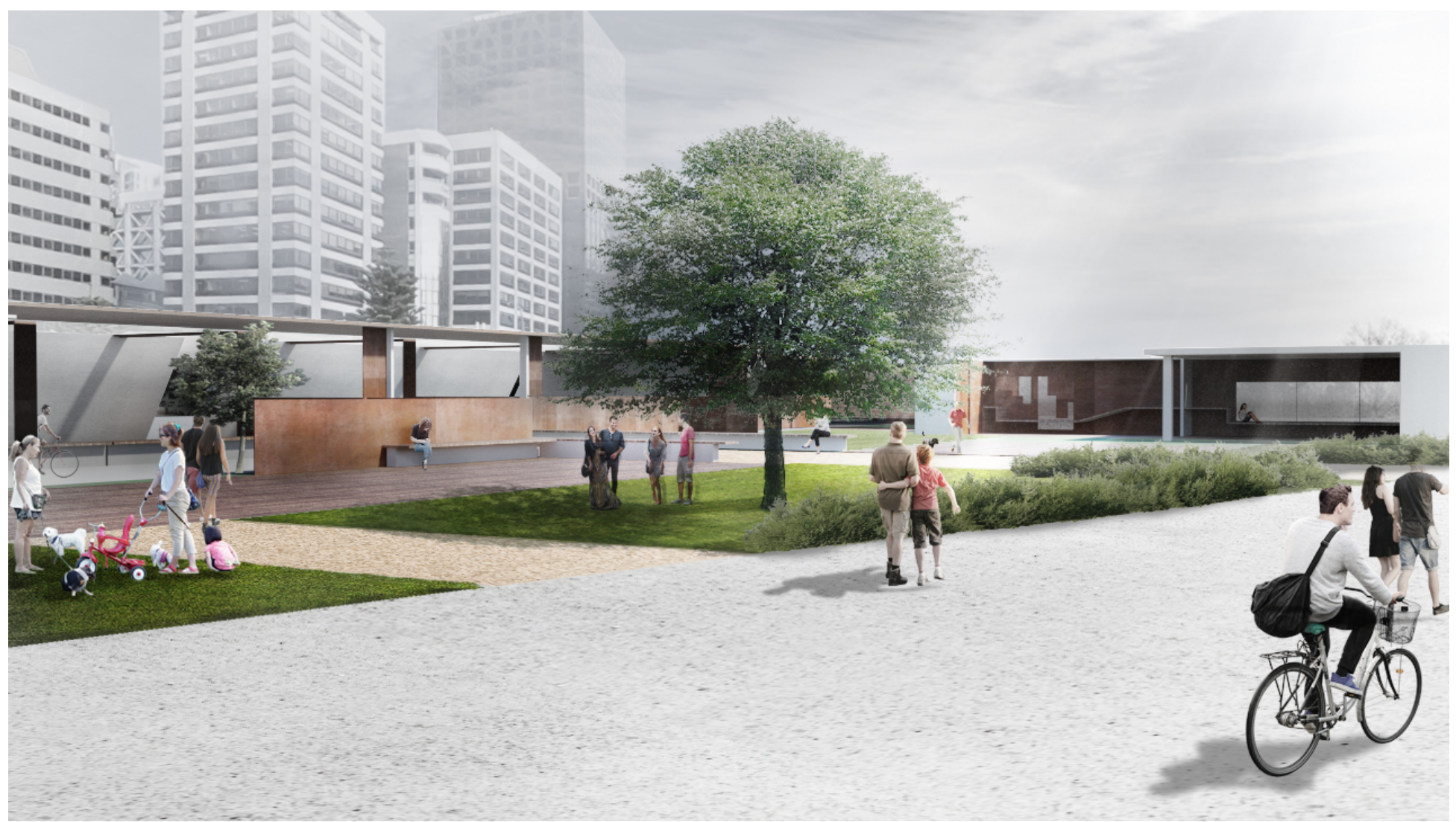

convergence of the soundtrack 


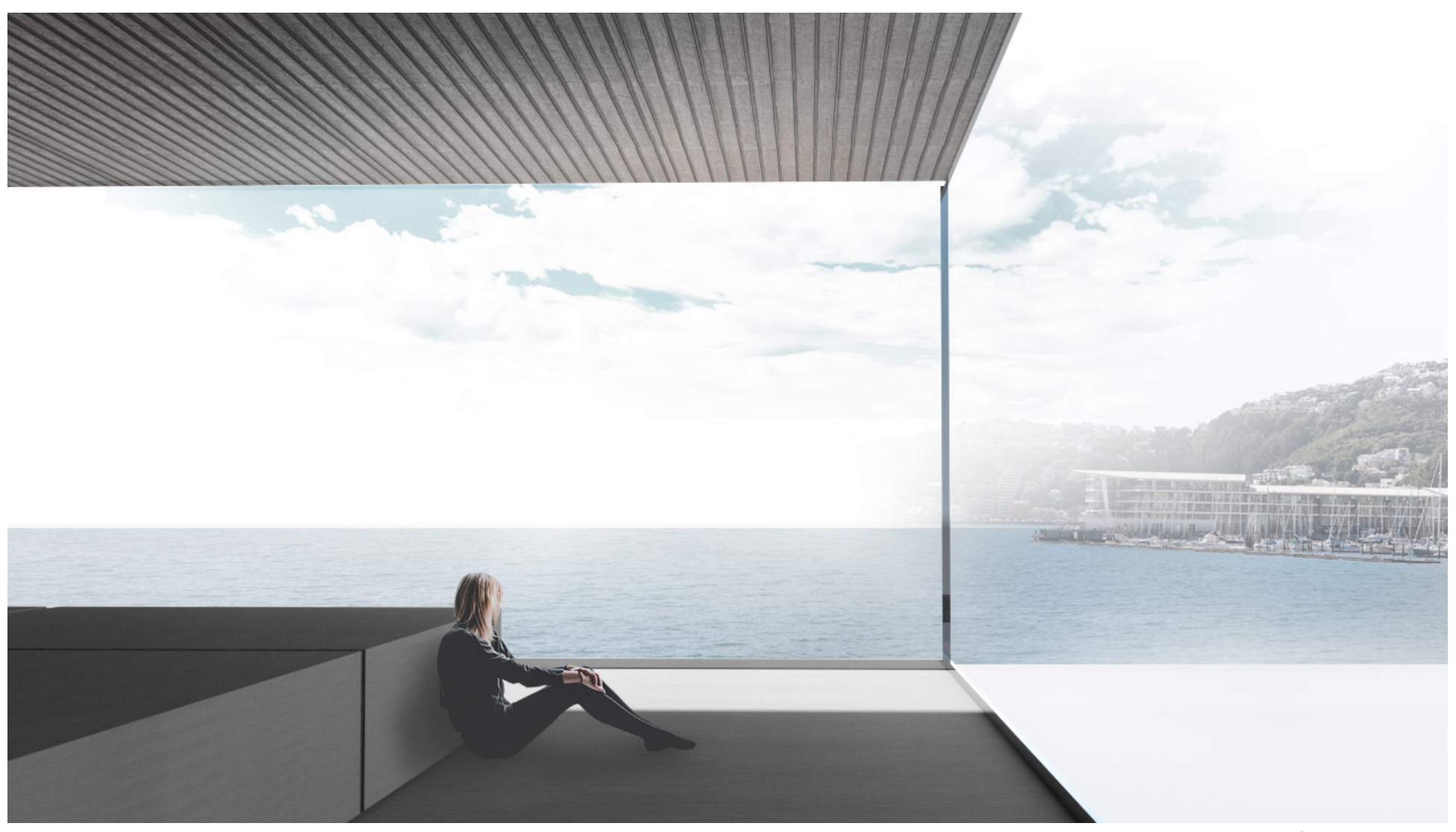

sensory focussing 
"We stroke the boundaries of space with our ears... but our cities have lost their echo altogether... our ears have been blinded"

(Pallasmaa, p.51). 


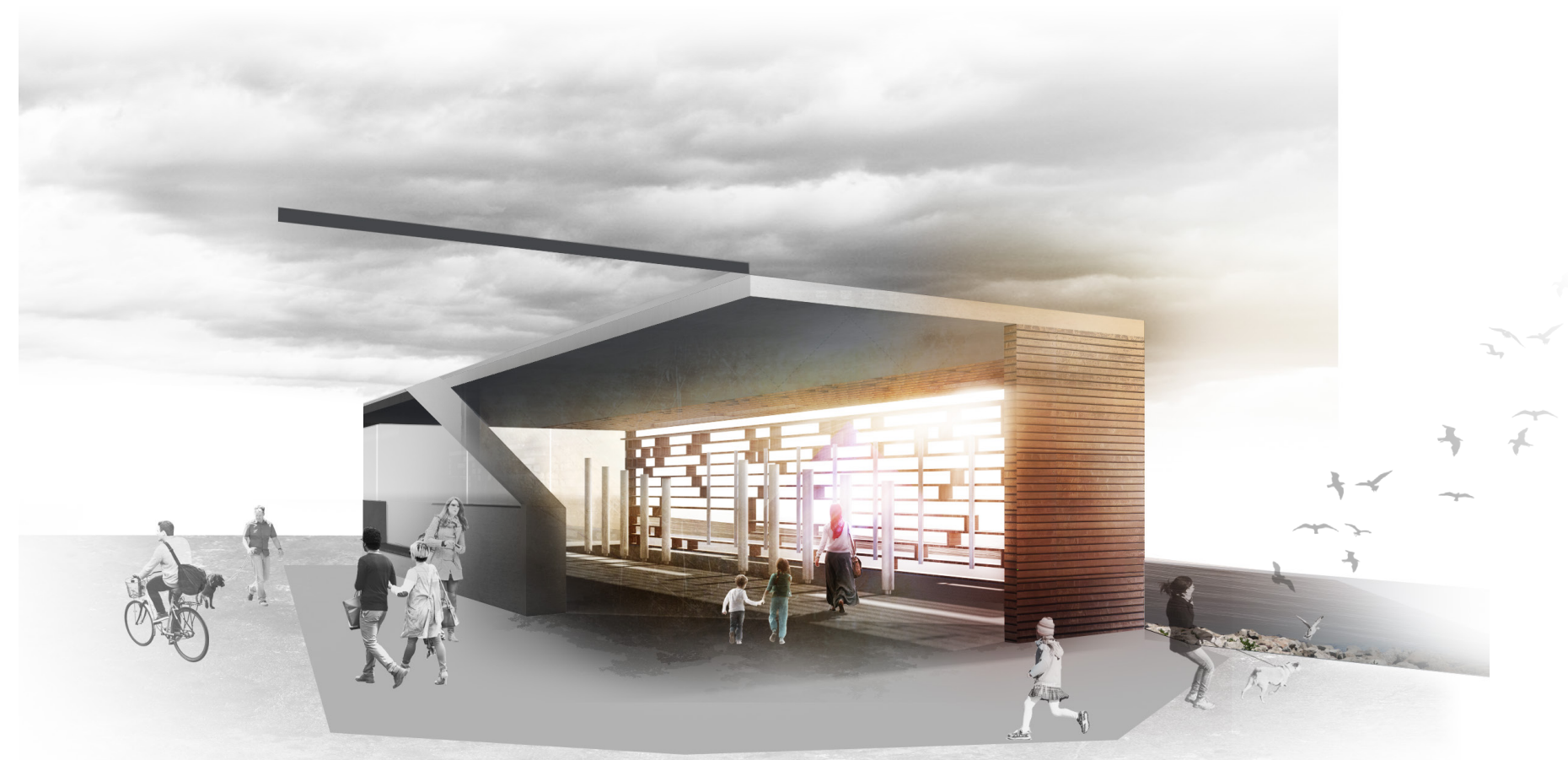


CONCLUSIONS 


\section{Process + methodology}

The project has strived to reimagine how urban spaces can be considered, analysed and designed. Following Quentin Stevens, the role of urban spaces was seen as being the antithesis to the everyday, facilitated through play, leisure and everyday performances. Experiencing Wellington's waterfront with this new lens reveals the subtle moments of interaction, engagement and reaction in public spaces. The spontaneous moments of play and notions of performance tacitly creates an atmosphere of freedom, and undergoing leisure encourages reflection of context and the city. The task of analysing urban spaces was strengthened by Lefebvre's Rhythmanalysis, Wunderlich's urban rhythms and Murray Schafer's soundscape. Utilising the experientially-led analysis techniques along Wellington's waterfront allowed the experience of people, the urban fabric and context to affect findings rather than mere observations. Additionally, the moments of play + leisure and everyday performances revealed patterns and events, and aided the measuring of successes and failings specific to the varying spaces along the waterfront. The sonic analysis detailed by Fowler (interpreting Schafer) especially assisted the analysis of Frank Kitts Park. These analyses provided a strong foundation for the design stages.
The initial design concepts were built from the analyses, as well as taking ideas from soundscape, aural architecture and Wagenfeld's notion of the soundtrack of the city. The emphasis on intuitive drawing as the primary design tool allowed the sensory qualities and experiential effects to be nurtured instead of solely forms and structures. The design further developed successfully from experiential and sensory details. The specific sensory qualities of the space took some time to develop. The produced iterations were necessary in order to reflect on how sound was influencing design decisions. The need for precedents or research of sound and sonic devices was becoming evident for further design development. 


\section{Designing with sound}

It is fair to say that to test the sonic ideas realistically is difficult. Existing installations with ideas from soundscape and aural architecture were used for inspiration. Soundscape and sound design is still a developing domain but it is gaining notice, this is shown by the growth of relevant literature. It is challenging to design pavilions and interventions on this scale due to two factors: the limitation of precedents and the fact that ideally sound installations need to be heard, felt and lived. This exposes the complexity of using sound to design and the unique problem for soundscape designs that the space cannot be completed satisfyingly until it is fully experienced. This project is aiming to shine a light on this powerful strategy. In the process of this research more questions are raised than answered.

In some parts of the design, difficulties were addressed by simulating the experience aspect, for example using existing structures in response to traffic etc. In other occasions where sonic events were noticed in everyday life and quickly noted, sound was blocked or distorted or reverberated etc. Wrongly, these were not always detailed or analysed. In reflection, the use of an 'experiential journal' of sorts would have helped to find strategies to manipulate and experience sound and understand Wagenfeld's soundtrack of the city more substantially.

Earlier in Chapter 3 colour was experimented to represent sound. This was helpful at first. The vibrant technique, however, was dominating and then abandoned to allow for focus of form, materials and light. More testing is was needed to find a successful balance between the techniques. 


\section{Interior within the Urban}

Sensory based design and the experiential aspect of space are primary concern in the discipline of interior architecture. This research sought to apply interior strategies into the urban domain. Scholars' work on Urban Interior and Soundscape helped meeting the challenge.

The design outcome of the project presents a Park that encourages people to connect with their environment and to the city through sound, play and leisure. Soundscape design begins to integrate sound in coalition with Stevens and Lefebvre's notion of play and leisure. These urban concepts integrate the interior focus of the experiential and sensory in this specific research. As a result, the experiences of the sonic environment become site specific, innate and significantly more meaningful to the urban environment.
Indeed, it is hoped that this thesis provides a path for professionals in the interior discipline to engage in the domain of urban design. In fact, a combination of knowing what interior strategies can bring to the urban realm and the willingness to explore new avenues can develop both the interior and urban disciplines. Additionally, this project tested interior strategies; the sense of meticulous control was challenged by the large scale and the surrounding environment, as well as the diversity of the space and its occupants presented a myriad of design considerations. The literature diminished these problems but readjustment of the standard modes of designing and thinking was required. Being aware of what each discipline offers can develop the urban fabric, and with intelligent mixing of literatures and disciplines it is proposed here that everyday performances of urban life can be enriched. 


\section{LIST OF FIGURES}

People + City

Fig. 1.1 Author (2017). Frank Kitts Park. [Photograph]. Wellington

Fig. 1.2 "Wellington waterfront". -41.290051, 174.780539. Google Earth. 2017. 10/05/17

Fig. 1.3 "Wellington waterfront". -41.290051, 174.780539. Google Earth. 2017. 10/05/17

Fig. 1.4 "Waitangi Park". -41.291454, 174.785088. Google Earth. 2017. 08/05/17

Fig. 1.5 Author (2017). Clyde Quay Wharf. [Photograph]. Wellington

Fig. 1.6 "Clyde Quay". Google earth. Jan 2015. 8/05/17

Fig. 1.7 "Waitangi Park". -41.291454, 174.785088. Google Earth. 2017. 08/05/17

Fig. 1.8 "Waitangi Park". -41.291454, 174.785088. Google Earth. 2017. 08/05/17

Fig. 1.9 "Waitangi Park". -41.291454, 174.785088. Google Earth. 2017. 08/05/17

Fig. 1.10 "Te Papa". -41.290116, 174.782192. Google Earth. 2017. 09/05/17

Fig. 1.11 "Te Papa". -41.290116, 174.782192. Google Earth. 2017. 09/05/17

Fig. 1.12 "Frank Kitts Park". -41.287036, 174.778801. Google Earth. 2017. 25/04/17

Fig. 1.13 Author (2017). Promenade / Park juxtaposition. [Photograph]. Wellington

Fig. 1.14 "Kumutoto". -41.283134, 174.779016. Google Earth. 2017. 10/05/17

Fig. 1.15 "Kumutoto". Google earth. Jan 2015. 10/05/17

Fig. 1.16 "Wellington waterfront". -41.290051, 174.780539. Google Earth. 2017. 10/05/17

Fig. 1.17 Author (2017). Comparing different areas. [Photograph]. Wellington

Fig. 1.18 Author (2017). Frank Kitts Park varying spaces. [Photograph]. Wellingtonww

\section{City + Performance}

Fig. 2.1 Author. LUX light festival. [Photograph]. Wellington. 2017

Fig. 2.2 "Wellington waterfront". -41.290051, 174.780539. Google Earth. 2017. 10/05/17

Fig. 2.3 Author (2017). People/performance relationship. [Photograph]. Wellington

Fig. 2.4 Author (2017). People on the periphery. [Photograph]. Wellington

Fig. 2.5 Author (2017). Intimacy in urban spaces. [Photograph]. Wellington

Fig. 2.6 Author (2017). Engagement with people. [Photograph]. Wellington

Fig. 2.7 Author (2017). LUX light festival. [Photograph]. Wellington 


\section{Performance $+I A$}

Fig. 3.1 Author. (2017). Sonic moments on the waterfront. [Photograph]. Wellington Fig. 3.2 "Frank Kitts Park". -41.287036, 174.778801. Google Earth. 2017. 25/04/17

Fig. 3.3 "Frank Kitts Park". -41.287036, 174.778801. Google Earth. 2017. 25/04/17

Fig. 3.4 "Frank Kitts Park". -41.287036, 174.778801. Google Earth. 2017. 25/04/17

Fig. 3.5 RS+. "Paprocany Lake Shore Redevelopment / RS+" 18 Oct 2015. ArchDaily. Accessed 14 Feb 2018. https://www.archdaily.com/775301/paprocany-lake-shoreredevelopment-rs-plus/

Fig. 3.6 RS+. "Paprocany Lake Shore Redevelopment / RS+" 18 Oct 2015. ArchDaily. Accessed 14 Feb 2018. https://www.archdaily.com/775301/paprocany-lake-shoreredevelopment-rs-plus/

Fig. 3.7 Kortmann, Anna Lena. "Thilo Frank: Ekko Spatial Installation." designboom | architecture \& design magazine. 2012. 7 July 2017. https://www.designboom.com/ readers/thilo-frank-ekko-spatial-installation/

Fig. 3.8 Kortmann, Anna Lena. "Thilo Frank: Ekko Spatial Installation." designboom | architecture \& design magazine. 2012. 7 July 2017. Web. https://www.designboom. com/readers/thilo-frank-ekko-spatial-installation/

Fig. 3.9 ALSA. "Peninsula Residence". American Society of Landscape (ASLA). 2011. Web. https://www.asla.org/2011awards/018.html

Fig. 3.10 Emily, Nonko. "Condos Padding The High Line Are Ridiculously Pricier Than Their Neighbors." Curbed NY. 2018. Web. 8 July 2017. https://ny.curbed. com/2016/8/8/12401622/high-line-real-estate-development-effect

Fig. 3.11 Klopfer Martin Design Group. "The Steel Yard”. Landzine. 2015. Web. http://www. landezine.com/index.php/2015/03/steel-yard-post-industrial-landscape-redesignklopfer-martin-design/

Fig. 3.12 "Hilgard Garden - Mary Barensfeld Architecture." Mary Barensfeld Architecture. 2015. Web. 29 July 2017. http://barensfeld.com/projects/hilgard-garden/ 
Fig. 3.13 Gertler, Carly. "A building in conversation". 2013. https://carlygertler.com/A-Building-inConversation

Fig. 3.14 Slavinsky, Dan. "A Series of Drawings from the End of Time". 2010. http://ardezart. com/?attachment_id=198

Fig. 3.15 "Mesmerizing Architecture Drawing Photos Of Wall Ideas Decoration Title". http:// houseofphy.com/architecture-drawing-ideas/mesmerizing-architecture-drawingphotos-of-wall-ideas-decoration-title/

Fig. 3.16 "Frank Kitts Park". Google earth. Jan 2015. 27/05/17

Fig. 3.17 "Frank Kitts Park". -41.287036, 174.778801. Google Earth. 2017. 25/04/17

Fig. 3.18 "Frank Kitts Park". -41.287036, 174.778801. Google Earth. 2017. 25/04/17

Fig. 3.19 Author. Threshold entrance. 2017. [Photograph] Wellington

Fig. 3.20 "Bostanlı Footbridge \& Sunset Lounge / Studio Evren Başbuğ" 13 Mar 2017. ArchDaily. Accessed 16 Aug 2017. https://www.archdaily.com/866903/bostanlifootbridge-and-sunset-lounge-steb/

Fig. 3.21 "Emperor Chimes Musical Instrument." https://www.playgroundcentre.com/products/ emperor-chimes-musical-instrument/

Fig. 3.22 "Sound Therapy - Ancient Solfeggio Frequencies". https://www.cosmic-energy. org/?product=sound-therapy-ancient-solfeggio-frequencies

Fig. 3.23 "ATLANTIQUE range- Aréa". Landzine. http://www.landezine.com/index.php/2016/08/ atlantique/

Fig. 3.24 "The Jingumae residence" 2013. Earthscape. 26 Aug 2017. http://www.earthscape. co.jp/works/landscape_design/the_ingumae_residence/ 


\section{BIBLIOGRAPHY}

ALSA. "Peninsula Residence”. American Society of Landscape (ASLA). 2011. Web. https://www.asla.org/2011awards/018.html

Bhartia, Ishita. "The role of perspective in Architecture." Plan N Design. March 2017. https://www.planndesign.com/articles/2768-role-perspective-architecture

Blesser, Barry, and Linda-Ruth Salter. "Spaces Speak, Are You Listening?" Cambridge (Massachusetts): The MIT Press, 2009. Print.

Bteich, Chady S. "Ambiguous Porosity - Integrated Urban Gaps Identification And Experimenting Urban Connectivity". PLEA2006 - The 23Rd Conference On Passive And Low Energy Architecture. 2006. Web. 20 Mar. 2017.

Chandler, Lisa. "The non-place". 2012. http://lisachandler.co.nz/phone/the-non-place. html

Doumpa, V; Doucet, B. "Music Performance in Public Space: Changing Perception, Changing Urban Experience?". EcHoPolis Conference. 2013. Web. 7 April. 2017

Edensor, T. "The Culture of the Indian Street" in N. Fyfe (ed.) Images of the Street: Planning, Identity and Control in Public Space, 1998. New York: Routledg.

Fowler, Michael D. "Soundscape As A Design Strategy For Landscape Architectural Praxis." Design Studies, vol 34, no. 1, 2013, pp. 111-128.

Gehl, Jan. "City to waterfront - Public space and public life study". Oct 2004. WCC. Print

Hadero, Meklit. "The unexpected beauty of everyday sounds". TED. October. 2015. Lecture

Hamilton, William L. "The World Of Sound." Dwell. 2012. Web. 28 Sept. 2017. https:// www.dwell.com/article/the-world-of-sound-2b3fbcf7 
Hinkel, Rochus Urban. "Private encounters and public occupations: a methodology for the exploration of public space". Urban Interior- Informal Explorations, Interventions And Occupations. 2011. Print.

Kimmelman, Michael. "Dear Architects: Sound Matters." Nytimes, 2018. Web. 8 June 2017. https://www.nytimes.com/interactive/2015/12/29/arts/design/sound-architecture. html?_r=0

Kortmann, Anna Lena. "Thilo Frank: Ekko Spatial Installation." designboom | architecture \& design magazine. 2012. 7 July 2017. https://www.designboom.com/ readers/thilo-frank-ekko-spatial-installation/

Lefebvre, Henri. The Production of Space. Oxford, OX, UK: Blackwell, 1991. p.294. Print.

Lehman, Maria Lorena. "Using sound to influence Architectural experience". https:// marialorenalehman.com/post/using-sound-to-influence-architectural-experience

Pallasmaa Juhani. The Eyes Of The Skin. Chichester: Wiley, 2014. Print.

Redman, A.S. "Aural architecture extended". 2012 http://auralarchitectureresources. tumblr.com/post/21142048590/aural-architecture-extended

Stevens, Quentin. The Ludic City: Exploring The Potential Of Public Spaces. 1st ed. 2007. Print.

Watkins, Ceri. "Representations Of Space, Spatial Practices And Spaces Of Representation: An Application Of Lefebvre's Spatial Triad." Culture and Organization 11.3 (2005): pp.209-220. Web.

Wunderlich, Filipa Matos. "Place-Temporality And Urban Place-Rhythms In Urban Analysis And Design: An Aesthetic Akin To Music". Journal of Urban Design, 18.3 (2013): 383-408. Web.

Whyte, W. H. The Social Life Of Small Urban Spaces. Washington DC: Conservation Foundation, 1980. Print. 
Thank You

\author{
A thesis by \\ Dylan Kanagaratnam
}

Supervisor : Philippe Campays 

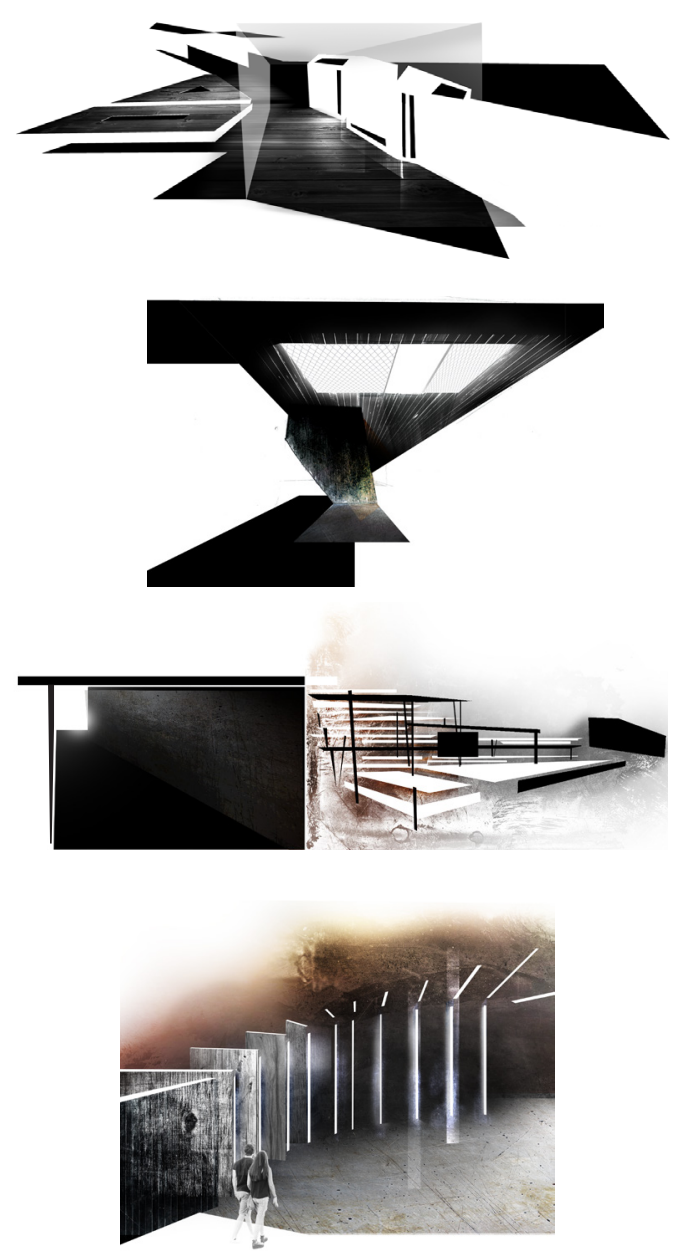